ANDRÉ ALARCON DE ALMEIDA PRADO

ANÁLISE DE DECISÃO MULTICRITÉRIO APLICADA NA SELEÇÃO DE FORNECEDORES DE LOGÍSTICA

São Paulo 


\section{ANÁLISE DE DECISÃO MULTICRITÉRIO APLICADA NA SELEÇÃO DE FORNECEDORES DE LOGÍSTICA}

Dissertação apresentada à Escola

Politécnica da Universidade de São

Paulo para obtenção do título de Mestre em Engenharia

São Paulo 


\section{ANÁLISE DE DECISÃO MULTICRITÉRIO APLICADA NA SELEÇÃO DE FORNECEDORES DE LOGÍSTICA}

Dissertação apresentada à Escola

Politécnica da Universidade de São

Paulo para obtenção do título de Mestre em Engenharia

Área de Concentração:

Engenharia de Sistemas Logísticos

Orientador:

Prof. Dr. Gilberto Montibeller Neto

São Paulo 


\section{DEDICATÓRIA}

A minha esposa Lyz e ao meu filho JV por me demonstrarem através dos mais puros sentimentos como seria importante minha presença nas noites e finais de semana de estudo e mesmo assim tenham se esforçado ao máximo para que essa dissertação fosse possível. 


\section{AGRADECIMENTOS}

A minha mãe Sandra que mostrou através de atos que com amor, esforço pessoal, autoconfiança e dedicação tudo que realmente é relevante pode ser alcançado.

Ao meu pai Vicente, in memoriam, que me fez ter amor pelo estudo, compromisso e retidão de caráter.

Ao professor Gualda pelos seus ensinamentos, confiança e por ter me apoiado quando tanto precisava.

Ao meu orientador, professor Gilberto, pelo respeito, capacidade de orientação e por dividir uma parte de seu vasto conhecimento na área. Agradeço também por, através de seus ensinamentos, evoluir meu modo de pensar e analisar os fatos.

Ao professor Hugo que através do seu olhar crítico, conhecimento e visão me auxiliou de forma fundamental na realização deste curso.

A professora Carmen por ceder parte do seu precioso tempo neste trabalho.

Aos amigos de turma, em especial ao Rafael, Bruno, Fabrício e Kátia, pelo esforço conjunto em busca do aprimoramento técnico.

Aos professores Barbieri, Brinati e Dario pelos ensinamentos recebidos nas aulas de mestrado.

A Atlas Transportes e Logística, e especialmente ao Fran, por acreditar na importância do conhecimento para o desenvolvimento deste país e me proporcionar totais condições para desenvolver este trabalho.

A todos que participaram dos estudos de caso, ou que, direta e indiretamente colaboraram para o desenvolvimento deste trabalho. 


\section{RESUMO}

A seleção de fornecedores é uma importante decisão na área de logística para obter menores custos e um melhor nível de serviço. Os modelos de seleção atualmente praticados nas empresas buscam estritamente minimizar custos, o que é bastante questionado por parte da literatura especializada. Este trabalho propõe um modelo de seleção de fornecedores de logística balizado em uma abordagem multicritério que busca a escolha ideal através da ótica do contratante. As suas principais contribuições são a adaptação do processo $M C D A$ na formulação e resolução desta escolha, a análise crítica dos fatores que influem neste tipo de decisão (critérios, subcritérios e curvas de impacto) e a apresentação do modelo proposto que utiliza um software de apoio à decisão. O modelo foi aplicado com sucesso em dois estudos de caso reais e em ambos os casos contribuiu para um maior entendimento do problema, tornando o processo de negociação mais assertivo e racional.

Palavras-chave: Seleção de fornecedores. MCDA. Análise Multicritérios. Logística. 


\begin{abstract}
Supplier's selection is a major alternative to obtain lower costs and a better level of service. The selection models currently practiced in the companies seeks strictly the minimization of costs, which is widely questioned by the literature. This paper proposes a model for supplier selection in logistics area using a multicriteria approach that finds the ideal choice from the perspective of the contractor. The main contributions are the adaptation of the MCDA process at formulating and solving this problem, the critical analysis of influence factors of this type of decision (criteria, subcriteria and value function) and the proposed model that uses software to support the decision of contractor. The model was successfully applied in two real cases and in both has contributed to a better understanding of their problem by making the negotiation process more explicit and rational.
\end{abstract}

Keywords: Suppliers selection. MCDA. Multicriteria Analysis. Logistic. 


\section{LISTA DE ILUSTRAÇÕES}

Figura 1 - Impacto sobre a evolução da complexidade e importância das decisões de compra

Figura 2 - Avaliação histórica da utilização dos critérios por grau de utilização .........31

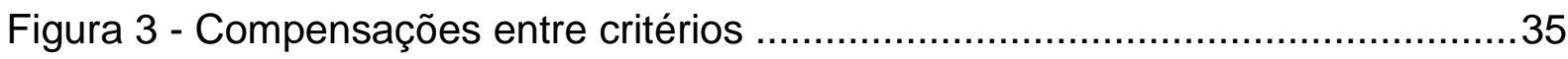

Figura 4 - Tipos de abordagem multicritério publicadas entre 2000 e 2008 ..............39

Figura 5 - Frequência de utilização por tipo de abordagem ........................................41

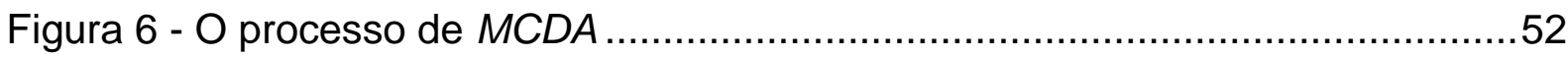

Figura 7 - Mapa Cognitivo com base no processo MCDA e VFT ...........................54

Figura 8 - Modelo de Decisão "Expert Mode" ...................................................... 58

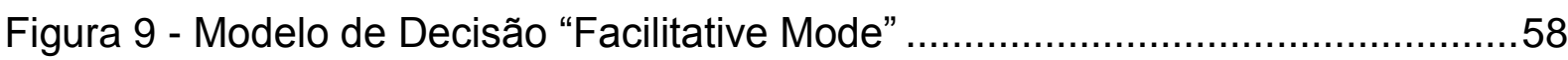

Figura 10 - Fluxo Comparativo das Abordagens VFT e AFT.................................59

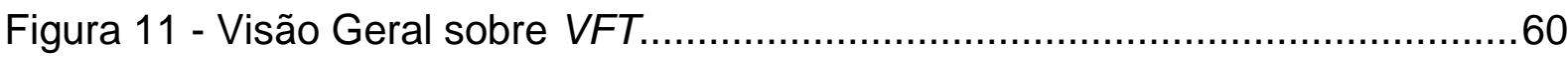

Figura 12 - A busca da solução ótima para o sistema via modelagem matemática

Figura 13 - Representação esquemática da otimização multicritérios para o

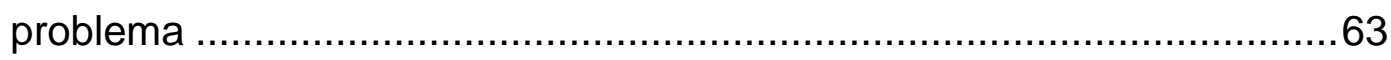

Figura 14 - Ciclo de pesquisa do método "Action-Research" ..................................73

Figura 15 - Solução do Problema e Metodologias de Pesquisa ...............................73

Figura 16 - Mapa Cognitivo desenvolvido pelo grupo de decisores para o estudo de caso 2

Figura 17 - Pesos de tomada de decisão entre custos de transporte e nível de serviço .82

Figura 18 - Árvore de valores da Transportadora (SP-Salvador) ............................ 83

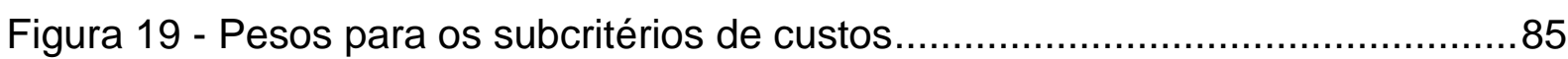

Figura 20 - Pesos dos subcritérios de Nível de Serviço ..........................................86

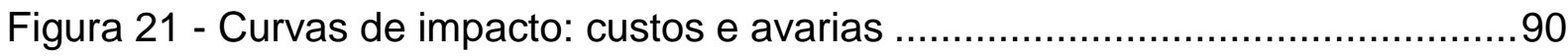

Figura 22 - Curvas de impacto: entregas e disponibilidade extra..............................91

Figura 23 - Curva de impacto: Prazo de Entrega ...............................................92

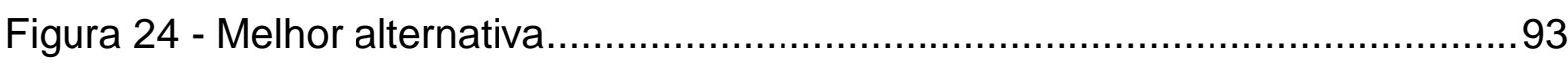


Figura 25 - Gráficos para tomada de decisão Custo de Transporte/Decisão

Transportadora

Figura 26 - Gráficos para tomada de decisão Nível de Serviço/Decisão

Transportadora 96

Figura 27 - Novo resultado com a alteração de custos para a transportadora "A" ....98

Figura 28 - Novos Gráficos para tomada de decisão Custo de

Transporte/Decisão Transportadora

Figura 29 - Novos Gráficos para tomada de decisão Nível de Serviço/Decisão Transportadora .99

Figura 30 - Pesos dos critérios para seleção de prestador de serviços logísticos ..101

Figura 31 - Árvore de valores para seleção de prestador de serviços logísticos ....103

Figura 32 - Pesos para os subcritérios de custos..............................................105

Figura 33 - Pesos dos subcritérios de Nível de Serviço ......................................107

Figura 34 - Pesos dos subcritérios de Capacitação Técnica....................................111

Figura 35 - Curvas de impacto: custos e avarias ……….................................114

Figura 36 - Curvas de impacto: gestão de estoque, expedição no prazo e prazo de recebimento

Figura 37 - Curva de impacto: Instalações e Licenças, Sistemas, Política da Qualidade, Capacidade Financeira, Experiência e Negócios Futuros....116

Figura 38 - Melhor alternativa preliminar.

Figura 39 - Gráficos para tomada de decisão Custo dos Serviços/Decisão Prestador.

Figura 40 - Gráficos para tomada de decisão Nível de Serviço/Decisão Prestador

Figura 41 - Gráficos para tomada de decisão Capacitação Técnica/Decisão

Prestador.

Figura 42 - Novo resultado após alteração dos dados negociados na visita técnica 


\section{LISTA DE TABELAS}

Tabela 1 - Revisões Bibliográficas sobre aplicação de $M C D A$ na seleção de Fornecedores .24

Tabela 2 - Estrutura do processo de seleção de fornecedores …...........................28

Tabela 3 - Nível de utilização dos critérios de seleção.............................................30

Tabela 4 - Métodos e técnicas para definição de problemas ....................................37

Tabela 5 - Métodos para formulação dos critérios …………………....................37

Tabela 6 - Sugestão de métodos de pré-qualificação de fornecedores .....................37

Tabela 7 - Avaliação do modelo na seleção de fornecedores ...................................42

Tabela 8 - Visão geral dos modelos utilizados nos experimentos .............................42

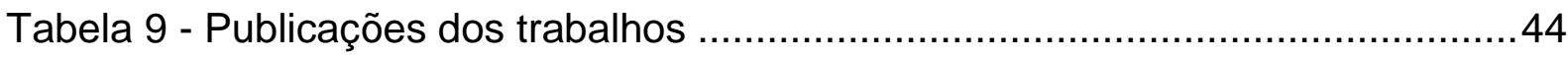

Tabela 10 - Frequência de publicações de seleção de fornecedores ………….......45

Tabela 11 - Classificação dos periódicos (conteúdo) …….........................................46

Tabela 12 - Quadro comparativo Expert versus Facilitated mode ..........................57

Tabela 13 - Visão geral das abordagens, métodos e ferramentas utilizados nos

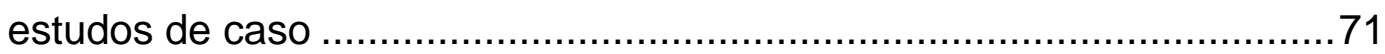

Tabela 14 - Critérios de inclusão e rejeição para o estudo de Caso 1 ......................80

Tabela 15 - Critérios de inclusão e rejeição para o estudo de Caso 2 …....................80

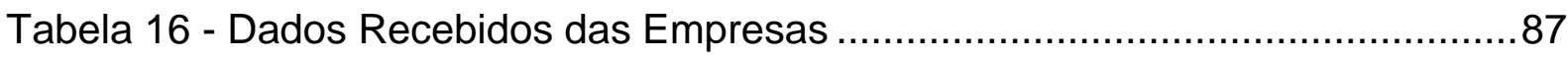

Tabela 17 - Pontuação das alternativas para cada critério avaliado .........................93

Tabela 18 - Alterações de custo para a transportadora "A" ......................................97

Tabela 19 - Alterações na pontuação por causa dos custos reavaliados pela

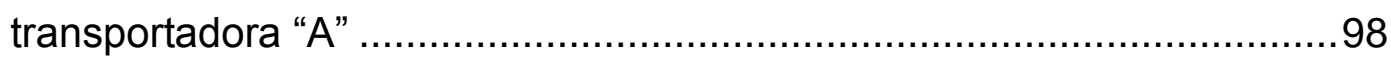

Tabela 20 - Escala qualitativa de valor para instalações e licenças........................108

Tabela 21 - Escala qualitativa de valor para sistemas .......................................109

Tabela 22 - Escala qualitativa de valor para política da qualidade .........................109

Tabela 23 - Escala qualitativa de valor para capacidade financeira ........................110

Tabela 24 - Escala qualitativa de valor para experiência no segmento....................110

Tabela 25 - Escala qualitativa de valor para possibilidade de negócios futuros ......111

Tabela 26 - Critérios de inclusão e rejeição ........................................................112

Tabela 27 - Dados Recebidos dos prestadores de serviços .................................113 
Tabela 28 - Pontuação das alternativas para cada critério avaliado ......................117

Tabela 29 - Alterações dos dados após negociação durante a visita técnica .........122

Tabela 30 - Alterações na pontuação após negociação durante a visita técnica ....122

Tabela 31 - Avaliações do modelo proposto na aplicação aos estudos de caso.....127 


\section{LISTA DE ABREVIATURAS E SIGLAS}

ABC - Activity Based Costing (Método ABC)

AFT - Alternative Focused Thinking

AHP - Analytic Hierarchy Process (Método de Análise Hierárquica)

ANP - Analytic Network Process (Processo de Análise de Rede)

CBR - Case Based Reasoning (Raciocínio baseado em casos)

DEA - Data Envelopment Analysis (Análise Envoltória de Dados)

EDI - Electronic Data Interchange (Troca Eletrônica de Dados)

FST - Fuzzy Set Theory (Teoria Fuzzy)

GP - Goal Programming

ISM - Interpretive Structural Modeling

KPI - Key Performance Indicator (Indicador de Performance)

LTL - Less than Truckload (Transporte Fracionado)

MACBETH - Measuring Attractiveness by a Categorical Based Evaluation Technique

MAUT - Multiple-attribute Utility Theory 
MAVT - Multiple-attribute Value Theory (Teoria de Valor Multiatributo)

MCDA - Multi Criteria Decision Analysis (Análise de Decisão Multicritérios ou Multicritérios em Apoio à Decisão)

MCDM - Multi Criteria Decision Making (Tomada de Decisão Multicritérios)

MOP - Multiobjective Programming (Programação Multiobjetivo)

OR - Operational Research (Pesquisa Operacional)

OTD - On Time Entrega (Entregas no Prazo)

OTIF - On Time In Full (Entregas Perfeitas no Prazo)

SODA - Strategic Options Development Analysis

RFI - Request For Information (Processo de Cotação - Informações)

RFP - Request For Propose (Processo de Cotação - Proposta)

RFQ - Request For Quotation (Processo de Cotação -Preços)

TCO - Total Cost of Ownership (Custo Total de Apropriação)

VFT - Value Focused Thinking

WMS - Warehouse Management System (Sistema de Gerenciamento de Armazéns) 


\section{SUMÁRIO}

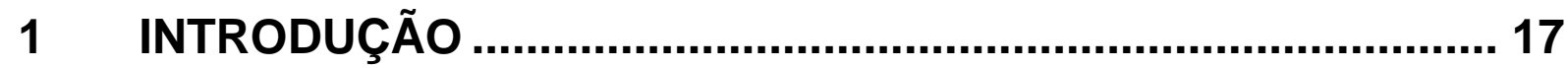

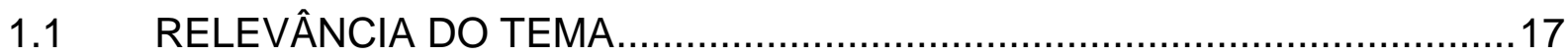

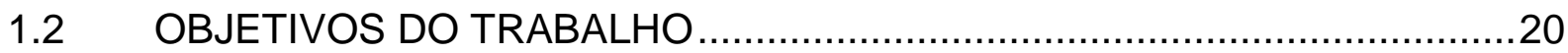

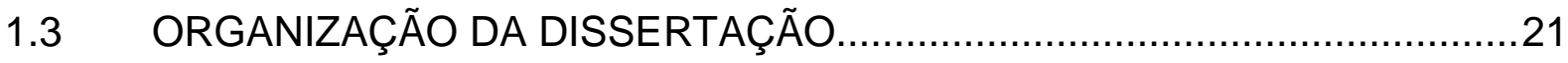

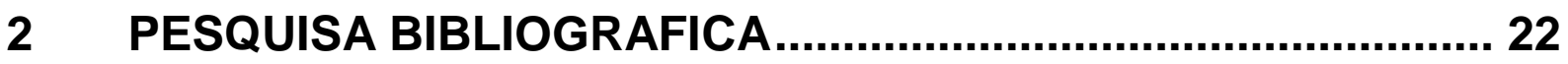

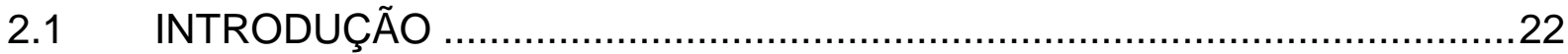

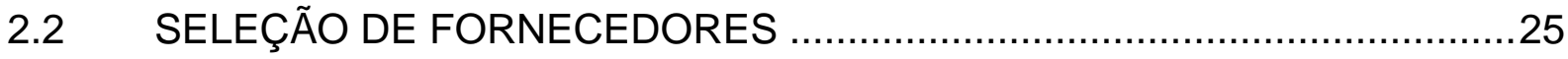

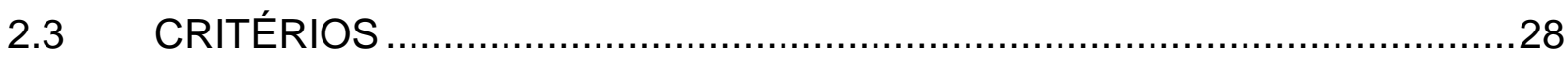

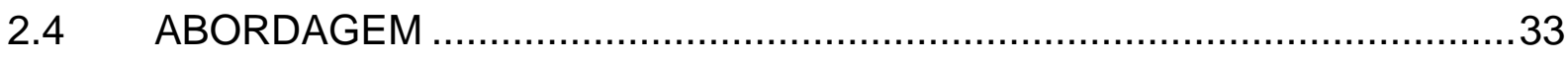

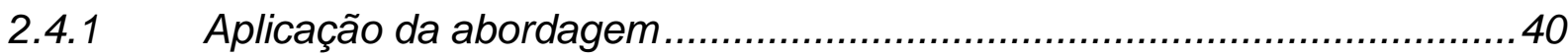

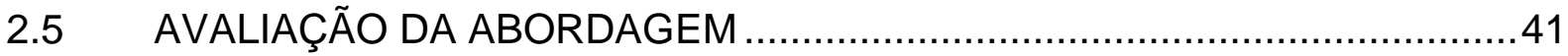

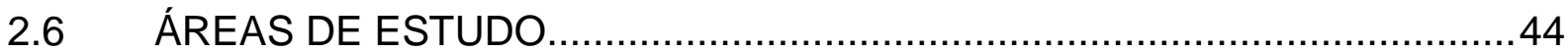

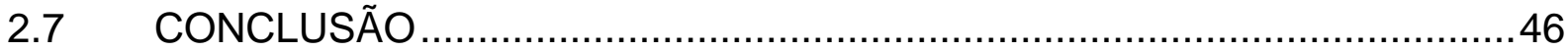

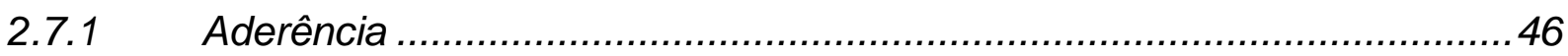

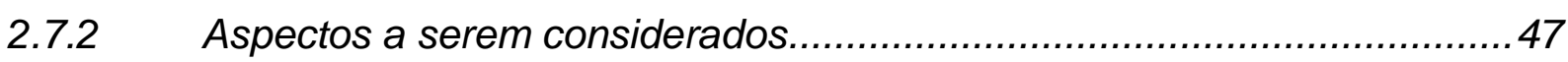

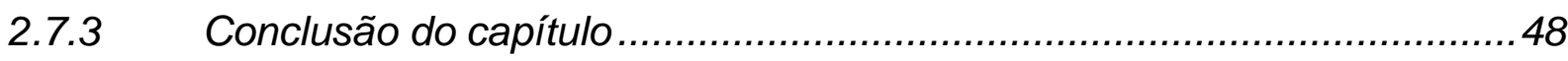

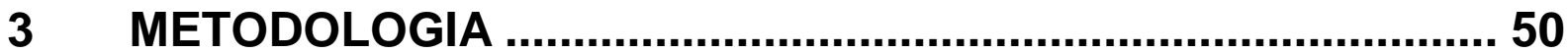

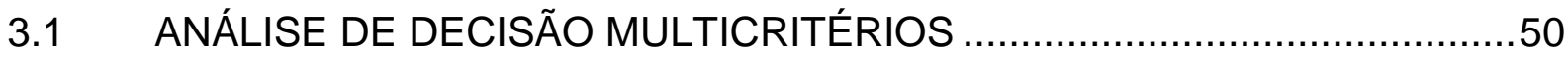

3.1.1 MCDA - Definição e utilização .........................................................

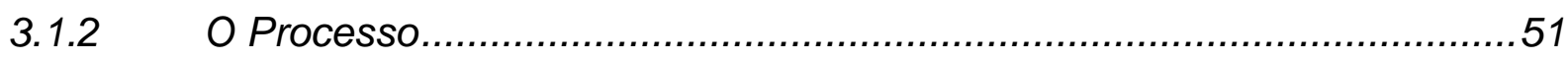

3.1.3 Identificação e estruturação do problema..............................................52

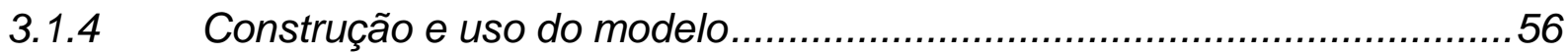

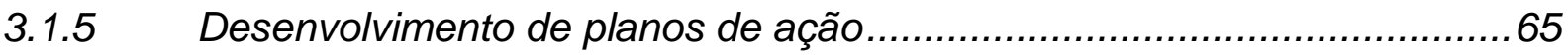

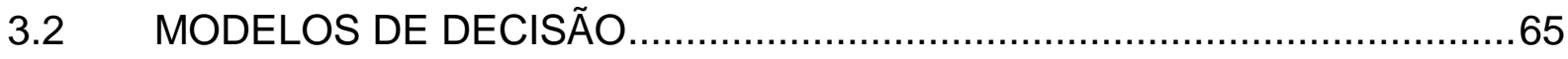

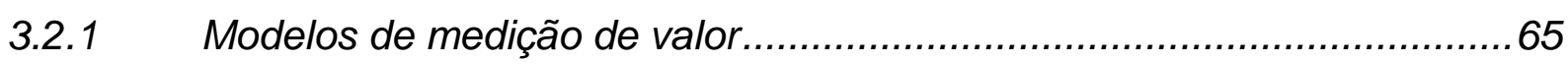

3.2.2 Modelos de aspiração ou nível de referência ..........................................66

3.2.3 Modelos de "outranking".................................................................6

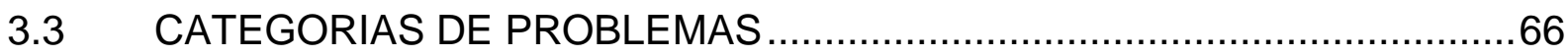

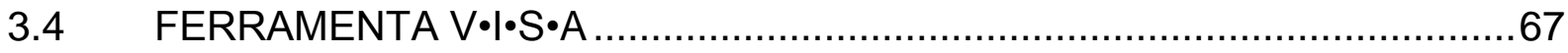

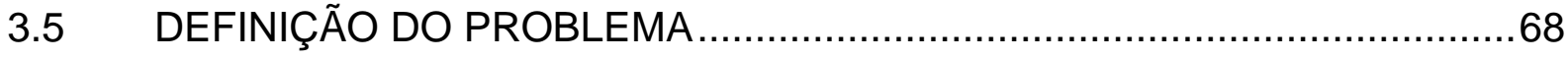




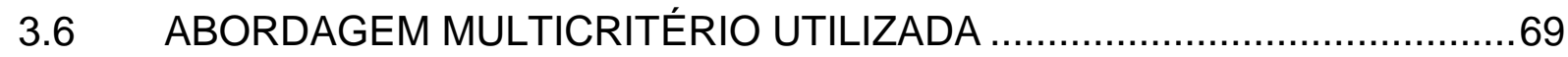

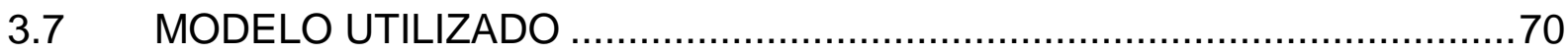

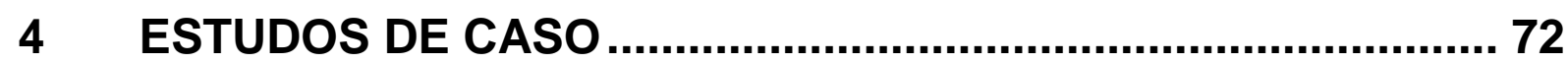

4.1 IDENTIFICAÇÃO E ESTRUTURAÇÃO DO PROBLEMA …........................75

4.1.1 Entendimento do problema e aplicação do modelo de decisão

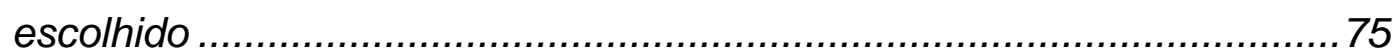

4.1.2 Obtenção de dados e empresas participantes do processo ....................77

4.1.3 Critérios de inclusão e rejeição........................................................ 79

4.2 CONTRUÇÃO E USO DO MODELO PARA O ESTUDO DE CASO $1 \ldots \ldots . . . . .81$

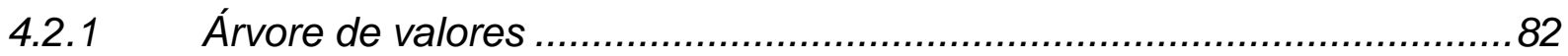

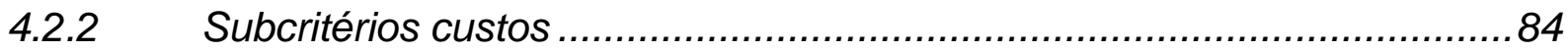

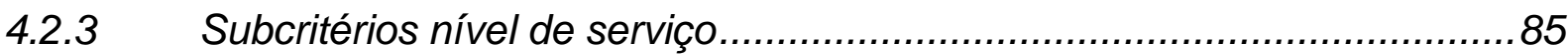

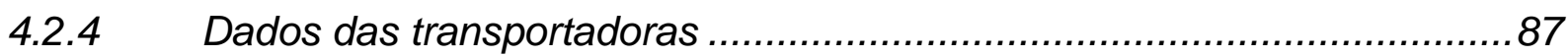

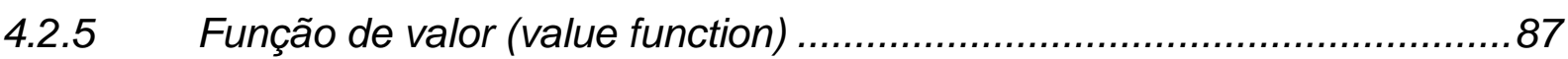

4.2.5.1 Custo por Kg, Custo Mínimo e Avarias .........................................88

4.2.5.2 Entregas no Prazo e Disponibilidade Extra ..................................90

4.2.5.3 Prazo de Entrega

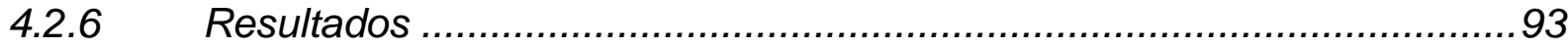

4.2.7 Análise de sensibilidade e robustez dos resultados ................................94

4.2.8 Conclusão do Estudo de Caso 1 ........................................................99

4.3 CONTRUÇÃO E USO DO MODELO PARA O ESTUDO DE CASO 2 ........101

4.3.1 Árvore de valores ....................................................................... 102

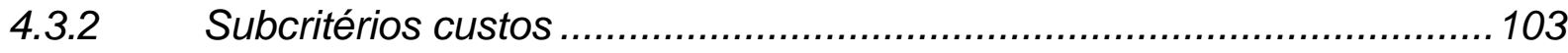

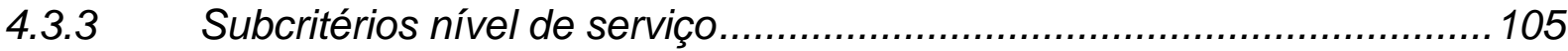

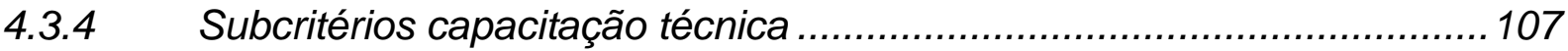

4.3.5 Critérios de inclusão e rejeição para capacitação técnica .......................111

4.3.6 Dados dos prestadores de serviços ................................................ 112

4.3.7 Função de valor (value function) ……….......................................113

4.3.7.1 Custo Fixo e Custo Variável .................................................113

4.3.7.2 Gestão de Estoque, Expedição no Prazo e Prazo de Recebimento 114

4.3.7.3 Instalações e Licenças, Sistemas, Política da Qualidade, Capacidade Financeira, Experiência e Negócios Futuros .................................116

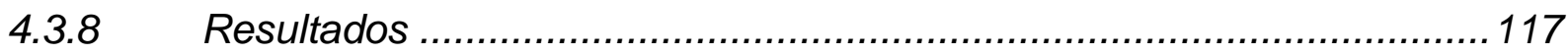


4.3.9 Análise de sensibilidade e robustez dos resultados .............................118

4.3.10 Conclusão do Estudo de Caso 2 .......................................................123

4.4 AVALIAÇÃO DO MODELO COM BASE NA LITERATURA ......................125

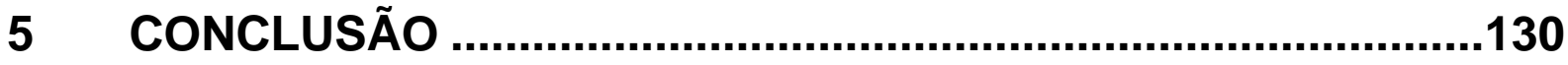

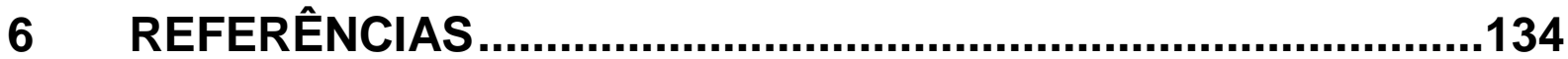

7 REFERÊNCIAS COMPLEMENTARES ..................................139

8 GLOSSÁRIO .......................................................................157

9 APÊNDICE A - INFORMAÇÕES SOBRE O MERCADO DE LOGÍSTICA RELATIVAS AO PROBLEMA ...............................159

10 APÊNDICE B - QUADRO RESUMO DAS FASES, ETAPAS E MODELOS AVALIADOS POR DE BOER ET

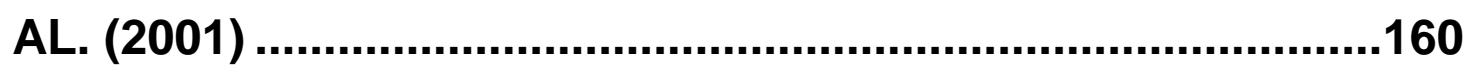

11 APÊNDICE C - MODELO DE PLANILHA PARA OBTENÇÃO DE DADOS DOS FORNECEDORES.....................161

12 APÊNDICE D - PREMISSAS CONSIDERADAS NOS ESTUDOS DE CASO .............................................................163

13 ANEXO A - PUBLICAÇÕES PESQUISADAS POR WEBER ET AL. (1991).............................................................166

14 ANEXO B - PUBLICAÇÕES PESQUISADAS POR DEGREAVE ET AL. (2000) ....................................................167

15 ANEXO C - PUBLICAÇÕES PESQUISADAS POR DE BOER ET AL. (2001) .........................................................168

16 ANEXO D - PUBLICAÇÕES PESQUISADAS POR HO ET AL. (2010) 


\section{INTRODUÇÃO}

\subsection{RELEVÂNCIA DO TEMA}

Logística e operações nunca desempenharam papel tão importante nas organizações. Mudanças nas expectativas dos clientes ou na localização geográfica continuamente transformam a natureza dos mercados, que, por sua vez geram restrições que obrigam as empresas a alterarem seu fluxo de mercadorias. Hoje, novas pressões estão mudando as cadeias logísticas utilizadas pelas empresas. As novas definições são significativamente diferentes daquelas que determinavam as antigas atividades relacionadas ao fluxo (DORNIER ET AL., 2000).

Ballou (1993) traduziu a importância da logística como fundamento para o comercio e competitividade e a caracterizou como o fluxo de produtos desde o ponto de aquisição da matéria prima até o ponto de consumo final, incluindo informação, a um nível de serviço adequado e custo competitivo.

A logística é um componente decisivo para o aumento de competitividade das empresas sendo a escolha de fornecedores um de seus pontos fundamentais. Uma vez que a escolha de um fornecedor qualificado e de confiança é um elemento chave na redução dos custos de compras e logística, a seleção de fornecedores é cada vez mais reconhecida como uma decisão crítica na gestão da cadeia de suprimento (DAHEL, 2003; MILLINGTON ET AL., 2006).

Concatenando essas análises, pode-se concluir que o mercado passa por um processo de transformação e a logística é um fator fundamental para garantir o nível de competitividade das empresas e consequentemente faz parte de um cenário que busca obter menores custos e um melhor nível de serviço. Um dos fatores fundamentais para obtenção destes resultados é a escolha dos fornecedores. Informações sobre o mercado de logística relativo ao problema de seleção de fornecedores estão descritas no Apêndice A.

Selecionar adequadamente fornecedores pode ser definido como um problema complexo, devido às seguintes características (KEENEY, 1982): 
- Múltiplos objetivos: Os objetivos principais são a busca por redução dos custos envolvidos na contratação e por atingir o nível de serviço esperado com a referida contratação, embora ainda existam outros objetivos secundários;

- Intangibilidade: Com relação ao custo e nível de serviço existe a intangibilidade consequente da percepção dos envolvidos sobre qual realmente seria a disponibilidade de recursos prevista e o nível de serviço esperado com esta contratação. Na ótica do departamento financeiro e de compras sistematicamente tem-se como objetivo reduzir os custos ao máximo, pois isso vai conduzir a uma melhor utilização dos recursos financeiros da empresa e do orçamento previsto enquanto a área comercial e de atendimento ao cliente objetiva o máximo do nível de serviço para ampliar e facilitar as relações comerciais e o tratamento de conflitos;

- Vários tomadores de Decisão: Normalmente em empresas de grande porte devem participar dessa decisão a área de compras que conduz o processo, a área financeira, a área comercial e a área de logística e operações representadas por seus respectivos executivos;

- Trade-off: Existe um trade-off principal que vai balancear todo esse processo de decisão, a relação entre custo e nível de serviço. Repare que conforme exposto a respeito da intangibilidade existe uma relação de conflito de interesses interna a organização e que neste momento será traduzida por uma "guerra" de forças políticas conduzindo a uma decisão final, que pode ser mais ou menos favorável, a cada um dos envolvidos;

- Dificuldade de identificar alternativas boas e robustas: A escolha das transportadoras que vão participar do processo e a confiabilidade nos dados apresentados, exceto no caso de atuais fornecedores, dificultam a identificação de quais alternativas são as melhores;

- Horizontes de Longo Prazo: A decisão deve ser consistente o suficiente para que após a escolha não sejam necessárias uma substituição e suas consequências;

- Riscos e Incertezas: Uma decisão incorreta na escolha de um fornecedor pode trazer resultados irrecuperáveis à organização. Ao operar com uma empresa de logística inadequada, o impacto no nível de serviço pode afetar de forma significativa a competitividade em determinados mercados. 
A seleção de fornecedores de logística é um problema complexo que possui diversos critérios de decisão e um grande número de potenciais fornecedores de serviço. Desta forma, é preciso analisar se os meios que estão sendo utilizados para alcançar os objetivos de redução de custos e melhora no nível de serviço estão levando em consideração todos os critérios necessários para uma correta tomada de decisão.

Portanto, a linha de estudo aqui sugerida busca desenvolver uma proposta de processo de seleção que contemple tais aspectos de maneira explícita e facilmente compreensível pelos contratantes e transparentes para os fornecedores. Esta proposta deve analisar e ponderar as características de problemas complexos de forma direta no modelo, ou não sendo possível, através de considerações durante a sua aplicação prática.

Ho et al. (2010) analisaram a utilização de abordagens multicritérios na tomada de decisão para avaliação e seleção de fornecedores entre 2000 a 2008. Em primeiro lugar, verificou-se que inúmeras abordagens individuais ou integradas, foram propostas para resolver o problema de seleção de fornecedores.

Todas essas abordagens analisadas foram capazes de lidar com múltiplos fatores quantitativos e qualitativos. Observou-se também que preço, ou custo, não é o critério mais amplamente adotado nos trabalhos acadêmicos, pois existem critérios que foram mais utilizados para avaliar o desempenho dos fornecedores: qualidade $\mathrm{e}$ prazo de entrega. Segundo os autores, isso prova que a abordagem tradicional de utilizar o custo mais baixo como único critério de seleção não é robusta o suficiente para suportar um processo de seleção contemporâneo.

Desta forma, a abordagem de custo tradicional não pode garantir que a escolha do fornecedor selecionado é a ideal porque os critérios de orientação (qualidade, entrega, flexibilidade, entre outros) não foram devidamente considerados (HO ET AL. 2010). 


\subsection{OBJETIVOS DO TRABALHO}

Este trabalho tem como principal objetivo propor um modelo de seleção de fornecedores que suporte a natureza multicriterial do problema, seja de fácil aplicação prática e possa auxiliar o processo de negociação com os fornecedores.

Este modelo será aplicado em dois problemas relevantes da logística: seleção de fornecedores de transporte fracionado $(L T L)$ e seleção de prestadores de armazenagem no modelo 4PL.

Os objetivos específicos deste trabalho são:

- Identificar na literatura especializada a utilização de abordagens multicritério para seleção de fornecedores;

- Apresentação conceitual da abordagem escolhida;

- Desenvolver um modelo multicritério de seleção de fornecedores que se adéque às necessidades das empresas contratantes;

- Aplicar o modelo proposto em dois casos práticos de logística relevantes com as respectivas análises de decisão e robustez dos resultados obtidos;

- Discussão dos resultados obtidos e possibilidade de renegociação junto aos fornecedores e apoio à decisão final de escolha do fornecedor.

- Analisar os resultados obtidos através de uma avaliação comparativa com outros trabalhos ou aplicações de periódicos publicados sobre o tema; 


\subsection{ORGANIZAÇÃO DA DISSERTAÇÃO}

A organização deste trabalho será estruturada da seguinte forma para se atingir os objetivos esperados:

- Capitulo 1: discussão sobre o objeto de estudo, sua relevância e apresentação dos objetivos deste trabalho;

- Capitulo 2: revisão bibliográfica da utilização de metodologia multicritérios em problemas de seleção de fornecedores. Inclui a evolução histórica do conhecimento científico sobre este assunto, os modelos existentes e amplitude de utilização;

- Capitulo 3: apresentação do modelo conceitual utilizado nesse trabalho de forma detalhada incluindo as premissas, sua aplicação prática, os benefícios gerados com essa aplicação e as potencialidades da ferramenta frente às outras aplicações semelhantes;

- Capitulo 4: descrição da aplicação prática do modelo em dois problemas: seleção de uma rota de transporte fracionado e seleção de um prestador de serviços de armazenagem. Estas aplicações foram realizadas em duas empresas de grande porte. Todas as partes práticas dos processos serão descritas e embasadas no modelo conceitual incluindo os resultados e sua aderência no mercado;

- Capitulo 5: Conclusão final do estudo, principais contribuições, limitações e possibilidades de aplicações futuras e evoluções no estudo. 


\section{PESQUISA BIBLIOGRÁFICA}

A pesquisa bibliográfica foi estruturada por assuntos considerados essenciais para um correto entendimento da evolução histórica das pesquisas sobre seleção de fornecedores: introdução sobre a pesquisa, características do processo de seleção de fornecedores, critérios utilizados, abordagens aplicadas, avaliação dessas abordagens e áreas de estudo das aplicações.

\subsection{INTRODUÇÃO}

A pesquisa bibliográfica foi centralizada na aplicação da abordagem $M C D A$ na seleção de fornecedores. Multiple Criteria Decision Analysis ou Multiple Criteria Decision Aid foi traduzido no Brasil por Ensslin et al. (2000) como Multicritérios em Apoio à Decisão.

MCDA pode ser definido como um termo amplo que descreve a coleção de abordagens formais que pretendem explicitar os vários critérios que ajudam os indivíduos ou grupos, explorarem as decisões que importam (BELTON E STEWART, 2002).

Pesquisando sobre o tema MCDA nos principais sites especializados (Emerald, Ingenta, MetaPress, ProQuest e ScienceDirect) foram identificados mais de 1.000 trabalhos publicados em periódicos científicos internacionais. Entre estes trabalhos foram encontradas algumas aplicações e revisões bibliográficas sobre a utilização de abordagens MCDA na seleção de fornecedores que é especificamente nosso objeto de estudo.

A utilização de abordagens multicritério na seleção de fornecedores é amplamente estudada no mundo, embora as citações com caso prático sejam em menor número. O foco desta pesquisa está concentrado nas publicações em referências dos últimos 20 anos. 
Conforme pode ser comprovado na Tabela 1, as revisões encontradas têm alto nível de inter-relação entre $\mathrm{si}$, ou seja, os trabalhos podem ser entendidos como evoluções do tema no decorrer do tempo, pois a quase totalidade dos trabalhos de revisão publicada faz referência direta ou indireta aos trabalhos que já haviam sido publicados. 
Tabela 1 - Revisões Bibliográficas sobre aplicação de $M C D A$ na seleção de Fornecedores

\begin{tabular}{|c|c|c|c|c|c|c|}
\hline Ref. & Título Traduzido & Autores & Periódico & Ano & Relevância para a dissertação & Inter-relação \\
\hline A & $\begin{array}{l}\text { Critérios de seleção de } \\
\text { fornecedores e métodos }\end{array}$ & $\begin{array}{l}\text { Charles A. Weber, } \\
\text { John R. Current e } \\
\text { W.C. Benton }\end{array}$ & $\begin{array}{l}\text { European Journal of } \\
\text { Operational Research }\end{array}$ & 1991 & $\begin{array}{c}\text { Embora este artigo não tenha foco somente em abordagens MCDA ele descreve de forma criteriosa a definição dos } \\
\text { critérios a serem utilizados em um processo de seleção e suas origens. Além disso, revisa os } 74 \text { artigos publicados } \\
\text { sobre seleçãoo de fornecedores entre } 1967 \text { e } 1990 \text {. }\end{array}$ & - \\
\hline B & $\begin{array}{l}\text { Uma abordagem } \\
\text { multiobjetivo para seleção de } \\
\text { fornecedores }\end{array}$ & $\begin{array}{l}\text { Charles A. Weber e } \\
\text { John R. Current }\end{array}$ & $\begin{array}{l}\text { European Journal of } \\
\text { Operational Research }\end{array}$ & 1993 & $\begin{array}{l}\text { Este artigo é um complemento ao assunto abordado em } 1991 \text { com um enfoque maior nos "trade offs" entre critérios e } \\
\text { na natureza multi-objetivo dos problemas de seleçẫo. }\end{array}$ & A \\
\hline C & $\begin{array}{l}\text { Uma abordagem de } \\
\text { otimização na determinação } \\
\text { do número de fornecedores a } \\
\text { ser empregado }\end{array}$ & $\begin{array}{l}\text { Charles A. Weber, } \\
\text { John Current e } \\
\text { Desai }\end{array}$ & $\begin{array}{l}\text { Supply Chain } \\
\text { Management: An } \\
\text { International Journal }\end{array}$ & 2000 & $\begin{array}{l}\text { Apresenta a proposta de uma abodagem que combina duas metodologias para seleçãa de fornecedores. O MOP é } \\
\text { utilizado para definir o número de fornecedores e posteriormente o DEA é utilizado para definir a eficiência de cada um } \\
\text { dos fornecedores escolhidos. A utilizaçâao do modelo para a área de logistica também é explorada. }\end{array}$ & $A$ e $B$ \\
\hline D & $\begin{array}{l}\text { Uma avaliação dos modelos } \\
\text { de seleção de fornecedores a } \\
\text { partir de uma perspectiva de } \\
\text { custo total de posse }\end{array}$ & $\begin{array}{l}\text { Zeger Degraeve, } \\
\text { Eva Labro, Filip } \\
\text { Roodhooft }\end{array}$ & $\begin{array}{l}\text { European Journal of } \\
\text { Operation Research }\end{array}$ & 2000 & $\begin{array}{l}\text { Este trabalho revisa os modelos utilizados para seleção de fornecedores entre } 1986 \text { e } 1999 \text {. Também são abordados } \\
\text { custos periféricos que interferem em um processo de seleção incluindo o próprio custo do processo de seleção. }\end{array}$ & $A$ e $B$ \\
\hline $\mathbf{E}$ & $\begin{array}{l}\text { Revisão de Métodos para } \\
\text { Suportar Seleção de } \\
\text { Fornecedores }\end{array}$ & $\begin{array}{l}\text { Luitzen de Boer, } \\
\text { Eva Labro, } \\
\text { Pierangela } \\
\text { Morlacchi }\end{array}$ & $\begin{array}{l}\text { European Journal of } \\
\text { Purchasing and Supply } \\
\text { Management }\end{array}$ & 2001 & $\begin{array}{l}\text { Uma criteriosa revisão da literatura é descrita aonde sãa apresentadas as principais metodologias aplicáveis em cada } \\
\text { uma das fases do processo de seleçãa, são elas: deaniçãa do problema, formulação de critérios, pré--qualificação dos } \\
\text { fornecedores e escolha do fornecedor. Fatos externos ao processo como globalizaçâa também sâo discutidos como } \\
\text { dificultadores do processo. }\end{array}$ & $A, B$ e D \\
\hline $\mathbf{F}$ & $\begin{array}{l}\text { Prática e formalização na } \\
\text { seleção de fornecedores: um } \\
\text { estudo de quatro casos } \\
\text { empíricos }\end{array}$ & $\begin{array}{l}\text { L. de Boer e L.L.M } \\
\text { van der Wegen }\end{array}$ & $\begin{array}{l}\text { Journal of Purchasing \& } \\
\text { Supply Management }\end{array}$ & 2003 & $\begin{array}{l}\text { São discutidos aspectos relativos a influência do decisor no processo de decisão e do modelo a ser utilizado. Deve ser } \\
\text { avaliada a utilização de softwares para apoio, a qualidade da informação, os custos do processo de seleção e a } \\
\text { impotância e os riscos desta decisão para que seja possivel definir o modelo a ser utilizado. }\end{array}$ & $\begin{array}{l}\text { A, B, C, } \\
\text { D e E }\end{array}$ \\
\hline G & $\begin{array}{l}\text { Seleção de fornecedores: } \\
\text { Revisão da Literatura sobre } \\
\text { Metodologia } \\
\end{array}$ & $\begin{array}{l}\text { M. Khurrum S. } \\
\text { Bhutta }\end{array}$ & $\begin{array}{l}\text { Journal of International } \\
\text { Technology and } \\
\text { Information Management }\end{array}$ & 2003 & $\begin{array}{l}\text { Através de uma pesquisa em } 154 \text { artigos entre } 1986 \text { e } 2002 \text { são classificados os artigos de acordo com a frequencia de } \\
\text { publicaçâao, conteúdo, ano de publicação, metodologias utilizadas e possibilidades de estudo futuro. Existe também } \\
\text { uma proposta de esquema para classificaçâão dos artigos de acordo com seu conteuudo. }\end{array}$ & $\begin{array}{l}\text { A, B, C } \\
\text { e D }\end{array}$ \\
\hline $\mathbf{H}$ & $\begin{array}{l}\text { Revisão e critica as Práticas } \\
\text { e Processos de seleção de } \\
\text { fornecedores }\end{array}$ & Mahmut Sonmez & $\begin{array}{l}\text { Business School Papers } \\
\text { Series } 2006\end{array}$ & 2006 & $\begin{array}{l}\text { Este artigo avalia o processo de selação através da pesquisa de } 147 \text { artigos entre } 1985 \text { e } 2005 \text {. São propostas fases } \\
\text { para seleção de fornecedores com base na literatura e a classificação dos artigos quanto o periódico de publicação e } \\
\text { abordagem escolhida. Um resumo dos trabalhos sobre critérios e apresentação de artigos que abordam os temas: } \\
\text { relaçâao compradorffornecedor, seleção internacional e seleção eletrônica também é apresentado. }\end{array}$ & $\begin{array}{l}\text { A, C, D, } \\
\text { E e F }\end{array}$ \\
\hline I & $\begin{array}{l}\text { Seleção de fornecedores na } \\
\text { indústria farmacêutica. Um } \\
\text { processo de abordagem de } \\
\text { rede analítica }\end{array}$ & $\begin{array}{l}\text { Konstantinos } \\
\text { Kirytopoulos, } \\
\text { Vrassidas } \\
\text { Leopoulos e Dimitra } \\
\text { Voulgaridou }\end{array}$ & $\begin{array}{l}\text { Benchmarking: An } \\
\text { International } \\
\text { Journal }\end{array}$ & 2008 & $\begin{array}{l}\text { Conclui-se que o processo de avaliação e seleção de fornecedores e os problemas relativos a cadeia de abastecimento } \\
\text { saáo problemas multicritério e a ferramenta de resolução deve suportar tal análise. Fatores em alinhamento com este } \\
\text { estudo como os critérios a serem definidos, número de alternativas e restriçôes sấo discutidos. }\end{array}$ & $C$ e E \\
\hline $\mathbf{J}$ & $\begin{array}{l}\text { O processo de hierarquia } \\
\text { analítica no problema de } \\
\text { seleção de fornecedores }\end{array}$ & $\begin{array}{l}\text { Giuseppe Bruno, } \\
\text { Emilio Esposito, } \\
\text { Andrea Genovese e } \\
\text { Renato Passaro }\end{array}$ & $\begin{array}{l}\text { Proceedings of the } \\
\text { International Symposium } \\
\text { on the Analytic } \\
\text { Hierarchy Process }\end{array}$ & 2009 & $\begin{array}{l}\text { Este artigo tem foco na aplicação da abordagem AHP, discutindo aspectos de sua potencialidade, para seleção de } \\
\text { fornecedores. Um estudo sobre os critérios mais utilizados, principais jornais de publicaçâa e modelos utilizados } \\
\text { complementam o estudo. }\end{array}$ & E e F \\
\hline $\mathbf{K}$ & $\begin{array}{l}\text { Abordagem MCDM para } \\
\text { suportar Avaliação e Seleção } \\
\text { de Fornecedores. Revisão da } \\
\text { Literatura. } \\
\end{array}$ & $\begin{array}{l}\text { William Ho, Xiaowei } \\
\text { Xu, Prasanta K. } \\
\text { Dey }\end{array}$ & $\begin{array}{l}\text { European Journal of } \\
\text { Operation Research }\end{array}$ & 2010 & $\begin{array}{c}\text { Este trabalho faz uma criteriosa análise sobre as abordagens multicritério, ou combinação de abordagens, que foram } \\
\text { publicadas entre } 2000 \text { e } 2008 \text { exclusivamente para seleção de fornecedores, sua representatividade, autores, principais } \\
\text { critérios e escopo de trabalho. Através desta compilação de informações chegamos a conclusão de quais são hoje as } \\
\text { abordagens mais utilizadas e também quais os critérios mais relevantes. }\end{array}$ & $\begin{array}{c}\text { A, C, D } \\
\text { e E }\end{array}$ \\
\hline
\end{tabular}




\subsection{SELEÇÃO DE FORNECEDORES}

Diversos fatores tornam complexa a tomada de decisão de compra e, ademais, a globalização e a internet ampliaram as possibilidades de escolha. Tais fatores exigem agilidade e um amplo processo de seleção de fornecedores. Regulamentações públicas exigem mais transparência no processo e o novo fluxo decisório nas organizações leva ao envolvimento de um maior número de agentes decisores. A Figura 1 demonstra o impacto sobre a evolução da complexidade e importância das decisões de compra (DE BOER ET AL., 2001).

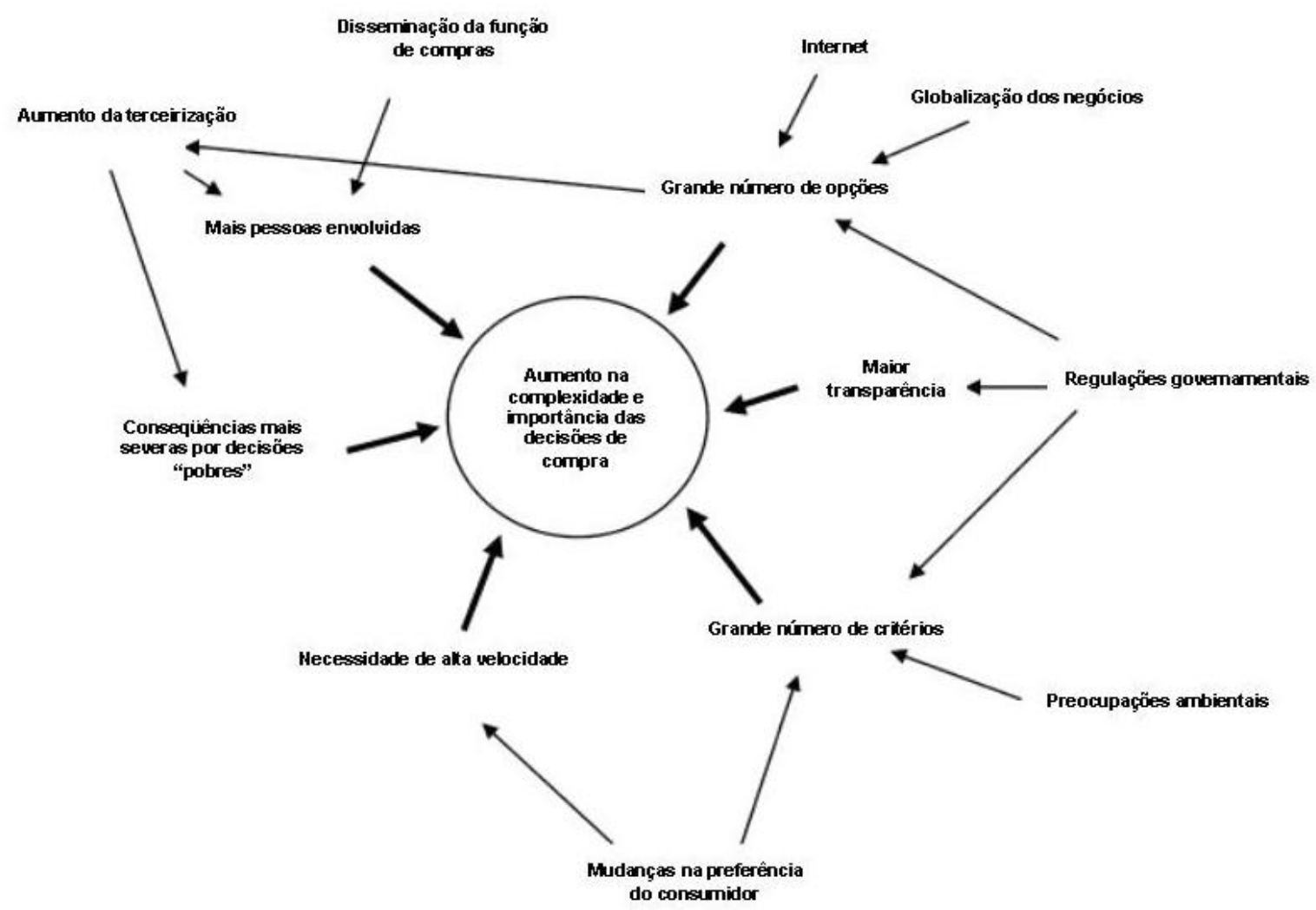

Figura 1 - Impacto sobre a evolução da complexidade e importância das decisões de compra Fonte: Tradução de De Boer et al. (2001)

O texto de Weber et al. (1991) já abordava a importância do grupo de fornecedores que serão escolhidos: "No atual ambiente operacional competitivo é impossível produzir com sucesso e baixo custo, produtos de alta qualidade, sem fornecedores satisfatórios. Assim, uma das mais importantes decisões de compra é a seleção e manutenção de um grupo competente de fornecedores". Tal afirmação faz referência ao trabalho de Howard Lewis que em 1943 apontava que o principal fator para a aquisição de materiais era a seleção adequada de fornecedores. 
Kirytopoulos et al. (2008) também abordou o tema e ressaltou que a escolha de um fornecedor qualificado e de confiança é um elemento-chave na redução de custos na aquisição de material e um fator essencial para se atingir os tempos de entrega necessários, sendo cada vez mais reconhecida como uma decisão crítica na gestão da cadeia de suprimento.

Weber et al. (2000) analisam que devido à importância estratégica e o número de incertezas e riscos associados ao processo de seleção de fornecedores, a atividade de compra é normalmente realizada por equipes multidisciplinares ao invés de decisões individuais do departamento de compras. O processo de seleção de fornecedores envolve direta e indiretamente diversos departamentos como produção, finanças, vendas e marketing. Assim, as equipes destes departamentos devem estar envolvidas no processo decisório de seleção de fornecedores em conjunto com a área de compras.

Outro fator de complexidade resulta de restrições políticas internas e externas que são impostas. Restrições políticas internas existem de forma implícita ou explicita no processo de compra, abordando questões como: número de fornecedores, quantidades mínimas e máximas, utilização de fornecedores de menor porte, etc. Da mesma forma, os fornecedores podem impor restrições sobre o processo, como quantidades mínimas e máximas a serem fornecidas ou sua vontade de fazer negócios com uma empresa particular. Estas restrições, em última análise, afetam o número de fornecedores e quantidades fornecidas (WEBER ET AL., 2000).

Kirytopoulos et al. (2008) concluíram em sua pesquisa que uma grande parcela do resultado no processo de seleção esta ligado ao aprendizado desenvolvido em outros processos.

Weber e Current (1993) analisaram que o problema de seleção de fornecedores tem aplicações específicas de acordo com sua natureza, isto é, as restrições adequadas e o valor relativo dos critérios de escolha na contratação variam de acordo com o tipo de problema. Portanto, não é possível especificamente que um modelo de contratação único seja funcional e apropriado para todos os cenários possíveis (DEMPSEY, 1979).

Em DeGraeve e Roodhooft (1999) é reconhecida uma estrutura hierárquica no processo de seleção: (1) o nível de atividades do fornecedor, (2) o nível de atividades dos pedidos e (3) o nível de atividades ligado aos produtos. Exemplos de 
custos ligados ao fornecedor incluem: custo de auditoria de qualidade para a avaliação de um fornecedor, custo de gerenciamento em compras, pesquisas adicionais e custos de desenvolvimento ligados ao processo. Os custos e as condições impostas cada vez que um pedido é feito com um determinado fornecedor incluem, entre outros, os custos associados com a recepção, faturamento, transporte, classificação, parte fiscal e contábil. Os custos e condições ligados aos produtos são: preço, falha interna, falha externa e inventário.

Sendo o processo de seleção um problema complexo, com várias alternativas de escolha e que envolve um grande número de diferentes decisores e custos parece conclusivo que existe a necessidade de uma metodologia que considere todos estes aspectos na resolução deste problema.

Devem-se considerar os modelos de decisão como instrumentos para divulgação, comunicação e exame das estruturas das preferências pessoais, da subjetividade e das incertezas ao invés de um formato rígido que não considere esses fatores. Vários pesquisadores têm relatado sobre os benefícios de se aplicar uma abordagem estruturada para a tomada de decisão na seleção de fornecedores (DE BOER ET AL., 2001).

Apesar de vários autores proporem uma variedade de fatores a serem considerados, foi avaliado que a importância no relacionamento e a complexidade do problema parecem ser realmente os fatores determinantes na escolha do modelo de decisão a ser aplicado. (DE BOER ET AL., 2001).

O quadro apresentado na Tabela 2 revisa os métodos de seleção de fornecedores e analisa a diversidade de situações em termos de complexidade e importância encontrada. Além disso, abrange as diferentes fases do processo de seleção de fornecedores: (1) descobrir exatamente qual objetivo na seleção de um fornecedor, (2) definir os critérios, (3) pré-qualificação de fornecedores adequados de acordo com os critérios e (4) fazer a escolha final. 
Tabela 2 - Estrutura do processo de seleção de fornecedores Fonte: Adaptação de De Boer, (1998)

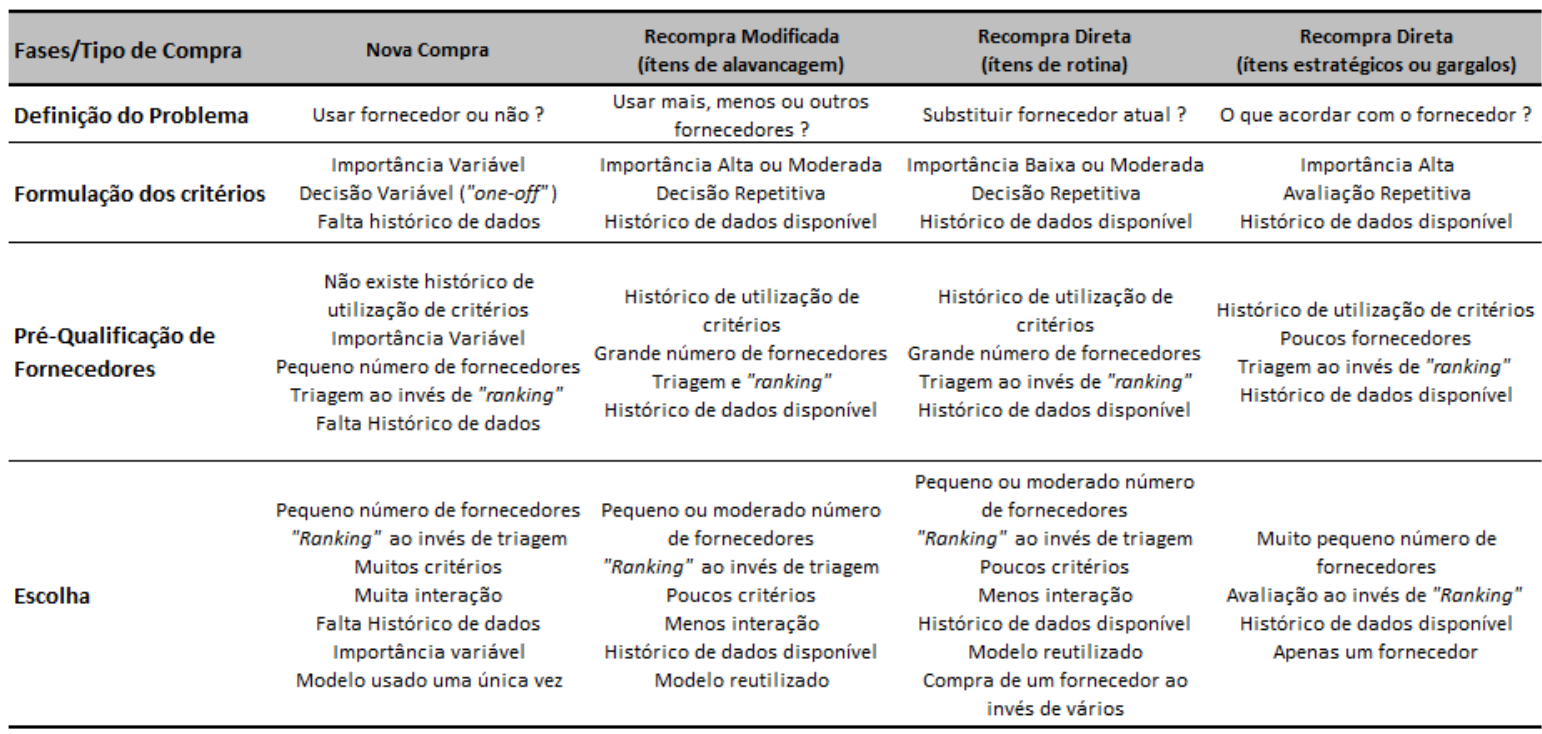

Finalmente, foi considerado que a análise da tomada de decisões estratégicas na seleção de fornecedores é outra área importante para pesquisas futuras. A grande maioria dos trabalhos publicados considera apenas as funções operacionais dentro das empresas, entretanto algumas empresas começaram a analisar também a função de compras como uma função estratégica (WEBER ET AL., 1991). O que parece ainda ser válido se for considerada a análise dos trabalhos mais recentes.

\subsection{CRITÉRIOS}

Weber et al. (1991) revisaram na literatura as publicações da área de compras sobre seleção de fornecedores. Uma atenção especial foi empregada ao trabalho desenvolvido por Dickson (1966), que forneceu uma visão abrangente dos critérios mais importantes que acadêmicos e profissionais encontraram para selecionar fornecedores.

Neste trabalho, foram apresentados os principais critérios na seleção de um fornecedor. Esses 23 critérios foram definidos com base em uma pesquisa que identificou mais de 50 fatores distintos que eram utilizados por acadêmicos e práticos na seleção de fornecedores, são esses os critérios escolhidos: 
1) O preço líquido (incluindo descontos e encargos);

2) A capacidade para atender especificações de qualidade;

3) O serviço de reparação oferecido por cada fornecedor;

4) A capacidade de cada vendedor para atender cronogramas de entrega;

5) A localização geográfica de cada fornecedor;

6) A situação financeira e crédito cada fornecedor;

7) As instalações de produção e capacidade produtiva;

8) A quantidade de negócios que já foram feitos;

9) A capacidade técnica (investigação e facilidades de desenvolvimento);

10) Organização e capacidade de gestão;

11) As futuras compras que cada fornecedor fará do contratante;

12) O sistema de comunicação entre contratante e fornecedor;

13) Os controles operacionais (relatórios, controle de qualidade e sistemas de controle de estoque);

14) A posição na indústria (produto, liderança e reputação) de cada fornecedor;

15) O registro das relações de trabalho de cada fornecedor;

16) O alinhamento da atitude de cada fornecedor com o contratante;

17) O desejo sobre o negócio do contratante mostrado por cada fornecedor;

18) As garantias e alinhamento de políticas;

19) A capacidade do fornecedor em atender os requisitos de embalagem;

20) A impressão através dos contatos pessoais;

21) A disponibilidade de treinamento e desenvolvimento;

22) Conformidade ou \% de cumprimento dos procedimentos;

23) Histórico do desempenho.

Esses critérios foram renomeados de forma resumida e classificados por Weber et al. (1991) com base no estudo de Dickson. A continuidade do trabalho foi avaliar os trabalhos publicados sobre o tema entre 1967 e $1990 \mathrm{com}$ base na utilização dos critérios listados acima. Os resultados, 74 trabalhos publicados, estão detalhados no Anexo A. 
Nestes 74 trabalhos publicados também foram classificados os critérios de acordo com o seu grau de utilização, conforme descrito na Tabela 3.

Tabela 3 - Nível de utilização dos critérios de seleção

Fonte: Adaptação aos dados de Weber et al., (1991)

\begin{tabular}{|c|c|c|}
\hline \multicolumn{3}{|l|}{ Critério } \\
\hline Preço Liquido & 61 & $82 \%$ \\
\hline Entrega & 44 & $59 \%$ \\
\hline Qualidade & 40 & $54 \%$ \\
\hline Capacidade e instalaçŏes de Produçăo & 23 & $31 \%$ \\
\hline Localizaçăio & 16 & $22 \%$ \\
\hline Capacidade técnica & 15 & $20 \%$ \\
\hline Organizaçăo e gerenciamento & 10 & $14 \%$ \\
\hline Reputaçăo e posiçăo na industria & 8 & $11 \%$ \\
\hline Situaçăo financeira & 7 & $9 \%$ \\
\hline Histórico de performance & 7 & $9 \%$ \\
\hline Serviço de reparaçăo & 7 & $9 \%$ \\
\hline Atitude & 6 & $\mathbf{8 \%}$ \\
\hline Habilidades de embalagem & 3 & $4 \%$ \\
\hline Controles operacionais & 3 & $4 \%$ \\
\hline Treinamento & 2 & $3 \%$ \\
\hline Alinhamento com o processo de seleçăo & 2 & $3 \%$ \\
\hline Relaçōes de trabalho & 2 & $3 \%$ \\
\hline Sistemas de comunicaçäo & 2 & $3 \%$ \\
\hline Reciprocidade & 2 & $3 \%$ \\
\hline Impressăo sobre a empresa & 2 & $3 \%$ \\
\hline Interesse pelo negócio & 1 & $1 \%$ \\
\hline Negócios neste segmento & 1 & $1 \%$ \\
\hline Garantias e créditos & 0 & $0 \%$ \\
\hline
\end{tabular}

A Tabela 3 indica que os critérios que tiveram o maior número de citações foram: Preço líquido (82\%), Entrega (59\%) e Qualidade (54\%). Estes valores estão um pouco divergentes dos valores encontrados no trabalho original, por terem sido calculados de forma mais precisa através de planilha eletrônica.

Ho et al. (2010) analisaram a frequência de utilização dos critérios de avaliação em 78 periódicos publicados entre 2000 e 2008 e chegaram à seguinte classificação:

- Qualidade: esteve presente em 68 destes trabalhos, representando 87,18\% de presença destes critérios nos 78 trabalhos publicados;

- Entrega: esteve em segundo lugar com 64 referências, 82,05\%;

- Custo: em terceiro com 63 referências, 80,77\%.

Conclui-se, analisando o período iniciado pelo trabalho de Dickson em 1966 até 2008, que as mudanças na definição dos principais critérios não são radicais. Em todos os trabalhos analisados: qualidade, entrega (que estão diretamente ligados ao nível de serviço) e custos são os critérios fundamentais. A Figura 2 demonstra a evolução histórica dos critérios de acordo com o grau de utilização. 


\begin{tabular}{|c|c|c|c|c|}
\hline Dickson (1966) & & Weber et. Al. (1991) & & Ho et. al. (2010) \\
\hline $\begin{array}{c}\text { Capacidade para atender especificações } \\
\text { de qualidade; }\end{array}$ & & Preço Liquido & & \\
\hline $\begin{array}{l}\text { Capacidade de cada vendedor para } \\
\text { atender cronogramas de entrega; }\end{array}$ & & Qualidade & & \\
\hline Histórico do desempenho. & & Serviço de reparação & & \\
\hline Garantias e alinhamento de politicas; & & Entrega & & \\
\hline $\begin{array}{c}\text { Instalações de produção e capacidade } \\
\text { produtiva; }\end{array}$ & & Localização & & \\
\hline $\begin{array}{l}\text { Preço liquido (incluindo descontos e } \\
\text { encargos); }\end{array}$ & & Situação financeira & & \\
\hline $\begin{array}{l}\text { Capacidade técnica (investigação e } \\
\text { facilidades de desenvolvimento); }\end{array}$ & & Capacidade e instalações de Produção & & \\
\hline $\begin{array}{l}\text { Situação financeira e crédito cada } \\
\text { fornecedor; }\end{array}$ & $\begin{array}{c}\text { Adaptação e } \\
\text { classificação } \\
\text { por } \\
\text { utilização }\end{array}$ & Negócios neste segmento & $\begin{array}{l}\text { Definição com } \\
\text { base na } \\
\text { utilização }\end{array}$ & \\
\hline $\begin{array}{l}\text { Conformidade ou } \% \text { de cumprimento dos } \\
\text { procedimentos; }\end{array}$ & & Capacidade técnica & & Qualidade \\
\hline $\begin{array}{l}\text { Sistema de comunicação entre } \\
\text { contratante e fornecedor; }\end{array}$ & & Organização e gerenciamento & & Entrega \\
\hline $\begin{array}{l}\text { Posição na indústria (produto, liderança e } \\
\text { reputação) de cada fornecedor; }\end{array}$ & & Reciprocidade & & Preço ou Custo \\
\hline $\begin{array}{l}\text { Desejo sobre o negócio do contratante } \\
\text { mostrado por cada fornecedor; }\end{array}$ & & Sistemas de comunicação & & \\
\hline Organização e capacidade de gestão; & & Controles operacionais & & \\
\hline $\begin{array}{l}\text { Controles operacionais (relatórios, } \\
\text { qualidade e sistemas de controle); }\end{array}$ & & Reputação e posição na industria & & \\
\hline $\begin{array}{l}\text { Serviço de reparação oferecido por cada } \\
\text { fornecedor; }\end{array}$ & & Relações de trabalho & & \\
\hline $\begin{array}{l}\text { Alinhamento da atitude de cada } \\
\text { fornecedor com o contratante; }\end{array}$ & & Atitude & & \\
\hline Impressão através dos contatos pessoais; & & Interesse pelo negócio & & \\
\hline $\begin{array}{l}\text { Capacidade do fornecedor em atender os } \\
\text { requisitos de embalagem; }\end{array}$ & & Garantias e créditos & & \\
\hline $\begin{array}{l}\text { Registro das relações de trabalho de } \\
\text { cada fornecedor; }\end{array}$ & & Habilidades de embalagem & & \\
\hline $\begin{array}{l}\text { Localização geográfica de cada } \\
\text { fornecedor; }\end{array}$ & & Impressão sobre a empresa & & \\
\hline $\begin{array}{l}\text { Quantidade de negócios que já foram } \\
\text { feitos; }\end{array}$ & & Treinamento & & \\
\hline $\begin{array}{l}\text { Disponibilidade de treinamento e } \\
\text { desenvolvimento; }\end{array}$ & & Alinhamento com o processo de seleção & & \\
\hline $\begin{array}{l}\text { Futuras compras que cada fornecedor } \\
\text { fará do contratante; }\end{array}$ & & Histórico de performance & & \\
\hline
\end{tabular}

Figura 2 - Avaliação histórica da utilização dos critérios por grau de utilização 
Parece indiscutível que os critérios devem se moldar ao problema e se adequar às expectativas dos decisores, visto que tal análise é abordada pela quase totalidade dos autores.

Situações específicas no processo de contratação podem requerer a utilização de novos critérios ou modificação das restrições do modelo para refletir suas necessidades (WEBER E CURRENT, 1993).

Diversos trabalhos sobre o assunto foram publicados e a maioria aborda que o processo de seleção é complexo devido ao grande número de critérios que devem ser analisados. Assim o processo de avaliação e seleção de fornecedores é um típico problema multicritério de tomada de decisão, envolvendo critérios qualitativos e quantitativos (KIRYTOPOULOS ET AL., 2008).

Além de existir mais de um critério de escolha na tomada de decisão, outra complexidade nas decisões de seleção é o fato de que um fornecedor pode ter diferentes características de desempenho para diferentes critérios. Por exemplo, um fornecedor pode fornecer um produto com o melhor preço por unidade, porém pode não ter o melhor desempenho de entrega ou de qualidade dentre os fornecedores concorrentes (WEBER ET AL., 2000).

Kirytopoulos et al. (2008) ainda ponderam que independente do método utilizado pelos pesquisadores, eles parecem concordar que o problema de seleção de fornecedores é agravado por objetivos conflitantes entre critérios e possibilidades atreladas a muitas alternativas (devido ao aumento da concorrência e da globalização), além das inúmeras restrições internas e externas impostas pelo processo de seleção. Tal conclusão explora a necessidade de escolher a mais adequada abordagem MCDA para resolução do problema.

Weber et al. (1991) concluíram que do fim da década de 60 até completar a década de $80,67 \%$ dos trabalhos eram multicritérios. Nos trabalhos mais recentes analisados praticamente a totalidade dos trabalhos analisados já utilizava uma abordagem multicritérios. 


\subsection{ABORDAGEM}

Considerando a natureza multicriterial da seleção de fornecedores e os outros fatores de complexidade do problema parece conclusivo que ferramentas de apoio devem ser utilizadas em sua solução.

Weber et al. (1991) realizaram uma análise dos trabalhos publicados entre 1967 e 1990 a respeito das abordagens quantitativas na seleção de fornecedores. Estes trabalhos estão descritos no Anexo A.

As abordagens presentes nestes trabalhos foram agrupadas em três categorias: (1) modelos de ponderação linear, (2) modelos de programação matemática e (3) estatística / abordagens probabilísticas. A abordagem mais utilizada foram os modelos de ponderação linear, que podem ser consideradas como uma abordagem multicritério (WEBER ET AL, 1991).

Dada a complexidade e importância econômica do assunto, os mesmos autores consideraram surpreendente a pouca atenção dada na literatura para a aplicação de métodos quantitativos para a seleção de fornecedores. À luz da natureza multiobjetivo do problema, foi considerado que a aplicação de técnicas de programação multi-objetivo seria outra área fértil de investigação no processo de seleção de fornecedores.

Weber e Current (1993) deram prosseguimento ao estudo de 1991 tratando especificamente da abordagem multi-objetivo. Foram estabelecidas as principais decisões no momento da seleção: quais fornecedores escolher e a quantidade a ser adquirida.

Os mesmos autores afirmaram que a análise multi-objetivo tem diversas vantagens: permite que diversos critérios sejam analisados em suas unidades de medida naturais e dessa forma elimina a necessidade de convergência em uma unidade única (tal como a monetarização de intangíveis).

A maior crítica às abordagens de otimização é que elas fornecem ao tomador de decisão uma única solução "ótima" e não um conjunto alternativo de decisões. Ao fornecer um conjunto de alternativas válidas e as compensações que Ihes são 
associadas, as técnicas multi-objetivo permitem ao tomador de decisão incorporar sua experiência pessoal e discernimento na tomada de decisão final.

Outra grande vantagem das técnicas multi-objetivo é que elas fornecem uma metodologia para analisar os impactos estratégicos e políticos nas decisões. Essas decisões frequentemente implicam em uma reordenação das prioridades estratégicas nos objetivos de uma empresa (WEBER E CURRENT, 1993).

Os dois métodos mais utilizados para geração de soluções para os problemas multiobjetivo são o método de ponderação (pesos) e o método de restrição (COHON, 1978).

De acordo com Weber e Current (1993), o método de ponderação resolve um problema que tenha objetivo único, onde este objetivo é uma combinação convexa das funções objetivo iniciais. Esta combinação convexa é determinada através da atribuição de pesos relativos aos objetivos iniciais e em sua combinação. A referida ponderação resulta em diversas soluções para o problema multi-objetivo original.

O método de restrição identifica soluções otimizando um dos objetivos iniciais (função objetivo) e criando restrições para considerar os outros objetivos. Várias soluções são geradas pela variação dos limites de restrição sobre os outros objetivos, (COHON, 1978).

As compensações entre os critérios são demonstradas na Figura 3 usando o perfil de performances (SCHILLING ET AL., 1983). Perfil de performance foi usado porque provou ser uma maneira eficaz de apresentar as compensações dos critérios em problemas com mais de dois objetivos. Na Figura 3 é exemplificado um eixo vertical para cada um dos três critérios (preço, entrega e qualidade). O valor a ser atribuído em cada critério, em seu eixo específico, é o valor atribuído para esse fornecedor dividido pela melhor solução possível para esse critério, neste caso, a melhor dentre os cinco fornecedores. Perfil de performance é um meio eficaz para demonstrar as compensações entre os critérios em problemas multi-objetivo. (WEBER E CURRENT,1993). 


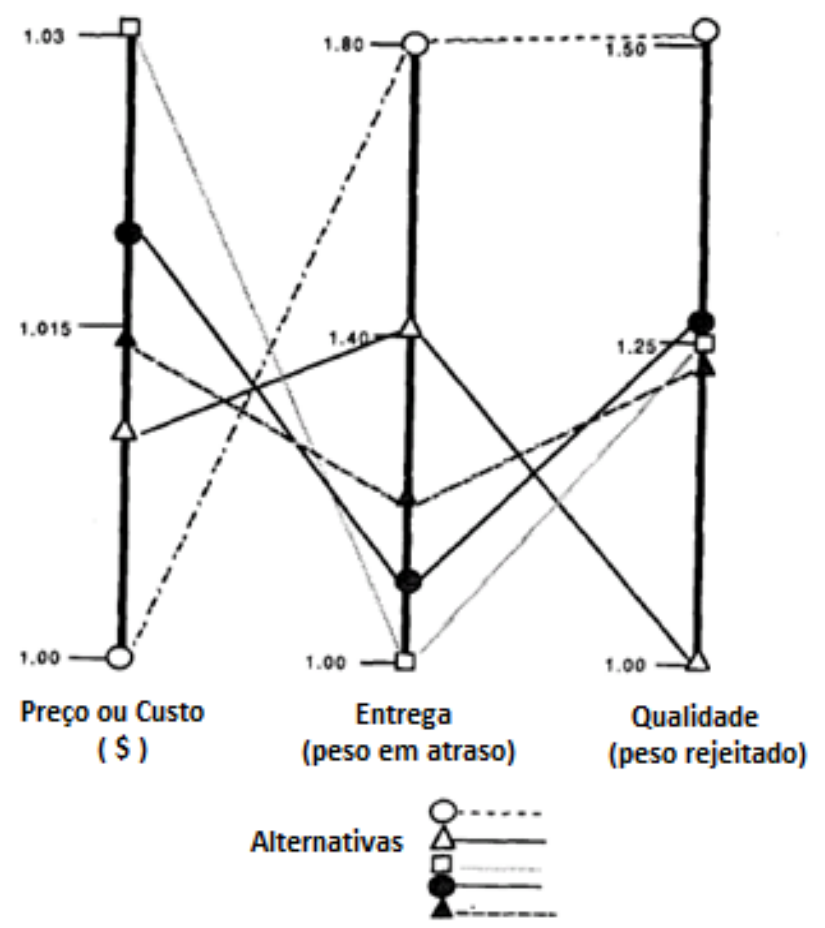

Figura 3 - Compensações entre critérios

Fonte: Adaptação de Weber e Current, (1993)

Degreave et al. (2000) propõe que programação multi-objetivos (MOP) e análise por envoltória de Dados (DEA) são ferramentas utilizadas como suporte ao MCDA.

Para esses autores a abordagem deve considerar, além do preço, todos os custos sobre o ciclo do serviço ou produto adquirido, tais como, aqueles relacionados ao próprio modelo de serviço, qualidade, entrega, administração, comunicação, falha, manutenção, etc. Tal consideração nos permite analisar as atividades e determinar os fatores de custo para as diferentes atividades definidas, denominado Método $\operatorname{ABC}(A B C)$.

Degreave et al. (2000) fizeram uma revisão da literatura e encontraram os periódicos publicados no período de 1986 a 1999 sobre seleção de fornecedores que estão descritos no Anexo B.

A revisão da literatura entre 1984 e 2000, realizada por De Boer (2001) é apresentada através da classificação dos trabalhos em relação à fase de aplicação da abordagem no processo de seleção e o tipo de compra que esta sendo avaliado. Tal análise esta detalhada no Anexo C.

De Boer et al. (2001) realizaram ainda uma pesquisa bibliográfica que incluí artigos sobre métodos ou técnicas que visam apoiar um decisor em uma ou mais das quatro etapas do processo de seleção do fornecedor, como anteriormente já foi definido. 
Os resultados da pesquisa foram divididos de acordo com o enquadramento das metodologias ou técnicas nas seguintes etapas:

1) Métodos de Decisão na definição do problema e formulação de critérios: Esta fase consiste em determinar qual é o problema principal e por que escolher um ou mais fornecedores;

2) Métodos de Decisão na pré-qualificação de fornecedores desejáveis: Esta etapa consiste em definir e determinar o conjunto de fornecedores aceitáveis (triagem) enquanto possíveis passos subsequentes servem para reduzir o número de fornecedores a considerar;

3) Modelos de Decisão na escolha final do fornecedor: A grande maioria dos modelos de decisão encontrados faz referência à fase de escolha do fornecedor no processo de seleção. Modelos de escolha do fornecedor podem ser distinguidos de acordo com a classificação: nova compra, recompra modificada e recompra direta, conforme relatado no Anexo C. Quase dois terços dos atuais modelos de escolha do fornecedor podem ser caracterizados como modelos únicos ou pacote de modelos, estes modelos consideram a seleção de um fornecedor para um produto ou um grupo de itens. Outra definição, modelos múltiplos, levam em conta as interdependências que podem existir entre os diferentes produtos ou grupos de produtos.

As aplicações em cada uma destas etapas, as fases de aplicação ou os métodos utilizados, os trabalhos publicados e os comentários dos autores da pesquisa, De Boer et al. (2001), estão descritos no Apêndice B.

Algumas abordagens na literatura de operações lidam explicitamente com a definição do problema e alguns exemplos destes métodos são mostrados na Tabela 4. Estas abordagens apresentadas podem contribuir de forma relevante para um melhor entendimento do problema e consequentemente a busca por uma melhor solução. 
Tabela 4 - Métodos e técnicas para definição de problemas Fonte: Adaptação de (De Boer et al., 2001)

\begin{tabular}{|c|c|}
\hline Método & Proposta para Seleção de Fornecedores \\
\hline WWS-analyse (Basadur et al., 1994) & $\begin{array}{l}\text { Investigar criticamente a mudança na base de fornecedores é apenas uma das várias } \\
\text { soluções. Talvez esta mudança não seja realmente necessária. }\end{array}$ \\
\hline Cognitive Mapping (Warren, 1995) & $\begin{array}{l}\text { Melhorar a compreensão dos fatores que desencadeiam a necessidade de mudanças } \\
\text { na base de fornecedores. }\end{array}$ \\
\hline AIDA (Rosenhead, 1989) & $\begin{array}{c}\text { Investigar se uma mudança na base de fornecedores é viável, e compativel com as } \\
\text { outras áreas de decisão. }\end{array}$ \\
\hline Strategy Generation Table (Howard, 1988) & $\begin{array}{l}\text { Propões uma única possibilidade possivel e razoável de mudança na base de } \\
\text { fornecedores fornecendo opções de desenvolvimentos e restrições. }\end{array}$ \\
\hline Influence Diagrams (Howard, 1988) & $\begin{array}{l}\text { Melhora a compreensão dos fatores que desencadeiam a necessidade de mudança na } \\
\text { base de fornecedores. Quadro de formulação de alternativas. }\end{array}$ \\
\hline (Arbel and Tong, 1982) & Gerar alternativas sistêmicas para alterar a base de fornecedores. \\
\hline
\end{tabular}

De forma análoga, a Tabela 5 mostra dois métodos existentes para formulação de critérios que não estão sendo utilizados na seleção de fornecedores e que também podem contribuir para um modelo mais eficaz.

Tabela 5 - Métodos para formulação dos critérios

Fonte: Adaptação de (De Boer et al., 2001)

\begin{tabular}{cc}
\hline Método & Proposta para Seleção de Fornecedores \\
\hline Rough sets (Slowinski, 1992) & $\begin{array}{c}\text { Avaliar a utilidade dos critérios existentes para avaliação e seleção de fornecedores. } \\
\text { Value focused thinking (Keeney, 1994) }\end{array}$ \\
\hline
\end{tabular}

Também foram identificados três métodos adicionais que parecem particularmente adequados para a fase de qualificação de fornecedores. Estes três modelos estão descritos na Tabela 6.

Tabela 6 - Sugestão de métodos de pré-qualificação de fornecedores Fonte: Adaptação de (De Boer et al., 2001)

\begin{tabular}{|c|c|}
\hline Método & Característica \\
\hline Conjunctive screening (Hwang and Yoon, 1981) & $\begin{array}{c}\text { Um fornecedor somente é aceitável se sua pontuação for igual ou superior a mínima } \\
\text { exigida em cada critério }\end{array}$ \\
\hline Disjunctive screening (Hwang and Yoon, 1981) & $\begin{array}{l}\text { Um fornecedor somente é aceitável se sua pontuação for igual ou superior a mínima } \\
\text { exigida em pelo menos um critério }\end{array}$ \\
\hline $\begin{array}{l}\text { Lexicographical screening } \\
\text { (Hwang and Yoon, 1981) }\end{array}$ & $\begin{array}{l}\text { Os critérios são classificados por ordem de importância. Os fornecedores serão } \\
\text { avaliados pelo critério mais importante. Os fornecedores que passam por este critério } \\
\text { são avaliados pelo segundo critério e assim por diante. }\end{array}$ \\
\hline
\end{tabular}

Esses modelos apresentados podem ser utilizados para excluir empresas do processo de seleção que não estejam aptas, reduzindo o número de participantes e qualificando o grupo de participantes. 
Em relação à aplicação de abordagens multicritérios, Sonmez (2006) revisou as abordagens utilizadas entre 1985 e 2005 na seleção de fornecedores e chegou à conclusão de que $22 \%$ dos métodos utilizados neste período eram MCDA.

O último trabalho a ser analisado, Ho et al. (2010), revisou na literatura a utilização das abordagens multicritérios na tomada de decisão para avaliação e seleção de fornecedores. Este objeto de estudo foi avaliado através dos artigos publicados nos periódicos entre 2000 e 2008.

Escolher efetivamente fornecedores envolve muito mais do que analisar uma série de lista de preços. As escolhas dependem de uma ampla gama de fatores que envolvem tanto dados quantitativos como qualitativos (HO ET AL., 2010).

Diversas abordagens para tomada de decisão em problemas multicritérios têm sido propostas na seleção de fornecedores: método de análise hierárquica $(A H P)$, o processo de análise de rede $(A N P)$, Raciocínio baseado em casos $(C B R)$, análise envoltória de dados $(D E A)$, teoria Fuzzy, algoritmo genético (GA), programação matemática, avaliação técnica com simples atributo (SMART) e híbridos de todas estas metodologias.

Outras conclusões a respeito da pesquisa de Ho et al., (2010) dizem respeito à frequência em que as abordagens estiveram presentes nos 78 trabalhos publicados de 2000 a 2008. Em 59\% dos trabalhos os pesquisadores utilizaram apenas uma metodologia de abordagem, por consequência $41 \%$ dos trabalhos utilizaram abordagens integradas. 


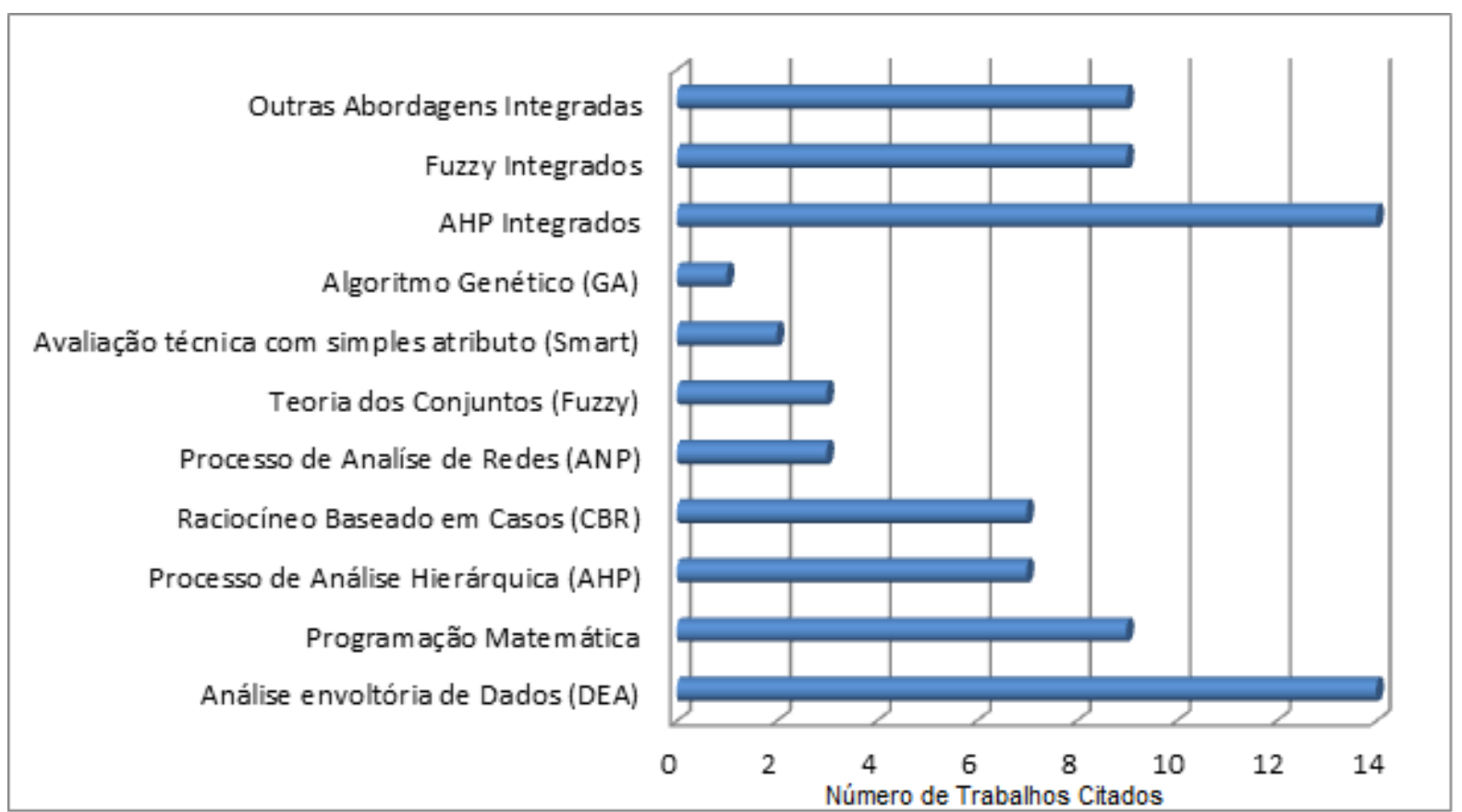

Figura 4 - Tipos de abordagem multicritério publicadas entre 2000 e 2008

Fonte: Dados extraídos de (Ho et AL., 2010)

A abordagem individual mais utilizada, conforme Figura 4, é o $D E A$, seguido de Programação Matemática, AHP, CBR, ANP, Fuzzy, SMART e GA. O DEA tem atraído mais atenção, principalmente por causa de sua robustez, (HO ET AL., 2010). Em relação às abordagens integradas, percebeu-se que as abordagens AHP são mais frequentes, Anexo D. Sua aplicabilidade está relacionada com a sua simplicidade, facilidade de uso, e grande flexibilidade (HO, 2008).

Além das razões citadas, outro ponto importante é que a verificação de consistência da abordagem $A H P$ contribui muito para evitar inconsistências porque a mesma atua como um mecanismo de feedback para os tomadores de decisão revisarem seus julgamentos. Tal mecanismo contribui para que as decisões tomadas sejam coerentes, o que pode ser considerado um ingrediente básico para boas tomadas de decisões.

Um ponto de atenção no método $A H P$ estaria relacionado com os resultados, pois esses seriam somente relacionados com os critérios estabelecidos e não considerariam as restrições de recursos. Por esse motivo a abordagem Goal Programming (GP) pode contribuir para o modelo incluindo essa compensação através de maiores informações geradas ao tomador de decisão. Talvez por esse motivo à abordagem AHP-GP foi a que apareceu com maior frequência entre as abordagens integradas (HO ET AL., 2010). 


\subsubsection{Aplicação da abordagem}

Weber et al. (1991) já havia concluído que na seleção de fornecedores a abordagem $M C D A$ era a mais utilizada entre os trabalhos pesquisados.

Entretanto, segundo análise de De Boer et al. (2001), não foi encontrada em nenhum dos trabalhos analisados a utilização de métodos de decisão na definição do problema. Na formulação de critérios foram encontradas apenas três aplicações, totalizando $2 \%$ dos trabalhos analisados. Para qualificação dos fornecedores foram encontrados 27 trabalhos, representando $20 \%$ do total, e o grande número de trabalhos publicados, $105 \mathrm{com} 78 \%$ de representatividade, foram aplicados na escolha dos fornecedores, Anexo C.

Em relação ao tipo de modelo utilizado, Degreave et al. (2000) avaliaram 24 modelos de 1986 a 1999. Foram utilizados quatro tipos de modelos na solução de problemas de seleção com a devida relevância: Modelos de Classificação (37\%), Custo Total (13\%), Programação Matemática (46\%) e Estatística (4\%). De Boer et al. (2001) refaz a análise incluindo cinco trabalhos que não haviam sido considerados no trabalho anterior e o resultado não demonstrou alterações relevantes: Modelos de Classificação (38\%), Custo Total (10\%), Programação Matemática (49\%) e Estatística (3\%).

Nos anos 2000, Weber et al. e Degreave et al. propõe a combinação de metodologias (MOP, $D E A, A B C$ ) na busca de uma melhor solução. Ho et al. (2010), 10 anos depois, constataram que aproximadamente $41 \%$ dos trabalhos publicados já utilizavam modelos integrados, o que demonstra um aumento substancial na utilização deste tipo de modelo.

Em complemento a análise sobre as abordagens de Ho et al. (2010), esta revisão faz uma avaliação do número de utilizações de cada uma dessas abordagens independente de tratar-se de uma abordagem individual ou integrada. Analisando todos os trabalhos do período obteve-se um número de 112 abordagens sendo utilizadas, sendo 46 utilizadas individualmente, 30 integradas duplas e duas integradas triplas. Apenas quatro modelos de abordagens representaram aproximadamente dois terços das utilizações, $66,07 \%$. Destes: $A H P$ teve frequência igual a 25 (22,32\%), DEA apareceu 21 vezes (18,75\%), Programação Matemática 16 
vezes (14,29\%) e Fuzzy 12 vezes (10,71\%). O resultado desta avaliação pode ser verificado na Figura 5.

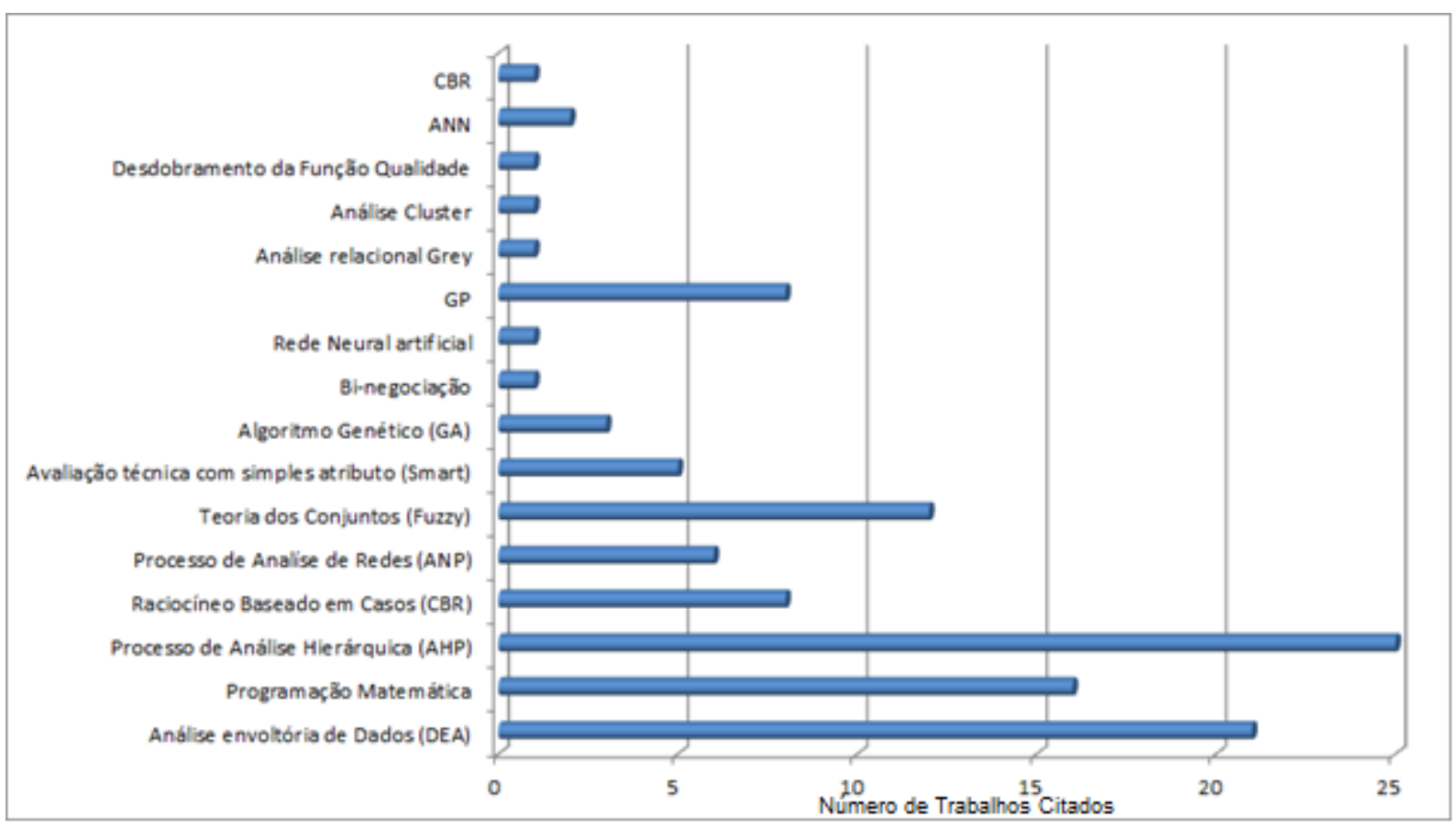

Figura 5 - Frequência de utilização por tipo de abordagem

Fonte: Dados extraídos de (Ho et AL., 2010)

\subsection{AVALIAÇÃO DA ABORDAGEM}

Baseado em um levantamento da literatura, Timmermans (1991) resume os critérios para avaliação de modelos de decisão em três categorias: critérios de resultados, critérios de processo e critérios práticos. Rohrmann (1986) sugere as seguintes categorias de critérios de avaliação: qualidade de decisão, benefícios indiretos, praticidade, satisfação do usuário e economia. Desta forma foi desenvolvido um modelo de avaliação que combina as contribuições de Timmermans e Rohrmann, e determina o grau em que o modelo se ajusta a complexidade da situação e pode ser implantado produzindo um custo/benefício favorável, conforme critérios descritos na Tabela 7 (DE BOER E WEGEN, 2003). 
Tabela 7 - Avaliação do modelo na seleção de fornecedores

Fonte: Adaptação de (De Boer e Wegen, 2003)

Complexidade
C1: O modelo agrega informação de forma adequada ?
C2: O modelo é suficientemente capaz de utilizar as informaçães disponiveis ?
C3: É possivel incorporar as opiniões e crenças dos envolvidos de forma satisfatória ?
C4: É possivel prover uma participação equitativa dos membros envolvidos, no caso de uma decisão em grupo, de forma satisfatória?
C5: O modelo é suficientemente flexivel para mudanças no processo decisório?
C6: O resultado do modelo de decisão é útil ? $\quad$ Custo / beneficio
C7: O resultado do modelo de decisão é aceitável?
C8: Os investimentos necessários são justificáveis?
C9: O modelo é de fácil utilização?
C10: A forma como o modelo de decisão funciona é suficientemente clara?
C11: O modelo de decisão foi capaz de aumentar a percepção sobre o processo decisório ?
C12: O modelo de decisão contribuiu para a comunicação dos envolvidos no processo de decisão?
C13: O modelo de decisão contribuiu para as habilidade necessárias em uma tomada de decisão?

Esta avaliação tem como objetivo avaliar o modelo de seleção escolhido através de sua complexidade e sua relação entre custo e benefício.

De Boer e Wegen (2003) estudaram problemas de seleção de fornecedores em quatro diferentes setores. O objetivo destas aplicações não era obter o "melhor método", mas descobrir o que os decisores consideram útil na utilização de modelos que suportam o processo de seleção de fornecedores utilizando diversas técnicas diferentes. A Tabela 8 sintetiza as informações sobre o contexto do experimento e os modelos de decisão utilizados. Este tipo de tabela possibilita uma visão geral sobre as escolhas propostas para o modelo em cada uma de suas fases através das ferramentas utilizadas.

Tabela 8 - Visão geral dos modelos utilizados nos experimentos Fonte: Tradução de (De Boer e Wegen, 2003)

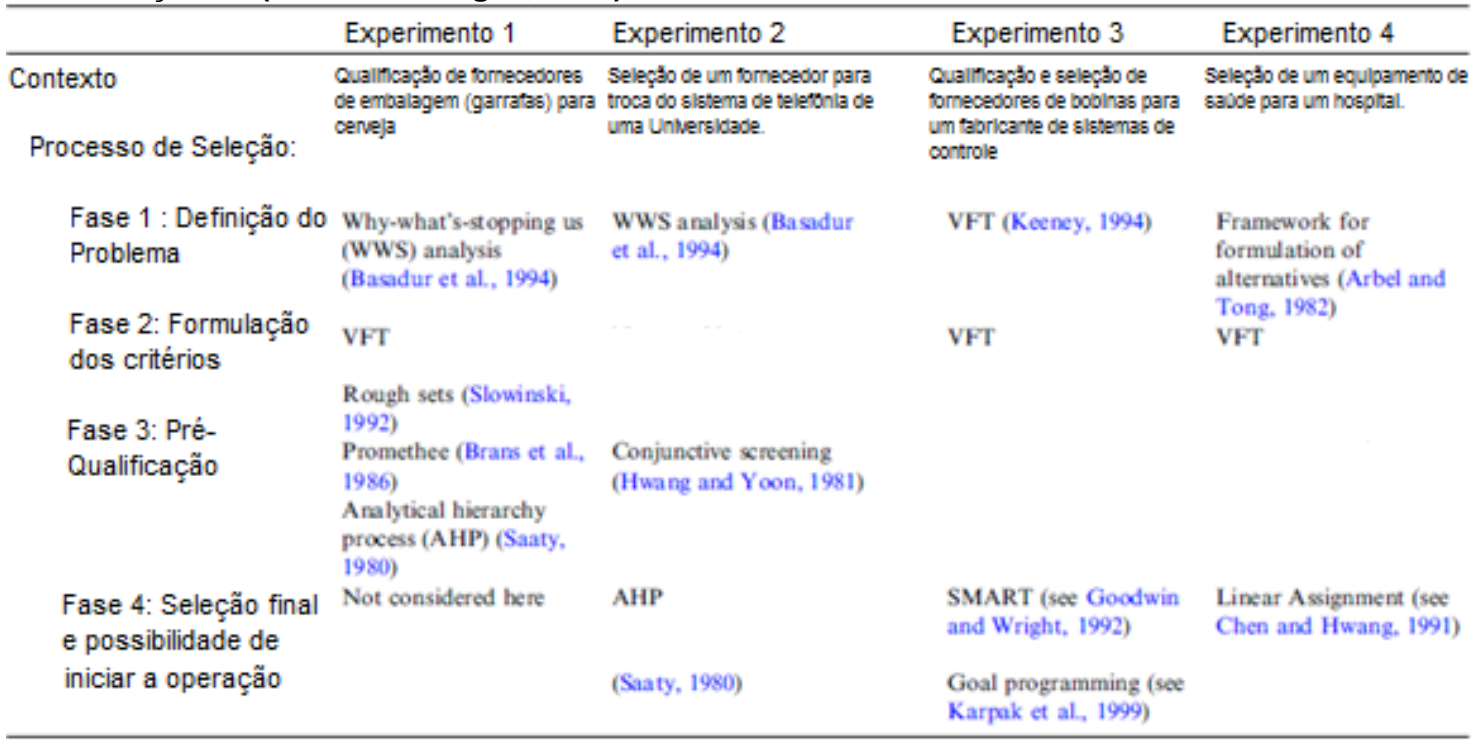


A análise de De Boer e Wegen (2003) revelou a importância de considerar a flexibilidade de um modelo de decisão ao longo do processo. Entretanto, um modelo de decisão extremamente flexível pode limitar a estrutura do modelo. Dependendo da respectiva importância da necessidade de flexibilidade para o tomador de decisão, modelos de decisão diferentes ou maneiras diferentes de utilização podem ser consideradas.

Além disso, requerem atenção específica à origem da informação fornecida pelos tomadores de decisão. Os resultados indicam a importância de uma abordagem diferenciada na aplicação de modelos de decisão em processos de seleção de fornecedores. Por exemplo, as diferenças quanto à quantidade e qualidade das informações disponíveis e o impacto financeiro da tomada de decisão tem influência nos diferentes tipos de modelos de decisão a serem escolhidos.

Isto implica que, em futuras pesquisas, a aplicabilidade de um novo modelo de decisão deve ser especificado de forma clara pois a maioria dos tomadores de decisão necessita de habilidade e treinamento para utilizar de forma eficaz os modelos de decisão (DE BOER E WEGEN, 2003).

Outro desafio, concluem os autores, é encontrar um equilíbrio adequado entre: (a) a variedade de modelos de decisão necessária para lidar com as muitas situações de compra diferentes em termos de importância e complexidade e (b) o custo total de implementação e manutenção dos modelos de decisão, que aumenta de acordo com o número de diferentes modelos de decisão utilizados.

Por último, deve ser considerada a importância no processo de seleção do aparecimento de ferramentas computacionais que cada vez mais oferecem oportunidades de apoio na tomada de decisão ao invés da tentativa de desenvolver todas as ferramentas de apoio localmente (GEOFFRION E KRISHNAN, 2001). 


\section{6 ÁREAS DE ESTUDO}

Outro ponto importante de análise são as áreas de estudo com um maior número de aplicações de abordagens multicritério na seleção de fornecedores.

Considerando o periódico em que estavam contidos os trabalhos publicados entre 1967 e 1990 como base, Anexo A, foi constatado que a área de compras era responsável por mais de $50 \%$ dos trabalhos publicados neste período sobre seleção de fornecedores enquanto periódicos da área de logística publicaram menos de $5 \%$ dos trabalhos. Se for incluída a área de produção, inventário e operações dentro da área de logística estar-se-ia tratando de um valor equivalente a $15 \%$ dos trabalhos publicados, vide Tabela 9.

Tabela 9 - Publicações dos trabalhos

Fonte: Tradução de Weber et al., (1991)

\begin{tabular}{lrr}
\hline $\begin{array}{l}\text { Neriódico } \\
\text { artigos }\end{array}$ & (\%) \\
\hline $\begin{array}{l}\text { Journal of Purchasing and Materials } \\
\quad \text { Management }\end{array}$ & 33 & 45 \\
$\begin{array}{l}\text { Journal of Purchasing } \\
\text { Management Science }\end{array}$ & 5 & 6 \\
Decision Sciences & 5 & 6 \\
Production and Inventory Management & 4 & 5 \\
Computers and Operations Research & 3 & 4 \\
Journal of Business Logistics & 3 & 4 \\
International Journal of Production & 3 & 4 \\
$\quad$ Research & 3 & \\
Journal of Marketing & 3 & 4 \\
Journal of Marketing Research & 2 & 4 \\
Journal of Operational Research Society & 1 & 3 \\
European Journal of Operational & & 1 \\
$\quad$ Research & 1 & \\
Journal of Retailing & 1 & 1 \\
Industrial Marketing Management & 1 & 1 \\
Journal of Operations Management & 1 & 1 \\
Interfaces & 1 & 1 \\
Harvard Business Review & 1 & 1 \\
Operations Research & 1 & 1 \\
Decision Sciences Institute Conf. Proc. & 1 & 1 \\
International Journal of Production & & 1 \\
$\quad$ Management & 1 & 1 \\
\hline & 1 & 1 \\
\hline
\end{tabular}

Bhutta (2003) avaliou 154 periódicos entre 1986 e 2002 e nos resultados, mostrados na Tabela 10, é possível observar um aumento considerável na representatividade da logística. Nestas publicações $29 \%$ eram relativos à área de logística e se for considerada a área de produção, inventário e operações este número será maior que $45 \%$. Neste novo estudo a área de compras era responsável por menos de $17 \%$ dos periódicos. 
Tabela 10 - Frequência de publicações de seleção de fornecedores

Fonte: Tradução de Bhutta, (2003)

\begin{tabular}{|c|c|c|}
\hline Períodico de Publicação & Quantidade & $\%$ \\
\hline Maiores Contribuidores & & 42.13 \\
\hline International Journal of Purchasing and Materials Management & 13 & 8.18 \\
\hline International joumal of Physical Distribution and Logistics Management & 10 & 6.29 \\
\hline Journal of Business Research & 10 & 6.29 \\
\hline Purchasing & 9 & 5.66 \\
\hline $\begin{array}{l}\text { The journal of Supply Chain Management - A Global Review of Purchasing } \\
\text { and Supply }\end{array}$ & 7 & 4.40 \\
\hline International Journal of Production Economics & 6 & 3.77 \\
\hline Journal of Purchasing and Materials Management & 6 & 3.77 \\
\hline Supply Chain Management: An International Joumal & 6 & 3.77 \\
\hline Médios Contribuidores & & 18.90 \\
\hline European Journal of Operational Research & 4 & 2.52 \\
\hline International Journal of Operations \& Production Management & 4 & 2.52 \\
\hline Production \& Inventory Management Joumal & 4 & 2.52 \\
\hline European Journal of Purchasing \& Supply Management & 3 & 1.89 \\
\hline International Journal of Retail \& Distribution Management & 3 & 1.89 \\
\hline Journal of Operations Management & 3 & 1.89 \\
\hline Logistics Focus & 3 & 1.89 \\
\hline Supply Management & 3 & 1.89 \\
\hline Menores Contribuidores & & 38.97 \\
\hline Decision Sciences & 2 & 1.26 \\
\hline Industrial Marketing Management & 2 & 1.26 \\
\hline Integrated Manufacturing Systems & 2 & 1.26 \\
\hline International Journal of Logistics Management & 2 & 1.26 \\
\hline International Journal of Physical Distribution \& Materials Management & 2 & 1.26 \\
\hline Journal of Accounting and Public Policy & 2 & 1.26 \\
\hline Journal of Cost Management & 2 & 1.26 \\
\hline Journal of Supply Chain Management & 2 & 1.26 \\
\hline Long Range Planning & 2 & 1.26 \\
\hline Management Science & 2 & 1.26 \\
\hline Production \& Inventory Management Review \& Apics News & 2 & 1.26 \\
\hline Purchasing \& Supply Management & 2 & 1.26 \\
\hline British Journal of Management & 2 & 1.26 \\
\hline International Journal of Physical \& Logistics management & 1 & 0.63 \\
\hline Logistics Information Management & 1 & 0.63 \\
\hline Logistics Management \& Distribution Report & 1 & 0.63 \\
\hline Production \& Operations Management & 1 & 0.63 \\
\hline Others $^{\text {in }}$ & 35 & 20.07 \\
\hline
\end{tabular}

Nestes trabalhos analisados foi avaliada também a área de estudo do conteúdo da publicação. Os resultados estão demonstrados na Tabela 11. 
Tabela 11 - Classificação dos periódicos (conteúdo)

Fonte: Tradução de Bhutta, (2003)

\begin{tabular}{|l|c|c|}
\hline & Quantidade & $\%$ \\
\hline Conceitual & 56 & 36 \\
\hline Estudo de Caso & 21 & 14 \\
\hline Critérios & 16 & 10 \\
\hline Revisão da Literatura & 2 & 1 \\
\hline Modelos matemáticos & 27 & 18 \\
\hline Metodologia & 32 & 21 \\
\hline
\end{tabular}

O resultado da análise confirma que o número de estudos de caso é reduzido, 14\%, e grande parte dos trabalhos publicados tem um desenvolvimento mais conceitual do que baseado em aplicações práticas.

\subsection{CONCLUSÃO}

\subsubsection{Aderência}

Avaliando a aderência desta dissertação com a pesquisa bibliográfica pode-se concluir que o tema escolhido é relevante, principalmente pelo reduzido número de casos práticos aplicados conforme observado por De Boer et al. (2001).

Conforme abordado na introdução, selecionar de forma correta fornecedores é fundamental para a garantia de competitividade, o que foi ratificado por Weber et al. (2001). Kirytopoulos et al. (2008) confirmou o caráter multicritério e defendeu a utilização da abordagens $M C D A$ para sua solução de problemas de seleção de fornecedores, assim como, Ho et al. (2010), que foram categóricos ao definir que uma abordagem multicritério pode ser considerada bem melhor que a abordagem atual utilizada em processos de seleção.

Como apoio à definição e maior entendimento do problema, De Boer et al. (2001), sugeriu a utilização do mapa cognitivo. 
De Boer et al. (2001) propõe a seguinte sequência ao processo: definir os objetivos esperados com o processo de seleção, definir os critérios para se atingir estes objetivos (incluindo inclusão/rejeição), qualificar os fornecedores segundo esses critérios e fazer escolha final.

Em seu trabalho posterior, ainda em relação ao formato do processo, De Boer e Wegen (2003) defendem a utilização de software na solução deste tipo de problema.

\subsubsection{Aspectos a serem considerados}

No desenvolvimento deste trabalho houve o foco na necessidade de adaptar o modelo ao problema proposto, ponderar os trade-offs entre critérios de decisão e criar uma ferramenta que fosse aplicável. Tentou-se também ampliar o escopo de análise com o objetivo de se obter análises mais estratégicas. Nos trabalhos de Weber (1991, 1993 e 2000) foram encontrados os fundamentos necessários para essas análises.

Degreave et al. (2000) e De Boer et al. (2001) alertam respectivamente para a ponderação de outros custos ligados ao processo e outros fatores externos e sua influência no processo de decisão. Esses fatores foram ponderados na definição dos critérios e de seus respectivos pesos.

Em relação à aplicação em logística, Weber et al. (1991) concluíram que entre os anos de 67 e 90,15\% dos trabalhos teriam relação com logística se for considerado como base o meio de publicação. Weber et al. (2000), Kirytopoulos et al. (2008) e Bhutta (2003) posteriormente demonstram a relevância das aplicações na área.

Com o aumento da importância da logística no contexto das organizações e a maior relevância da aplicabilidade de abordagens multicritério para problemas de seleção, parece natural um aumento no número de publicações na área. 


\subsubsection{Conclusão do capítulo}

A totalidade dos trabalhos analisados considera que as abordagens $M C D A$ são uma importante ferramenta no processo de seleção de fornecedores, pois possibilitam ao contratante analisar outros aspectos relevantes no processo de contratação ao invés de uma abordagem usual de mercado que acaba focando quase que exclusivamente no critério custos.

Conforme abordado por Weber e Current (1993), a maioria dos trabalhos publicados até a data de análise não apresentavam aplicações práticas. De Boer e Wegen (2003) observaram que enquanto o número de ferramentas de decisão parece crescer cada vez mais, há pouca evidência empírica de aplicações práticas de tais ferramentas na seleção de fornecedores.

De Boer et al. (2001) avaliaram também as possibilidades de futuras aplicações sobre o tema. Fica claro que o apoio na fase de definição do problema é uma área pouco desenvolvida na seleção de fornecedores, pois não foi encontrado na literatura de compras qualquer modelo de compra que aborde esta importante fase, conforme pode ser observado no Anexo C.

Portanto, os resultados obtidos levam a concluir que os modelos de decisão utilizados na seleção de fornecedores, desde que sejam cuidadosamente selecionados e dentro de condições adequadas, podem ser úteis de diversas formas durante todo o processo de seleção e em situações de compra totalmente diferentes. Baseada nessa opinião, fica comprovada a utilidade e a importância de um maior aprofundamento nesta área.

Pode-se também concluir que a ampla gama de métodos e técnicas que surgiram durante os últimos 50 anos em Pesquisa Operacional parece fornecer a variedade de abordagens necessárias para lidar com a diversidade encontrada na prática de compra. Além disso, implica na necessidade de dispor de uma mudança na ênfase do desenvolvimento de modelos de decisão que atualmente estão focados na fase final de seleção para um novo modelo que também analise as fases iniciais, incluindo definição do problema e formulação de critérios (DE BOER E WEGEN, 2003). 
Baseado no que foi estudado, aplicado e das conclusões dos trabalhos que foram analisados segue desenvolvimento do modelo conceitual, Capitulo 3, desta dissertação. 


\section{METODOLOGIA}

Para analisar de forma satisfatória aspectos relevantes à decisão de selecionar um prestador de serviços logísticos para contratação utilizou-se a análise de decisão multicritérios (MCDA) conforme detalhado em Montibeller e Franco (2007). Esses autores descrevem uma metodologia para a modelagem de compensações entre preferências e valores e a posterior análise de sensibilidade da robustez das decisões tomadas.

No caso deste trabalho, essa metodologia foi selecionada porque permite realizar análises formais e estruturadas de uma decisão com múltiplos critérios e alternativas discretas em ambiente interativo, onde os tomadores de decisão podem experimentar as várias facetas, critérios e consequências em tempo real. Para implementar o caso, foi empregada a ferramenta de gestão V.I.S.A (www.visadecisions.com) que apoiou a transcrição do problema, descrição dos critérios, análise dos resultados e escolha do fornecedor. Um maior detalhamento sobre o tema será realizado a seguir.

\subsection{ANÁLISE DE DECISÃO MULTICRITÉRIOS}

\subsubsection{MCDA - Definição e utilização}

O campo da $M C D A$, também chamada suporte à decisão multicritérios ou tomada de decisão multicritérios (MCDM), tem se desenvolvido rapidamente nos últimos 40 anos. Critério, por definição significa "princípio que se toma por referência e que permite distinguir; padrão de julgamento", que num contexto de tomada de decisão implicaria em algum tipo de padrão no qual uma escolha particular ou sequência de ações poderiam ser julgadas como mais desejadas que outras (TABUCANON, 1988). 
Se for considerado que dentre estas diferentes escolhas existem padrões tais que conflitem entre si de forma substancial, aborda-se claramente um problema de tomada de decisão multicritérios (BELTON E STEWART, 2002).

Gerenciar decisões de nível corporativo tipicamente envolve grande gama de critérios, especialmente se o consenso precisa ser conseguido através de um grupo de pessoas de interesses distintos e conflitantes. Casos onde as consequências de cada escolha são significativas, os impactos são de longo prazo e podem afetar muitas pessoas e os erros não podem ser facilmente remediados representam circunstâncias ideais para a MCDA (BELTON E STEWART, 2002).

Afinal, a MCDA auxilia tomadores de decisão a organizar e sintetizar a informação, integrando medidas objetivas e julgamento de valor, explicitando e gerenciando a subjetividade. Isto permite conduzi-los para que se sintam confortáveis e confiantes na tomada de decisão, pois minimiza o potencial arrependimento após o processo decisório, dado que todos os critérios julgados relevantes foram levados em consideração.

\subsubsection{O Processo}

Franco e Montibeller (2011) atestam que a abordagem MCDA tem sido utilizada para apoiar uma grande variedade de problemas de decisão complexos. Embora a literatura sobre os aspectos ligados a MCDA seja extensa, menos atenção é dada ao processo de estruturação destes modelos. A tarefa de estruturar modelos MCDA em intervenções no mundo real está longe de ser trivial, principalmente devido à complexidade intrínseca dos modelos, onde vários objetivos têm de ser articulados, definidos e medidos por critérios.

Outro ponto importante é que a definição de um conjunto de alternativas a ser avaliada nem sempre é simples, pois os tomadores de decisão podem ter dificuldades para pensar criativamente sobre o problema e considerar alternativas inovadoras (FRANCO E MONTIBELLER, 2011). 
O processo da MCDA deve fazer parte do processo mais amplo de estruturação e resolução de um problema. A Figura 6 mostra os estágios deste processo, desde a identificação de um problema, passando por sua definição e estruturação, a construção do modelo e seu uso para informação e análises, até a determinação de um plano de ação. Os principais objetivos dos estágios estão descritos nos próximos tópicos de acordo com a classificação definida por (BELTON E STEWART, 2002).

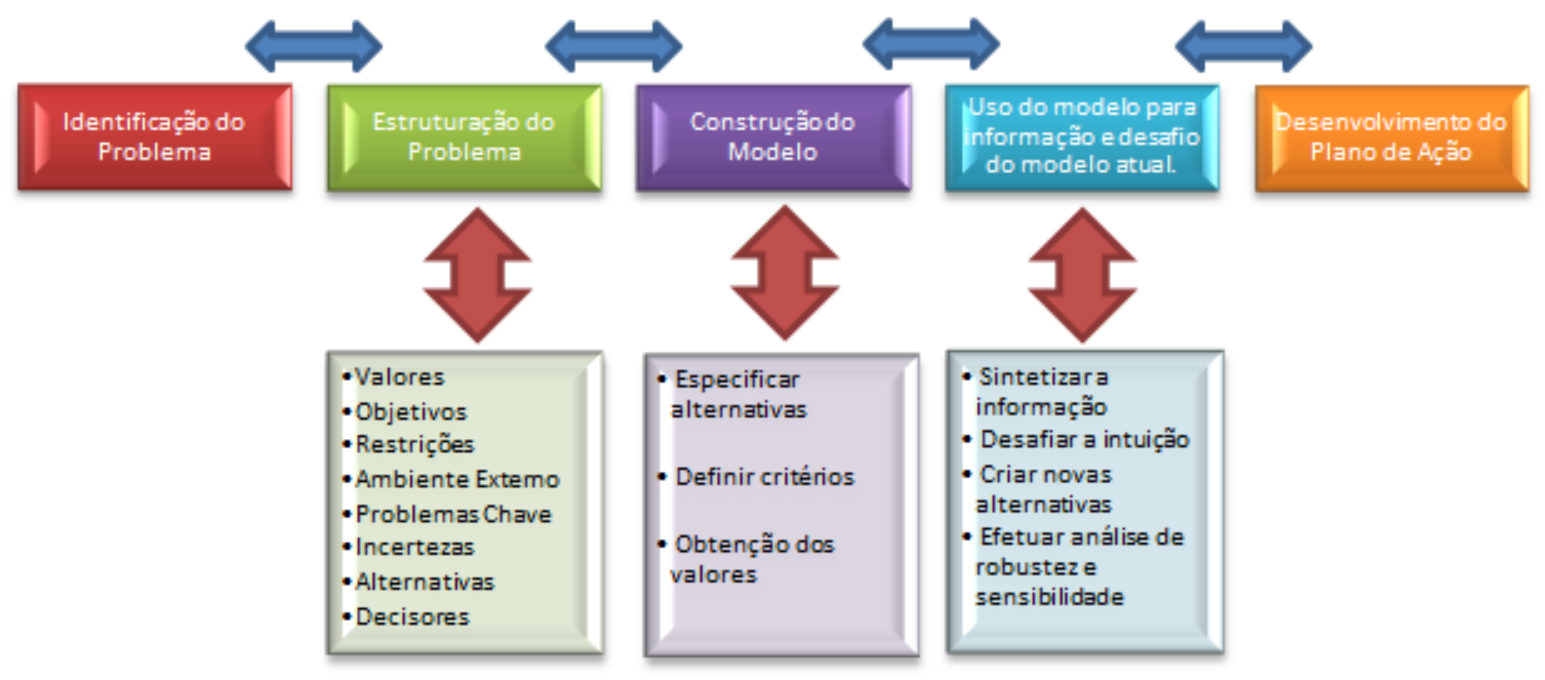

Figura 6 - O processo de $M C D A$

Fonte: Adaptado de Belton e Stewart, 2002

\subsubsection{Identificação e estruturação do problema}

Antes de qualquer análise começar os envolvidos no processo, incluindo facilitadores e/ou analistas técnicos, precisam desenvolver um entendimento comum do problema, das decisões que devem ser feitas e dos critérios com os quais estas decisões estão sendo julgadas e avaliadas.

Eden e Sims (1978) citam a importância de se definir corretamente um problema para que ele possa ser resolvido. Partindo de um princípio básico, será definido o que é um problema.

Um problema é uma questão ou um obstáculo que dificulta a realização de metas, objetivos, ou propostas. Ele refere-se a uma situação, condição, ou questão que ainda não foi resolvida. Em um sentido mais amplo, um problema existe quando um 
indivíduo conhece uma diferença significante entre o que é de fato e o que é desejado (ALEXANDRIA, 1989).

Partindo-se desta definição e da introdução no parágrafo anterior percebe-se que antes de se iniciar a resolução de um problema é necessário que ele seja corretamente definido e que os envolvidos saibam quais resultados são esperados, ou pelo menos parte significante deles, para que seja possível definir também o que seria desejado com sua resolução.

Para entendimento e estruturação do problema optou-se pelo método de estruturação denominado Strategic Options Development Analysis (SODA), que será descrito a seguir baseado nos estudos de (ROSENHEAD E MINGERS, 2001).

SODA é um método para trabalhar com problemas complexos podendo ser definido como uma aproximação projetada para auxiliar problemas que envolvem Pesquisa Operacional.

O SODA, de acordo com a definição do IFM - Cambridge (2009), utiliza como metodologia entrevistas e utiliza um mapa cognitivo para capturar visões individuais de uma questão. Os mapas podem ser construídos em grupo, pela agregação de mapas cognitivos individuais e são usados para facilitar a negociação sobre sistemas com relação valor/objetivo, pontos de atenção estratégicos e problemas multicritérios.

Além do conteúdo do problema, a atenção é prestada as questões psicológicas, políticas e a dinâmica do processo em grupo.

O SODA também auxilia a uma equipe de gerenciamento prover um modelo de suporte a negociação trabalhando com a individualidade e subjetividade na definição do problema e gerando criatividade no grupo. Tal abordagem tende a gerar modelos mais ricos, ao invés de mover em direção a abstração ou simplicidade priorizando uma gestão estratégica através da modificação do pensamento e ação ao invés de planejamento.

O método busca desenvolver altos níveis de entendimento de um problema focando na definição do problema e negociação do grupo, sendo sugerido para grupos de quatro a dez participantes. O SODA foi originalmente desenvolvido por Colin Eden na Universidade do Bath. (IFM - CAMBRIDGE, 2009)

A metodologia SODA utiliza o mapa cognitivo que pode ser definido como o ponto inicial para análise de um problema, desenvolvimento, estratégia de questionamento 
(inquiry strategy) e exploração de possíveis soluções. Todas estas soluções devem estar alinhadas com a visão do cliente (EDEN E SIMS, 1978).

Um mapa cognitivo é a representação de pensamento a respeito de um problema que segue os processos de um mapa. O mapa é uma conexão entre nós e setas como ligações aonde a direção da seta indica a casualidade acreditada. Mapas cognitivos usualmente derivam de entrevistas e buscam representar o seu mundo subjetivo (EDEN, 2003)

Na Figura 7 é apresentado um exemplo de mapa cognitivo que foi construído para o referido problema.

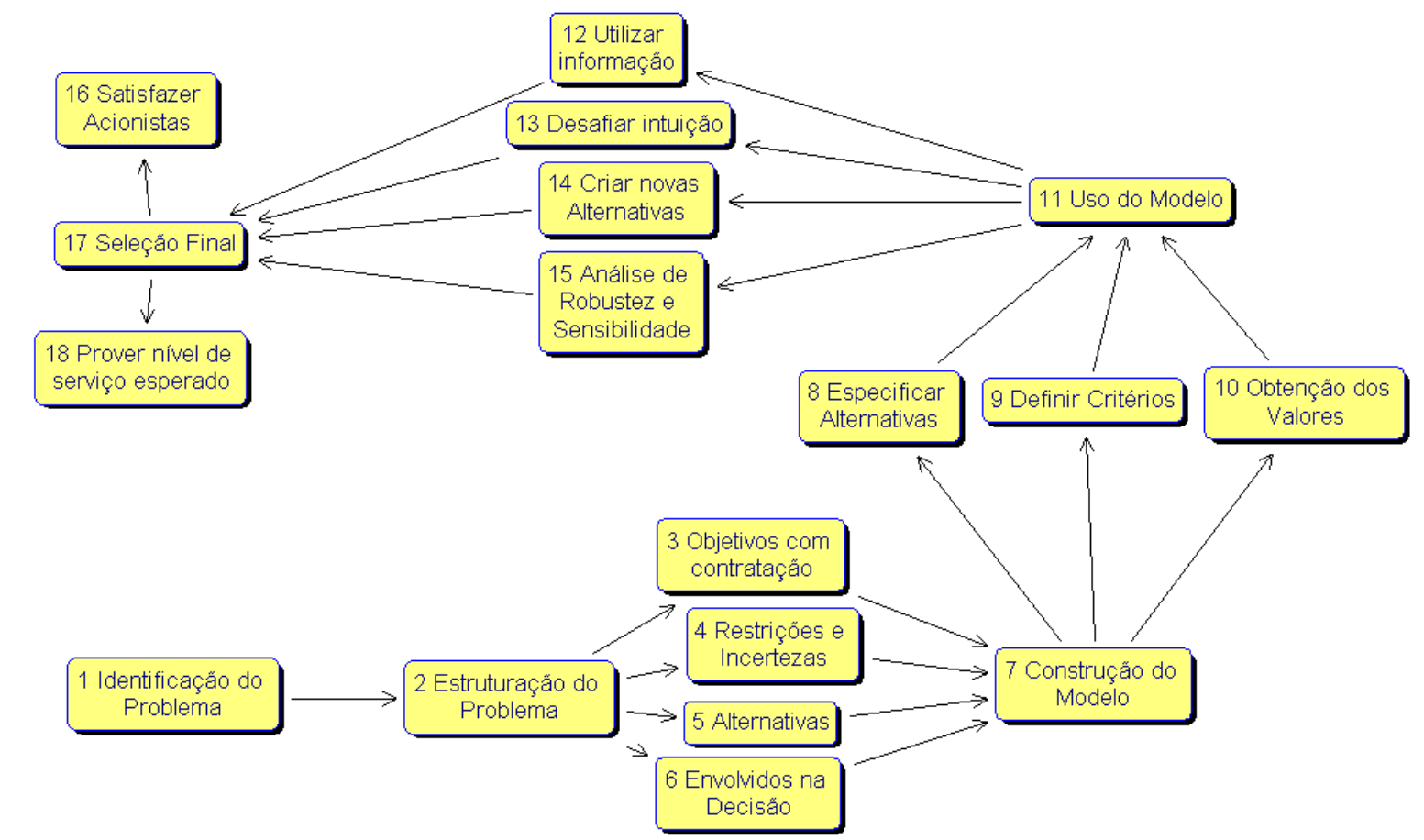

Figura 7 - Mapa Cognitivo com base no processo MCDA e VFT Fonte: Extraído do software (Banxia Decision Explorer)

Este mapa retrata as etapas do processo de seleção proposto e as premissas utilizadas para desenvolvimento do processo MCDA descrito neste mapa serão melhor discutidas no desenvolvimento deste capítulo.

A construção de um mapa cognitivo deve atender as orientações de Ackermann et al. (1992): 
1) Separar a sentença em frases que não tenham mais do que 10-12 palavras. Dividir a apresentação em camadas de hierarquia e cada camada geralmente usa simples objetivos, direções estratégicas e potenciais opções.

2) Colocar os objetivos na parte superior do mapa com conceitos indicando a orientação estratégica e mais do que isso as opções potenciais;

3) Os objetivos devem terminar no topo do mapa. Isso contribui na busca pelos objetivos enquanto se escreve o mapa.

4) Os direcionamentos estratégicos que parcialmente ou totalmente se relacionam com: implicações de longo prazo, altos custos, irreversibilidade, necessidade de um grande número de ações para ocorrer e necessidade de mudança na cultura da organização, devem ter uma maior atenção.

5) Analisar as definições durante os levantamentos dos conceitos e garantir que seu significado terá o correto entendimento;

6) Colocar os conceitos na forma imperativa e sempre que possível introduzir ator e ações;

7) Conservar a propriedade não abreviando e mantendo o texto inicial de forma a deixar claras as implicações de tal conceito;

8) Identificar a inter-relação entre conceitos de forma a gerar adequadamente a seta que conecta os conceitos;

9) Garantir que um conceito genérico é superordenado pelos específicos itens que contribuem para ele;

10) O primeiro polo de um conceito é aquele que tende a se destacar quando o mapa é visualizado. A última sentença deve falar a respeito do gerenciamento das iniciativas conduzindo a uma maior autoridade.

11) A disposição dos conceitos e sua estrutura conduzem a um melhor entendimento do problema original;

12) Iniciar o desenho em dois terços do mapa caminhando para cima e para o centro e tentar manter os conceitos em pequenos retângulos ao invés de linhas contínuas.

Ainda durante o processo de identificação do problema, avaliar corretamente os seguintes aspectos é fundamental na resolução de qualquer problema de $M C D A$ e mitiga as complexidades e incertezas (Belton e Stewart, 2002): 
1) Relevância de Valores: Os tomadores de decisão devem estar prontos para fazer a conexão entre os conceitos e seus objetivos;

2) Entendimento: Compartilhar o entendimento dos conceitos que serão utilizados nas análises;

3) Capacidade de Mensuração: Os critérios devem ser definidos de forma que possam ser mensuráveis e medidos pelos tomadores de decisão;

4) Redundância: Dois critérios não podem ser medidos por um mesmo fator. Uma regra geral é combinar um mesmo critério em um único conceito.

5) Independência de Julgamento: Dois critérios não são julgados de forma independente se existem dependências nos julgamentos de performance dentre estes dois critérios;

6) Balancear perfeição e concisão: Todos os aspectos importantes devem ser capturados mantendo o mínimo de nível de detalhe requerido (KEENEY E RAIFFA, 1976);

7) Operacionalização: A capacidade de capturar os dados necessários para determinado critério não deve exigir um nível excessivo de esforço que dificulte o andamento do processo;

\subsubsection{Construção e uso do modelo}

A característica primária do MCDA é o desenvolvimento de modelos formais de preferências para tomada de decisão, "trade-offs" de valor, critérios de escolha e objetivos. Consequentemente, alternativas ou ações que estejam sendo consideradas podem ser comparadas entre si de uma forma sistemática e transparente.

Conforme definido por Franco e Montibeller (2010), entre as formas de suporte a decisão a mais utilizada para aplicações em Pesquisa Operacional tem sido a "Expert Mode". Neste caso, o desenvolvedor que esta implementado o trabalho cria o modelo, resolve este modelo na busca de uma solução ótima, ou quase ótima, e fornece ao cliente uma recomendação com base na solução obtida. 
Uma forma de suporte a decisão alternativa é a realização de todo o processo em conjunto com o cliente: estruturação e definição do problema, apoio na avaliação de alternativas e desenvolvimento dos planos de implementação. Nesta última modalidade, denominada "Facilitative Mode", o desenvolvedor não atua apenas como um analista, mas também como um facilitador para que o cliente compreenda melhor o problema e sua solução.

Na tabela 12 é apresentado um quadro comparativo entre os dois modelos:

Tabela 12 - Quadro comparativo Expert versus Facilitated mode Fonte: Adaptado de Franco e Montibeller, (2010)

\begin{tabular}{|c|c|c|}
\hline & "Expert Mode" & "Facilitative Mode" \\
\hline Estruturação do problema & $\begin{array}{l}\text { Os problemas são uma entidade real sendo a } \\
\text { principal tarefa do analista a correta } \\
\text { representação do problema que o cliente está } \\
\text { lidando, evitando "preconceitos" sobre as } \\
\text { diferentes "visões". }\end{array}$ & $\begin{array}{l}\text { Os problemas são construções humanas e o } \\
\text { desenvolvedor do modelo deve ajudar o cliente, } \\
\text { através de sua equipe, na negociação das } \\
\text { diferentes "visões" sobre o problema de forma a } \\
\text { defini-lo. }\end{array}$ \\
\hline Formulação do problema & $\begin{array}{l}\text { O problema real tem de ser formulado de forma } \\
\text { tão precisa quanto possivel. É tarefa do analista } \\
\text { formular o problema. }\end{array}$ & $\begin{array}{l}\text { O problema tem de ser estruturado pela equipe } \\
\text { gerencial, cujos membros estão conscientes sobre } \\
\text { os seus diferentes aspectos e contextualização. O } \\
\text { processo de estruturação dos problemas é } \\
\text { suportado pelo desenvolvedor, agindo como um } \\
\text { facilitador, no desenvolvimento de um modelo que } \\
\text { melhor represente a estrutura do problema. }\end{array}$ \\
\hline Definição das Métricas & $\begin{array}{l}\text { O analista define as métricas para avaliar o } \\
\text { desempenho das alternativas baseado } \\
\text { principalmente na natureza do problema que } \\
\text { está sendo analisado. }\end{array}$ & $\begin{array}{l}\text { As métricas para avaliar o desempenho das } \\
\text { alternativas deve refletir os objetivos e prioridades da } \\
\text { organização conforme definido pela equipe } \\
\text { gerencial, com o apoio do desenvolvedor. }\end{array}$ \\
\hline A coleta de dados & $\begin{array}{l}\text { A coleta de dados é sempre extensa e de } \\
\text { natureza quantitativa. É o analista que define, } \\
\text { com base na natureza do problema, que as } \\
\text { informações devem ser recolhidas. }\end{array}$ & $\begin{array}{l}\text { Dependendo do problema a coleta de dados pode } \\
\text { ser extensa e envolve não apenas a análise } \\
\text { quantitativa mas também a qualitativa dos dados e } \\
\text { preferências. Os objetivos e as prioridades são } \\
\text { estabelecidos pelo facilitador da equipe de gestão } \\
\text { em que as informações serão recolhidas. }\end{array}$ \\
\hline Avaliação das alternativas & $\begin{array}{l}\text { O modelo é resolvido pelo analista e as } \\
\text { melhores soluções para o problema são } \\
\text { encontrados. }\end{array}$ & $\begin{array}{c}\text { A avaliação das alternativas é realizada de forma } \\
\text { interativa com a equipe gerencial. As conseqüências } \\
\text { da adoção de cada alternativa são analisadas e } \\
\text { discutidas pelos gestores. }\end{array}$ \\
\hline Apresentação dos resultados & $\begin{array}{c}\text { As melhores soluções são comunicadas ao } \\
\text { cliente, geralmente, através de um relatório } \\
\text { detalhado. É fundamental que o relatório detalhe } \\
\text { todas as premissas utilizadas visto que o cliente } \\
\text { não estava envolvido na formulação do } \\
\text { problema. }\end{array}$ & $\begin{array}{l}\text { Os resultados são apresentados de forma interativa } \\
\text { com a equipe gerencial. Existe a possibilidade de } \\
\text { "testar" alternativas utilizando o modelo de forma a } \\
\text { verificar todas as conseqüências da implementação } \\
\text { de determinada alternativa. O relatório tem } \\
\text { normalmente um papel menos importante porque é } \\
\text { apenas um suporte para o processo decisório. }\end{array}$ \\
\hline Nivel de comprometimento & $\begin{array}{l}\text { O analista espera que o cliente, dada a natureza } \\
\text { cientifica da análise, se comprometa a } \\
\text { implementar as suas prescrições. }\end{array}$ & $\begin{array}{l}\text { O processo participativo de tomada de decisão, } \\
\text { utilizando uma abordagem facilitativa, tende a } \\
\text { aumentar o nivel de comprometimento do grupo na } \\
\text { execução das opções selecionadas. }\end{array}$ \\
\hline Objetivo da Intervenção & Fornecer as soluções ideais para o cliente. & $\begin{array}{c}\text { Ajudar o cliente em um maior entendimento sobre o } \\
\text { seu problema de forma a ganhar confiança no seu } \\
\text { desenvolvimento. }\end{array}$ \\
\hline
\end{tabular}

O modelo de decisão escolhido para a primeira aplicação deste problema foi baseado no "Expert Mode", descrito na Figura 8. Tal escolha se deve principalmente porque os participantes tinham acesso às informações necessárias para formulação do problema, o nível de conhecimento necessário para tomada de decisão e havia familiaridade com o modelo escolhido. 


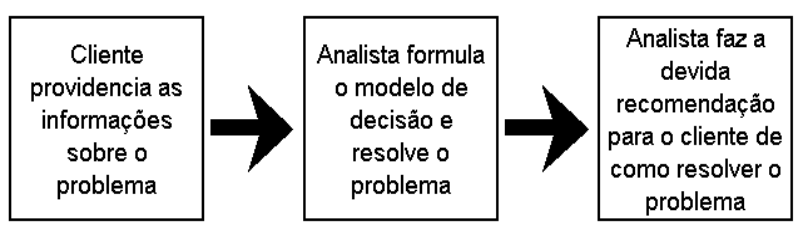

Figura 8 - Modelo de Decisão "Expert Mode"

Fonte: Adaptado de Keeney, (1992)

O segundo estudo de caso utilizou o "Facilitative Mode". Esta forma de condução, Figura 9, sugere a intervenção de um analista na modelagem através de uma metodologia de Pesquisa Operacional adequada para representar o entendimento do grupo sobre o problema e de um facilitador no desenvolvimento do trabalho em grupo que apoie a discussão e interação entre seus membros. Desta forma, o grupo fornece as informações para que o analista possa modelar o problema e, inversamente, o modelo gera respostas que suportam as discussões do grupo sobre as questões que estão sendo tratadas (FRANCO E MONTIBELLER 2010).

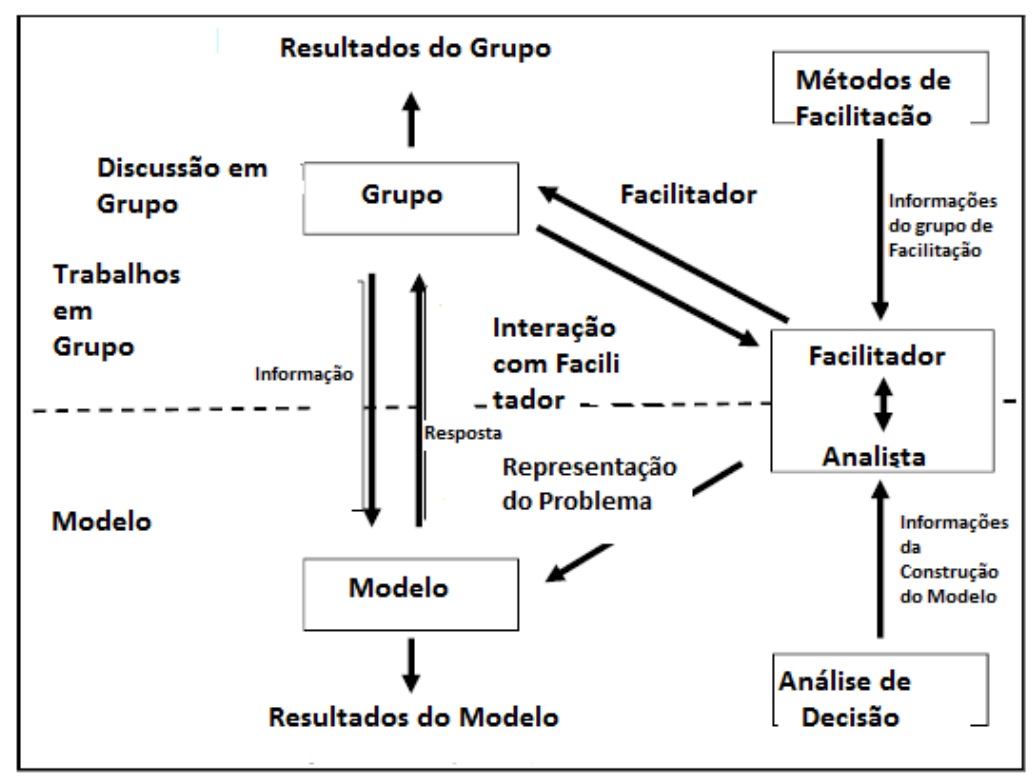

Figura 9 - Modelo de Decisão "Facilitative Mode"

Fonte: Adaptado de Franco e Montibeller, (2010)

Serão analisadas e comparadas às implementações e os seus resultados nas duas formas utilizadas para suporte a decisão.

Para estruturar o processo de decisão e consequentemente fazer a escolha desejada é necessário o entendimento de outros conceitos. 
O conceito "valores" pode ser definido como o conjunto de elementos que realmente preocupa os decisores e que os conduz ao processo decisório. Os "valores" devem ser à base de tempo e esforços gastos na decisão.

Podem ainda ser utilizadas duas abordagens para conduzir o processo decisório. A primeira, Value Focused Thinking (VFT), essencialmente consiste em duas atividades: primeiro decidir o que se quer com a decisão e posteriormente imaginar as alternativas para que se consiga o seu objetivo. Na outra abordagem usualmente utilizada, Alternative Focused Thinking ( $A F T)$, primeiro são definidas as alternativas e então será escolhida a melhor entre elas (KEENEY, 1992).

Ambas as abordagens são demonstradas na Figura 10. (PARNELL ET AL., 2008)

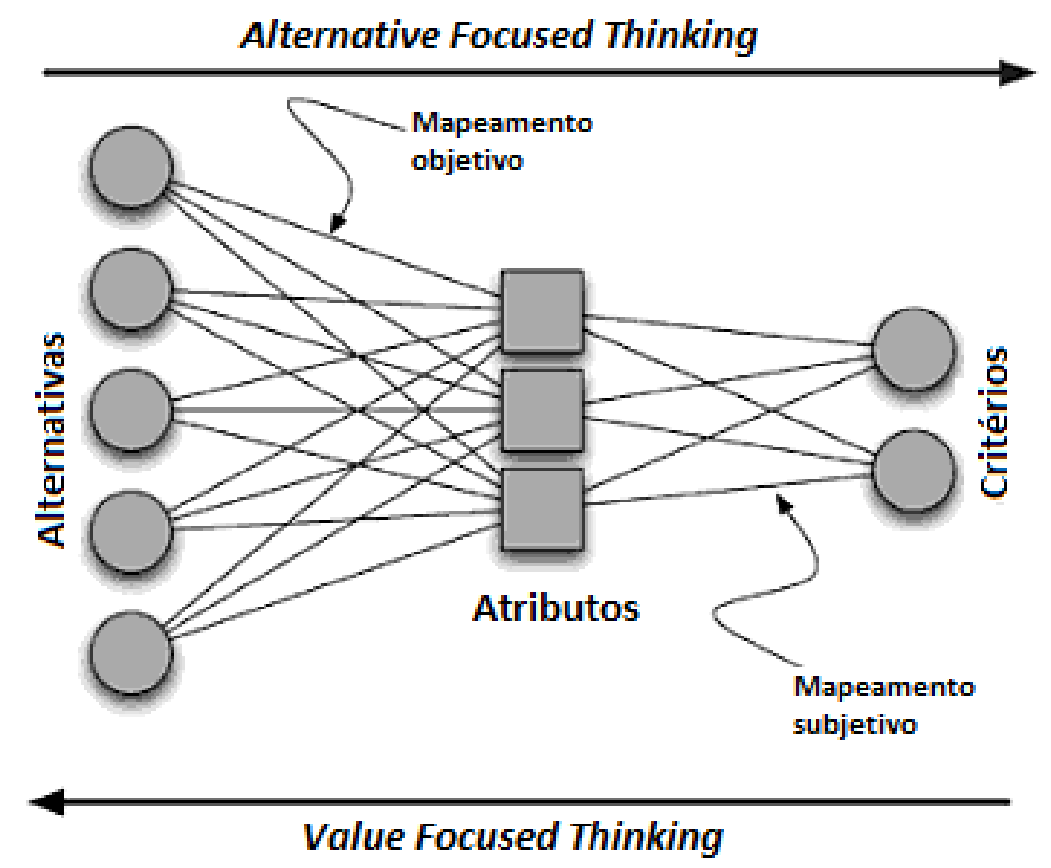

Figura 10 - Fluxo Comparativo das Abordagens VFT e AFT

Fonte: Adaptado de Parnell et al., (2008)

Para estruturar o modelo multicritério neste trabalho será utilizada a abordagem VFT pois conforme definido por Keeney (1992) este modelo deve produzir resultados superiores se comparados com o $A F T$.

Qualquer aplicação do VFT deve resultar no mínimo em igual nível e provavelmente será muito melhor do que os melhores empregos disponíveis do AFT. VFT implica em partir do melhor e trabalhar para que isso se torne realidade. AFT inicia com o que esta prontamente disponível e produz o que for melhor dentro desses parâmetros (KEENEY, 1992). 
O mesmo autor definiu a ordem de implantação do VFT para obtenção dos resultados esperados:

1) Reconhecer o problema de decisão:

2) Especificar valores;

3) Criar alternativas de decisão;

4) Evoluir nas alternativas;

5) Selecionar uma alternativa.

A Figura 11 apresenta os principais aspectos que devem ser observados, identificados e aplicados durante a utilização da abordagem VFT (KEENEY, 1992).

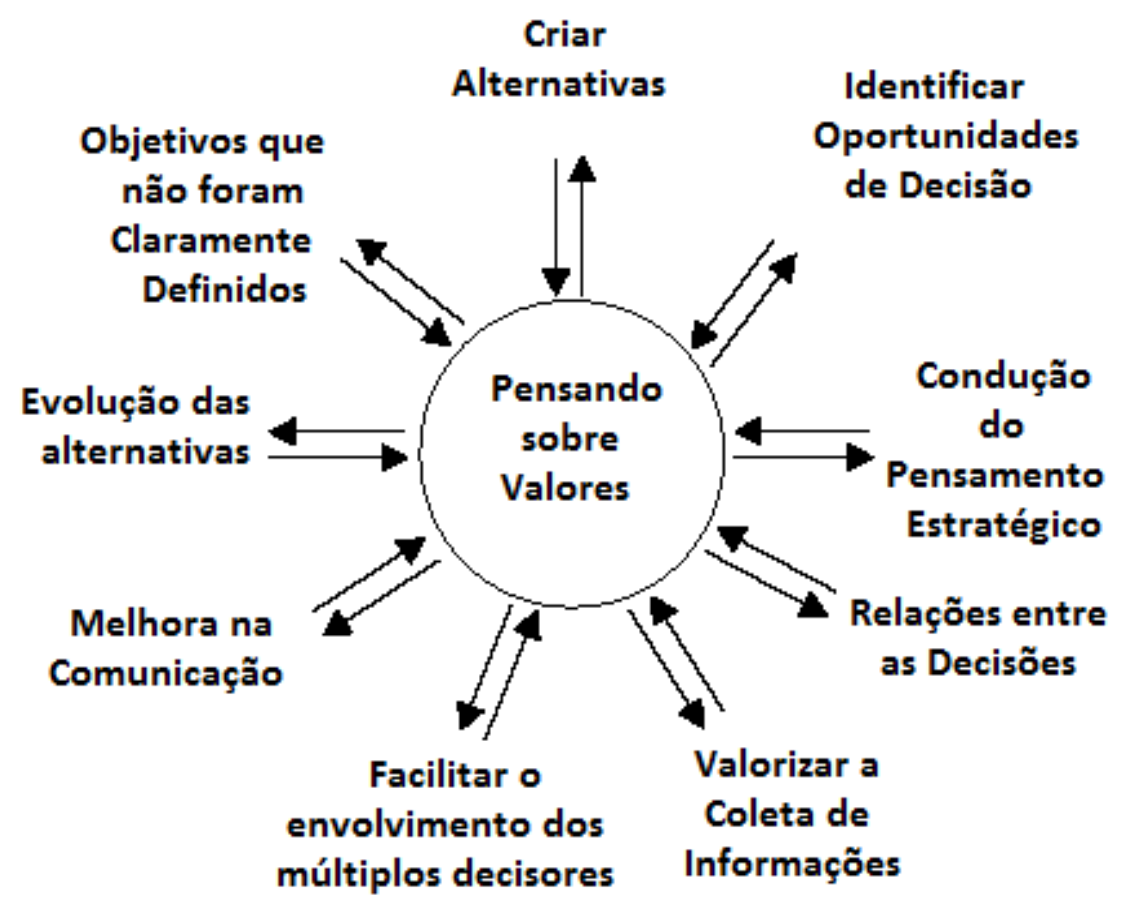

Figura 11 - Visão Geral sobre VFT

Fonte: Traduzido de Kenney, (1992)

Voltando ao inicio do texto, foi comentado que o processo de seleção de fornecedores é um problema aonde se busca a solução ideal pela ótica do contratante.

No mercado brasileiro, a contratação de prestadores de serviços normalmente é baseada em uma escolha lógica aonde se busca o prestador com menor custo dentro de um padrão mínimo de nível de serviço. Tal tipo de escolha não parece garantir a solução ideal. 
De forma divergente ao que o mercado utiliza, a proposta deste trabalho é que no processo de seleção de fornecedores sejam considerados outros critérios além dos custos. Este processo deve ser realizado de forma que a solução tenha origem na escolha de alternativas discretas e que essas escolhas sejam realizadas com base nos parâmetros de modelamento de preferência. Estas definições (parâmetros) devem gerar os valores e pesos dos respectivos critérios e subcritérios para o problema.

O desenvolvimento do modelo matemático para o problema de seleção de fornecedores de transporte (primeiro estudo de caso aplicado) será realizado com base na proposta de modelagem descrita na Figura 12 (BRINATI, 2009).

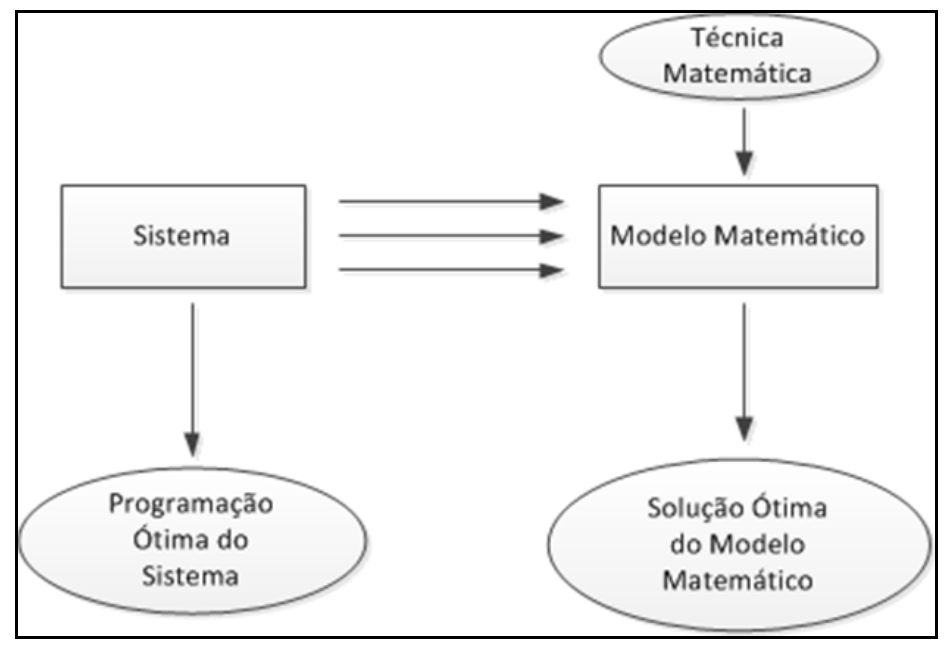

Figura 12 - A busca da solução ótima para o sistema via modelagem matemática Fonte: Adaptado de Brinati, (2009)

O modelo matemático usual do mercado brasileiro para seleção de fornecedores de transporte, se existisse na prática, objetivaria tão somente a minimização de custos na escolha de uma única rota de transporte. Para a representação desse modelo, seriam conhecidos os seguintes conjuntos e constantes:

- $\quad N=\{1,2, \ldots, i, \ldots, n\}$ conjunto de transportadoras, onde $n=|N|$;

- $c t_{i}$ : custo relacionado à transportadora $i \in N$;

- $C T=$ Orçamento (quanto o contratante esta disposto a pagar por esse serviço específico);

- $l_{i}$ : Tempo de entrega ("lead-time") relacionado à transportadora $i \in N$;

- $\quad L=$ Tempo de entrega máximo aceitável; 
O custo da transportadora $\left(c t_{i}\right)$ e o tempo de entrega $\left(l_{i}\right)$ são dados fechados repassados por cada transportadora $i \in N$. As variáveis de decisão do modelo $x_{i}$, definidas para cada transportadora $i \in N$, representam as decisões binárias aonde $x_{i}=1$ significa que a transportadora $i \in N$ é contratada e, caso contrário $x_{i}=0$, não é contratada.

O modelo de otimização para cada rota implícito pelas empresas fica então:

$$
\begin{gathered}
\operatorname{Min} \sum_{i \in N}\left(c t_{i} \times x_{i}\right) \\
\sum_{i \in N}\left(c t_{i} \times x_{i}\right) \leq C T \\
\sum_{i \in N}\left(l_{i} \times x_{i}\right) \leq L \\
\sum_{i \in N} x_{i}=\mathbf{1} \\
x_{i}=\{0,1\} \forall i \in N
\end{gathered}
$$

A função objetivo é definida pela Equação (1), onde é minimizado o custo ( $\left.c t_{i}\right)$ da transportadora ser contratada $\left(x_{i}\right)$. Este custo também é restringido pelo orçamento $(C T)$, conforme Equação (2). O tempo de entrega $\left(l_{i}\right)$ é limitado pelo tempo máximo $(L)$ na Equação (3). A condição de que somente uma transportadora deverá ser contratada é satisfeita pela Equação (4). E, por fim, a variável de decisão ( $\left.x_{i}\right)$ é definida pela Equação (5) para cada transportadora $i \in N$.

Segue a proposta de um novo modelo matemático para o problema, baseado na Teoria de Valor Multiatributo (MAVT, de "Multi-Atribute Value Theory"), que se baseia na utilização de otimização com múltiplos critérios, (BELTON E STEWART, 2002). A Figura 13 representa, de forma esquemática, o modelo proposto para o problema de seleção de fornecedor para uma única rota de transporte. 


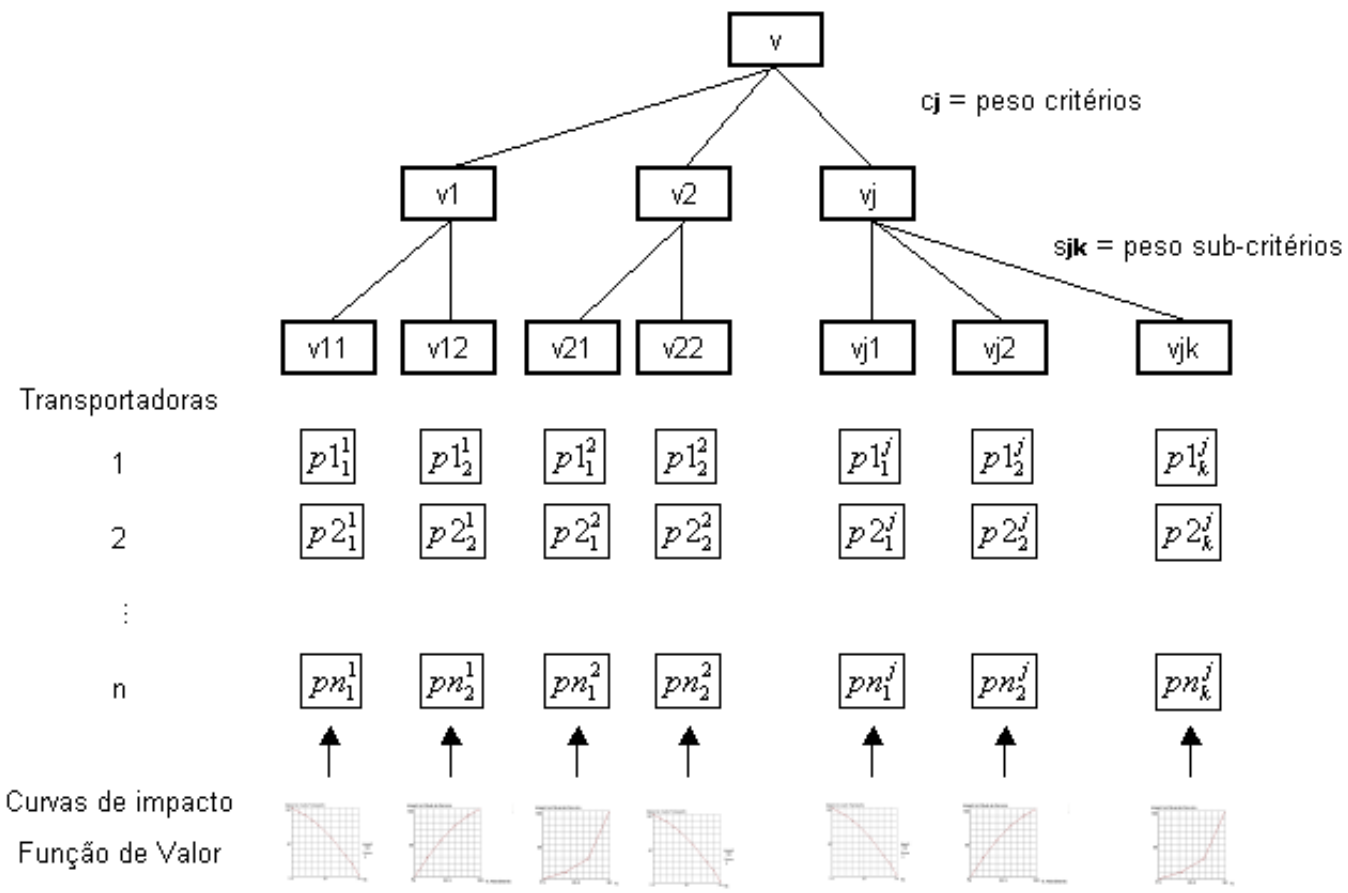

Figura 13 - Representação esquemática da otimização multicritérios para o problema

O novo modelo proposto, quando comparado com o modelo definido pelas equações (1) a (5), apresenta uma nova função objetivo, conforme Equação (6), com um novo objetivo de maximização do valor da escolha, na ótica do contratante. As equações (2) a (5), são tratadas através dos critérios de inclusão e rejeição no novo modelo.

$$
\operatorname{Max} \sum_{i \in \mathbb{N}} \sum_{j \in J} \sum_{k \in K_{j}}\left(c^{j} \times s_{k}^{j} \times p_{i, k}^{j} \times x i\right)
$$

Para a nova função objetivo foram definidos novos conjuntos e constantes, relacionados aos critérios e subcritérios, bem como os pesos aplicados:

- $J=\{1,2, \ldots, j, \ldots,|J|\}$ conjunto dos critérios aplicados à decisão de seleção;

- $K_{j}=\left\{1,2, \ldots, k, \ldots,\left|K_{j}\right|\right\}$ conjunto dos subcritérios do critério $j \in J$;

- $c^{j}$ : peso definido para o critério $j \in J$;

- $s_{k}^{j}$ : peso definido para o subcritério $k \in K_{j}$ referente ao critério $j \in J$;

- $p_{i, k}^{j}$ : pontuação obtida através da curva de impacto na função de valor correspondente à transportadora $i \in N$ para o subcritério $k \in K_{j}$, definido para o critério $j \in J$ 
Considerando que os valores da pontuação das transportadoras, os pesos dos critérios e pesos dos subcritérios são conhecidos, essa equação é linear e pode ser resolvida, se necessário, através de programação linear.

Importante ressaltar que esta nova proposta muda de forma substancial a avaliação sobre o problema original. O próprio aprendizado adquirido durante o processo (qualificação e quantificação dos critérios, subcritérios e funções de valor) nos possibilita considerar novos aspectos e avaliar de forma criteriosa alguns pontos que antes poderiam passar despercebidos.

Em relação ao novo problema de otimização, utilizando multicritérios, fica evidente que houve uma alteração considerável na função objetivo que antes era uma função de minimização de custos e passou para uma função de maximização de pontuação das transportadoras, que através dos critérios e subcritérios consideram um grande número de fatores envolvidos no processo de seleção e trade-offs entre eles. Tal proposta esta alinhada com o objetivo inicial de criar um modelo de seleção que pondere os fatores relevantes para contratação e não apenas o critério custo.

Percebe-se também que a alteração não é apenas na função objetivo, conforme apresentado dois parágrafos acima, a nova ótica de avaliação pode gerar alteração também no limite das restrições, neste exemplo o orçamento e prazo de entrega. Mais do que isso, pode favorecer a criação de novas restrições.

Neste modelo o contratante poderia perceber os custos resultantes de um alto índice de avarias e limitar a contratação de transportadoras que se comprometessem com aquele novo limite máximo de avarias, consequentemente, criar-se-ia um novo critério de restrição. Este assunto será melhor detalhado no capítulo 4, pois serão definidos os critérios de inclusão e rejeição que devem ser atendidos além das restrições do problema.

É importante ressaltar que essa modelagem matemática, com poucas alterações, pode ser realizada para o segundo estudo de caso que será aplicado e também para outros problemas de seleção de fornecedores. 


\subsubsection{Desenvolvimento de planos de ação}

As análises não resolvem o problema de decisão. A MCDA em particular está relacionada também com a implementação dos resultados, que é a tradução da análise em planos de ação específicos. O processo da MCDA é visto não somente em termos de modelagem técnica e analítica, mas também em termos de suporte e ideias para a implementação.

No desenvolvimento deste trabalho serão desenvolvidos dois estudos de caso em empresas de grande porte no mercado brasileiro utilizando os conceitos SODA, respectivamente Expert e Facilitative Mode e VFT. No capitulo 4 serão demonstradas todas as etapas destas implementações.

\subsection{MODELOS DE DECISÃO}

Dentre os diferentes modelos que tem sido desenvolvidos para tratar as preferências num contexto de problemas de multicritério, os mesmos podem ser classificados em três categorias, escolas ou pensamentos:

\subsubsection{Modelos de medição de valor}

Belton e Stewart (2002) descrevem que nestes modelos indicadores numéricos são construídos de forma a representar o grau em que uma opção pode ser preferida à outra. Tais indicadores são desenvolvidos inicialmente para cada critério individualmente e então são sintetizados e agregados em níveis maiores no modelo de preferência. Neste modelo pode se utilizar a abordagem MAVT (teoria de valor multiatributo) ou AHP (método de análise hierárquica). Outra abordagem de medição de valor em que se localizaram aplicações é o Measuring Attractiveness by a Categorical Based Evaluation Technique (MACBETH). 


\subsubsection{Modelos de aspiração ou nível de referência}

Para estes modelos, níveis de satisfação ou desejo são estabelecidos para cada critério. O processo então busca descobrir as opções que estejam mais próximas de atingir as metas desejáveis ou aspirações (BELTON E STEWART, 2002). A abordagem que melhor exemplifica este modelo é o Goal Programming (GP).

\subsubsection{Modelos de "outranking"}

São aqueles nas quais as alternativas são comparadas em pares, inicialmente para cada critério a fim de identificar a extensão na qual a preferência de uma sobre a outra pode ser considerada assertiva. Agregando tais informações de preferências através de todos os critérios relevantes, o modelo busca estabelecer a "força" de cada evidencia favorecendo a seleção de uma alternativa sobre a outra (BELTON E STEWART, 2002). Abordagens típicas são a família ELECTRE I, II e III e também a família PROMETHE.

\subsection{CATEGORIAS DE PROBLEMAS}

Mesmo quando se pressupõe que as alternativas estão claramente definidas, o resultado desejado pode não ser uma simples escolha discreta, e sim, um subconjunto de alternativas. Roy (1996) identificou quatro diferentes problemáticas de escolha, isto é, amplas tipologias ou categorias de problemas para os quais a MCDA pode ser útil. Abaixo a classificação de Roy (1996) que foi analisada e complementada por Oliveira e Filho (2007): 
1) De escolha: Aplicada a uma simples escolha entre um conjunto de alternativas. Os tomadores de decisão são orientados a prover uma seleção das "melhores" ações de modo que uma alternativa singular possa finalmente ser escolhida;

2) Da classificação: Aplicado para a designação de cada ação potencial para uma determinada categoria que foi julgada a mais apropriada dentre uma família de categorias pré-definidas. Portanto, não é necessário saber qual é a melhor alternativa, mas apenas discriminá-las segundo os diferentes critérios estabelecidos. Um exemplo, seria a classificação ou categorização dos resultados como "definitivamente aceitável", "possivelmente aceitável mas necessita de mais informações" e "definitivamente não aceitável";

3) De ordenação: Aplicado pela ordenação das preferências. Os tomadores de decisão podem ordenar as ações potenciais de modo decrescente de preferência ou elaborar um procedimento de posicionamento (ranking);

4) Da descrição: Aplicado essencialmente ao aprendizado, onde o tomador de decisão busca conseguir um maior entendimento do que pode ou não ser alcançado.

\subsection{FERRAMENTA $\mathrm{V} \cdot 1 \cdot S \cdot A$}

$\mathrm{V} \cdot \mid \cdot S \cdot A($ Visual Interactive Sensitivity Analysis) é um software de apoio à decisão desenvolvido pela SIMUL8 (www.simul8.com/visa) especificamente para suportar MCDA, para problemas de escolha discreta aplicando modelo de medição de valor e metodologia de função de valor com múltiplos atributos, onde as decisões são modeladas usando uma hierarquia de funções (critérios) ponderados entre si. Uma importante característica deste software está em sua interface baseada na interação visual, permitindo aos usuários explorar em tempo real as implicações das trocas de diferentes prioridades, valores e pesos durante sua análise de sensibilidade.

Conforme definido anteriormente no item 3.2 esta ferramenta foi desenvolvida com base na teoria Multi Attribute Value Theory (MAVT) que utiliza o processo de desenvolvimento denominado Multiattribute Value Function (MAVF). O MAVF é 
baseado na árvore de valor resultante do processo de estruturação do problema que já foi aqui descrito. O próximo capitulo irá demonstrar a construção da árvore de valor para o problema em questão e as potencialidades da ferramenta.

\subsection{DEFINIÇÃO DO PROBLEMA}

Neste trabalho será apresentado um problema de escolha. Entretanto o modelo proposto pode ser utilizado, total ou parcialmente, em todos os tipos de problemas que foram apresentados no item 3.3.

Este problema é inicialmente tático para encontrar prestadores de serviços que melhor atendam os desejos da empresa contratante, nesse caso representada pelos executivos responsáveis pelo projeto de contratação, pela gestão operacional diária e pelo sistema de controle de custos da empresa.

É importante ressaltar que será desenvolvido um modelo de processo de seleção de fornecedores que será propagado em outros processos de contratação. Considerando que este modelo será um padrão de contratação da empresa trata-se também de um problema estratégico.

O espectro de envolvimento do tema dentro de uma organização é de media e alta gerência, diretoria e em casos relevantes para o futuro da organização, como utilização do modelo para definição da rede logística da empresa, pode envolver o(s) principal (is) executivo(s) da empresa e seu conselho de administração.

O primeiro grande desafio na resolução deste problema é identificar mercadologicamente as melhores alternativas viáveis, evitando ao máximo que potenciais fornecedores de serviços não sejam inclusos no processo por desconhecimento, dificuldade de acesso, falta de relacionamento ou motivos políticos.

Em relação às empresas participantes do processo de seleção percebe-se que grande parte das alternativas de escolha disponíveis no mercado não seriam aceitas se fossem impostas simples análises restritivas. Entretanto, mesmo com essas 
restrições, o número de alternativas de escolha pode ser grande o que aumenta consideravelmente a complexidade do problema.

Também é necessário que este fornecedor tenha um nível de serviço igual ou superior ao fixado como mínimo pelo contratante e que seu custo esteja dentro dos limites aprovados para esta contratação.

Portanto o modelo proposto deve conduzir a obtenção de um prestador de serviços, ou prestadores de serviços, que atendam as restrições do contratante e que resulte na recomendação de um fornecedor que seja a melhor escolha possível, com base nos critérios definidos pelo contratante, entre as alternativas viáveis.

O problema de seleção de fornecedores utilizando abordagem multicritério já foi amplamente abordado na literatura e existem algumas utilizações em logística. Nenhum dos trabalhos encontrados tem uma aplicação prática similar à proposta nesta dissertação.

\subsection{ABORDAGEM MULTICRITÉRIO UTILIZADA}

De acordo com a pesquisa realizada por Ho et al. (2010) a abordagem AHP é hoje a mais utilizada para processos de seleção. Bruno et al. (2009) sugere que a abordagem AHP é a mais utilizada em problemas de seleção, pois é capaz de estruturar o problema dentro de uma hierarquia, comparar os julgamentos e sintetizar as prioridades.

Entretanto, Bruno et al. (2009) conclui que o modelo proposto nesta dissertação também pode ser capaz de estruturar o problema dentro de uma hierarquia, comparar os julgamentos e sintetizar as prioridades. Tal conclusão foi demonstrada ao longo deste capítulo.

Dyer (1990) analisa a utilização da abordagem AHP e a proposta neste trabalho: "Em um nível maior de abstração, assumimos que os pesquisadores da teoria da utilidade (MAVT/MAUT) e das metodologias AHP estão tentando modelar as preferências de um decisor a fim de que os rankings das alternativas produzidos por estas abordagens reflitam estas preferências. Portanto, parece razoável concluir que 
ambos os campos se beneficiam de esforços para sintetizar essas duas abordagens para o mesmo problema".

Sonmez (2006) também suporta a escolha de um modelo de medição de valor, sugerindo que quando a seleção busca a escolha de apenas um fornecedor ela procura a "melhor" escolha entre os fornecedores que atendem os requisitos exigidos. Neste caso, o modelo escolhido deve ser capaz de ordenar as alternativas e gerar a melhor escolha, sendo sugeridas as abordagens Multiple-attribute Utility Theory (MAUT) e AHP.

Existe ainda a indicação de Bhutta (2003) que dentre todas as abordagens avaliadas sugeriu que a abordagem escolhida para esta dissertação era a mais adequada para o problema de seleção de fornecedores por ser capaz de manipular multicritérios inerentes ao processo de seleção. Entretanto tal análise não é conclusiva pois o AHP também poderia manipular multicritérios.

Pelos autores analisados fica claro que tanto a abordagem (MAUT/MAVT) quanto à abordagem $A H P$ podem se adequar ao problema de seleção de fornecedores. Um dos motivos para escolha pelo MAVT, ao invés do $A H P$, se deve ao menor estudo sobre sua aplicação neste tipo de problema, o que possibilita novas aplicações, desenvolvimento de um novo modelo, aplicação em estudos de caso inéditos e a avaliação das potencialidades e fraquezas da ferramenta aqui proposta. Outro motivo faz referência aos problemas axiomáticos do $A H P$, tais como a reversão de rankings.

Independente da escolha da abordagem, um ponto favorável ao modelo proposto é baseado nas considerações de De Boer e Wegen (2003) e Geoffrion e Krishnan (2001) que sugerem a utilização de ferramentas computacionais de apoio (software).

\subsection{MODELO UTILIZADO}

Conforme definido por Belton e Stewart (2002) o processo MCDA deve fazer parte de um processo mais amplo de estruturação e resolução do problema, Figura 6. 
$\mathrm{Na}$ Tabela 13, são apresentadas as abordagens, métodos e ferramentas utilizados em cada uma das fases da aplicação do modelo proposto.

Tabela 13 - Visão geral das abordagens, métodos e ferramentas utilizados nos estudos de caso Fonte: Adaptação de (De Boer e Wegen, 2003)

\begin{tabular}{lcc}
\hline \multicolumn{1}{c|}{ Fases } & $\begin{array}{c}\text { Seleção de um transportador rodoviário no } \\
\text { modelo fracionado para a rota São Paulo } \\
\text { Salvador } \\
\text { (Estudo de Caso 1) }\end{array}$ & $\begin{array}{c}\text { Seleção de um prestador de serviços } \\
\text { logísticos para uma operação 4PL } \\
\text { (Estudo de Caso 2) }\end{array}$ \\
\hline Fase 1: Definição do problema & VFT e Mapa Cognitivo & VFT, SODA e Mapa Cognitivo \\
Fase 2: Formulação dos Critérios & VFT e Software (VISA) & VFT e Software (VISA) \\
Fase 3: Pré-Qualificação & Critérios de Inclusão e Rejeição e & Conjunctive Screening \\
Fase 4: Seleção final e possibilidade de iniciar operação & Conjunctive Screening de Inclusão e Rejeição e \\
\hline
\end{tabular}

Para definição do problema (Fase 1) utilizou-se o Mapa Cognitivo e no trabalho em grupo, estudo de caso 2, o Mapa Cognitivo foi desenvolvido sob os preceitos da metodologia SODA.

As intervenções foram conduzidas, durante a definição do problema (Fase 1) e formulação dos critérios (Fase 2), pela forma Value Focused Thinking sendo que o software VISA teve uma contribuição relevante na Fase 2.

A Fase 3 , pré-qualificação, se deu pelos critérios de inclusão e rejeição que utilizaram o método "Conjunctive Screening" para definir os proponentes que participariam do processo de seleção.

No estudo de caso 2 a RFI (Request For Information) e a RFQ (Request For Quotation) auxiliaram provendo as informações necessárias respectivamente nas Fases 3 e 4.

Por último, na seleção do fornecedor (Fase 4), a abordagem MAVT suportou a escolha pela ótica do contratante.

Após a execução dos dois estudos de caso, no capítulo 5 , será feita uma análise sobre a qualidade da escolha deste modelo e sua aplicabilidade, com base na proposta de avaliação do modelo na seleção de fornecedores de De Boer e Wegen (2003), visto na Tabela 7. 


\section{ESTUDOS DE CASO}

Este capitulo foi estruturado com base nas fases do processo $M C D A$, desenvolvido por Belton e Stewart (2002) e, conforme abordado na introdução, o modelo proposto será aplicado em dois estudos de caso relevantes.

Para conduzir o processo de estruturação e aplicação prática dos referidos estudos de caso, foi utilizado o método de pesquisa "Action-Research". Montibeller (2007) define pesquisa "Action-research" (AR) como uma estratégia que permite a investigação sistemática de um problema durante uma intervenção prática e que tem sido defendida como um método adequado para estudar essas aplicações em $M C D A$.

Este método auxilia simultaneamente na resolução de problemas práticos e amplia o conhecimento científico, além de melhorar as competências dos envolvidos nesta resolução. Deve ser executado de forma colaborativa em uma situação de feedback imediato, através de um processo cíclico que visa uma maior compreensão de uma dada situação, sendo aplicado principalmente para a compreensão dos processos de mudança e realizado dentro de um quadro ético aceitável (HULT E LENNUNG, 1980) .

O método "Action-research" (AR) pode ser dividido em dois processos: solução do problema e pesquisa (MCKAY E MARSHALL, 2001). Pode-se considerar que o processo de solução do problema é o próprio processo MCDA descrito nesta dissertação. O processo de pesquisa é demonstrado na Figura 14. 


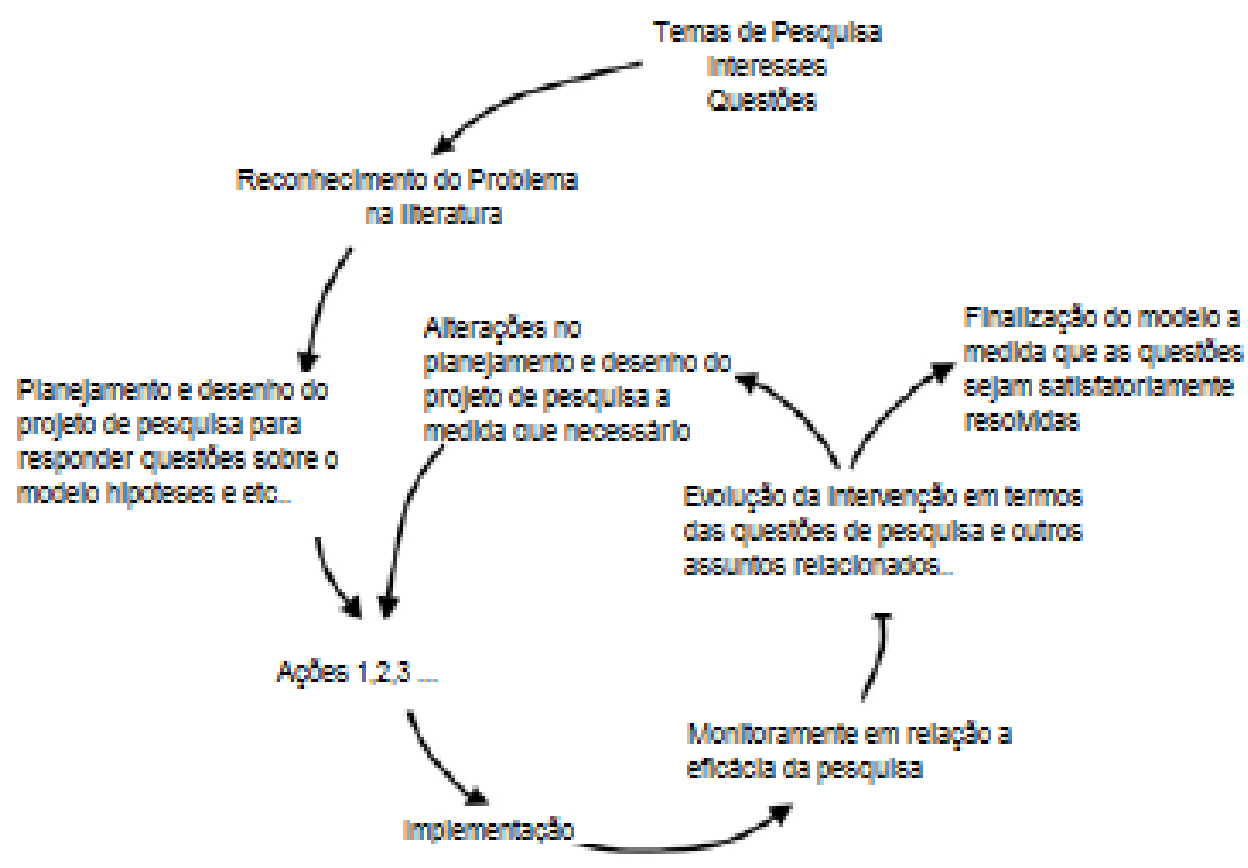

Figura 14 - Ciclo de pesquisa do método "Action-Research" Fonte: Traduzido de McKay e Marshall (2001)

A inter-relação entre estes dois processos está demonstrada na Figura 15, durante a condução de um processo de $A R$.

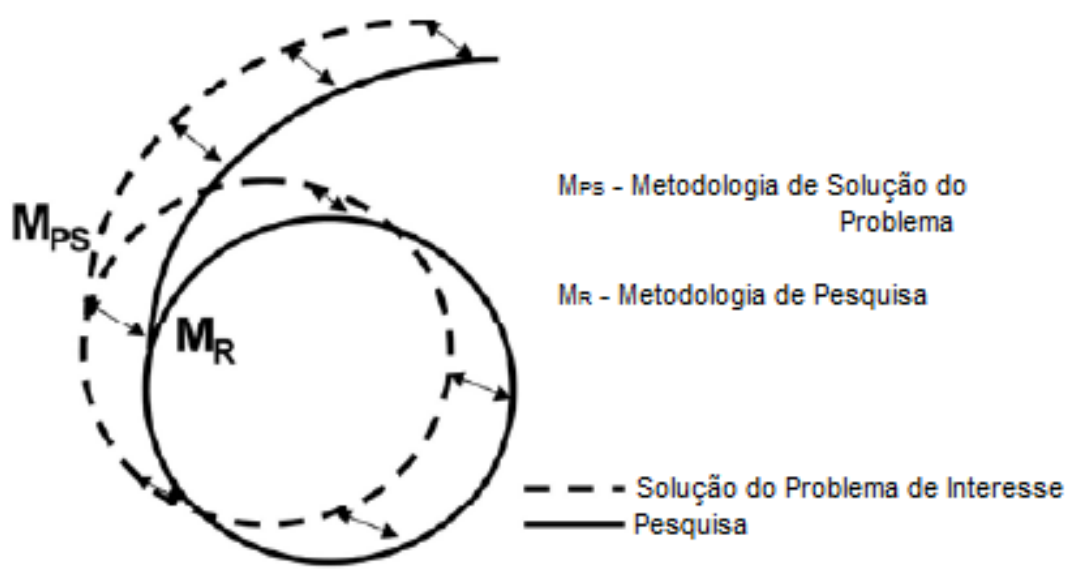

Figura 15 - Solução do Problema e Metodologias de Pesquisa Fonte: Traduzido de McKay e Marshall (2001)

Agora serão apresentadas as informações relevantes sobre os estudos de caso que foram aplicados e que estão complementadas no Apêndice D: 
Estudo de caso 1 - o modelo foi aplicado no "Expert Mode" com base na experiência prática dos envolvidos em eventos de seleção e contratação de prestadores de serviços logísticos. Como a metodologia sugere que as escolhas devem ser feitas utilizando aspectos reais para balizar os seus parâmetros, foi exemplificado um processo de contratação de um único transportador para atender uma rota típica em uma empresa de bens de consumo não duráveis, que está entre as líderes no segmento em que atua.

Estudo de caso 2 - neste caso o modelo foi aplicado em uma empresa nacional de grande porte do segmento de prestação de serviços logísticos. $O$ objetivo deste processo de seleção era encontrar outros prestadores de serviços logísticos para operar em sete estados brasileiros, no modelo 4PL. De forma simplificada, a empresa prestadora de serviços logísticos contratante (denominada neste modelo por contratante) é a responsável pelo serviço prestado pela empresa contratada (contratada), tendo como principais responsabilidades a definição da solução logística, gestão de desempenho e interface com a empresa detentora dos direitos do produto (cliente). A contratada é responsável pela disponibilização da área, manipulação dos produtos e administração diária dos ativos.

Este tipo de modelo foi o escolhido, pois o compartilhamento local de recursos proporcionados pela estrutura atual da contratada, em cada uma destas praças, produz uma drástica redução de custos operacionais sem perder a qualidade na solução logística escolhida e nos níveis operacionais, pois esses são executados e/ou controlados pela contratante.

A contratante, que estava sendo selecionada pelo cliente, também tinha uma restrição de tempo, pois deveria entregar em 20 dias o projeto completo. Este projeto envolvia, entre outras informações, a proposta técnica em cada uma das praças citadas. Frente a esta restrição, os envolvidos no processo de decisão optaram por restringir o processo de seleção em duas ou três empresas para cada uma das praças, dependendo do desempenho destas empresas na RFI. Além da decisão dos participantes ainda haveria toda a aplicação do modelo de decisão, pré-qualificação, visita técnica aos escolhidos para validação e complementação dos dados, acordos comerciais, acordos contratuais e demais aspectos para suportar a futura implantação. 
Utilizando o modelo "Facilitative Mode", o grupo que representava a empresa contratante foi composto por quatro participantes: diretor geral, controller, gerente operacional e a farmacêutica responsável pela área de qualidade. Auxiliando o grupo de decisores havia um facilitador e um analista, que conduziram a aplicação conforme a descrição do modelo, Figura 9. O autor desta dissertação, além de ser um dos participantes (diretor geral), foi também o facilitador do grupo. Entretanto, durante todo o processo, este agente teve como objetivo pessoal intervir somente quando necessário, seja como decisor ou facilitador, de forma a não alterar os resultados do estudo de caso. De qualquer forma, sua ascendência sobre os demais oriunda do seu nível hierárquico e o poder de influência como facilitador não devem ser descartados.

A condução do processo decisório, em ambos os casos, utilizou o método VFT e, desta forma, foi utilizada a ordem de implantação do problema definida por Keeney (1992): reconhecer o problema de decisão, especificar valores, criar alternativas de decisão, evoluir nas alternativas e selecionar uma alternativa. Tal ordem de implantação está alinhada com a estratégia da $A R$ proposta.

\subsection{IDENTIFICAÇÃO E ESTRUTURAÇÃO DO PROBLEMA}

\subsubsection{Entendimento do problema e aplicação do modelo de decisão escolhido}

Em ambos os estudos de caso foram discutidos os aspectos fundamentais na resolução de um problema de MCDA definidos por Belton e Stewart (2002) e detalhados no item 3.1.3 para auxiliar o processo de identificação e estruturação do problema.

No primeiro estudo de caso, embora um número maior de pessoas tenha se envolvido nesta aplicação, a sua construção foi conduzida por dois analistas, utilizando o modelo "Expert Mode". 
A primeira envolvida é a gerente de logística da empresa em que o processo foi aplicado. Esta executiva já havia participado de dezenas de processos de seleção de fornecedores em conjunto com sua área de compras e contribuiu com sua experiência na aplicação do modelo.

O segundo envolvido é diretor da divisão de logística de um dos maiores prestadores de serviços logísticos do Brasil e, nos últimos três anos, participou de mais de 300 processos de seleção como fornecedor de serviços logísticos para empresas nacionais e multinacionais de grande porte. Nestas seleções foi o responsável técnico pela entrega dos projetos logísticos nas áreas de operações de transporte, armazenagem e logística integrada. Este profissional é também o autor desta dissertação.

Devido à experiência dos envolvidos, que representam duas das principais partes de um projeto de seleção de serviços de transporte (contratante e contratado) o processo de entendimento e estruturação do problema foi relativamente simples e realizado através da discussão detalhada de cada uma das fases do mapa cognitivo desenvolvido com base no processo MCDA e VFT, Figura 7.

Após discussão e entendimento geral do problema, os analistas definiram as premissas necessárias que balizarão o desenvolvimento do processo de seleção. Os resultados desta análise podem ser observados no Apêndice D.

No segundo estudo de caso, considerando que não havia uma familiaridade de todas as partes envolvidas sobre quais seriam os objetivos com aquele processo de seleção, a aplicação do método SODA foi fundamental para o correto entendimento do problema e alinhamento das visões estratégicas sobre o mesmo. O resultado deste trabalho foi a criação do Mapa Cognitivo, Figura 16, desenvolvido pelo grupo de decisores. 


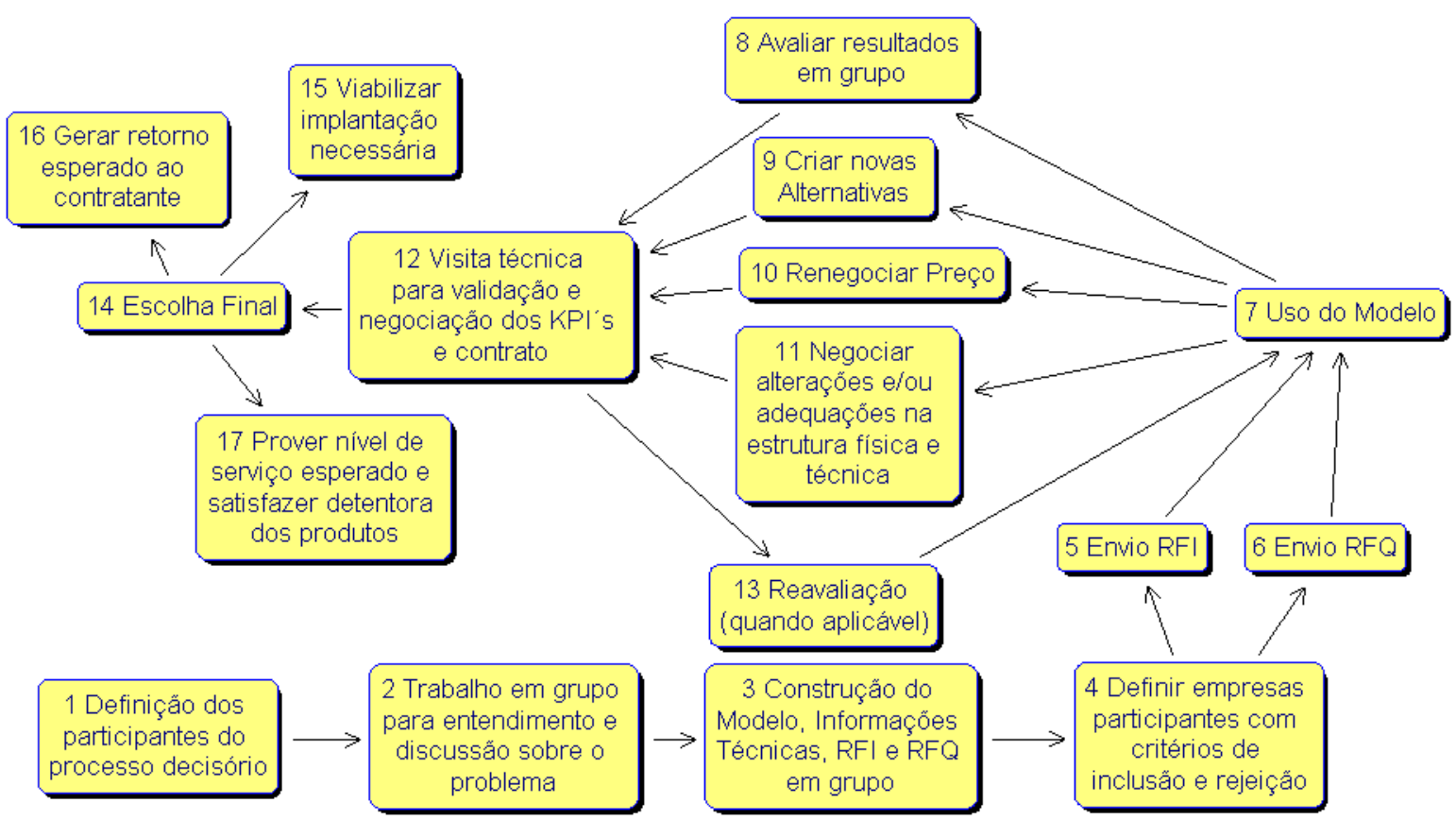

Figura 16 - Mapa Cognitivo desenvolvido pelo grupo de decisores para o estudo de caso 2 Fonte: Extraído do software (Banxia Decision Explorer)

\subsubsection{Obtenção de dados e empresas participantes do processo}

Um fator importante na obtenção dos dados é a clareza de informação e simplicidade do modelo de resposta. Assim, tem-se um aumento na confiabilidade dos dados obtidos e um maior número de alternativas de fornecedores. Sustentando essa análise, Keeney e Gregory (2005) destacam as características fundamentais em um modelo de medição e obtenção de dados:

- Não ambíguo: uma relação clara entre os resultados e suas medições pode ser obtida;

- Amplo: Os níveis de medição cobrem a gama de possíveis resultados para o critério correspondente. E os juízos de valor sobre o modelo de medição são razoáveis;

- Direto: O modelo de medição mede diretamente os resultados de seu interesse;

- Operacional: De forma prática e compreensível, são obtidos os resultados e o valor dos trade-offs;

- Compreensível: Os resultados e o valor dos trade-offs obtidos podem ser claramente entendidos e comunicados pelos usuários. 
Outro ponto importante é garantir o compromisso do fornecedor postulante com os dados fornecidos. Uma alternativa seria a inclusão dos dados apresentados no contrato de prestação de serviços. Outra possibilidade é a utilização dos critérios de seleção como indicadores de desempenho da operação, pois podem auxiliar no acompanhamento entre os dados apresentados e os resultados operacionais.

Existe também a alternativa de incluir uma multa contratual referente à confiabilidade dos dados que foram apresentados. Ou seja, caso não sejam atingidos os objetivos propostos, haveria uma penalização financeira ao fornecedor. Esta multa não tem como objetivo principal penalizar financeiramente o fornecedor de serviços, porque provavelmente esse valor seria repassado direta ou indiretamente aos custos pagos pelo contratante, mas sim escolher empresas realmente capazes de executar seus serviços de acordo com os dados propostos durante o processo de seleção.

Parece fundamental para o sucesso do processo de seleção a garantia da veracidade, e o compromisso de realização, referentes aos dados informados pelo fornecedor, uma vez que essas informações irão balizar o processo decisório e conduzir a escolha ideal.

O processo de busca dessas informações começa com a decisão de quais serão as transportadoras a serem consultadas. Essa decisão normalmente é feita com base no histórico de negociação da empresa, através de consulta a revistas especializadas, apoio de profissionais internos ou externos experientes ou contratação de consultorias especializadas nesse tipo de serviço.

Em consulta a empresas que estavam em processo de seleção, foram 215 processos controlados nos últimos dois anos, nos quais o autor participou como fornecedor. Praticamente a totalidade dos contratantes que forneceram esta informação, indica que a escolha dos participantes foi realizada por uma destas quatro vias.

Analisando as alternativas existentes para obtenção das empresas participantes do processo de seleção, as empresas de consultoria normalmente buscam as opções que constam de sua base de dados de parceiros qualificados, os "experts" são limitados pelo seu nível de conhecimento de mercado e velocidade de atualização, enquanto as revistas especializadas são limitadas na grande maioria das vezes a empresas que possuem ou são prospectadas em relacionamento comercial ou de 
conteúdo. As mesmas limitações normalmente estão presentes quando a escolha é realizada através do histórico de negociação da contratante.

Entretanto, é importante ressalvar, que se deve ter como objetivo que todos os prestadores de serviços, ou o maior número possível e viável deles, capazes de oferecer o nível de serviço definido, estejam presentes no processo de seleção.

Esse processo de seleção é normalmente denominado por Request for Quotation (RFQ), Request for Propose (RFP) ou Bidding e consiste no envio de um modelo de convite, normalmente em planilha eletrônica, a ser preenchido pelos proponentes. Através deste processo, são obtidos os dados necessários para condução do processo de seleção. Por uma questão de padronização os processos de seleção serão tratados por RFQ.

O Apêndice $\mathrm{C}$ demonstra um exemplo de planilha eletrônica simples que foi utilizado no primeiro estudo de caso aplicado, a seleção de uma rota de transportes entre São Paulo e Salvador.

Em uma parte relevante dos casos, anteriormente ao envio do processo de tomada dos dados necessários para a seleção, é enviado um questionário técnico, normalmente denominado $R F I$, para que os fornecedores possam ser previamente qualificados através de suas características estruturais e técnicas. Esta etapa não envolve tomada de preços e pode ser entendida como um apoio à obtenção de dados para análise dos critérios escolhidos, dentre eles, os critérios de inclusão e rejeição.

\subsubsection{Critérios de inclusão e rejeição}

Conforme já discutido na metodologia, os postulantes que não sejam capazes de atender aos limites aceitáveis em estrutura, capacidade técnica, nível de serviço ou condições comerciais, devem ser eliminados da análise através dos critérios de inclusão e rejeição. Baseado no método de pré-qualificação de fornecedores "Conjunctive Screening", Tabela 6, um fornecedor é aceitável se sua pontuação for igual ou superior à mínima exigida em cada um dos critérios. 
Para o primeiro estudo de caso, os critérios de inclusão e rejeição foram definidos conforme apresentado na Tabela 14, que apresenta o nível de serviço mínimo a ser prestado e os custos que devem ser utilizados nas cotações. Os limites de nível de serviço foram definidos com base nas necessidades, entendidas como mínimas, da empresa contratante. Os limites de custos foram definidos como base em um valor médio de mercado, em 2009, no setor analisado, pois deveria servir de padrão para todas as cotações.

Todas as empresas que não atingiram esses limites automaticamente foram excluídas do processo de seleção. No Apêndice D estão descritas as empresas que restaram no processo após a aplicação dos limites impostos.

Tabela 14 - Critérios de inclusão e rejeição para o estudo de Caso 1

\begin{tabular}{|c|c|}
\hline CRITÉRIOS DE INCLUSÁO E REJEIÇÁO & \\
\hline $\begin{array}{l}\text { Nivel de Servico } \\
\text { Entregas no Prazo (On Time Delivery) } \\
\text { Avarias } \\
\text { Prazo de Entrega (Lead Time) } \\
\text { Disponibilidade Extra }\end{array}$ & $\begin{array}{l}>85,0 \% \\
<3,0 \% \\
<7 \text { dias } \\
>40 \%\end{array}$ \\
\hline $\begin{array}{l}\text { Gris } \\
\text { Pedágio } \\
\text { Frete Valor (Sẫo Paulo - Salvador) } \\
\text { É vetada a inclusẫo de qualquer outra generalidade }\end{array}$ & $\begin{array}{c}=0,12 \% \\
=\mathrm{R} \$ \mathrm{~B} / 100 \mathrm{Kg} \\
=0,35 \%\end{array}$ \\
\hline
\end{tabular}

No estudo de caso 2 os critérios de inclusão e rejeição mínimos para o nível de serviço estão descritos na Tabela 15. Esses critérios foram definidos pelo grupo de decisores com a prerrogativa de ser o mínimo nível de serviço aceitável pelo cliente, pois o atual nível de serviço que o contratante presta ao cliente é significativamente superior aos critérios definidos.

Tabela 15 - Critérios de inclusão e rejeição para o estudo de Caso 2

\begin{tabular}{|c|c|}
\hline \multicolumn{2}{|c|}{ CRITÉRIOS DE INCLUSẢO E REJEIÇẢO } \\
\hline $\begin{array}{l}\text { Nivel de Serviço } \\
\text { Entregas Perfeitas no Prazo (OTIF) } \\
\text { Gestão de Estoque } \\
\text { Prazo de Recebimento }\end{array}$ & $\begin{array}{l}>99,0 \% \\
>99,0 \% \\
<24 \text { horas }\end{array}$ \\
\hline
\end{tabular}


Os outros critérios de inclusão e rejeição foram aplicados com base nas informações recebidas através da $R F I$ e serão detalhados no item 4.3.5. Esta $R F I$ trouxe informações a respeito de faturamento, disponibilidade de área, qualidade, licenças e outros fatores relevantes para a empresa contratante. O modelo desta RFI será apresentado de forma resumida no Apêndice C, através de uma das 10 pastas presentes na $R F I$, por ser considerada uma informação estratégica dada a pouca utilização do modelo 4PL no mercado brasileiro.

Considerando que o modelo adaptado ao estudo de caso 2 deveria ser aplicado em sete diferentes estados, o mesmo precisava ser genérico o suficiente para que pudesse ser aplicado em diversas regiões, necessitava também ser amplo para que as informações relevantes pudessem ser levantadas e deveria possibilitar aos tomadores de decisão convergir em cada uma das praças para a escolha dos dois ou três prestadores mais qualificados para participar do processo de seleção.

Importante ressaltar que o número de participantes não deve ser encarado como uma limitação do modelo, pois este processo de contratação é bastante restrito devido às suas necessidades específicas, sendo que em nenhuma destas praças foi possível obter mais do que cinco prestadores qualificados. Em quatro das sete praças, não há mais do que dois prestadores capacitados para realizar este tipo de serviço. Existia ainda uma defasagem técnica entre estes prestadores que possibilitou a restrição no número de participantes, reveladas nos critérios de inclusão e rejeição e $R F I$.

Portanto os critérios de inclusão e rejeição, em ambos os estudos de caso, foram definidos pelos decisores e podem ser considerados como restrições na busca pela solução ideal do nosso problema.

\subsection{CONTRUÇÃO E USO DO MODELO PARA O ESTUDO DE CASO 1}

De acordo com as premissas descritas, Apêndice D, este estudo de caso busca selecionar um fornecedor de transporte rodoviário fracionado para a rota São PauloSalvador. 
Conforme abordado na metodologia, para tomada de decisão sobre qual fornecedor será escolhido, serão atribuídos pesos para os critérios e subcritérios de relevância. Em nosso caso, serão detalhados a partir de agora os pesos e suas respectivas justificativas para as atribuições.

Por tratar-se de um caso aplicado, deve-se ponderar também a situação de mercado da contratante. Como a contratante disputa um mercado de grande competitividade, que exige preços baixos, o principal critério de definição da transportadora escolhido foram os custos. Porém, foi discutido também sobre a necessidade da empresa vencedora melhorar os níveis atuais de serviço.

Consensualmente, entre os dois analistas, foi atribuído $59 \%$ de valor relativo na tomada de decisão ao fator custo e $41 \%$ ao fator nível de serviço, conforme a Figura 17. A soma desses fatores deve compor $100 \%$.
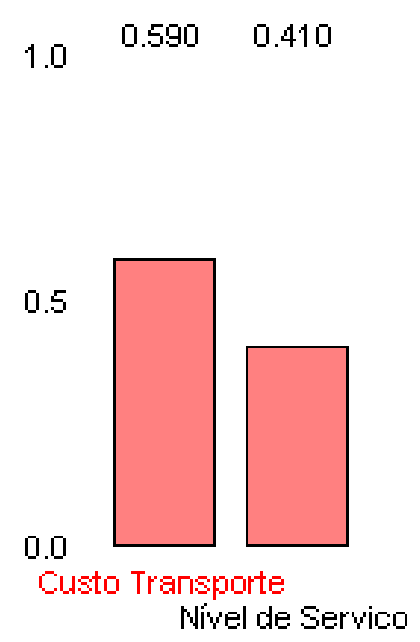

Figura 17 - Pesos de tomada de decisão entre custos de transporte e nível de serviço Fonte: Extraído do software (VISA)

\subsection{1 Árvore de valores}

Para definição de todos os critérios, subcritérios e pesos foi utilizado como apoio na transcrição do modelo a ferramenta VISA. Este software utiliza a árvore de valores para demonstrar as definições tomadas pelos decisores, o que facilita 0 entendimento e execução do processo decisório (Figura 18). 
A árvore de valores é utilizada para estruturação do problema utilizando-se de níveis para atribuição dos pesos. A definição dos pesos pode ser feita, conforme Belton e Stewart (2002), no formato "top-down" quando os pesos são definidos primeiramente para os critérios e depois para os subcritérios, ou "bottom-up" quando inicialmente são quantificados os subcritérios e posteriormente os critérios. No objeto de estudo foi utilizado o primeiro modelo, pois os analistas entenderam que estavam mais aptos para decidir qual seria a relevância na relação entre o custo e nível de serviço, e posteriormente nos subcritérios de cada um destes critérios.

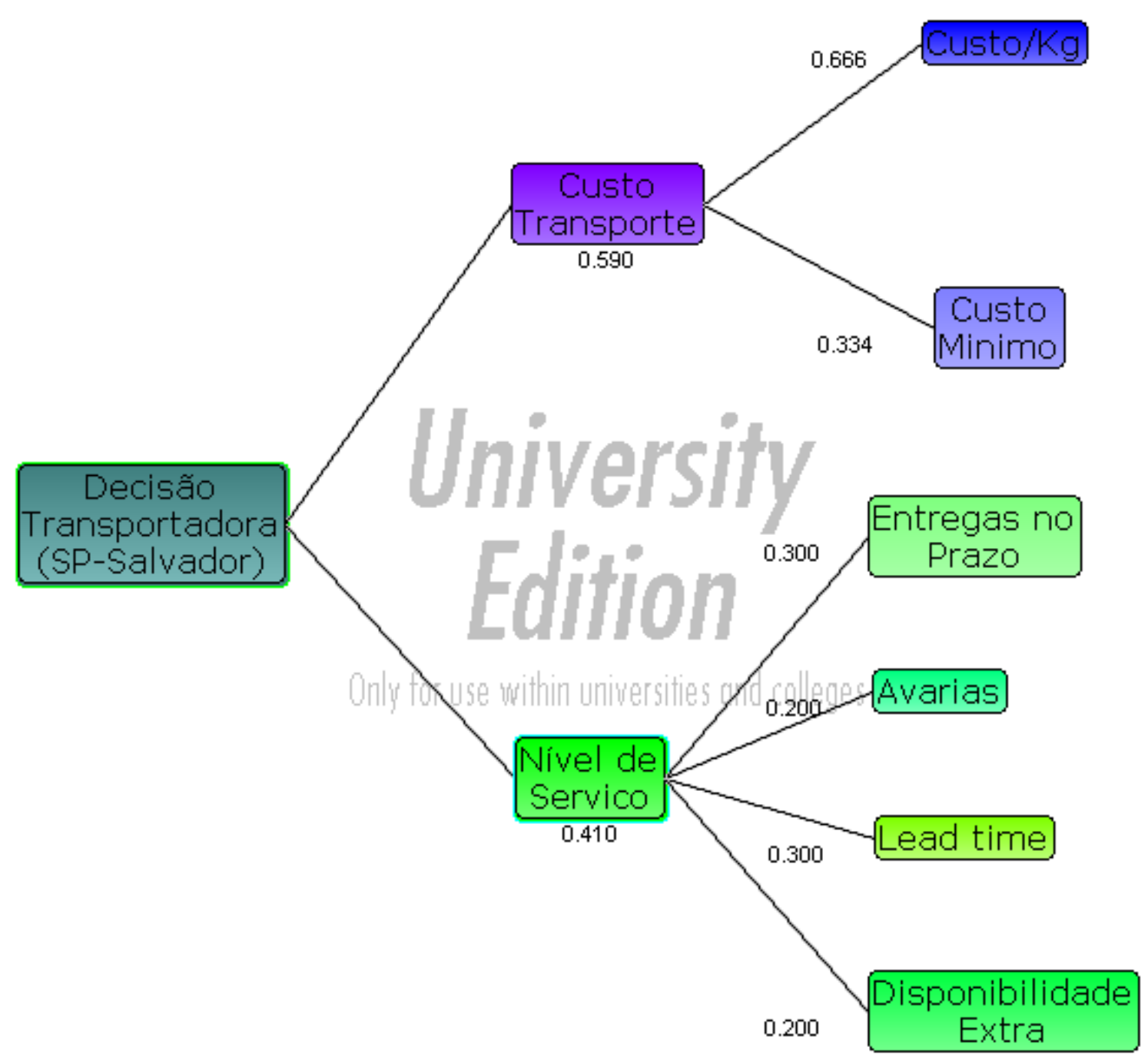

Figura 18 - Árvore de valores da Transportadora (SP-Salvador)

Fonte: Extraído do software (VISA) 
$\mathrm{Na}$ aplicação deste modelo, os analistas concluíram que a construção da árvore de valores foi determinante para o entendimento geral do problema, quantificação dos pesos e apoio à decisão.

\subsubsection{Subcritérios custos}

Em uma operação de transporte fracionado é comum a utilização de uma tabela de preços padrão, formada por custos equivalentes a cada faixa de peso e taxas agregadas de acordo com o tipo de serviço oferecido. A NTC\&Logística divulga anualmente, em um trabalho desenvolvido pelo Departamento de Custos Operacionais e Estudos Técnicos e Econômicos, a planilha referencial de custos do transporte rodoviário de cargas, NTC\&Logística (2010).

Os custos divulgados nesta planilha são utilizados como base, mas cada transportadora pratica seus preços de acordo com sua política comercial. Entretanto, - modelo divulgado pela NTC\&Logística é amplamente utilizado e se tornou praticamente um padrão de mercado. Este estudo foi baseado neste modelo de cobrança.

Nos preços apresentados pelas transportadoras, baseado no modelo da NTC\&Logística (2010) e no perfil de embarques, existem dois tipos preponderantes de custos: frete peso e frete mínimo (Figura 19). A soma desses fatores deve compor $100 \%$.

- Frete peso (por quilo): valor em moeda corrente, cobrado pelo peso da mercadoria transportada. Na planilha referência de custos, este custo é calculado de acordo com a faixa de peso da mercadoria. O referido valor incide sobre toda carga transportada e sua valorização de atribuição foi de $66,66 \%$.

- Frete mínimo: O frete mínimo é o valor mínimo cobrado por embarque, independente do peso a ser transportado. Ou seja, quando o peso total de um embarque (conhecimento emitido) não ultrapassar a faixa inicial de peso, será cobrado o valor equivalente a esta taxa. Na planilha referência de custos este custo é a somatória da taxa de despacho com a coluna inicial de cobrança do 
transportador. Considerando que o perfil da carga é de médio fracionamento, aproximadamente um terço dos embarques são inferiores ao frete mínimo. Foi utilizado 33,34\% como índice para quantificar a importância do frete mínimo.

$$
\begin{array}{lll}
1.0 & 0.666 & 0.334
\end{array}
$$

Figura 19 - Pesos para os subcritérios de custos

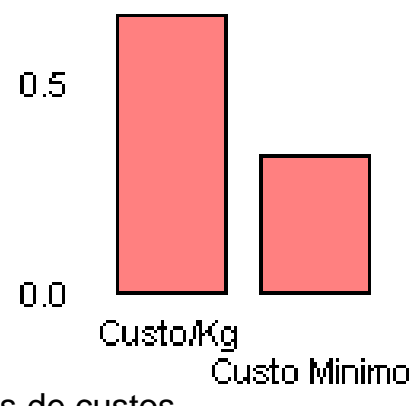

Fonte: Extraído do software (VISA)

Uma premissa do modelo foi que as demais taxas - custo valor ou "ad-valorem" e taxa de riscos e segurança (GRIS), deveriam ser utilizadas com base no valor base da planilha referência de custos, NTC\&Logística (2010). Tal simplificação não limitou os transportadores em sua planilha de custos porque foi possível adequá-las alterando os valores de frete peso e frete mínimo. E simplificou o modelo, pois reduziu o número de variáveis no critério custos.

Caso a opção fosse por não definir valores fixos para as taxas, a única alteração seria a inclusão nos subcritérios de todas as taxas com valores divergentes entre as transportadoras. Repare que neste caso haverá uma maior complexidade na definição dos pesos e a probabilidade de um pior julgamento é maior. Outro ponto de atenção é que o modelo de tabela a ser enviado pelas transportadoras deve ser igual para que se possa comparar os custos em condições equivalentes.

\subsubsection{Subcritérios nível de serviço}

O nível de serviço pode ser subdividido em vários subcritérios. Os quatro itens mais significativos que foram escolhidos para essa análise com base no perfil de controles 
da operação são os seguintes: entregas no prazo, prazo de entrega, avarias e disponibilidade extra (Figura 20). A soma desses fatores deve compor $100 \%$.

- Entregas no prazo (OTD): descreve o percentual de conhecimentos de transporte que foram efetivamente entregues no prazo acordado em contrato. Por tratar-se de um indicador fundamental para a satisfação dos clientes, seu peso foi de $30 \%$.

- Prazo de Entrega (Lead time): é o prazo acordado contratualmente em dias úteis para que a mercadoria seja efetivamente entregue. A satisfação dos clientes é inversamente proporcional ao prazo definido e um maior prazo de entrega pode obrigar a contratante a ter que alterar os seus processos para se adequar às necessidades de seus clientes. Para esse subcritério também foi definido um peso de $30 \%$.

- Avarias: percentual de cargas danificadas ou extraviadas durante o processo. Apesar de este índice ser integralmente indenizado pelas transportadoras, existem dezenas de aspectos envolvidos em uma não efetivação da entrega: atraso para o cliente, necessidade de reposição (quando possível), prazo de retorno, custos financeiros decorrentes do atraso, etc. Seu peso determinado foi de $20 \%$.

- Disponibilidade Extra: definiu-se como disponibilidade extra o percentual de atendimento da transportadora para os veículos extras (acima do nível contratado de coleta). Repare que este atendimento se refere a todos os destinos com igual indicador, pois a coleta é única. Para essa disponibilidade o peso foi de $20 \%$, porque normalmente essa necessidade é gerada nos momentos operacionais mais críticos.

$1.0 \quad 0.300 \quad 0.200 \quad 0.300 \quad 0.200$

0.5

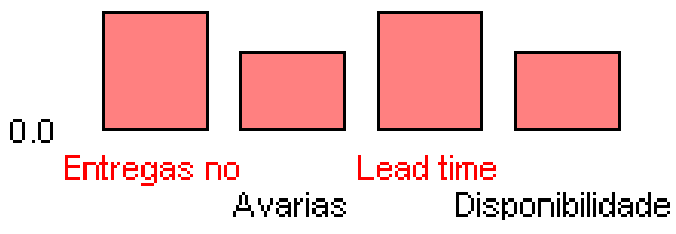

Figura 20 - Pesos dos subcritérios de Nível de Serviço

Fonte: Extraído do software (VISA) 


\subsubsection{Dados das transportadoras}

De acordo com a metodologia detalhada no item 4.1.2, os dados foram obtidos junto às quatro transportadoras escolhidas, Apêndice $\mathrm{D}$, através do retorno da $R F Q$ enviada, Apêndice C.

Embora tenha se tentado ao máximo garantir a legitimidade do processo, que ocorreu em meados de 2009, antes da tomada de preços os três participantes foram informados que se tratava de um piloto e não de um processo efetivo de contratação. Desta forma pode-se entender que os preços apresentados foram referenciais e não valores que tinham como objetivo o fechamento do negócio.

Para a transportadora "D" os dados foram confrontados com os indicadores realizados na operação atual e para as outras transportadoras foi solicitada referência dos seus três principais clientes e os níveis de serviço apresentados deveriam ser validados com esses clientes. Considerou-se que não existia nenhuma inconsistência nos dados e, conforme prerrogativa do processo, esse índice deve fazer parte de um possível contrato a ser assinado entre as partes, inclusive, com a exigência de cumprimento do serviço apresentado. Na Tabela 16 constam os dados recebidos dos fornecedores.

Tabela 16 - Dados Recebidos das Empresas

\begin{tabular}{lcccccc}
\hline Empresas & Custo/kg & $\begin{array}{c}\text { Custo } \\
\text { Mínimo }\end{array}$ & $\begin{array}{c}\text { Entregas } \\
\text { no Prazo }\end{array}$ & Avarias & $\begin{array}{c}\text { Prazo } \\
\text { Entrega }\end{array}$ & $\begin{array}{c}\text { Disponibilidade } \\
\text { Extra }\end{array}$ \\
\hline Transportadora "A" & $\mathrm{R} \$ 0,74$ & $\mathrm{R} \$ 42,50$ & $98 \%$ & $0,75 \%$ & 3 dias & $95 \%$ \\
Transportadora "B" & $\mathrm{R} \$ 0,70$ & $\mathrm{R} \$ 45,00$ & $93 \%$ & $1,1 \%$ & 3 dias & $100 \%$ \\
Transportadora "C" & $\mathrm{R} \$ 0,60$ & $\mathrm{R} \$ 39,50$ & $87 \%$ & $2,9 \%$ & 4 dias & $50 \%$ \\
Transportadora "D" & $\mathrm{R} \$ 0,40$ & $\mathrm{R} \$ 30,00$ & $73 \%$ & $4,0 \%$ & 7 dias & $5 \%$ \\
\hline
\end{tabular}

\subsubsection{Função de valor (value function)}

De posse dos dados, deve-se proceder à construção das funções de valor, realizada pelos analistas em sessão interativa com o auxílio do software.

Por definição será utilizada uma escala local, definida em Belton e Stewart (2002), aonde será atribuído como pontuação o valor mínimo, "0", correspondente ao valor mais desfavorável apresentado na RFQ e o valor máximo, "100", como o valor mais 
favorável. Por coerência, para custos, avarias e prazo de entrega o valor mais favorável será o menor valor e nos outros subcritérios, entregas no prazo e disponibilidade, o valor mais favorável será o maior valor.

As pontuações estarão entre o valor mínimo e o valor máximo e serão definidas através da função de valor desenhada para aquele subcritério específico, ou seja, esses valores variam de "0" a "100" de acordo com a pontuação daquele subcritério na função de valor.

Conforme observado por Belton e Stewart (2002), funções de valor complexas são raras, ou inexistem, na prática. Será utilizado como apoio à construção das funções a primeira abordagem do método das diferenças descrita por Watson e Buede (1987), aonde a escala é dividida em partes e os decisores são convidados a avaliar qual deve ser o impacto de uma alteração de valores referente ao intervalo em questão.

\subsubsection{Custo por Kg, Custo Mínimo e Avarias}

A função inicia-se atribuindo 100, maior pontuação, para o menor valor e 0, pior pontuação, para o maior valor recebido. Dividindo-se o eixo horizontal (eixo dos valores) em cinco partes, em cada uma dessas partes aumentou-se a penalização em $5 \%$ do valor total, fixando as penalizações por faixa em 10\%, 15\%, 20\%, 25\% e $30 \%$, respectivamente, por considerar que quanto maior o aumento de preço em relação ao preço atual (o transportador atual teve o menor preço) maior o impacto interno em relação aos custos, vide Figura 21.

Caso a percepção de custos do contratante fosse diferente, a função poderia ser adequada à nova realidade. No caso das avarias, acredita-se que essa função possa ser utilizada para qualquer análise, pois quanto maior o percentual de avarias maior o nível de problemas no relacionamento com os clientes e maior o nível de custos não mensuráveis, como multas por não recebimento, atrasos de atendimento, entre outros. O que poderia ser reavaliado neste caso é o índice de penalização e/ou o número de partes a serem divididas as curvas. 
a) Custo por kg

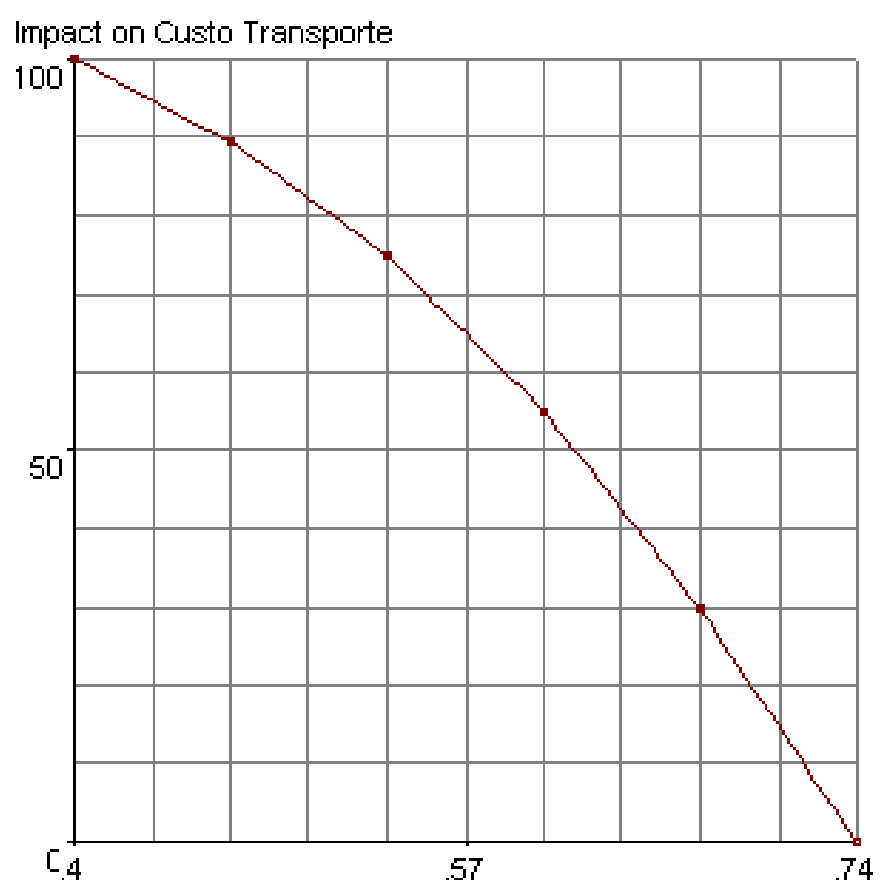

b) Custo Mínimo

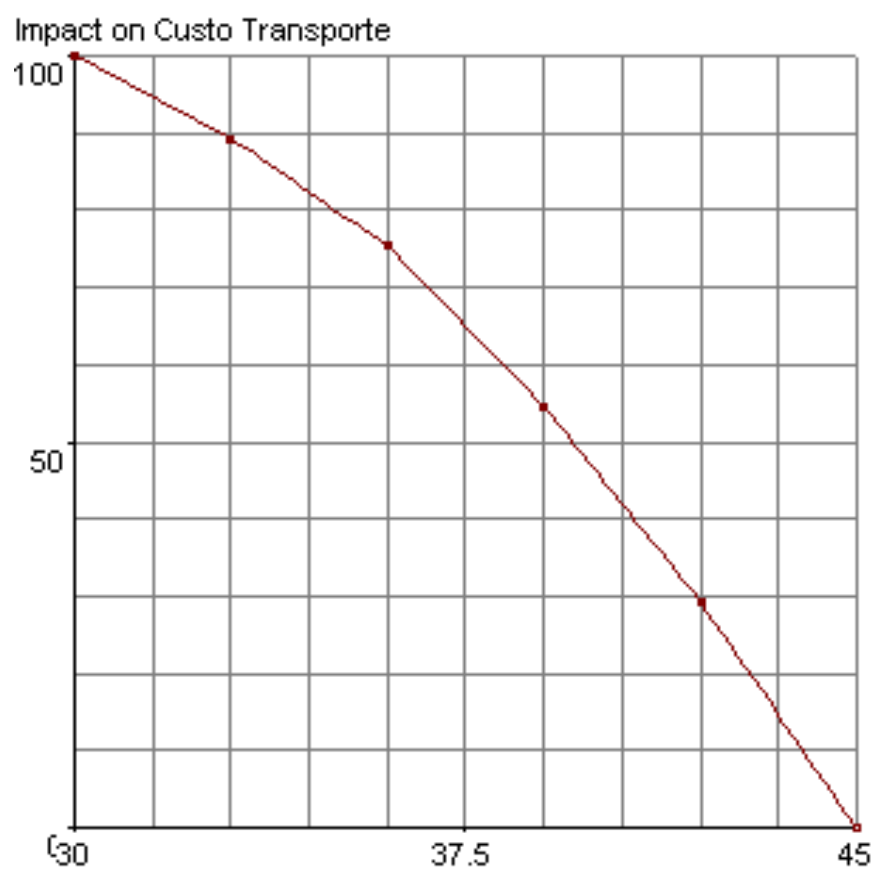


c) Avarias

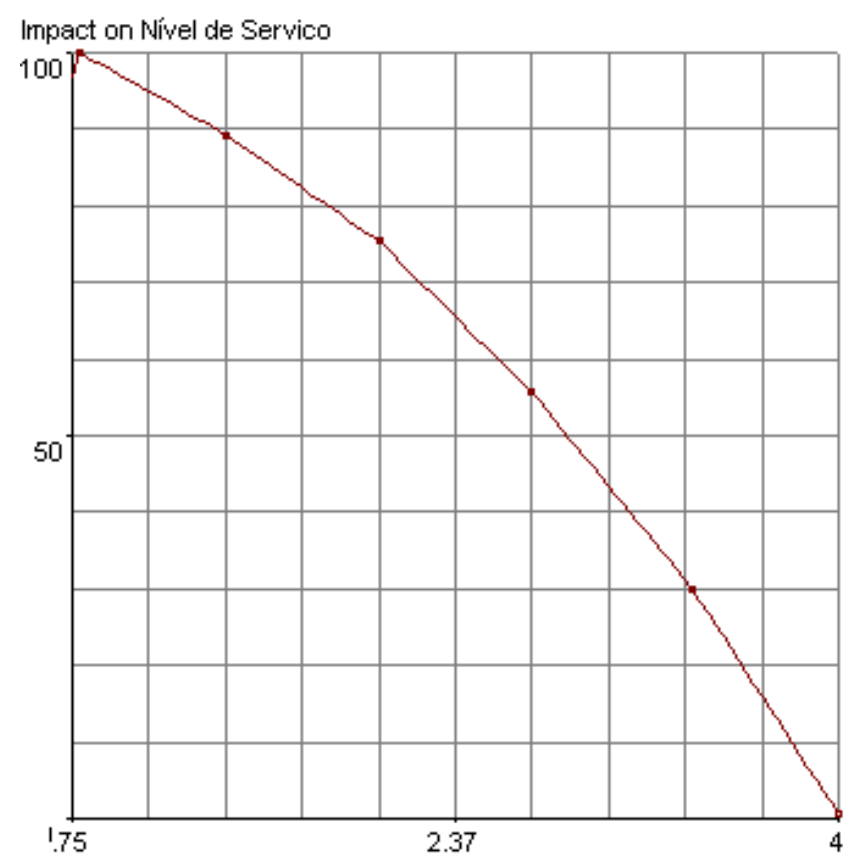

Figura 21 - Curvas de impacto: custos e avarias Fonte: Extraído do software (VISA)

\subsubsection{Entregas no Prazo e Disponibilidade Extra}

Agora a função inicia-se atribuindo "0" para o menor valor percentual apresentado e " 100 " para o maior valor percentual apresentado.

Avaliando a função das entregas no prazo, o que foi acordado pelos analistas, é que o nível mínimo necessário de entregas no prazo deveria ser de $90 \%$, dado o comprometimento operacional de um nível de serviço inferior ao estipulado. Desta forma, a punição para quem atingir resultados abaixo do esperado ( $90 \%$ de entregas no prazo) será grande e equivalente a $70 \%$ da pontuação. Por consequência, valores acima de $90 \%$ são bem cotados, $8,75 \%$ de bonificação para cada $1 \%$ de melhora no desempenho. Resultados de $73 \%$ a $90 \%$ de entrega no prazo recebem bonificação por ponto percentual de $1,17 \%$ na faixa de $73 \%$ a $81,5 \%$ de desempenho e $2,35 \%$ de $81,6 \%$ a $90 \%$, o que fica mais claro através da curva descrita na Figura 22 a.

Para disponibilidade extra, dividiu-se o eixo horizontal (valores) em partes. A cada uma delas reduziu-se o mérito por faixa em $5 \%$ do valor total, fixando os méritos por faixa em $30 \%, 25 \%, 20 \%, 15 \%$ e $10 \%$, respectivamente, por considerar que quanto 
menor for o valor de atendimento a operação de coletas, maior deve ser o nível de penalização dado os problemas causados na distribuição dos produtos, vide Figura 22 b.

a) Entregas no Prazo

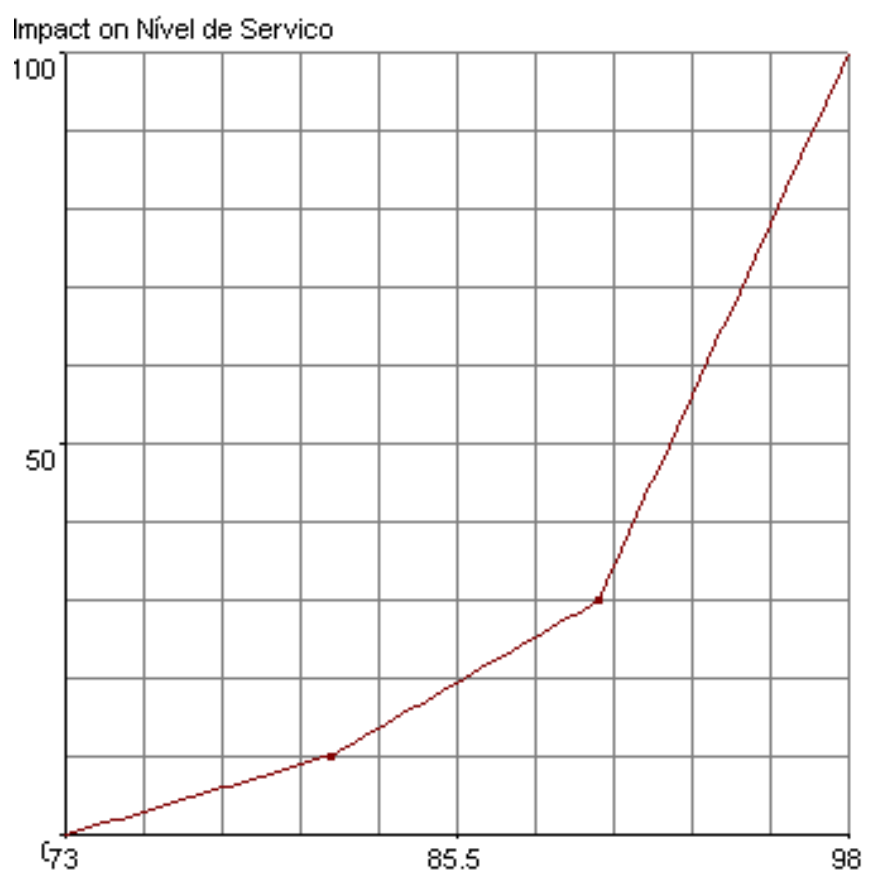

b) Disponibilidade Extra

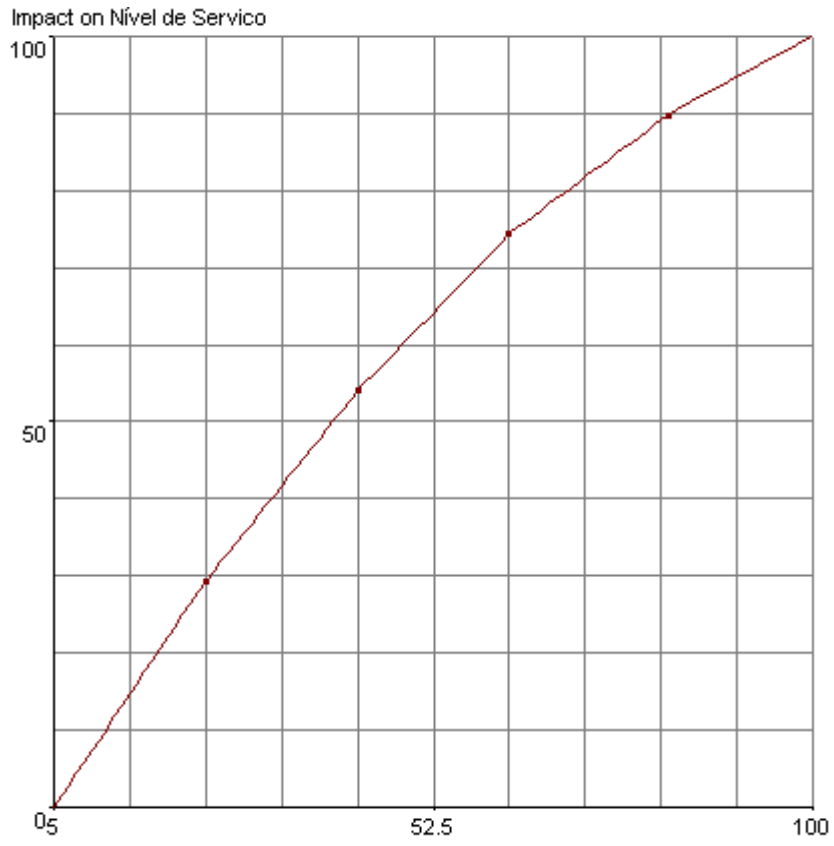

Figura 22 - Curvas de impacto: entregas e disponibilidade extra Fonte: Extraído do software (VISA) 


\subsubsection{Prazo de Entrega}

Essa é a única função constante. Os analistas entenderam que é possível adequar os processos internos para atender uma variação no prazo de entrega, considerando que esta alteração seja favorável, pois o transportador atual tem o pior prazo de entrega apresentado. Ao menor valor foi atribuído 100 e ao maior valor 0, Figura 23.

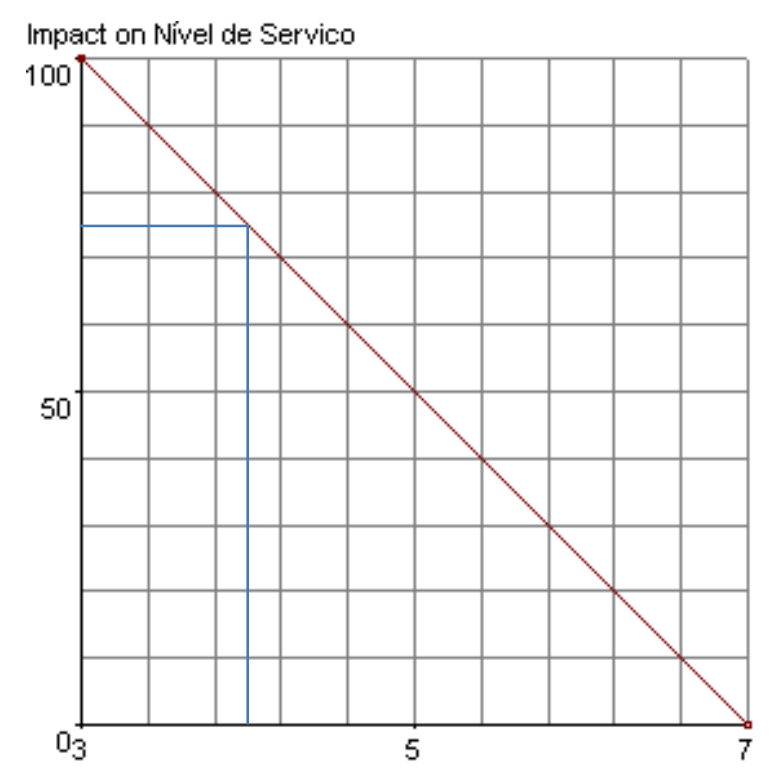

Figura 23 - Curva de impacto: Prazo de Entrega

Fonte: Extraído do software (VISA)

Estabelecidos os comportamentos das curvas de impacto, obtém-se a pontuação para aquele subcritério através do valor encontrado, entre "0" e "100", para determinado Transportador no referido subcritério. Por exemplo, na Figura 23 podese observar que a Transportadora "C", com 4 dias de prazo de entrega, recebe 75 pontos pelo comportamento linear desta curva de impacto. A extração destes valores é realizada automaticamente através do software, o que aumenta a precisão do modelo e acelera o processo de avaliação das transportadoras.

De acordo com a pontuação, para cada subcritério será utilizada a fórmula $\operatorname{Max} \sum_{i \in N} \sum_{j \in J} \sum_{k \in K_{j}}\left(c^{j} \times s_{k}^{j} \times p_{i, k}^{j} \times x i\right)$

, detalhada no capitulo 3, para calcular as pontuações finais de cada transportadora. Esta etapa também é realizada automaticamente pelo software. 
As pontuações para cada subcritério, os pesos determinados e as pontuações finais calculadas, sem o auxílio do software, são demonstrados na Tabela 17. Por ter sido utilizada a mesma metodologia de cálculo, obviamente os valores encontrados foram os mesmos apresentados pelo software.

Tabela 17 - Pontuação das alternativas para cada critério avaliado

\begin{tabular}{|c|c|c|c|c|c|c|c|}
\hline Pesos Critérios & \multicolumn{2}{|c|}{$59,00 \%$} & \multicolumn{4}{|c|}{$41,00 \%$} & \multirow{3}{*}{$\begin{array}{l}\text { Pontuação Final } \\
\text { (Curvas de } \\
\text { Impacto) }\end{array}$} \\
\hline Pesos Subcritérios & $66,60 \%$ & $33,40 \%$ & $30,00 \%$ & $20,00 \%$ & $30,00 \%$ & $20,00 \%$ & \\
\hline Empresas & Custo/kg & Custo Min. & Ent. No Prazo & Avarias & Prazo Ent. & Disp. Extra & \\
\hline Transportadora "A" & 0 & 25 & 100 & 100 & 100 & 97 & 45,68 \\
\hline Transportadora "B" & 20 & 0 & 56 & 94 & 100 & 100 & 42,95 \\
\hline Transportadora "C" & 56 & 51 & 23 & 48 & 75 & 61 & 53,05 \\
\hline Transportadora "D" & 100 & 100 & 0 & 0 & 0 & 0 & 59,00 \\
\hline
\end{tabular}

\subsubsection{Resultados}

Após os cálculos, chega-se ao resultado que é determinado pela pontuação de cada uma das transportadoras, representada na Figura 24.

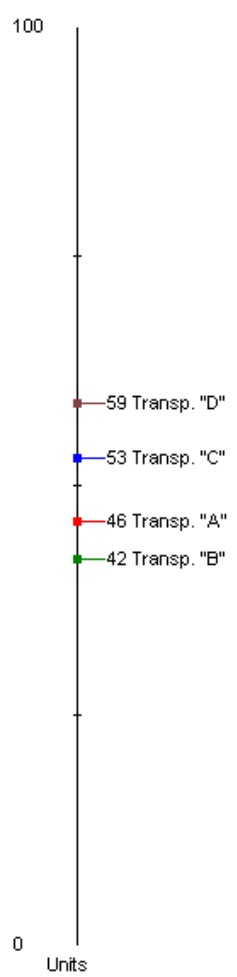

Figura 24 - Melhor alternativa Fonte: Extraído do software (VISA) 
Para os critérios, subcritérios e funções de valor que foram definidos, a transportadora "D", com 59 pontos, foi a que resultou uma melhor pontuação. A transportadora "C" ficou em segundo com 53. Em terceiro, a transportadora "A" com 46 e, por último, a transportadora "B" com 43 pontos.

\subsubsection{Análise de sensibilidade e robustez dos resultados}

Foi aplicado o modelo de análise de sensibilidade e robustez proposto por Belton e Stewart (2002) e descrito na metodologia.

A perspectiva individual foi utilizada durante toda a aplicação, inclusive durante as definições de critérios, pesos, funções de valor e resultados. Tais análises estão sendo discutidas durante o capitulo em seus momentos mais relevantes e, se referem aos questionamentos que são propositadamente impostos durante o processo no sentido de buscar o resultado mais robusto.

A análise sobre as perspectivas técnicas foi realizada através da avaliação dos dados de entrada (funções de valor, pesos e pontuações) e sua influência nos resultados obtidos. O software auxilia bastante na visualização destas influências, observadas através de pequenas alterações nos dados de entrada, e seus resultados vieram a contribuir com as implementações realizadas no decorrer desta análise.

Por último, a perspectiva de grupo foi aplicada através do questionamento e geração de novas propostas para os critérios e seus pesos. Foram analisados dois gráficos extraídos do software, Figuras 25 e 26. Esses gráficos demonstram 0 comportamento da decisão de qual transportadora deveria ser escolhida, em função dos pesos dos dois critérios definidos: custos e nível de serviço. A linha pontilhada, em ambos os gráficos, demonstra o coeficiente atribuído ao quesito.

Percebe-se na avaliação da Figura 25, que a transportadora "D" recebe maior pontuação quanto maior for a representatividade dos custos na decisão final. Mais precisamente, baseado nos valores iniciais apresentados pelas transportadoras, se a relevância do critério custos for maior ou igual a 53,5\%, a melhor solução sempre 
será o transportador atual, pois seus custos são consideravelmente mais baixos que os concorrentes.

No momento desta constatação, retornando a análise de perspectiva individual, surgiu o questionamento sobre as pontuações atribuídas aos critérios, e foi realizada uma profunda discussão sobre o valor relativo do fator "custos". Este questionamento teve como ponto focal o nível de concorrência de preços imposto pelo mercado em que estão inseridos os produtos da contratante e sua necessidade constante de aumento de participação no mercado, através de preço, e manutenção e ampliação de sua competitividade.

A conclusão desta discussão foi que o peso atribuído de $59 \%$ estava adequado à realidade da empresa, pois nenhum aumento de custo poderia ser agregado ao processo sem que exista um plano de viabilidade que apresente maiores ganhos financeiros como, por exemplo: redução de outros custos com esta implantação ou aumento de competitividade que justificasse o investimento.

Para um dos analistas, e gerente de logística da empresa contratante, a ideia inicial de construção deste modelo era conseguir ponderar outros fatores, além de custos. No seu sentimento, a transportadora atual, mesmo tendo um serviço considerado "satisfatório" por seus pares e superiores, estava aquém de um fornecedor que pudesse proporcionar resultados que suportariam o desenvolvimento do negócio.

Sua expectativa era encontrar um fornecedor que pudesse gerar novas oportunidades oriundas de um melhor nível de serviço como: maior confiabilidade operacional, menor nível de ruptura frente aos concorrentes e maior agilidade no atendimento de pedidos. Fatores que, além do preço, são fundamentais para atingir os objetivos esperados.

A analista tinha o sentimento de que os ganhos com essa melhora no nível de serviço seriam bem maiores do que o provável valor de acréscimo nos custos de transporte, embora não pudesse suportar um aumento no peso do nível de serviço, pois isso viria de encontro com as visões de seus superiores e da empresa. 


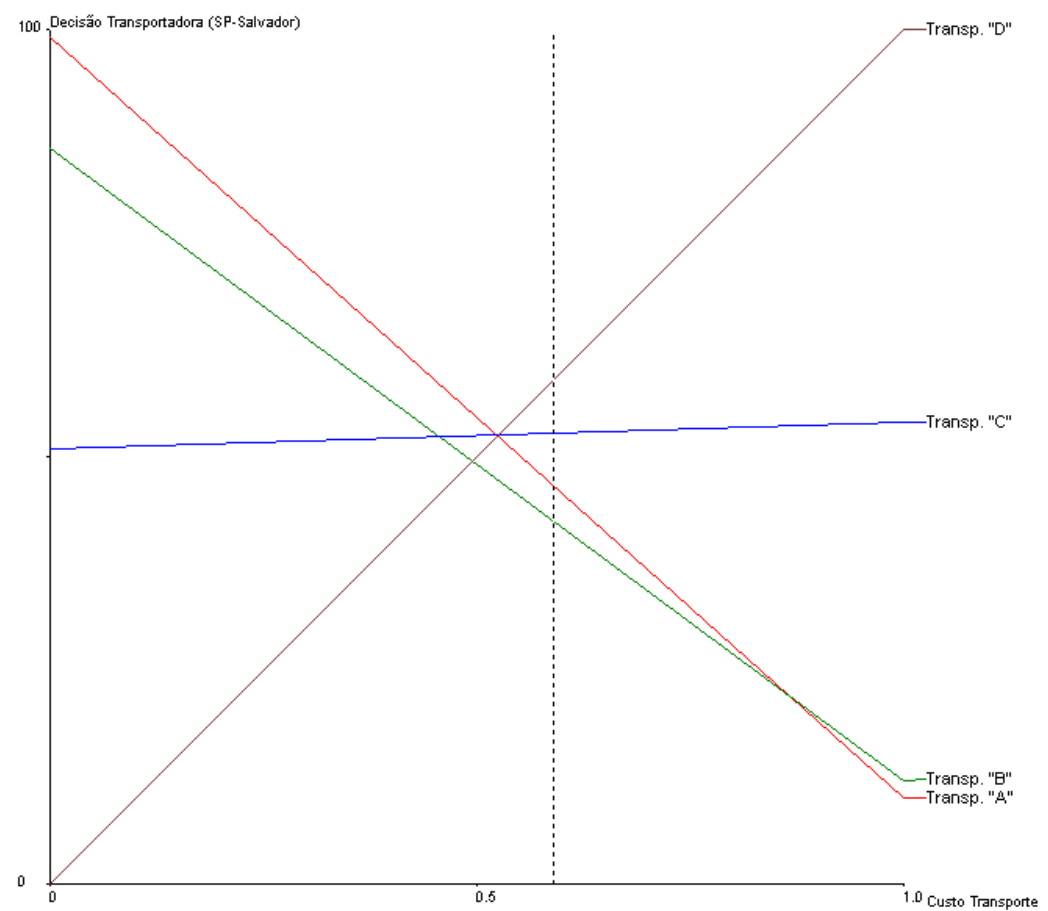

Figura 25 - Gráficos para tomada de decisão Custo de Transporte/Decisão Transportadora Fonte: Extraído do software (VISA)

Retornando a análise dos gráficos, de forma inversa, a análise relativa ao nível de serviço, Figura 26, apontou que as transportadoras "A" e "B" têm melhor desempenho à medida que fosse ampliada a relatividade deste item, fato já descartado.

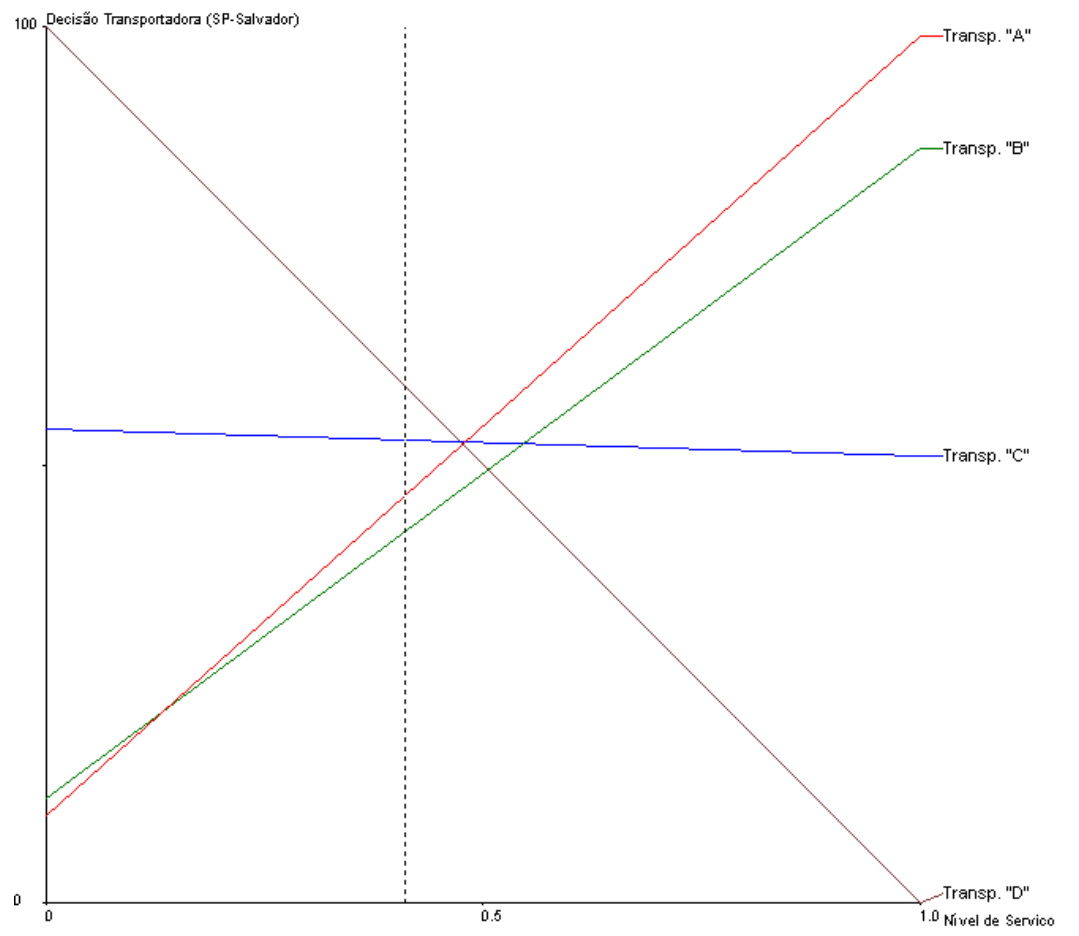

Figura 26 - Gráficos para tomada de decisão Nível de Serviço/Decisão Transportadora Fonte: Extraído do software (VISA) 
Considerando que a ponderação entre custo e nível de serviço estava correta com as diretrizes da empresa, os analistas decidiram renegociar com as transportadoras com objetivo de reduzir os custos apresentados. Havia a prerrogativa também de que nesta revisão, caso os níveis de serviço fossem alterados, deveriam atender os critérios de inclusão e rejeição.

A proposta foi gerar uma proatividade nesta negociação, ou seja, avaliar utilizando o software às condições necessárias para que as propostas enviadas se tornassem as mais atrativas e encaminhar estas propostas aos participantes. No desenvolvimento destas propostas, a alternativa escolhida foi optar pela manutenção do nível de serviço apresentado e calcular a necessidade de redução de custos, proporcionalmente igual em ambos os subcritérios, para que aquela proposta se tornasse a mais competitiva.

Foi formalizado aos participantes que, baseado no princípio de isonomia, esta oportunidade seria oferecida a todos. A transportadora "D", atual transportador da rota, há algum tempo já havia formalizado sua impossibilidade de reduzir custos. Assim, esta etapa foi dirigida às outras três transportadoras.

As transportadoras foram consultadas e apenas a transportadora "A" optou por continuar no processo, por se tratar de um programa piloto, sem garantia de contratação.

Substituindo os valores no software foi possível observar que, com apenas 7\% de redução nos valores de custo - Custo Mínimo alterado para $\mathrm{R} \$ 39,52$ e Custo por $\mathrm{Kg}$ para $\mathrm{R} \$ 0,688$ (Tabelas 18 e 19), a transportadora "A" seria considerada a melhor opção (Figura 27).

Tabela 18 - Alterações de custo para a transportadora "A"

\begin{tabular}{ccccccc}
\hline Empresas & Custo/kg & $\begin{array}{c}\text { Custo } \\
\text { Mínimo }\end{array}$ & $\begin{array}{c}\text { Entregas no } \\
\text { Prazo }\end{array}$ & Avarias & $\begin{array}{c}\text { Prazo } \\
\text { Entrega }\end{array}$ & $\begin{array}{c}\text { Disponibilidade } \\
\text { Extra }\end{array}$ \\
\hline Transportadora "A" & $\mathrm{R} \$ 0,688$ & $\mathrm{R} \$ 39,52$ & $98 \%$ & $0,75 \%$ & 3 dias & $95 \%$ \\
Transportadora "B" & $\mathrm{R} \$ 0,700$ & $\mathrm{R} \$ 45,00$ & $93 \%$ & $1,10 \%$ & 3 dias & $100 \%$ \\
Transportadora "C" & $\mathrm{R} \$ 0,600$ & $\mathrm{R} \$ 39,50$ & $87 \%$ & $2,90 \%$ & 4 dias & $50 \%$ \\
Transportadora "D" & $\mathrm{R} \$ 0,400$ & $\mathrm{R} \$ 30,00$ & $73 \%$ & $4,00 \%$ & 7 dias & $5 \%$ \\
\hline
\end{tabular}


Tabela 19 - Alterações na pontuação por causa dos custos reavaliados pela transportadora "A"

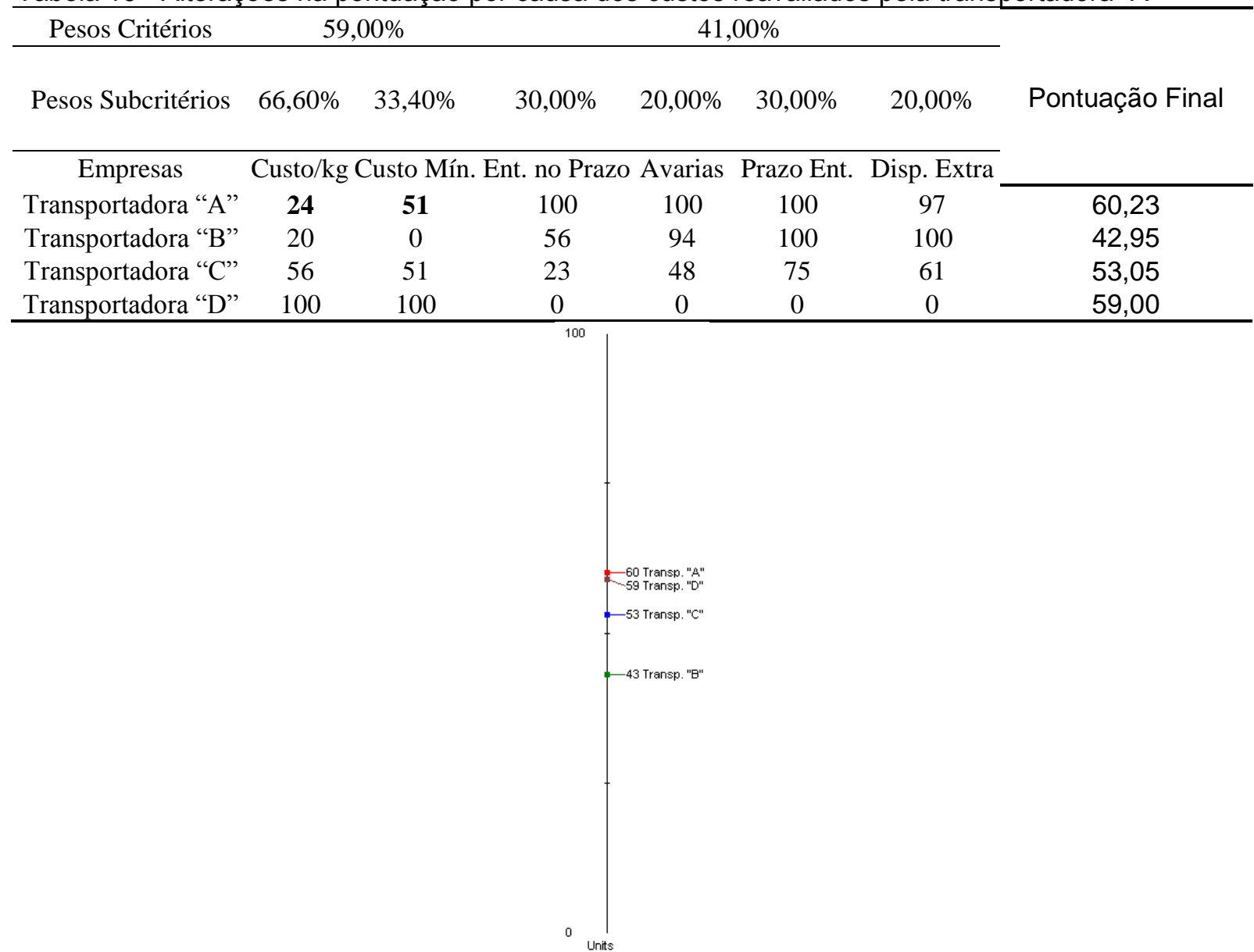

Figura 27 - Novo resultado com a alteração de custos para a transportadora "A" Fonte: Extraído do software (VISA)

Os novos gráficos para a decisão final de escolha da Transportadora são apresentados a seguir, Figuras 28 e 29.

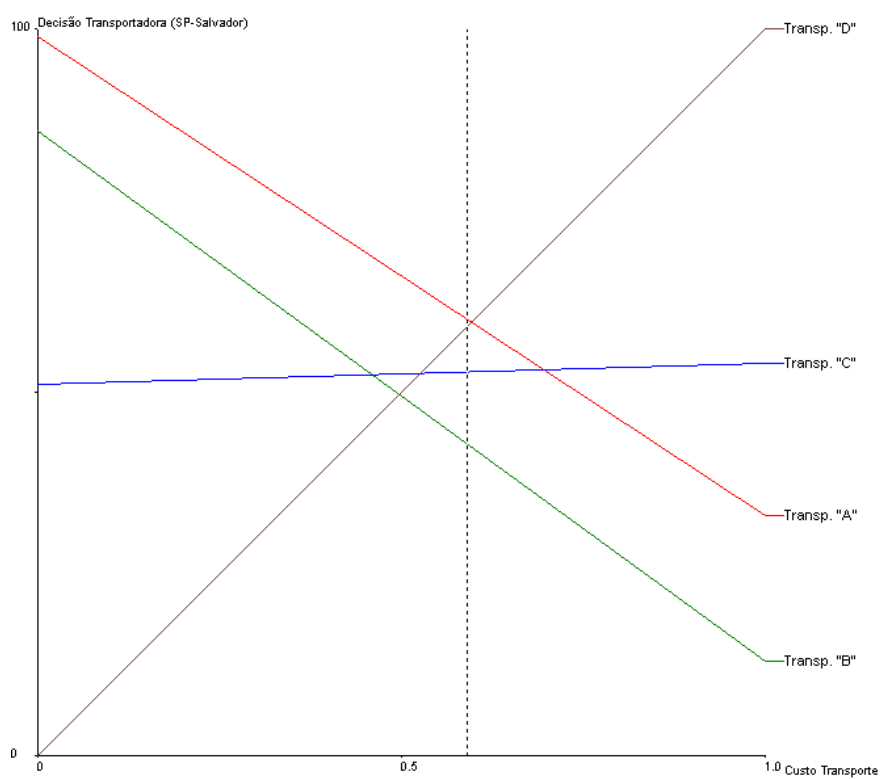

Figura 28 - Novos Gráficos para tomada de decisão Custo de Transporte/Decisão Transportadora Fonte: Extraído do software (VISA) 


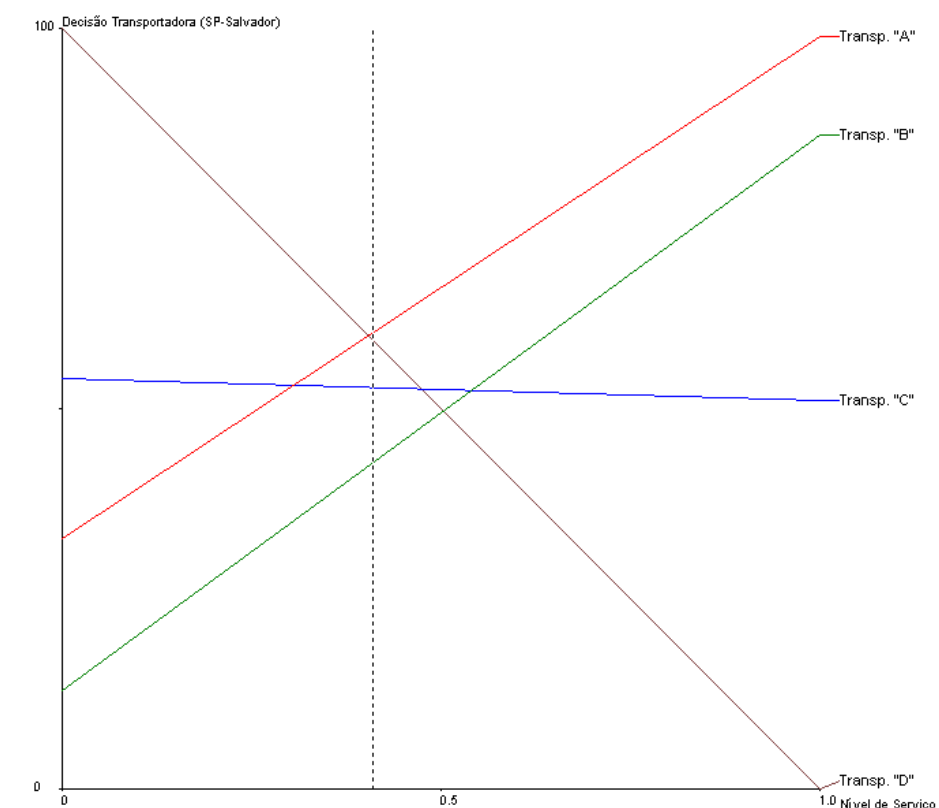

Figura 29 - Novos Gráficos para tomada de decisão Nível de Serviço/Decisão Transportadora Fonte: Extraído do software (VISA)

A proposta de redução de custos apresentada foi aprovada pela transportadora "A", que se tornou desta forma a melhor opção de escolha com base no modelo desenvolvido.

O modelo foi encaminhado pela gerente de logística aos seus superiores em escala mundial e aguarda uma aprovação externa para início do piloto nessa rota específica, sustentado pelo modelo aqui apresentado. Até a publicação desta dissertação, 18 meses após a aplicação, não houve um retorno formal sobre o assunto.

\subsubsection{Conclusão do Estudo de Caso 1}

A discussão sobre a importância dos fornecedores que devem participar do processo de seleção e dos critérios de pré-qualificação desses fornecedores, é salutar e deve ser um ponto de atenção em futuras aplicações do modelo.

A experiência deste primeiro estudo de caso aplicado no "Expert Mode" foi enriquecedora, principalmente por dois aspectos: 
1) Toda a experiência adquirida durante a construção do modelo (conceitual e prática) pela necessidade de aprofundamento no entendimento do problema e a preocupação em adquirir uma visão mais ampla sobre o processo e seus desdobramentos estratégicos, fez com que os envolvidos adquirissem um conhecimento maior sobre este processo de seleção e por consequência estivessem mais preparados para tomar uma decisão assertiva.

2) A potencialidade do modelo escolhido é demonstrada pela sua aplicabilidade e facilidade de utilização. Uma vez construído o modelo para este problema específico, ele pode ser replicado em diversos outros casos com muita facilidade. Para se aplicar este modelo em outras rotas de transporte seria necessário apenas os novos dados dos fornecedores, e a partir destes, seria desenvolvido o mesmo modelo.

O software utilizado, além de contribuir ativamente para a aplicabilidade e facilitação do processo, se mostrou uma ferramenta poderosa na estruturação do modelo, definição dos critérios, subcritérios e das funções de valor. Outro ponto importante da ferramenta foi o apoio durante a análise de sensibilidade, que possibilitou aos envolvidos ter um maior conhecimento sobre as potencialidades de cada fornecedor em relação a cada um dos critérios.

Este conhecimento adquirido durante a análise de sensibilidade foi de grande valia para negociações junto aos fornecedores, pois possibilita demonstrar de forma explícita o quanto aquele fornecedor deve alterar sua proposta para se tornar mais competitivo. Tal clareza e robustez no processo de seleção, em conjunto com uma precisa informação sobre o que está tornando aquele participante menos competitivo frente a seus concorrentes, sem dúvida nenhuma, gera argumentos poderosos na negociação junto aos fornecedores e, faz com que eles possam levantar quais são os motivos internos de sua organização que estão contribuindo para a falta de competitividade. Repare que tudo isso pode ser realizado sem a abertura dos dados entre concorrentes, o que garante a legitimidade do processo e proporciona condições equivalentes a todos os participantes.

Analisando a escolha dos critérios pelos envolvidos e comparando com as conclusões de $\mathrm{Ho}$ et al. (2010) sobre os três critérios mais utilizados: qualidade $(87,18 \%)$, entrega $(82,05 \%)$ e custo $(80,77 \%)$, pode-se concluir que: 
- Qualidade: está representada por avarias que garantem a integridade física da carga até o destino final (qualidade do serviço) e disponibilidade extra de veículos que garante a qualidade da operação através da disponibilidade dos ativos necessários.

- Entrega: índice de entregas no prazo e prazo de entrega falam diretamente sobre o tema.

- Custo: a utilização do critério "custo" e seus subcritérios também faz referência direta.

Conclui-se que houve comprovação do alinhamento das escolhas dos analistas com o que vem sendo praticado para o problema, o que era esperado frente à relevância e amplitude dos critérios mais populares.

\subsection{CONTRUÇÃO E USO DO MODELO PARA O ESTUDO DE CASO 2}

Para seleção de um prestador de serviços logísticos no modelo $4 P L$, as premissas estão descritas no Apêndice $D$.

A decisão do grupo de envolvidos em relação aos critérios mais importantes, além do binômio custo e nível de serviço, incluiu o critério capacitação técnica, pois o problema tratava, ao mesmo tempo, de uma seleção que exigia capacidades físicas e técnicas especificas para os prestadores, além de um alto nível de regionalização que restringia a capacitação dos concorrentes.

Os decisores chegaram a uma conclusão conjunta de que os pesos dos critérios deveriam ser $40 \%$ para custos, $30 \%$ para nível de serviço e $30 \%$ para capacitação técnica, conforme a Figura 30.

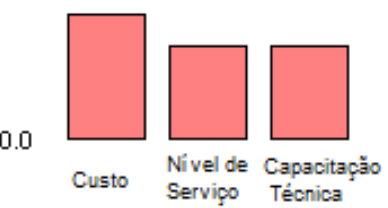

Figura 30 - Pesos dos critérios para seleção de prestador de serviços logísticos Fonte: Extraído do software (VISA) 


\subsection{1 Árvore de valores}

Frente a essas definições do grupo, o valor relativo da soma do nível de serviço e capacitação técnica foi consideravelmente maior do que o valor relativo do nível de serviço no caso anterior, o que demonstra uma maior preocupação com a "qualidade operacional" do que simplesmente o custo da operação.

A opção de atribuição dos pesos obedeceu ao formato "top-down", assim como no caso anterior, por decisão unânime dos envolvidos após explicação detalhada dos dois níveis de atribuições de pesos. No entendimento do grupo, dividir o processo decisório em partes facilitaria as escolhas, como foi comentado por um dos participantes, o que foi rapidamente aceito pelo restante do grupo.

Outro ponto que gerou surpresa foi a velocidade e o nível de alinhamento entre os participantes para tomada de decisão. Sem dúvida, o profundo entendimento comum pelo problema, o nível de conhecimento dos envolvidos por trabalharem no segmento e a experiência de trabalho conjunto em grupo, simplificou o processo e intensificou a convergência das decisões. Quando determinado assunto que ainda não havia sido abordado era introduzido, havia um rápido alinhamento de conceitos e exemplos sobre o assunto, uma análise consistente era realizada e uma nova convergência de resultados era observada.

Também em alinhamento com o estudo de caso anterior, a construção da árvore de valores foi determinante para o entendimento geral do problema, quantificação dos pesos e apoio à decisão. A árvore de valores para este estudo de caso está representada pela Figura 31 . 


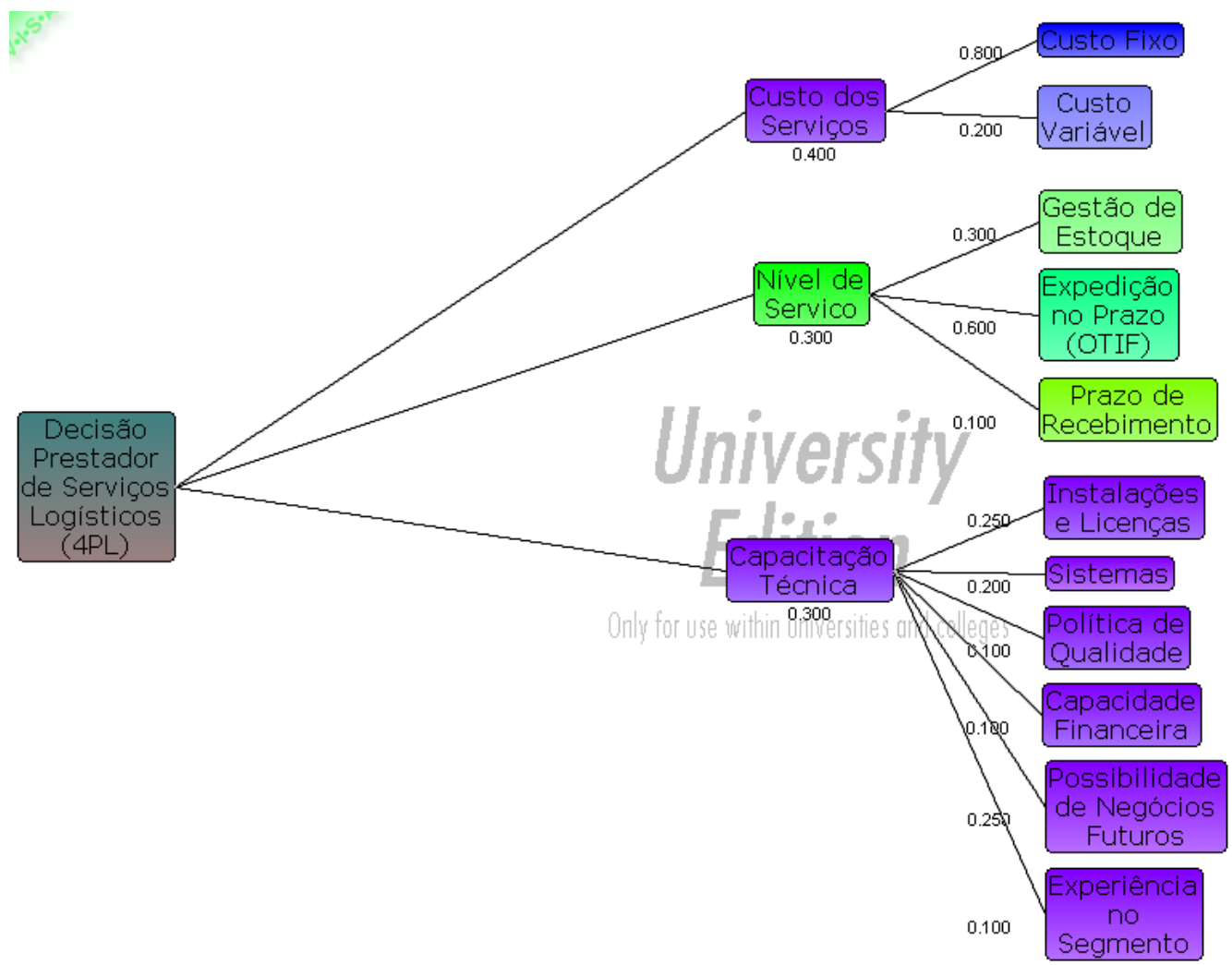

Figura 31 - Árvore de valores para seleção de prestador de serviços logísticos Fonte: Extraído do software (VISA)

\subsubsection{Subcritérios custos}

No mercado de prestação de serviços logísticos, denominação normalmente utilizada no Brasil para prestação de serviços de armazenagem ou logística integrada, as operações de armazenagem são compostas principalmente pelos seguintes custos variáveis:

- Custo de recebimento: custo para recebimento da mercadoria no armazém, unitização (quando necessário), conferência em seus mais variados níveis e disponibilização para armazenagem.

- Custo de armazenagem: custo relativo a um tempo de guarda, 15 ou 30 dias, por área ocupada. Esta cobrança normalmente é realizada em posições paletes, mas pode ser cobrada em $\mathrm{m}^{2}, \mathrm{~m}^{3}$ ou equivalentes de ocupação de área.

- Custo de expedição: normalmente trata-se do componente que mais retrata a complexidade operacional. O picking, (processo de busca e coleta das 
mercadorias presentes nos pedidos) e o packing (processo de embalagem desses produtos) normalmente estão contidos neste custo.

- Custo de seguro: O custo de seguro normalmente é dividido em seguro de incêndio (relativos a possíveis problemas nas instalações do armazém) e seguro de roubo.

- Custos de valor agregado: são custos relativos a serviços que podem ser agregados ao processo de armazenagem dos produtos, como: etiquetagem, nacionalização, testes, embalagens, rotulagens, etc.

Além dos custos variáveis podem haver custos fixos de acordo com o tipo de área utilizada, necessidades específicas e adaptações na área operacional, necessidade de segregação física, tipos especiais de segurança, entre outros.

Neste caso, foram escolhidos os custos que tinham maior relação com a natureza operacional e, os participantes do processo de seleção foram restringidos a enviar suas propostas com remuneração limitada a esses custos. Ou seja, nenhum outro custo, que não os constantes na $R F Q$, deveria ser agregado.

O fator mais preponderante neste caso era o alinhamento com a origem da receita do contratante, ou seja, os gastos com esta operação deveriam estar em acordo, valor e risco, com a receita resultante desta operação.

Portanto essa escolha, de manter o modelo de receita, conduziu a uma proposta de um custo fixo que sustente a operação, somado a um custo variável que possa remunerar um aumento de movimentação e serviços prestados, visto que tais alterações produzem um aumento nos custos de contratação de funcionários, material de movimentação, serviços administrativos, entre outros, Figura 32.

Apresentação e detalhamento dos subcritérios custos:

- Custo Fixo: valor mínimo cobrado para sustentar a operação prevista e suportar um crescimento de até $10 \%$ no valor mensal de faturamento. Além das razões descritas anteriormente entende-se que tal modelo facilita o entendimento e operacionalização do contratado por minimizar seu risco operacional (garantia de receita), proporcionando cotações mais justas e por não incluir uma previsão financeira para esse risco. Outro fator importante é a simplicidade de cálculo, que facilita a velocidade de acordos comerciais e minimiza desgastes futuros com renegociações. Considerando que este custo tem como proposta cobrir os níveis operacionais esperados, seu peso foi fixado em $80 \%$. 
- Custo Variável (\% sobre faturamento): valor em moeda corrente cobrado pelo valor faturado em produtos (venda) com origem naquele armazém. Na verdade este custo tem como finalidade garantir receita sobre o aumento da volumetria operacional resultante de um maior faturamento e, desta forma, também minimizar o risco do contratado. Repare que um aumento na expedição dos produtos origina diretamente um aumento na recepção (para não produzir reduções de estoque) e um aumento na movimentação. Conforme já descrito, este custo apenas será relevante se a movimentação ultrapassar $10 \%$ do volume previsto e sua valorização foi estimada em $20 \%$.

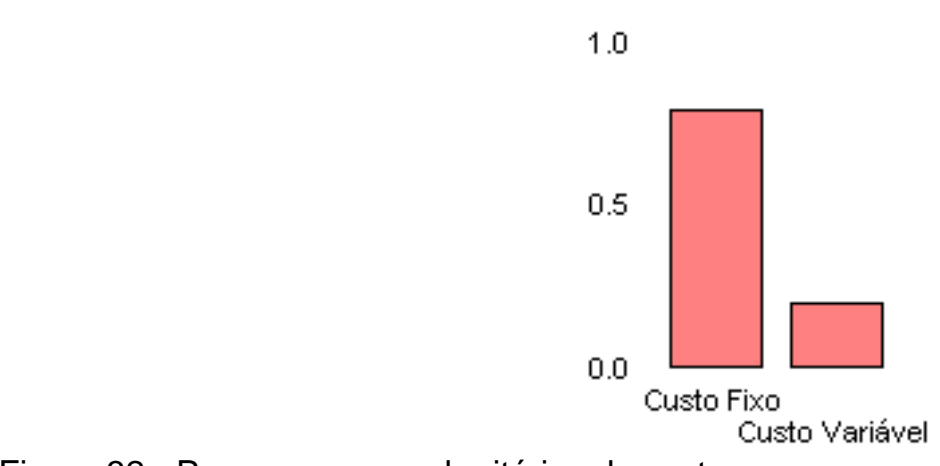

Figura 32 - Pesos para os subcritérios de custos

Fonte: Extraído do software (VISA)

\subsubsection{Subcritérios nível de serviço}

Será preciso garantir o nível de serviço, ou minimizar ao máximo o risco de falhas, na prestação dos serviços pelo contratado, pois a garantia deste serviço será responsabilidade do contratante. Importante ressaltar que a relação entre o contratante e o cliente envolve um conjunto de operações que resulta em um montante financeiro consideravelmente maior que o estudo de caso analisado.

Em relação à operacionalização, o portfólio de clientes do prestador e seu nível técnico são alguns dos fatores importantes para a garantia no nível de serviço e esses fatores serão analisados e pontuados no critério de capacitação técnica.

A avaliação do nível de serviço vai estar atrelada aos indicadores de desempenho da operação, (Key Performance Indicators). O compromisso de desempenho do prestador será assinado em contrato (metas operacionais) e, caso não sejam cumpridos, vão possibilitar ao contratante rescindir o contrato sem aviso prévio e 
sem direito a uma indenização sobre o investimento realizado (investimento realizado pelo contratado) ou necessidade de reembolso pelo contratado de todo o investimento realizado pelo contratante (investimento realizado pelo contratante). Vale lembrar que os ativos resultantes dos investimentos ficam de posse do contratado na rescisão.

Considerando essas características específicas, o grupo decidiu que seria melhor uma negociação pessoal, para os devidos detalhamentos e esclarecimentos, e que os resultados definitivos em relação a esse critério (dados de entrada) seriam obtidos após a visita técnica. Repare que no mapa cognitivo para este problema (Figura 16), existe a citação da visita técnica na qual serão negociados os indicadores operacionais (KPl's).

Desta forma, para este critério e seus subcritérios, optou-se que em uma primeira fase de qualificação, a entrada de dados seria igual para todos os participantes e com valores considerados pelo grupo como viáveis de realização pelos prestadores que foram avaliados como qualificados através das informações da RFl. Após a visita, os valores negociados foram inclusos no modelo, em conjunto com outras validações que serão discutidas, para a decisão final de escolha do prestador.

Os subcritérios de nível de serviço escolhidos (KPl's) e seus valores relativos são, Figura 33:

- Gestão de estoque: inclui a acuracidade de estoque, garantia dos ativos enviados, reembolso de avarias e extravios. Seu peso foi de $30 \%$.

- Entregas perfeitas no prazo (OTIF): descrevem o percentual de pedidos que foram expedidos no prazo sem nenhum erro de faltas ou trocas de produto. Por tratar-se do indicador mais importante para a satisfação do cliente, pois já existe um horário de corte definido para a operação que não será alterado, seu peso foi de $60 \%$.

- Prazo de recebimento: é o prazo acordado contratualmente em horas para que a mercadoria esteja disponível no sistema para faturamento. Quanto menor este prazo, mais ágil será o faturamento dos produtos que não estejam disponíveis em estoque. Para esse subcritério foi definido um peso de $10 \%$, uma vez que ele apenas melhora o nível de serviço nos casos em que exista ruptura no estoque. 


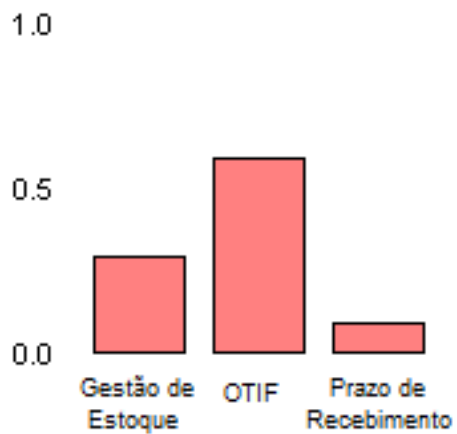

Figura 33 - Pesos dos subcritérios de Nível de Serviço

Fonte: Extraído do software (VISA)

\subsubsection{Subcritérios capacitação técnica}

Conforme anteriormente abordado, a existência de uma instalação física compatível com as exigências operacionais é fundamental para a implantação da operação. A disponibilidade do prestador em alterar as suas instalações físicas de forma a se adequar às necessidades, embora similar à característica anterior, também é um fator fundamental.

Diversos outros fatores estruturais e técnicos vão compor as necessidades esperadas deste prestador para que ele possa realizar esta operação dentro das exigências legislativas, do contratante e do cliente.

Repare que para avaliar os subcritérios de capacitação técnica será necessário a construção de uma escala de valor qualitativo, pois nem sempre é possível encontrar uma escala mensurável para definir um critério. Conforme definido por Belton e Stewart (2002), uma escala de valores qualitativos deve ter as seguintes características:

- Operacional: permite aos decisores classificar alternativas dentro de uma escala qualitativa;

- Confiança: duas avaliações independentes para a mesma alternativa devem conduzir a uma mesma pontuação;

- Relevância de valores: devem relatar os objetivos dos tomadores de decisão;

- Justificável: um observador independente deve ser convencido de que a escala é razoável. 
Todas essas características foram consideradas na construção das escalas qualitativas pelo grupo de decisores, sendo que o analista foi utilizado na aprovação das escalas propostas conforme sugerido.

Os subcritérios de capacitação técnica e suas escalas qualitativas são:

- Instalações e Licenças: Avalia o prestador a respeito de sua estrutura física e capacidade legal em absorver a operação proposta. Número de instalações, equipamentos de movimentação, licenças e demais aspectos relevantes para a garantia da operacionalização são abordados. Para esse subcritério o peso atribuído foi de $25 \%$, ratificando a importância deste subcritério para o sucesso da operação. A escala qualitativa foi definida na Tabela 20:

Tabela 20 - Escala qualitativa de valor para instalações e licenças

\begin{tabular}{|c|c|}
\hline Força & Condições \\
\hline 1 & $\begin{array}{c}\text { Nẫo possui as condiçốes físicas necessárias para instalação da } \\
\text { operaçẫo e nem os equipamentos necessários mas existe a } \\
\text { possibilidade e autorizaçẫo para a adequação física }\end{array}$ \\
\hline 2 & $\begin{array}{l}\text { Não possui as condiçỗes físicas necessárias para instalação da } \\
\text { operaçẫo ou nẫo possui equipamentos necessários mas em ambos os } \\
\text { casos existe a possibilidade e autorizaçẫo para a adequaçẫo física }\end{array}$ \\
\hline 3 & $\begin{array}{l}\text { Possui as condiçốes físicas e de equipamentos necessárias mas a } \\
\text { estrutura deve ser montada em área segregada dada a incompatibilidade } \\
\text { dos produtos armazenados }\end{array}$ \\
\hline 4 & $\begin{array}{c}\text { As instalaçỗes atendem e nẫo existe incompatibilidade de produtos } \\
\text { devendo apenas serem executadas as obras necessárias para a } \\
\text { operaçẫo proposta }\end{array}$ \\
\hline 5 & $\begin{array}{c}\text { As instalaçỗes atendem, nẫo existe incompatibilidade de produtos e nẫo } \\
\text { será necessária nenhuma adequaçẫo relevante }\end{array}$ \\
\hline
\end{tabular}

- Sistemas: ferramentas como Warehouse Management System (WMS), Electronic Data Interchange (EDI), radiofrequência e processos implementados de forma conjunta são avaliados. Para esse subcritério foi definido um peso de $20 \%$ e a seguinte escala, Tabela 21. 
Tabela 21 - Escala qualitativa de valor para sistemas

\begin{tabular}{|c|c|}
\hline Força & Condições \\
\hline 1 & $\begin{array}{l}\text { Os sistemas nẫo atendem as necessidades mas existe um projeto } \\
\text { conjunto de viabilidade }\end{array}$ \\
\hline 2 & $\begin{array}{l}\text { Possui WMS e troca eletrônica de dados dentro dos padrốes } \\
\text { necessários mas os sistemas de radio-frequência, coletores e } \\
\text { liberaçẫo de link nẫo existem ou nẫo atendem as necessidades }\end{array}$ \\
\hline 3 & $\begin{array}{l}\text { Possui WMS e troca eletrônica de dados dentro dos padrốes } \\
\text { necessários mas os sistemas de radio-frequência, coletores e } \\
\text { liberaçẫo de link atendem as necessidades de forma parcial }\end{array}$ \\
\hline 4 & $\begin{array}{c}\text { Possui WMS, radio-frequência, coletores e troca eletrônica de dados } \\
\text { dentro dos padrốes necessários mas existem restriçốes quanto a } \\
\text { operar com o sistema da contratante }\end{array}$ \\
\hline 5 & $\begin{array}{c}\text { Possui WMS, radio-frequência, coletores e troca eletrônica de dados } \\
\text { dentro dos padrốes necessários e existe disponibilidade de liberaçẫo } \\
\text { de link a um custo compatível }\end{array}$ \\
\hline
\end{tabular}

- Política da Qualidade: certificações da área, estruturação do processo da qualidade e suas necessidades específicas são abordados. A possibilidade de desenvolvimento do sistema da qualidade em parceria também é avaliada. A escala qualitativa está descrita na Tabela 22, e seu peso foi definido pelo grupo em $10 \%$.

Tabela 22 - Escala qualitativa de valor para política da qualidade

\begin{tabular}{|c|c|}
\hline Força & Condições \\
\hline 1 & $\begin{array}{c}\text { Empresa sem processos estruturados mas existe um projeto } \\
\text { conjunto de viabilidade }\end{array}$ \\
\hline 2 & $\begin{array}{l}\text { Empresa nẫo certificada, com processos estruturados mas nẫo } \\
\text { compativeis com a natureza da operaçẫo proposta }\end{array}$ \\
\hline 3 & $\begin{array}{l}\text { Empresa nẫo certificada, com processos estruturados e compativeis } \\
\text { com a natureza da operaçẫo proposta }\end{array}$ \\
\hline 4 & $\begin{array}{l}\text { Empresa certificada, com processos estruturados mas nẫo } \\
\text { compatíveis com a natureza da operaçẩo proposta }\end{array}$ \\
\hline 5 & $\begin{array}{c}\text { Empresa certificada, com processos estruturados e compativeis } \\
\text { com a natureza da operaçẫo proposta }\end{array}$ \\
\hline
\end{tabular}

- Capacidade Financeira: os participantes são avaliados através de envio de balanços financeiros atualizados, consulta aos órgãos específicos, estimativa de crescimento e capacidade de investimento. Seu peso determinado foi de $10 \%$ e sua escala está descrita na Tabela 23. 
Tabela 23 - Escala qualitativa de valor para capacidade financeira

\begin{tabular}{|c|c|}
\hline Força & Condições \\
\hline 1 & $\begin{array}{c}\text { Empresa possui restriçốes e apresenta fragilidade no balanço em } \\
\text { um nivel que nẫo compromete suas operaçốes }\end{array}$ \\
\hline 2 & $\begin{array}{c}\text { Empresa possui restriçỗes ou apresenta fragilidade no balanço em } \\
\text { um nível considerado pouco relevante }\end{array}$ \\
\hline 3 & $\begin{array}{l}\text { Empresa nẫo possui restriçốes e nẫo apresenta fragilidade no } \\
\text { balanço }\end{array}$ \\
\hline 4 & $\begin{array}{l}\text { Empresa nẫo possui restriçỗes, nẫo apresenta fragilidade no } \\
\text { balanço e tem uma proposta de crescimento relevante }\end{array}$ \\
\hline 5 & $\begin{array}{c}\text { Empresa nẫo possui restriçốes, nẫo apresenta fragilidade no } \\
\text { balanço, tem uma proposta de crescimento relevante e quer investir } \\
\text { no desenvolvimento do negócio }\end{array}$ \\
\hline
\end{tabular}

- Experiência no segmento: esse subcritério tem como objetivo avaliar o nível técnico do proponente em relação à operação proposta. Temas como tempo de experiência, tipos de operações, clientes, alinhamento com o perfil da operação e modelos de controles são abordados. Seu peso não foi maior, $10 \%$, porque o grupo entendeu que pode apoiar o contratado na operacionalização do projeto, desde que os outros subcritérios sejam favoráveis. Sua escala qualitativa é demonstrada na Tabela 24.

Tabela 24 - Escala qualitativa de valor para experiência no segmento

\begin{tabular}{cc}
\hline Força & Condições \\
\hline 1 & $\begin{array}{c}\text { Empresa possui experiência no segmento e necessita de apoio na } \\
\text { administraçấo da operaçẫo proposta }\end{array}$ \\
\hline 2 & $\begin{array}{c}\text { Empresa possui experiência no segmento e na administraçẫo de } \\
\text { operaçốes de menor complexidade que a proposta mas esta apta a } \\
\text { administra-la }\end{array}$ \\
\hline 3 & $\begin{array}{c}\text { Empresa possui experiência no segmento e na administraçẫo de } \\
\text { operaçốes do mesmo nivel de complexidade que a proposta }\end{array}$ \\
\hline 4 & $\begin{array}{c}\text { Empresa possui experiência no segmento e na administraçẫo de } \\
\text { operaçốes mais complexas que a proposta }\end{array}$ \\
\hline 5 & $\begin{array}{c}\text { Empresa possui experiência no segmento a ponto de agregar } \\
\text { valores relevantes no desenvolvimento da contratante }\end{array}$ \\
\hline
\end{tabular}

- Possibilidade de Negócios Futuros: embora este projeto tenha como objetivo a contratação de um prestador para uma operação específica, as possibilidades de negócios conjuntos são fundamentais para o projeto de expansão da empresa contratante. Por esse motivo, o diretor geral expôs sua visão e sugeriu uma maior representatividade a este subcritério 25\%, que foi aceita pelo grupo e apresentada na Tabela 25. 
Tabela 25 - Escala qualitativa de valor para possibilidade de negócios futuros

\begin{tabular}{cc}
\hline Força & Condiçóes \\
\hline 1 & Empresa nẫo demonstra interesse em desenvolver uma parceria \\
\hline 2 & $\begin{array}{c}\text { Empresa demonstra interesse em desenvolver uma parceria mas } \\
\text { parece baixo o nivel de sinergia para o desenvolvimento do negócio } \\
\text { de forma conjunta }\end{array}$ \\
\hline 3 & $\begin{array}{c}\text { Empresa demonstra interesse em desenvolver uma parceria e existe } \\
\text { um nivel médio de sinergia para o desenvolvimento do negócio de } \\
\text { forma conjunta }\end{array}$ \\
\hline 4 & $\begin{array}{c}\text { Empresa demonstra interesse em desenvolver uma parceria e existe } \\
\text { um nivel alto de sinergia para o desenvolvimento do negócio de forma } \\
\text { conjunta }\end{array}$ \\
\hline & $\begin{array}{c}\text { Empresa demonstra interesse em desenvolver uma parceria, existe } \\
\text { um nivel alto de sinergia para o desenvolvimento do negócio de forma } \\
\text { conjunta e esta empresa pode suportar nosso desenvolvimento na } \\
\text { regiấo }\end{array}$ \\
\hline
\end{tabular}

$\mathrm{Na}$ Figura 34 é detalhado o resumo dos pesos dos subcritérios relativos à capacitação técnica.

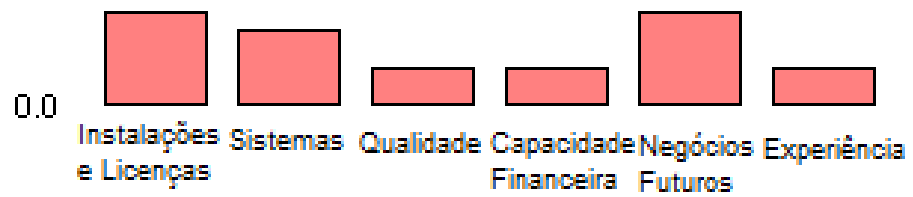

Figura 34 - Pesos dos subcritérios de Capacitação Técnica Fonte: Extraído do software (VISA)

\subsubsection{Critérios de inclusão e rejeição para capacitação técnica}

A experiência adquirida na construção das escalas de valores qualitativos possibilitou que fosse desenvolvida a Tabela 26 que definiu novos critérios de inclusão e rejeição para este processo de seleção. Repare que não serão definidos critérios de inclusão e rejeição com origem no custo, pois o grupo entende que para estes dois subcritérios existe uma flexibilidade que estará ligada à capacidade de negociação e possibilidades futuras de negócios entre as empresas. 
Tabela 26 - Critérios de inclusão e rejeição

\begin{tabular}{cc}
\hline Sub-Critério & Condições \\
\hline Instalaçốes e Licenças & $\begin{array}{c}\text { Não possui as licenças necessárias e/ou nẫo existe } \\
\text { autorizaçẫo para as devidas adequaçổes }\end{array}$ \\
\hline Sistemas & $\begin{array}{r}\text { Nẫo existe possibilidade de desenvolver um projeto conjunto } \\
\text { de viabilidade para o sistema }\end{array}$ \\
\hline Política da Qualidade & $\begin{array}{r}\text { Não existe possibilidade de desenvolver um projeto conjunto } \\
\text { de viabilidade para a política de qualidade }\end{array}$ \\
\hline Capacidade Financeira & $\begin{array}{r}\text { Empresa possui restriçổes e apresenta fragilidade no balanço } \\
\text { em um nível que compromete suas operaçôes }\end{array}$ \\
\hline Experiência & Empresa nẫo possui experiência no segmento \\
\hline Negócios Futuros & Empresa nẫo esta apta ou nẫo quer trabalhar no modelo 4PL \\
\hline
\end{tabular}

\subsubsection{Dados dos prestadores de serviços}

Os dados foram obtidos de acordo com as informações constantes na $R F I$ e $R F Q$ enviadas e posteriormente recebidas dos participantes. As planilhas eletrônicas foram enviadas, em alguns casos, para mais do que três participantes, mas apenas os prestadores que não foram excluídos pelos critérios de inclusão e rejeição, através da RFI, foram utilizados no modelo. Para o estudo de caso analisado essa ação resultou no envio das planilhas para três participantes e todos foram classificados.

Por questões confidenciais não serão informados quais são os sete estados aonde o estudo foi aplicado e será demonstrado o desenvolvimento do modelo em uma destas praças. De qualquer forma a aplicação do modelo foi realizada, com sucesso, para os sete estados.

Em termos de resultados, diferente do estudo de caso anterior, as propostas aqui descritas representavam a melhor oferta do prestador de serviços, pois trata-se de um caso aplicado e implantado. Na própria $R F Q$ era solicitado aos participantes que a melhor condição econômica e técnica fosse apresentada. Na Tabela 27 constam os dados recebidos dos fornecedores e os dados previamente considerados para o nível de serviço. 
Tabela 27 - Dados Recebidos dos prestadores de serviços

\begin{tabular}{|c|c|c|c|c|c|c|c|c|c|c|c|}
\hline Enpresas & $\begin{array}{c}\text { Custo Fixo } \\
\text { (R\$) }\end{array}$ & $\begin{array}{c}\text { Custo } \\
\text { Variável } \\
(\%)\end{array}$ & $\begin{array}{c}\text { Gestão de } \\
\text { Estoque } \\
(\%)\end{array}$ & $\begin{array}{c}\text { Expedição } \\
\text { no Prazo } \\
(\%)\end{array}$ & $\begin{array}{c}\text { Prazo de } \\
\text { Recebimento } \\
\text { (horas) }\end{array}$ & $\begin{array}{c}\text { Intalações e } \\
\text { Licenças }\end{array}$ & Sistemas & $\begin{array}{c}\text { Política da } \\
\text { Qualidade }\end{array}$ & $\begin{array}{l}\text { Capacidade } \\
\text { Financeira }\end{array}$ & $\begin{array}{c}\text { Possibilidade } \\
\text { de Negócios } \\
\text { Futuros } \\
\end{array}$ & $\begin{array}{c}\text { Experiência } \\
\text { no Segmento }\end{array}$ \\
\hline Prestador "A" & 16500 & 3,8 & 100 & 99,5 & 12 & 3 & 3 & 2 & 3 & 2 & 3 \\
\hline Prestador "B" & 21000 & 4,5 & 100 & 99,5 & 12 & 4 & 4 & 3 & 4 & 4 & 4 \\
\hline Prestador "C" & 18760 & 4,2 & 100 & 99,5 & 12 & 2 & 2 & 1 & 1 & 1 & 2 \\
\hline
\end{tabular}

\subsubsection{Função de valor (value function)}

Após compilação dos dados, com apoio do software, serão descritas as construções das funções de valor para cada um dos subcritérios escolhidos. As escalas locais e os modelos de construção propostos por Belton e Stewart (2002), continuam válidos para essa aplicação.

\subsubsection{Custo Fixo e Custo Variável}

Para os dois custos propostos a função inicia-se atribuindo 100, maior pontuação, para o menor valor e 0 , pior pontuação, para o maior valor recebido. Dividindo-se o eixo horizontal (eixo dos valores) em cinco partes, em cada uma dessas partes aumentou-se a penalização em $5 \%$ do valor total, fixando as penalizações por faixa em $10 \%, 15 \%, 20 \%, 25 \%$ e $30 \%$, respectivamente, vide figura 35 .

Repare que a proposta do grupo foi igual à dos analistas no primeiro estudo de caso. Tal escolha foi motivada pela proposta da curva pelo facilitador, entendimento do grupo e unanimidade na concordância com a referida proposta. 
a) Custo Fixo

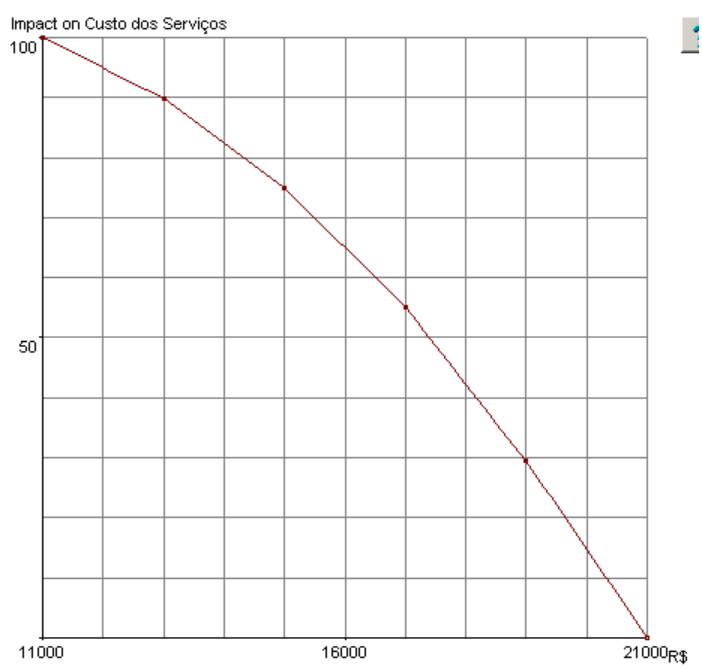

b) Custo Variável

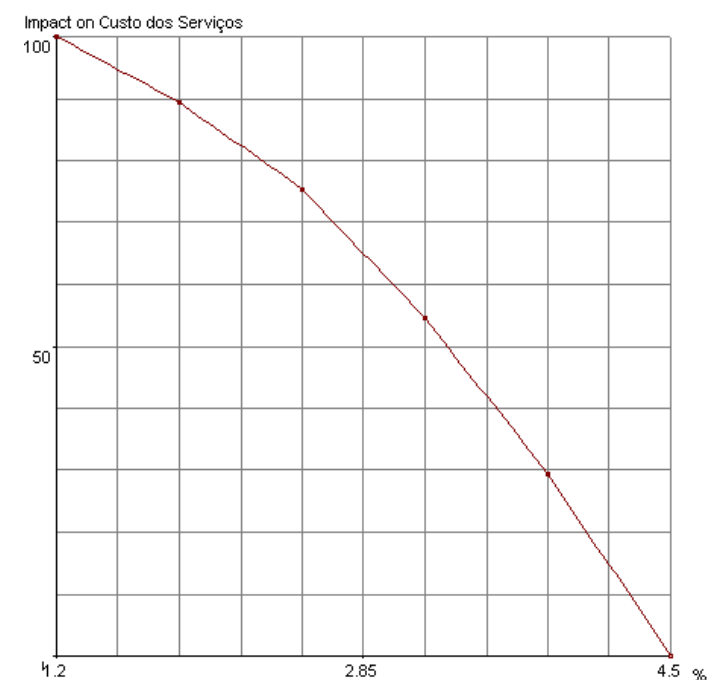

Figura 35 - Curvas de impacto: custos e avarias

Fonte: Extraído do software (VISA)

4.3.7.2 Gestão de Estoque, Expedição no Prazo e Prazo de Recebimento

Para gestão de estoque e expedição no prazo, a função inicia-se atribuindo 0 para o menor valor percentual e 100 para o maior valor percentual apresentado. Para prazo de recebimento a análise é inversa, pois quanto maior o prazo menor o nível de serviço. 
Foi acordado pelo grupo que o nível mínimo de serviço aceito pelo cliente para os dois primeiros subcritérios seria de $99 \%$ e, para o terceiro, 24 horas. Entretanto, os atuais níveis de serviços prestados ao cliente são bem eficientes e a proposta utilizada no estudo de caso anterior, de dividir a função em três partes e penalizar o equivalente a $70 \%$ da pontuação, foi bem avaliada, pois o grupo entendeu que iria representar a real relevância sobre o nível de serviço esperado.

Desta forma, nos dois primeiros subcritérios, na primeira faixa de 99,00 a 99,33\% existe uma valorização linear de 10, enquanto resultados de 99,33 a 99,67\% recebem uma valorização linear de 20 dentro da faixa e, valores acima de 99,67\% de desempenho são bem valorizados: 70, na faixa até 100 .

De forma análoga, mas inversa, para o prazo de recebimento que se inicia com 100 de valorização, na primeira faixa de 6 a 12 horas existe uma penalização linear de 70 , enquanto resultados de 12 a 18 horas recebem penalização de 20 dentro da faixa e, valores acima de 18 horas, uma penalização de mais 10 de forma a zerar a função.

Estas curvas foram demonstradas na figura 36.

a) Gestão de Estoque e Expedição no Prazo

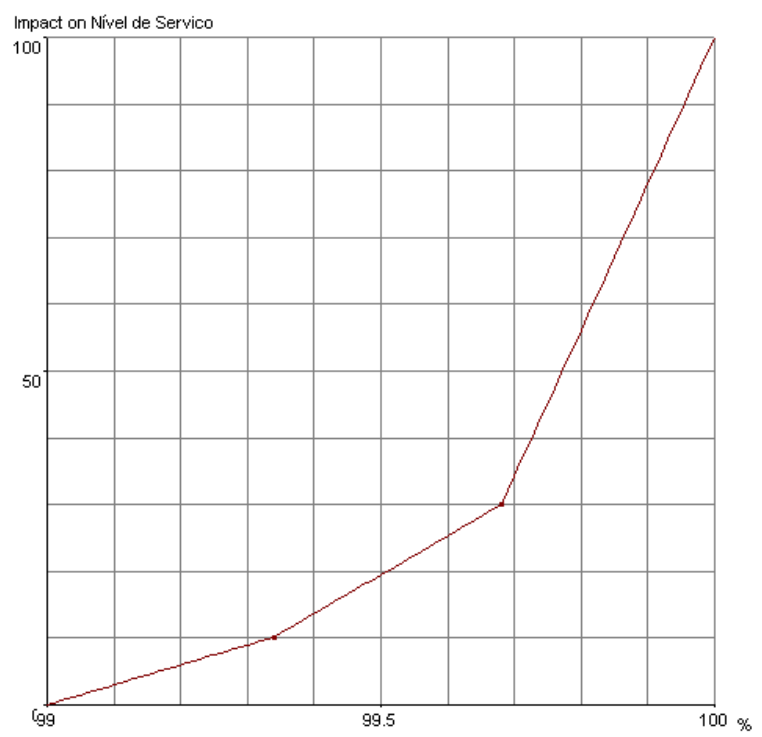


b) Prazo de Recebimento

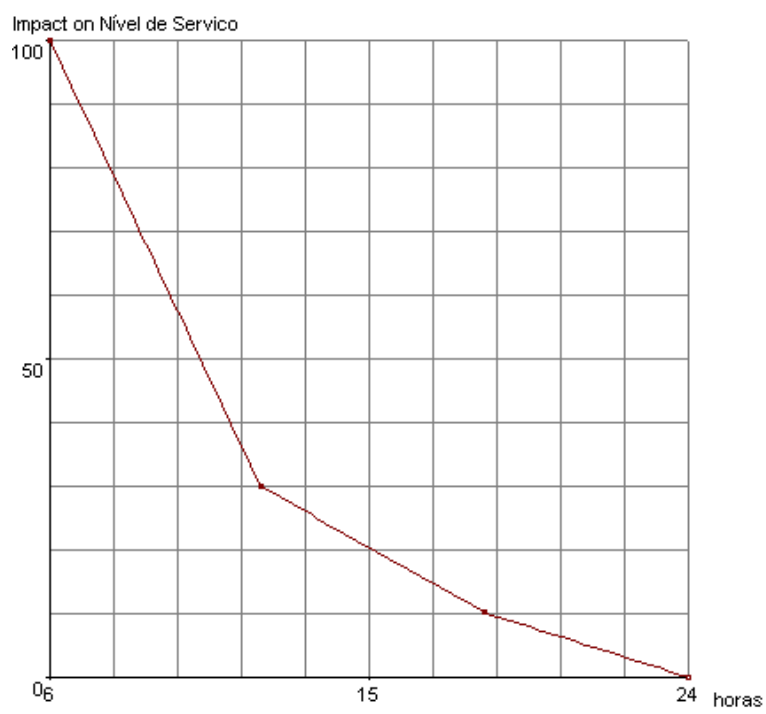

Figura 36 - Curvas de impacto: gestão de estoque, expedição no prazo e prazo de recebimento Fonte: Extraído do software (VISA)

4.3.7.3 Instalações e Licenças, Sistemas, Política da Qualidade, Capacidade Financeira, Experiência e Negócios Futuros

Pelas sua características, esses seis subcritérios foram definidos por escalas qualitativas e suas avaliações são decorrentes de sua força dentro da faixa qualitativa de enquadramento.

A opção de valorização destas faixas é linear e a pontuação será crescente de acordo com a faixa avaliada. A curva de impacto para esses subcritérios varia de 0 a 100, conforme Figura 37.

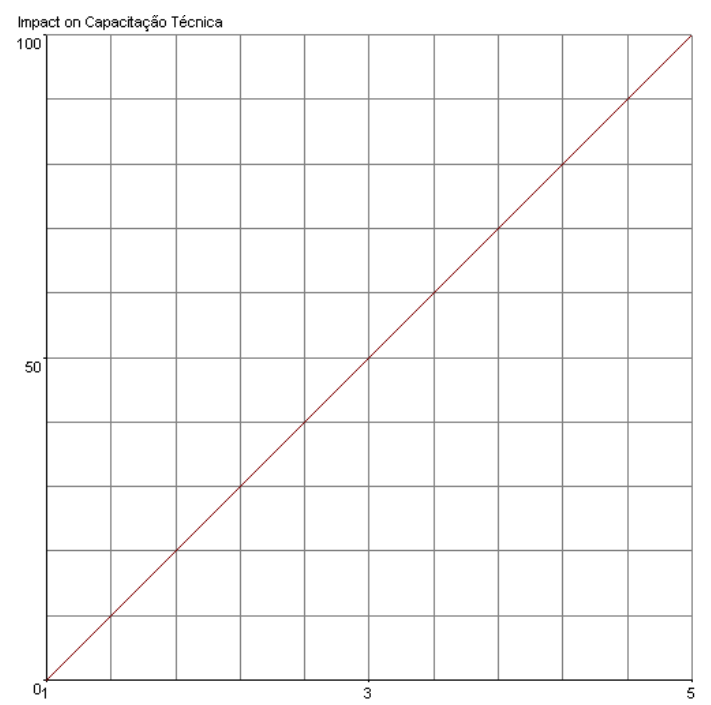

Figura 37 - Curva de impacto: Instalações e Licenças, Sistemas, Política da Qualidade, Capacidade Financeira, Experiência e Negócios Futuros

Fonte: Extraído do software (VISA) 
As pontuações para cada subcritério, os pesos determinados e as pontuações finais calculadas são demonstrados na Tabela 28.

Tabela 28 - Pontuação das alternativas para cada critério avaliado

\begin{tabular}{|c|c|c|c|c|c|c|c|c|c|c|c|c|}
\hline $\begin{array}{c}\text { Pesos } \\
\text { Critérios }\end{array}$ & \multicolumn{2}{|c|}{$40,00 \%$} & \multicolumn{3}{|c|}{$30,00 \%$} & \multicolumn{6}{|c|}{$30,00 \%$} & \multirow{3}{*}{$\begin{array}{c}\text { Pontuação } \\
\text { Final }\end{array}$} \\
\hline $\begin{array}{l}\text { Pesos Sub- } \\
\text { Critérios }\end{array}$ & $80,00 \%$ & $20,00 \%$ & $30,00 \%$ & $60,00 \%$ & $10,00 \%$ & $25,00 \%$ & $20,00 \%$ & $10,00 \%$ & $10,00 \%$ & $25,00 \%$ & $10,00 \%$ & \\
\hline Empresas & Custo Fixo & $\begin{array}{l}\text { Custo } \\
\text { Variável }\end{array}$ & $\begin{array}{l}\text { Gestão de } \\
\text { Estoque }\end{array}$ & $\begin{array}{c}\text { Expedição } \\
\text { no Prazo }\end{array}$ & $\begin{array}{c}\text { Prazo de } \\
\text { Recebimento }\end{array}$ & $\begin{array}{l}\text { Intalações e } \\
\text { Licenças }\end{array}$ & Sistemas & $\begin{array}{l}\text { Politica da } \\
\text { Qualidade }\end{array}$ & $\begin{array}{l}\text { Capacidade } \\
\text { Financeira }\end{array}$ & $\begin{array}{l}\text { Possibilidade } \\
\text { de Negócios } \\
\text { Futuros }\end{array}$ & $\begin{array}{l}\text { Experiência } \\
\text { no Segmento }\end{array}$ & \\
\hline Prestador "A" & 60 & 31 & 100 & 20 & 30 & 50 & 50 & 25 & 50 & 25 & 50 & 47,56 \\
\hline Prestador "B" & 0 & 0 & 100 & 20 & 30 & 75 & 75 & 50 & 75 & 75 & 75 & 35,25 \\
\hline Prestador "C" & 32 & 13 & 100 & 20 & 30 & 25 & 25 & 0 & 0 & 0 & 25 & 28,91 \\
\hline
\end{tabular}

\subsubsection{Resultados}

Após os cálculos, segue o resultado preliminar determinado pela pontuação de cada um dos prestadores de serviços logísticos concorrentes, antes das visitas técnicas e negociação dos níveis de serviço, Figura 38.

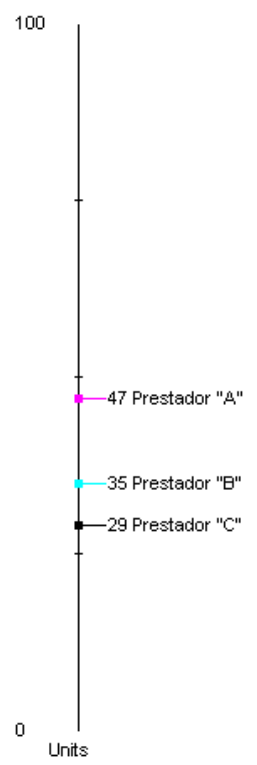

Figura 38 - Melhor alternativa preliminar Fonte: Extraído do software (VISA)

Para os critérios, subcritérios e funções de valor que foram definidos o prestador "A" foi o que obteve a melhor pontuação com 47 pontos, o prestador "B" ficou em segundo com 35 e em terceiro, o prestador "C" com 29. 


\subsubsection{Análise de sensibilidade e robustez dos resultados}

Essa análise era de fundamental importância para que na visita aos prestadores fosse possível avaliar de forma criteriosa as informações que levaram ao resultado preliminar e, principalmente, negociar com os fornecedores dentro de bases reais e em alinhamento com os objetivos da contratação.

A análise de sensibilidade e robustez proposta por Belton e Stewart (2002) também foi utilizada para este caso, inclusive com as proposições dentro de cada uma das alternativas.

As observações da análise sobre as perspectivas técnicas com a avaliação dos dados de entrada (funções de valor, pesos e pontuações) e sua influência nos resultados obtidos utilizando o software, também contribuíram de forma relevante com as implementações realizadas. Tal fato será melhor detalhado na conclusão do capítulo.

A perspectiva de grupo, de forma similar à aplicada anteriormente, provocou o questionamento do grupo e a geração de novas propostas para os critérios e seus pesos. Como apoio, foram analisados três gráficos extraídos do software, Figuras 39,40 e 41.

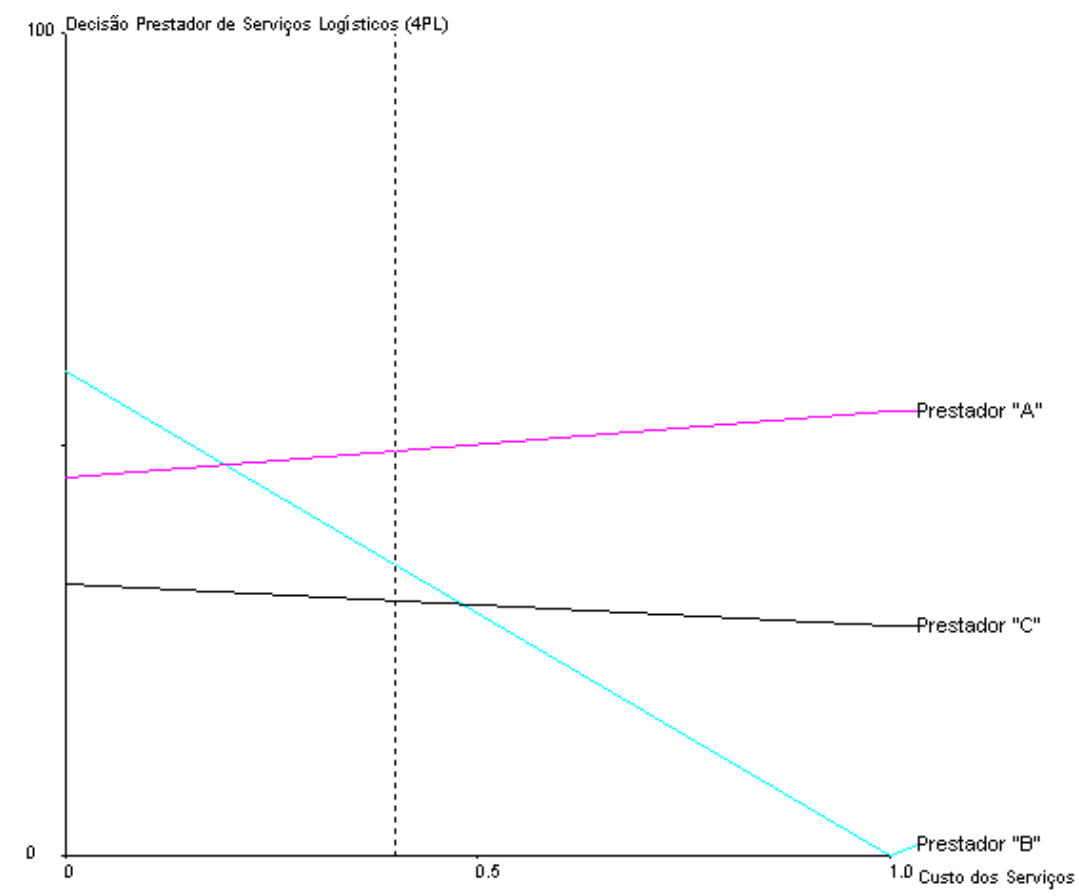

Figura 39 - Gráficos para tomada de decisão Custo dos Serviços/Decisão Prestador Fonte: Extraído do software (VISA) 


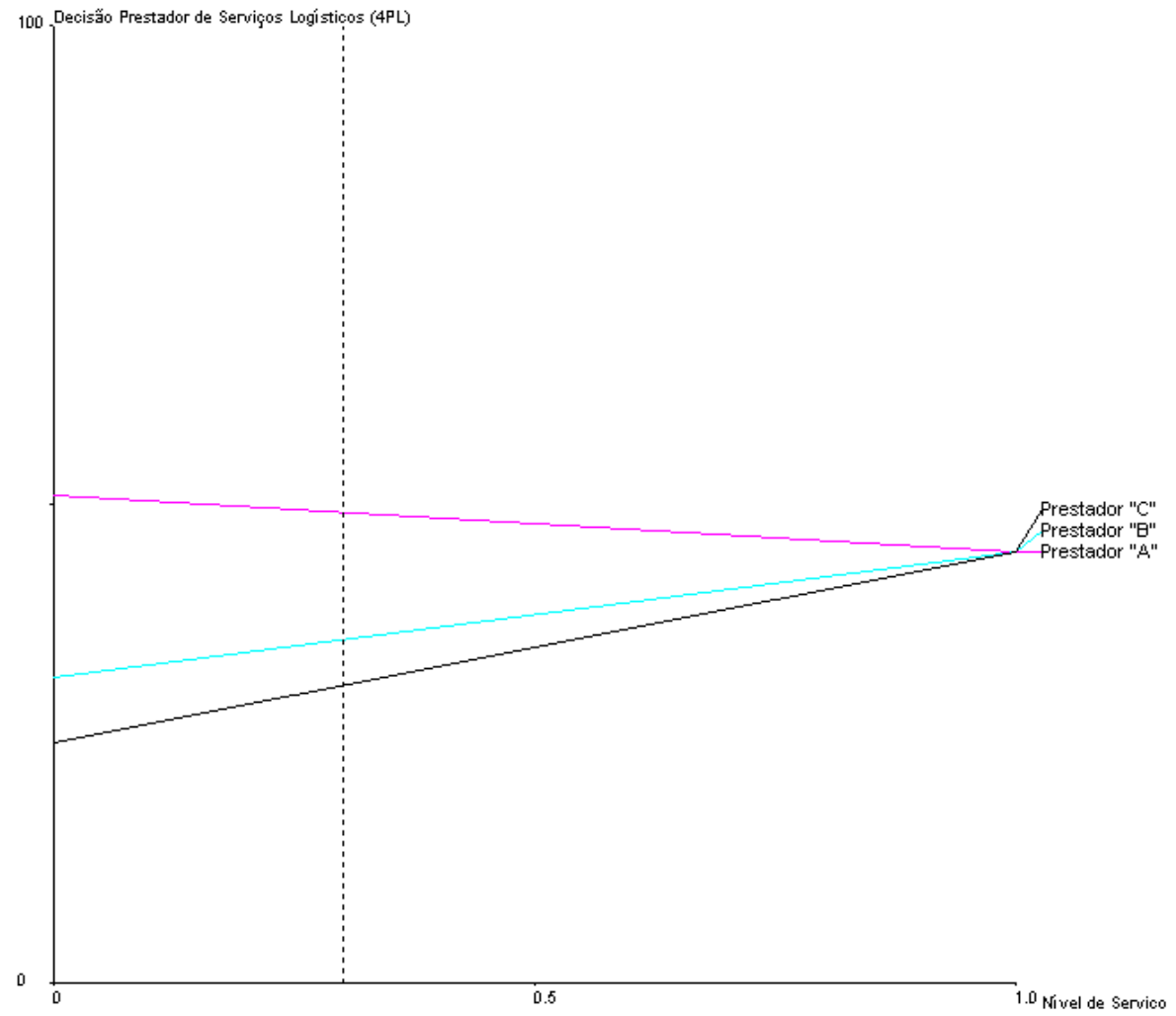

Figura 40 - Gráficos para tomada de decisão Nível de Serviço/Decisão Prestador Fonte: Extraído do software (VISA)

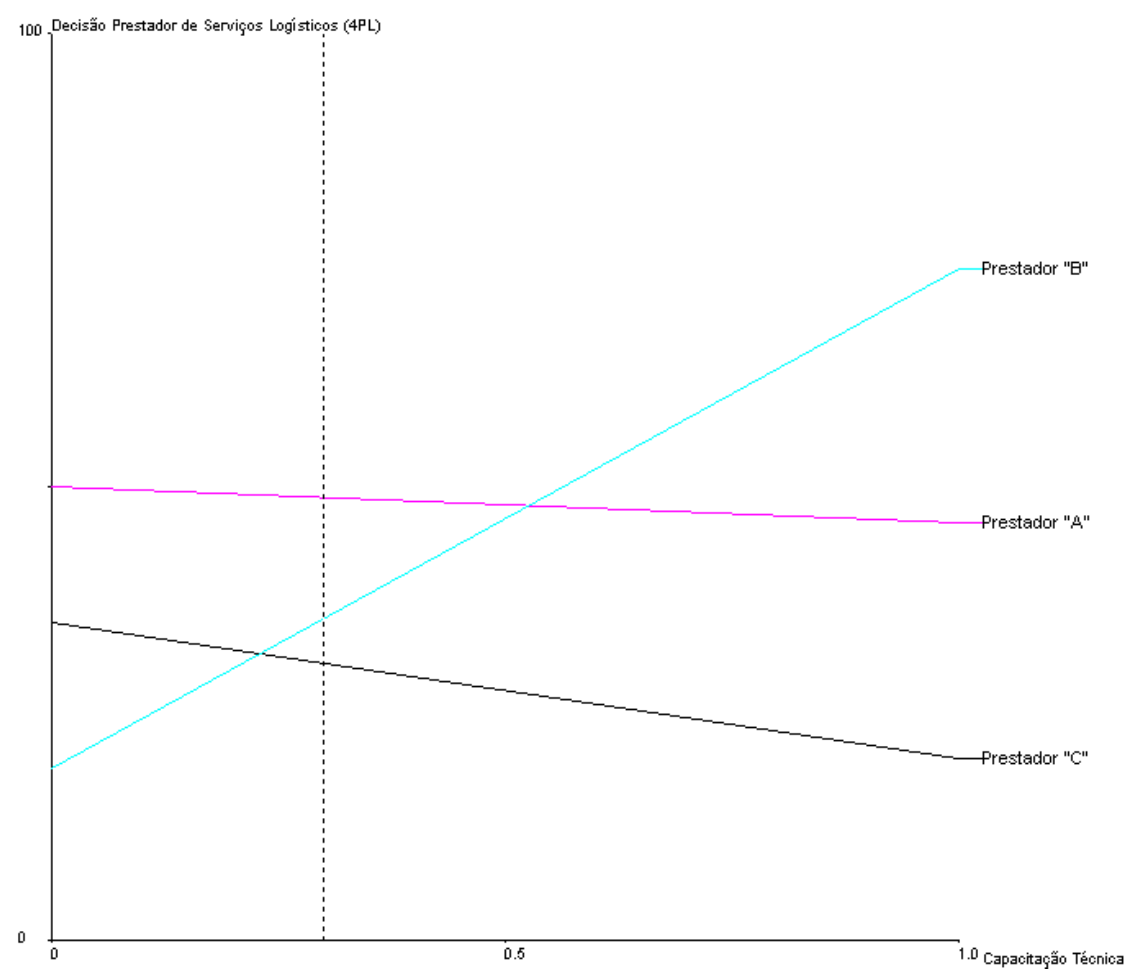

Figura 41 - Gráficos para tomada de decisão Capacitação Técnica/Decisão Prestador Fonte: Extraído do software (VISA) 
Percebe-se na Figura 39 que o prestador "A", por seu melhor preço, sempre será a melhor escolha a partir do momento que o custo tenha valor relativo pouco maior que $20 \%$.

Considerando que até o momento da visita técnica os dados serão iguais para nível de serviço entre os três prestadores, Figura 40, os prestadores " $B$ " e "C" estão dominados neste critério pelo prestador "A".

Para capacitação técnica, Figura 41, caso o valor relativo do critério fosse alterado para um valor acima de 50\%, a opção "B" seria a mais pontuada. De forma análoga ao modelo anterior, perspectiva individual, houve uma discussão no grupo sobre a possibilidade de alteração dos valores relativos dos critérios o que foi rapidamente descartado. De qualquer forma, através de simulações no modelo, percebeu-se que uma renegociação com o prestador "B" poderia aumentar consideravelmente sua competitividade, pois naquele momento o critério custos era aonde havia desvantagem frente a seu principal concorrente, o prestador "A".

A área de qualidade, naquele momento, tentava sugerir que o prestador "B" seria a melhor escolha devido à sua capacitação técnica. Entretanto, o grupo defendeu que a escolha deveria ser realizada através do modelo desenvolvido, o que acabou se tornando um consenso.

Importante salientar também que o prestador "C", com os atuais dados de entrada, em nenhum momento seria a melhor opção, independente dos valores relativos aplicados, pois ele sempre se encontra dominado por um ou ambos os prestadores.

Com um maior entendimento sobre o problema e o comportamento do modelo em relação aos dados apresentados, o diretor geral foi visitar os prestadores. Repare que esta visita tinha três funções primordiais:

- Dados Capacitação Técnica: ratificar os dados apresentados, com principal atenção aos dados qualitativos devido seu caráter interpretativo. Novas perguntas, com base nas dúvidas sobre as respostas da $R F I$, foram formuladas e pontos de atenção e observação foram propostos pelo grupo para serem validados junto às empresas;

- Dados Nível de Serviço: negociação na busca do mais alto nível de serviço possível e com os limites estipulados nos critérios de inclusão e rejeição que ainda não haviam sido apresentados aos proponentes; 
- Dados Custos: renegociação no sentido de se obter o menor custo possível sem que exista interferência no nível de serviço e na capacitação técnica disponibilizada para a operação.

A primeira empresa visitada, por opção estratégica, foi o prestador "C". Em poucos minutos de conversa o participante foi excluído do processo por dois critérios de inclusão e rejeição: possibilidade de negócios futuros, pois a empresa não estava apta para operar em um modelo $4 P L$ e sua proposta na negociação sobre o percentual de expedição no prazo (OTIF) estava abaixo de 99,0\%.

Tal exclusão, em momento algum gerou desconforto, visto que na análise de sensibilidade já estava claro a pouca competitividade da referida empresa.

Posteriormente iniciou-se o processo com o prestador "A". Todos os dados estavam condizentes com a $R F I$, sendo que houve um aumento na força do subcritério possibilidade de negócios futuros de 2 para 3 , devido à maior sinergia com esta empresa do que pode ser observado na devolução dos dados.

$\mathrm{Na}$ negociação do nível de serviço o resultado foi satisfatório. Entretanto, para gestão de estoque houve um acordo em 99,5\% o que obriga o contratante pagar ao cliente valores de até $0,5 \%$ do valor de estoque, caso exista diferença de inventário. De qualquer forma esta consequência já estava prevista no modelo.

Na renegociação do custo, dificultado pelo argumento proposto na própria $R F Q$ de envio da melhor proposta, não houve alteração no custo fixo e uma redução no custo variável de 3,8 para 3,2\%, depois de longas horas de renegociação. Para se conseguir a redução no custo variável, foi necessário apresentar o impacto futuro nos custos originados por um aumento de volume operacional. Ficou claro que não haveria mais espaço para uma renegociação com este prestador.

$\mathrm{Na}$ terceira e última visita técnica, com o fornecedor "B", o modelo já havia sido atualizado com a retirada do prestador "C" pelos motivos já explicados e alteração dos dados conforme renegociação com o prestador "A". Os dados apresentados foram validados e conforme já havia sido observado através da $R F I$, o que de certa forma comprovou sua eficiência, aquele era o melhor prestador em termos de capacitação técnica em todos os seus subcritérios.

A negociação do nível de serviço foi rápida e tranquila e resultou na manutenção dos dados que foram inclusos no modelo, o que foi considerado satisfatório por estarem próximos aos resultados alcançados pela contratante. Considerando que não houve 
alteração nos dados dos critérios de nível de serviço e capacitação técnica, a única alternativa do prestador "B" ser a escolha ideal seria uma redução de custos, pois conforme consultado no modelo atualizado, a diferença de pontuação final era de 44 para o prestador "A" e continuava 35 para o prestador "B".

O prestador se interessou pelo modelo de escolha, elogiou o profissionalismo e qualidade do processo de seleção em todas as suas etapas e se mostrou bastante interessado na realização do projeto, pois havia claramente um foco nas possibilidades futuras de negócio e as consequências para sua empresa.

Após uma apresentação do modelo, sem visualização dos dados de entrada e incluindo o detalhamento da árvore de valor, o proponente perguntou quanto seria necessário reduzir o custo apresentado para que ele se tornasse a melhor escolha.

Diferente do modelo anterior, por uma questão comercial na busca pelo menor custo, não houve uma proposta de redução de custos com base no modelo. O que foi combinado foi que o prestador apresentaria em 12 horas a sua menor proposta sem que houvesse alteração nos outros critérios e que ele seria informado sobre o resultado do processo de seleção antes de sua finalização, o que abriria a oportunidade de mais uma renegociação.

Em menos de duas horas os resultados da renegociação foram recebidos: redução no custo fixo de $14,3 \%$ e $15,6 \%$ no Custo Variável. O modelo foi atualizado conforme descrito nas Tabelas 29 e 30 e Figura 42.

Tabela 29 - Alterações dos dados após negociação durante a visita técnica

\begin{tabular}{|c|c|c|c|c|c|c|c|c|c|c|c|}
\hline Enpresas & $\begin{array}{l}\text { Custo Fixo } \\
\text { (R\$) }\end{array}$ & $\begin{array}{c}\text { Custo } \\
\text { Variável } \\
(\%)\end{array}$ & $\begin{array}{c}\text { Gestão de } \\
\text { Estoque } \\
(\%)\end{array}$ & $\begin{array}{c}\text { Expedição } \\
\text { no Prazo } \\
(\%) \\
\end{array}$ & $\begin{array}{c}\text { Prazo de } \\
\text { Recebimento } \\
\text { (horas) }\end{array}$ & $\begin{array}{c}\text { Intalações e } \\
\text { Licenças }\end{array}$ & Sistemas & $\begin{array}{l}\text { Política da } \\
\text { Qualidade }\end{array}$ & $\begin{array}{l}\text { Capacidade } \\
\text { Financeira }\end{array}$ & $\begin{array}{c}\text { Possibilidade } \\
\text { de Negócios } \\
\text { Futuros } \\
\end{array}$ & $\begin{array}{c}\text { Experiência } \\
\text { no Segmento }\end{array}$ \\
\hline Prestador "A" & 16500 & 3,2 & 99,5 & 99,5 & 12 & 3 & 3 & 2 & 3 & 3 & 3 \\
\hline Prestador "B" & 18000 & 3,8 & 100 & 99,5 & 12 & 4 & 4 & 3 & 4 & 4 & 4 \\
\hline
\end{tabular}

Tabela 30 - Alterações na pontuação após negociação durante a visita técnica

\begin{tabular}{|c|c|c|c|c|c|c|c|c|c|c|c|c|}
\hline Pesos Critérios & 40,00 & & & $30,00 \%$ & & & & & $30,00 \%$ & & & \\
\hline $\begin{array}{l}\text { Pesos Sub- } \\
\text { Critérios }\end{array}$ & $80,00 \%$ & $20,00 \%$ & $30,00 \%$ & $60,00 \%$ & $10,00 \%$ & $25,00 \%$ & $20,00 \%$ & $10,00 \%$ & $10,00 \%$ & $25,00 \%$ & $10,00 \%$ & Pontuação \\
\hline Empresas & Custo Fixo & $\begin{array}{l}\text { Custo } \\
\text { Variável }\end{array}$ & $\begin{array}{c}\text { Gestão de } \\
\text { Estoque }\end{array}$ & $\begin{array}{c}\text { Expedição } \\
\text { no Prazo }\end{array}$ & $\begin{array}{c}\text { Prazo de } \\
\text { Recebimento }\end{array}$ & $\begin{array}{c}\text { Intalações e } \\
\text { Licenças }\end{array}$ & Sistemas & $\begin{array}{l}\text { Politica da } \\
\text { Qualidade }\end{array}$ & $\begin{array}{c}\text { Capacidade } \\
\text { Financeira }\end{array}$ & $\begin{array}{l}\text { Possibilidade } \\
\text { de Negócios } \\
\text { Futuros }\end{array}$ & $\begin{array}{l}\text { Experiência } \\
\text { no Segmento }\end{array}$ & Final \\
\hline Prestador "A" & 60 & 53 & 19 & 20 & 30 & 50 & 50 & 25 & 50 & 50 & 50 & 43,90 \\
\hline Prestador "B" & 42 & 31 & 100 & 20 & 30 & 75 & 75 & 50 & 75 & 75 & 75 & 51,17 \\
\hline
\end{tabular}




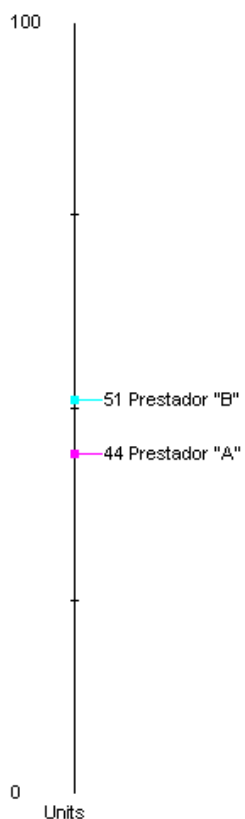

Figura 42 -Novo resultado após alteração dos dados negociados na visita técnica Fonte: Extraído do software (VISA)

O prestador "B" foi informado sobre a sua escolha e iniciaram as negociações finais referentes à formalização do contrato entre as empresas.

\subsubsection{Conclusão do Estudo de Caso 2}

A experiência deste segundo estudo de caso aplicado no "Facilitative Mode" também foi enriquecedora pelos seguintes aspectos:

1) A experiência adquirida durante a construção do mapa cognitivo fez com que o grupo adquirisse um conhecimento maior sobre o processo de seleção dos prestadores e por consequência estivessem mais capacitados para tomar uma decisão assertiva. A diferença observada em relação ao modelo anterior foi que uma equipe multidisciplinar produziu uma riqueza maior de informações nas mais variadas áreas. Inicialmente existia um receio por parte do facilitador de que utilizando um maior número de pessoas, haveria uma maior discordância de opiniões. Porém o que foi observado é que sempre que uma nova ideia surgia, havia as 
ponderações necessárias para um melhor entendimento e rapidamente o grupo produzia um resultado consensual.

2) Novamente a potencialidade do modelo escolhido é demonstrada pela sua aplicabilidade e facilidade de utilização. Neste estudo o modelo foi replicado em sete diferentes estados e em todos obteve sucesso. Até os contratados, que recebem um nível de informação mais restrito, apoiam o modelo e demonstram através de fatos sua preocupação em se desenvolver nos mais variados critérios e subcritérios na busca por uma melhor avaliação.

3) Neste estudo de caso o modelo foi mais amplo pois incluiu uma $R F I$ e $R F Q$. Embora por questões estratégicas não exista um aprofundamento nos documentos, a assertividade na execução destas planilhas produziu um modelo simples e aplicável que traduziu com elevado grau de precisão as características físicas e técnicas dos envolvidos. Tal análise, pode ser comprovada pelo alinhamento entre as avaliações preliminares (RFI) com a validação nas visitas técnicas.

O software novamente contribuiu em todas as fases do processo. Embora neste caso não se tenha utilizado a ferramenta diretamente para negociar com os fornecedores, ela auxiliou de forma fundamental na análise de sensibilidade, escolha do prestador mais qualificado e produziu a documentação necessária para justificar a escolha para os acionistas e para o cliente.

A escolha dos critérios também produziu um alinhamento com a literatura sobre 0 tema. Entretanto, em relação à representatividade do critério custo, houve uma relativa divergência ao modelo anterior. Por tratar-se de uma operação bastante específica, armazenagem de produtos combinados de farma e químicos, era necessário encontrar um prestador de serviços que fosse capaz de fornecer instalações compatíveis com as exigências operacionais da ANVISA e que pudesse ser adequada às exigências de manipulação de produtos químicos.

Outro ponto observado foi em relação ao trabalho do facilitador. Na maior parte do tempo parecia desnecessário sua função, pois todo o processo foi conduzido como se os envolvidos tivessem pleno domínio sobre o modelo. Tal fato fica ainda mais latente quando é possível avaliar que a velocidade e convergência de opiniões, sem perder a qualidade analítica, foi maior no segundo estudo de caso do que no 
primeiro, que envolvia profissionais em menor número, maior familiaridade com o software e com o modelo.

\subsection{AVALIAÇÃO DO MODELO COM BASE NA LITERATURA}

Conforme sugerido por De Boer et al. (2001) a utilização do mapa cognitivo foi fundamental para um melhor entendimento do problema. No primeiro estudo de caso a consulta ao mapa que havia sido desenvolvido auxiliou os analistas na aplicação do modelo e na criação da árvore de valor. No segundo estudo caso, aonde o mapa foi desenvolvido pelo grupo, sua construção foi enriquecedora porque alinhou 0 entendimento geral sobre o problema e produziu um desenvolvimento conceitual em todas as fases do processo de seleção, dada a natureza multidisciplinar do grupo.

A utilização do software, que havia sido sugerida por De Boer e Wegen (2003), fez com que o processo de seleção fosse dinâmico e rápido. Outro ponto importante é a contribuição visual no desenvolvimento dos critérios, subcritérios, seus respectivos pesos e curvas de impacto. Além disso, a ferramenta ofereceu um suporte relevante na negociação com os fornecedores, conforme previamente descrito.

A opção pela abordagem MAVT, proposta por Buttha (2003) por considerá-la a mais adequada a processos de seleção, parece ter sido assertiva, pois o modelo desenvolvido se adaptou perfeitamente ao problema e não gerou restrição durante seu desenvolvimento. Além do fato, sustentou a contratação efetiva de um prestador no estudo de caso 2, comprovando sua aplicabilidade prática.

Para o processo de avaliação da abordagem e do modelo, com base no item 2.5, foram apresentadas na Tabela 13 as técnicas de apoio propostas neste modelo de acordo com os critérios definidos por (DE BOER E WEGEN, 2003).

$\mathrm{Na}$ Tabela 31 é apresentada a avaliação do modelo proposto de acordo com os mesmos critérios estabelecidos por De Boer e Wegen (2003). A primeira avaliação foi realizada pelos dois analistas que aplicaram o estudo de caso $1 \mathrm{e}$, a segunda avaliação foi realizada, em conjunto, pelo grupo que aplicou o modelo no estudo de caso 2, incluindo-se o facilitador e o analista. 
No único ponto aonde os avaliadores julgaram que o modelo proposto não atendia totalmente, estudo de caso 1 , o fator motivador de tal avaliação não necessariamente pode ser atribuído ao modelo, pois a não implantação por parte dos decisores pode ser justificada por um grande número de fatores políticos internos à empresa aonde o estudo de caso foi aplicado. Também existe o argumento favorável (escolha do modelo) de que o mesmo modelo foi aplicado de forma similar no estudo de caso 2 e devidamente implantado.

Quanto às ressalvas da segunda aplicação, citadas na Tabela 31, a primeira diz respeito ao trabalho em grupo, pois não houve unanimidade na avaliação (assim como ocorreram outras vezes durante o estudo de caso), visto que a discussão se concentrou no questionamento do grupo que avaliava se $100 \%$ das opiniões e crenças individuais haviam sido incorporadas. A escolha "Atende Totalmente com Ressalvas" foi motivada pelo entendimento do grupo de que a opção "Atende Totalmente" somente deveria ser escolhida se em todas as oportunidades houvesse unanimidade no grupo, o que teoricamente não é necessário.

A segunda ressalva parece ser consequência de tratar-se da primeira utilização do modelo, pois o grupo foi entendendo o processo durante sua execução. Dificilmente haveria esta ressalva a partir da próxima aplicação com o mesmo grupo.

Em ambos os casos, o resultado da avaliação do modelo proposto foi favorável e pode-se concluir que o modelo desenvolvido se adapta tanto para aplicações no Expert quanto no Facilitative Mode. 
Tabela 31 - Avaliações do modelo proposto na aplicação aos estudos de caso Fonte: Adaptação de (De Boer e Wegen, 2003)

a) Estudo de Caso 1

\begin{tabular}{|c|c|}
\hline Complexidade & $\begin{array}{c}\text { Estudo de Caso } 1 \\
\text { (Expert Mode) }\end{array}$ \\
\hline C1: O modelo agrega informação de forma adequada ? & $\begin{array}{l}\text { Sim. Todas as informações recebidas dos fornecedores e } \\
\text { propostas pelos analistas foram passíveis de inclusão. }\end{array}$ \\
\hline $\begin{array}{l}\text { C2: O modelo é suficientemente capaz de utilizar as } \\
\text { informações disponiveis? }\end{array}$ & $\begin{array}{c}\text { Todas as informações inclusas foram ponderadas e } \\
\text { influenciaram no processo decisório de acordo com seu grau de } \\
\text { importância atribuído. }\end{array}$ \\
\hline $\begin{array}{l}\text { C3: É possivel incorporar as opiniões e crenças dos } \\
\text { envolvidos de forma satisfatória? }\end{array}$ & De forma plena. \\
\hline $\begin{array}{l}\text { C4: É possivel prover uma participação equitativa dos } \\
\text { membros envolvidos, no caso de uma decisão em grupo, } \\
\text { de forma satisfatória? }\end{array}$ & NA. \\
\hline $\begin{array}{l}\text { C5: O modelo é suficientemente flexivel para mudanças no } \\
\text { processo decisório? }\end{array}$ & $\begin{array}{c}\text { Nesta aplicação } 100 \% \text { das mudanças propostas foram } \\
\text { atendidas. }\end{array}$ \\
\hline Custo / beneficio & $\begin{array}{c}\text { Estudo de Caso } 1 \\
\text { (Expert Mode) }\end{array}$ \\
\hline C6: O resultado do modelo de decisão é útil? & $\begin{array}{l}\text { Embora o resultado tenha sido satisfatório pela ótica dos } \\
\text { analistas até o momento não foi impantado pelos decisores. }\end{array}$ \\
\hline C7: O resultado do modelo de decisão é aceitável? & Pelos analistas foi visto como a melhor solução. \\
\hline C8: Os investimentos necessários são justificáveis ? & $\begin{array}{l}\text { Quase inexistentes, exceto fator humano. Totalmente } \\
\text { justificáveis. }\end{array}$ \\
\hline C9: O modelo é de fácil utilização? & Sim. Não houve dificuldades relevantes. \\
\hline $\begin{array}{l}\text { C10: A forma como o modelo de decisão funciona é } \\
\text { suficientemente clara? }\end{array}$ & Sim \\
\hline $\begin{array}{l}\text { C11: O modelo de decisão foi capaz de aumentar a } \\
\text { percepção sobre o processo decisório? }\end{array}$ & $\begin{array}{l}\text { Através de um maior conhecimento sobre o problema, dos } \\
\text { critérios de decisão e seu valor relativo os envolvidos se } \\
\text { sentiram mais aptos a tomar decisão. }\end{array}$ \\
\hline $\begin{array}{l}\text { C12: O modelo de decisão contribuiu para a comunicação } \\
\text { dos envolvidos no processo de decisão? }\end{array}$ & NA. \\
\hline $\begin{array}{l}\text { C13: O modelo de decisão contribuiu para as habilidades } \\
\text { necessárias em uma tomada de decisão? }\end{array}$ & $\begin{array}{l}\text { Sem dúvida. Um dos fatores mais importantes do modelo é o } \\
\text { aumento no nivel de entendimento sobre o problema e avaliação } \\
\text { correta da potencialidade de cada um dos fornecedores de } \\
\text { acordo com os critérios definidos. }\end{array}$ \\
\hline
\end{tabular}

Atende Totalmente

Atende Totalmente com Ressalvas

Atende Parcialmente

Não Atende 
b) Estudo de Caso 2

\begin{tabular}{|c|c|}
\hline Complexidade & $\begin{array}{l}\text { Estudo de Caso } 2 \\
\text { (Facilitative Mode) }\end{array}$ \\
\hline C1: O modelo agrega informação de forma adequada? & $\begin{array}{l}\text { Sim. Todas as informações recebidas dos fornecedores e } \\
\text { propostas pelos decisores foram passiveis de inclusão. }\end{array}$ \\
\hline $\begin{array}{l}\text { C2: O modelo é suficientemente capaz de utilizar as } \\
\text { informações disponiveis? }\end{array}$ & $\begin{array}{l}\text { Todas as informaçōes inclusas foram ponderadas e } \\
\text { influenciaram no processo decisório de acordo com seu grau de } \\
\text { importância atribuído. }\end{array}$ \\
\hline $\begin{array}{l}\text { C3: É possivel incorporar as opiniões e crenças dos } \\
\text { envolvidos de forma satisfatória? }\end{array}$ & \begin{tabular}{|c|} 
Sim. Desde que respeitados os poderes de influência de cada \\
um dos decisores em cada um dos critérios atribuidos. Embora \\
nem sempre exista uma unanimidade inicial, ela foi conseguida \\
através de negociações em grupo.
\end{tabular} \\
\hline $\begin{array}{l}\text { C4: É possivel prover uma participação equitativa dos } \\
\text { membros envolvidos, no caso de uma decisão em grupo, } \\
\text { de forma satisfatória? }\end{array}$ & De forma plena. \\
\hline $\begin{array}{l}\text { C5: O modelo é suficientemente flexivel para mudanças no } \\
\text { processo decisório? }\end{array}$ & $\begin{array}{c}\text { Nesta aplicação } 100 \% \text { das mudanças propostas, validadas pelo } \\
\text { grupo, foram atendidas. }\end{array}$ \\
\hline Custo / beneficio & $\begin{array}{l}\text { Estudo de Caso } 2 \\
\text { (Facilitative Mode) } \\
\end{array}$ \\
\hline C6: O resultado do modelo de decisão é útil ? & $\begin{array}{c}\text { A contratação do prestador foi executada com base no modelo } \\
\text { de decisão. }\end{array}$ \\
\hline C7: O resultado do modelo de decisão é aceitável? & $\begin{array}{l}\text { Criteriosamente avaliado durante o desenvolvimento do modelo } \\
\text { foi consenso do grupo e considerado a melhor solução. }\end{array}$ \\
\hline C8: Os investimentos necessários são justificáveis ? & $\begin{array}{l}\text { Quase inexistentes, exceto fator humano. Totalmente } \\
\text { justificáveis. }\end{array}$ \\
\hline C9: O modelo é de fácil utilização? & $\begin{array}{l}\text { Foi utilizado o apoio de um facilitador e de um analista. Em } \\
\text { todas as etapas os envolvidos entenderam suas } \\
\text { responsabilidades e proveram o resultado esperado. Vale } \\
\text { lembrar que foi a primeira experiência do grupo e próximas } \\
\text { implantações seriam ainda mais simples de acordo com o } \\
\text { aprendizado do próprio grupo. }\end{array}$ \\
\hline $\begin{array}{l}\text { C10: A forma como o modelo de decisão funciona é } \\
\text { suficientemente clara? }\end{array}$ & $\begin{array}{c}\text { Embora o grupo não tenha o embasamento teórico para } \\
\text { entender de forma profunda o modelo, o que pode ter gerado } \\
\text { um certo cetisismo no início do processo, após a etapa de } \\
\text { entendimento do problema houve uma unanimidade na } \\
\text { potencialidade da ferramenta que se manteve a até a escolha } \\
\text { final do prestador. }\end{array}$ \\
\hline $\begin{array}{l}\text { C11: O modelo de decisão foi capaz de aumentar a } \\
\text { percepção sobre o processo decisório? }\end{array}$ & $\begin{array}{c}\text { Através de um maior conhecimento sobre o problema, dos } \\
\text { critérios de decisão e seu valor relativo e de um aprendizado } \\
\text { em grupo multidisciplinar, os envolvidos se sentiram mais aptos } \\
\text { a tomar decisão. }\end{array}$ \\
\hline $\begin{array}{l}\text { C12: O modelo de decisão contribuiu para a comunicação } \\
\text { dos envolvidos no processo de decisão? }\end{array}$ & $\begin{array}{l}\text { Indiscutivelmente e potencializou o entendimento geral sobre } \\
\text { áreas distintas incluindo problemas e conhecimentos } \\
\text { específicos. }\end{array}$ \\
\hline $\begin{array}{l}\text { C13: O modelo de decisão contribuiu para as habilidades } \\
\text { necessárias em uma tomada de decisão? }\end{array}$ & $\begin{array}{l}\text { Houve um aumento no nivel de entendimento do grupo sobre o } \\
\text { problema e avaliação correta da potencialidade de cada um dos } \\
\text { fornecedores de acordo com os critérios definidos. De forma } \\
\text { ainda mais latente, através do trabalho em grupo } \\
\text { multidisciplinar, existe a abordagem de assuntos de diversas } \\
\text { áreas e uma convergência de opiniões com um alto nivel de } \\
\text { entendimento sobre o problema e amplitude analítica. }\end{array}$ \\
\hline
\end{tabular}

Atende Totalmente

Atende Totalmente com Ressalvas

Atende Parcialmente

Não Atende 
A aplicação de um modelo multicritérios, defendida pela totalidade dos autores aqui citados, parece ser fundamental na busca pela escolha ideal. A excelente avaliação do método, sua facilidade de aplicação e os resultados alcançados, reforçam a conclusão de Ho et al. (2010) de que uma aplicação multicritérios é melhor do que a abordagem atual utilizada em processos de seleção. 


\section{CONCLUSÃO}

A seleção de fornecedores é uma etapa fundamental na busca por menores custos e por um melhor nível de serviço, e contribui para garantir a competitividade das empresas. Historicamente, o processo de seleção está muito focado no fator custos e, na maioria das vezes, não leva em consideração todos os critérios necessários para uma correta tomada de decisão.

Pelas características do problema: múltiplos objetivos, intangibilidade, vários tomadores de decisão, trade-offs, dificuldade de identificar boas e robustas alternativas, horizontes de longo prazo, riscos e incertezas, é justificada a sua classificação como um problema complexo. Para lidar com um problema complexo e com múltiplos critérios qualitativos e quantitativos, a abordagem tradicional de utilizar o custo mais baixo como único critério de seleção não é robusta o suficiente para suportar um processo de seleção contemporâneo.

Esta dissertação desenvolveu um modelo multicritério para seleção de fornecedores de logística, de fácil aplicação prática e com o objetivo de contribuir com o conhecimento científico da área, propondo um formato mais racional e sistemático de escolha. Este modelo foi aplicado em dois estudos de caso: seleção de fornecedores de transporte fracionado e seleção de prestadores de armazenagem no modelo $4 P L$.

Os objetivos inicialmente propostos para esta dissertação foram cumpridos e desenvolvidos da seguinte forma:

Foram identificados nos principais sites especializados mais de 1.000 trabalhos publicados em periódicos científicos internacionais. Entre estes trabalhos foram encontradas algumas aplicações e revisões bibliográficas sobre a utilização da abordagem MCDA em seleção de fornecedores nas publicações em referências dos últimos 20 anos. Com base nessas publicações, detalhou-se as características do processo de seleção, critérios mais utilizados, abordagens aplicadas, avaliação das abordagens e áreas de estudo da aplicação.

O modelo proposto para resolução do problema de seleção de fornecedores é baseado no processo MCDA e composto das seguintes fases: identificação e 
estruturação do problema, construção e uso do modelo e desenvolvimento do plano de ação.

Para a identificação e estruturação do problema foram utilizados o Mapa Cognitivo e o método SODA. Na construção e uso do modelo utilizou-se o conceito Value Focused Thinking (VFT) para estruturação do processo decisório. A condução deste processo foi realizada por um software e suportada pela abordagem Multi Attribute Value Theory (MAVT), com base nas recomendações encontradas na literatura sobre as potencialidades na aplicação desta abordagem para o problema de seleção e sua pouca utilização em casos práticos. O desenvolvimento dos planos de ação referem-se à aplicação prática do modelo.

Nos dois estudos de caso aplicados, todas as etapas relativas ao processo de seleção foram abordadas e as potencialidades do modelo desenvolvido foram detalhadas e comparadas com os periódicos publicados sobre o tema.

Finalmente, o modelo foi avaliado com base no desenvolvimento do processo de seleção e sua capacidade de aplicação. O resultado da avaliação comprova sua potencialidade na resolução do problema de seleção de fornecedores, o que foi comprovado pelo segundo estudo de caso que utilizou o modelo proposto para efetivar a contratação de um prestador de serviços logísticos.

A construção de um modelo de seleção não é uma tarefa trivial, porque as restrições, preferências pessoais, incertezas e o valor relativo dos critérios variam de acordo com o problema e, desta forma, não é possível que um modelo de contratação único seja funcional e apropriado para todos os cenários possíveis. $\mathrm{O}$ que é suportado pela quase totalidade dos autores e pelos trabalhos acadêmicos mais recentes que utilizam uma abordagem multicritérios.

O resultado da pesquisa bibliográfica comprova que a maioria dos trabalhos publicados é estritamente acadêmica e há pouca evidência de aplicações práticas de tais ferramentas na seleção de fornecedores. O que parece de certa forma incoerente frente às pesquisas, que concluem que a ampla gama de métodos e técnicas que surgiram nos últimos 50 anos parece fornecer a variedade de abordagens necessárias para lidar com a diversidade encontrada na prática de compra. 
O modelo proposto neste trabalho mostrou-se de fácil utilização, adaptável aos mais variados segmentos de mercado e com um custo de implantação muito baixo. Tais características possibilitam, e sugerem, sua aplicação prática em larga escala.

Como principais contribuições deste modelo, são apresentadas as seguintes ideias que foram analisadas e implementadas e, todavia, pouco exploradas na literatura:

1) Este modelo foi estruturado com base no processo MCDA (e toda sua amplitude) e propôs abordagens, métodos e ferramentas para todas as fases de um processo de seleção: definição do problema, formulação de critérios, pré-qualificação dos fornecedores e escolha final do fornecedor;

2) Escolha da abordagem MAVT para este tipo de problema;

3) A aplicação prática do modelo, em especial ao estudo de caso 2 , na qual o modelo é aplicado e efetivamente utilizado para a seleção de um fornecedor de serviços logísticos no modelo $4 P L$;

4) $O$ processo de seleção foi analisado como uma função estratégica na construção do modelo e na sua aplicação prática. Atenção especial é dada ao relacionamento entre contratante e contratado e modelos de formalização contratual;

5) O formato de aplicação do modelo se mostrou uma poderosa ferramenta de negociação junto aos fornecedores.

Os resultados apresentados neste trabalho estão em alinhamento com diversos outros autores em relação à importância do profundo entendimento do problema, antes de sua solução, aplicação de uma abordagem multicritério na solução deste problema, aos critérios utilizados e à utilização de software como apoio no desenvolvimento do processo de seleção.

Como limitação ao modelo proposto, pode-se considerar a aplicação em apenas um segmento da economia (logística) e a utilização de uma abordagem MCDA única para escolha final do fornecedor. Tais condições não produziram efeito comparativo para o modelo, embora os resultados tenham sido aprovados pelos participantes do processo de seleção e tomadores de decisão.

Outra limitação do modelo foi não abordar de forma direta em sua construção as características do problema de seleção relativas a horizontes de longo prazo e riscos 
e incertezas (embora estas características tenham sido analisadas no desenvolvimento dos critérios, subcritérios e seus pesos).

Portanto, as conclusões aqui apresentadas devem ser consideradas como meramente indicativas do sucesso e potencial das metodologias.

Aplicações futuras e evoluções para continuidade no estudo do modelo aqui proposto, são sugeridas:

- Aplicação deste modelo em um estudo de caso relevante em outro segmento da economia, podendo não estar relacionada com a compra de serviços;

- Utilizar outra abordagem MCDA nas mais variadas fases do processo de seleção e comparar os resultados;

- Discussão sobre a importância dos fornecedores que devem participar do processo de seleção e dos critérios de pré-qualificação desses fornecedores;

- Estudo sobre o efeito nos resultados, se considerarmos o nível de relacionamento entre contratante e contratado, complexidade do problema, relevância financeira e qualidade das informações para a tomada de decisão;

- Aplicação de técnicas de programação multi-objetivo (MOP) para solução deste problema. 


\section{REFERÊNCIAS}

ACKERMANN, F.; EDEN, C.; CROPPER, S. Getting started with cognitive mapping. Coventry: University of Warwick, 1992.

ALEXANDRIA, V. The puzzle master. Virginia, USA: Time-Life Books , p. 32., 1989

ANTT - Agência Nacional de Transportes Terrestres. 2008. Disponível em $<$ http://appeantt.antt.gov.br:8765/query.html?st=11\&charset=iso-8859-

$1 \& \mathrm{qt}=$ dados $+2008>$ Acesso em 05 jul. 2011.

ARBEL, A., TONG, R.M. On the generation of alternatives in decision analysis problems. Journal of the Operations Research Society 33, 377-387, 1982.

BALLOU, R. H. Logística empresarial. São Paulo: Atlas, 1993.

BASADUR, M.S. ELLSPERMAN, S.J. EVANS, G.W. A new methodology for formulating ill-structured problems. Omega International Journal of Management Science, 22, 6, 627-645, 1994.

BELTON, V.; STEWART, J. T. Multiple criteria decision analysis: an integrated approach. London: Kluwer Academic Publishers, 2002.

BHUTTA, M. K. Supplier selection problem: literature review. Journal of international technology and information management .12, pp 53-72, 2003.

BRINATI, M. Notas de aula. Curso de pesquisa operacional. Escola Politécnica da Universidade de São Paulo, 2009.

BRUNO, G.; ESPOSITO, E.; GENOVESE, A.; PASSARO, R. . The analytical hierarchy process in the supplier selection problem. Proceedings of the International Symposium on the Analytic, 10, 1-15, 2009.

CENTRO DE ESTUDOS LOGÍSTICOS - CEL/COPPEAD. Relatório de pesquisa Panorama logístico: custos logísticos no Brasil 2006/2008. Cel - Coppead, 2008.

$\mathrm{COHON}$, J. L. Multiobjective programming and planning. 331p. New York: Editorial Academic Press, 1978.

DAHEL, N. Vendor selection and order quantity allocation in volume discount environments. Supply Chain Management: An International Journal, Vol. 8 No. 4, pp. 334-42, 2003.

DE BOER, L.; LABRO, E.; MORLACCHI, P. A review of methods supporting supplier selection. European Journal of Purchasing and Supply Management. 7 (2), $75-$ 89, 2001. 
DE BOER, L.; WEGEN, L.. Practice and promise of formal supplier selection: a study of four empirical cases. European Journal of Purchasing and Supply Management. 9, 109-118, 2003.

DE BOER, L., VAN DER WEGEN, L., TELGEN, J. Outranking methods in support of supplier selection. European Journal of Purchasing and Supply Management 4 (2/3), 109-118, 1998.

DEGRAEVE, Z.; LABRO, E.; ROODHOOFT, F. An evaluation of supplier selection methods from a total cost of ownership perspective. European Journal of Operational Research. 125 (1), 34-59, 2000.

DEGRAEVE, Z.; ROODHOOFT, F. Improving the efficiency of the purchasing process using total cost of ownership information: the case of heating electrodes at Cockerill Sambre S. A. European Journal of Operational Research. 112 (1), 42-53, 1999.

DEMPSEY, W.A. Vendor selection and the buying process. Industrial Marketing Management. 7, 257-267, 1979.

DICKSON, G.W. An analysis of vendor selection systems and decisions. Journal of Purchasing 2/1, 5-17, 1966.

DORNIER, P.; ERNST R.; FENDER M.; KOUVELIS P. Logística e Operações Globais - Textos e Casos. São Paulo: Atlas, 2000.

DYER J. S. Remarks on the analytic hierarchy process. Management Science. Vol. 36, No. 3, 1990.

EDEN, C. Analyzing cognitive maps to help structure issues problems. University Strathclyde Glasgow, 2003.

EDEN, C.; SIMS, D. On the nature of problems in consulting practice. United Kingdom: University Bath, 1978.

ENSSLIN L.; MONTIBELLER G. N.; NORONHA, S. M. Apoio à decisão: metodologias para estruturação de problemas e avaliação multi-critério de alternativas. Florianópolis: Insular, 2001.

ENSSLIN, L.; MONTIBELLER, G.; LIMA, M. V. A. Constructing and implementing a DSS to help evaluate perceived risk of accounts receivable. In: HAIMES, Y.Y.; STEUER, R. E. (eds). Research and practice in multi-criteria decision making. Springer: Berlin, 2000.

FISHER, M. L. What is the right supply chain for your product?. Harvard Business Review. Vol. 75 No. 2, pp. 105-16.,1997.

FRANCO, L.; MONTIBELLER, G. Facilitated modeling in operation research. European Journal of Operational Research. 205(3), 489-500, 2010. 
FRANCO, L.; MONTIBELLER, G. Problem structuring for multicriteria decision analysis interventions. Wiley Encyclopedia of Operation Research and Management Science. United Kingdom: Ed. J. Cochran (Forthcoming), 2011.

GEOFFRION, A. M.; KRISHNAN, R. Prospects for operations research in the ebusiness era. Interfaces. 31 (2), 6-36, 2001.

HARTLEY, J.L.; CHOI, T. Y. Supplier development: customers as a catalyst of process change. Business Horizons. Vol. 39 No. 4, pp. 37-44.,1996.

HO, W. Integrated analytic hierarchy process and its applications - A literature review. European Journal of Operational Research. 186 (1), 211-228, 2008.

HO, W.; XU, X.; DEY P. Multi-criteria decision making approaches for supplier evaluation and selection - A literature review. European Journal of Operational Research. 202, 16-24, 2010.

HOWARD, R.A. Decision analysis: practice and promise. Management Science 34 (6), 679-695, 1988.

HULT, M.; LENNUNG, S. Towards a definition of action research: a note and bibliography. Journal of Management Studies. Vol. 17, pp.241-250, 1980.

HWANG, C.L., YOON, K. Multi Attribute Decision Making. Springer, New York, 1981.

IBGE/PAS - Instituto Brasileiro de Geografia e Estatística. Pesquisa anual de serviços. $2005 . \quad$ Disponível em $<$ http://www.ibge.gov.br/home/presidencia/noticias/noticia visualiza.php?id noticia=9 34\&id pagina=1> Acesso em 05 jan. 2011.

IFM - Cambridge Institute for Manufacturing. Disponível em <http://www.ifm.eng.cam.ac.uk/dstools/control/soda.html> Acesso em 15 out. 2009.

IHS Global Insight. Disponível em http://www.insglobalinsight.com/Perspective/PerspectiveDetail13453. Acesso em 20 mai. 2009.

KEENEY, R.L. Creativity in decision making with value-focused thinking. Sloan Management Review 35 (4), 33-41, 1994.

KEENEY, R. L. Decision Analysis: an overview. Operations Research,50, 935-945, 1982.

KEENEY, R. L. Value-focused thinking: A path to creative decision making. Los Angeles: University of Southern California, 1992.

KEENEY, R. L.; GREGORY R. Selecting attributes to measure the achievement objectives. Operations Research. 53: 1-11, 2005. 
KEENEY, R., RAIFFA,H. Decisions with multiple objectives: preferences and value tradeoffs. New York, Wiley, 274p, 1976.

KIRYTOPOULOS K.; LEOPOULOS V.; VOULGARIDOU D. Supplier selection in pharmaceutical industry: An analytic network process approach. Benchmarking: An International Journal. Vol.15, n 4, 2008.

LEWIS, H. Industrial purchasing principles and practices. Chicago: Richard Erwin.,1943.

MCKAY, J.; MARSHALL, P. The dual imperatives of action research. Information Technology \& People. Vol. 14, No. 1, pp. 46-59, 2001.

MILLINGTON, A.; EBERHARDT, M.; WILKINSON, B. Supplier performance and selection in China. International Journal of Operations \& Production Management. Vol. 26 No. 2, pp. 185-201, 2006.

MONTIBELLER, G.. Action-Researching MCDA Interventions. In: SHAW, D. (Ed.) Key-Note Papers, 49th British Operational Research Conference (OR 49), 46Sep,Univ. of Edinburgh, 2007.

MONTIBELLER, G.; FRANCO L .A. Decision and risk analysis for the evaluation of strategic options. in: O'BRIEN, F.A.; DYSON, R.G. (Eds.). Supporting strategy: frameworks, methods and models, p. 251-284. Wiley: Chichester, 2007,

NTC\&LOGÍSTICA. 2009. Dados do IBGE/PAS (2005) e ANTT (2008). Disponível em <www.ntcelogistica.org.br/tecnico/tecnico estatistica.asp $>$ Acesso em 20 mai. 2009

NTC\&LOGÍSTICA. Planilha referencial de custos do transporte rodoviário de cargas. Departamento de Custos Operacionais e Estudos Técnicos e Econômicos, 2010.

OGDEN, J. A. Critical success factors of supply base reduction efforts. Journal of Supply Chain Management. Vol. 42, No. 4, 30-40. ,2006

OLIVEIRA A.; FILHO, E. Relatório Técnico. IEMB - Intituto Tecnológico de Aeronáutica - ITA, 2007.

PARNELL, G.; DRISCOLL, P.; HENDERSON, D. Decision making in systems engineering and management. series In: Systems Engineering and Management., 2008.

ROHRMANN, B. Evaluating the usefulness of decision aids: a methodological perspective. In: BREHMER, (Ed.). New Directions in Research on Decision Making. Amsterdam: Elsevier, 1986.

ROSENHEAD, J. Rational Analysis for a Problematic World New York, Wiley, 1989. 
ROSENHEAD, J.; MINGERS, J. Problem structuring methods for complexity: uncertainty and conflict. Toronto: John Wiley and Sons, 2001.

ROY, B. Multicriteria methodology for decision aiding. Dordrecht: Kluwer Academic Publishers, 1996.

SCHILLING, D. A.; REVELLE, C.; COHON, J. An approach to the display and analysis of multiobjective problems. Socio-Economic Planning Science. 17, 57-63, 1983.

SLOWINSKI, R. Intelligent Decision Support: Handbook of Applications and Advances of the Rough Sets Theory. Kluwer Academic Publishers, Dordrecht, 1992.

SONMEZ, M. A Review and critique os supplier selection process and practices. Business School papers series 2006, vol. 1, Loughborough University, 2006.

TABUCANON, M.T. Multiple criteria decision making in industry. Amsterdam: Elsevier, 1988.

TELGEN, J. Inzicht en overzicht: de uitdagingen van Besliskunde en Inkoopmanagement. Academical address at the University of Twente. Enschede: The Netherlands, 1994.

TIMMERMANS, D.R.M. Decision aids for bounded rationalists: an evaluation study of multi-attribute decision support in individual and group settings. Ph.D. Thesis: University of Groningen, 1991.

V.I.S.A. Manual. Disponível em <www.visadecisions.com> Acesso em 16 jul. 2009.

WARREN, K. Exploring competitive futures using cognitive mapping. Long Range Planning 28 (5), 10-21, 1995.

WATSON, S. R., BUEDE, D M Decision Synthesis The principles and practice of decision analysis. Cambridge: Cambridge University Press.,1987.

WEBER, C. A.; CURRENT, J. R.; DESAI, A. An optimization approach to determining the number of vendors to employ. Supply Chain Management: An International Journal, Vol. 5 No. 2, pp. 90-8, 2000.

WEBER, C.A., CURRENT J.R. BENTON, W.C. Vendor selection criteria and methods. European Journal of Operational Research. No. 50, pp. 2-18, 1991.

WEBER, C.A., CURRENT, J.R. A multi-objective approach to vendor selection. European Journal of Operational Research. No. 68, pp. 173-84, 1993. 


\section{REFERÊNCIAS COMPLEMENTARES}

ADAMSON, J., Corporate long-range planning must include Procurement. Journal of Purchasing and Materials Management, 16, 25-32, 1980

AKARTE, M., SURENDRA, N., RAVI, B., RANGARAJ, N. Web based casting supplier evaluation using analytical hierarchy process. Journal of the Operational Research Society 52 (5), 511-522, 2001.

AKINC, U. Selecting a set of vendors in a manufacturing environment. Journal of Operations Management 11, 107-122, 1993.

ALBINO, V., GARAVELLI, A. A neural network application to subcontractor rating in construction firms. International Journal of Project Management 16 (1), 914, 1998.

ALENCAR, L E ALMEIDA, A. Multicriteria decision group model for the selection of suppliers. Pesquisa Operacional, vol.28, no.2, p.321-337. ISSN 0101-7438, 2008.

ANSARI, A., MODARRESS, B. Just-in-time purchasing: Problems and solutions, Journal of Purchasing and Materials Management, 11-15, 1986.

ANSARI, A.; MODARRESS, B.JIT purchasing as a quality and productivity centre, International Journal of Production Research 26/1, 19-26, 1980.

ANTHONY, T.F.; BUFFA, F.P. Strategic purchase scheduling, Journal of Purchasing and Materials Management, 27-31, 1977.

ANZIAM, J \& SHI, P \& BAKER,S. Formulation of a tactical logistics decision analysis problem using an optimal control. Approach Stephen and Baker Peng Shi,82-113, 2002.

B2WINC. Disponível:<http://www.b2winc.com/pt-br/institucional/comercioeletronicono-brasil>Acesso em: 03janeiro de 2010

BANERJEE, A. A joint economic-lot-size model for purchaser and vendor. Decision Sciences 17, 292-311, 1986.

BARBAROSOGLU, G., YAZGAÇ, T. An application of the analytic hierarchy process to the supplier selection problem. Production and Inventory Management Journal 1st quarter, 14-21, 1997.

BARLA, S.B. A case study of supplier selection for lean supply by using a mathematical model. Logistics Information Management 16 (6), 451-459, 2003.

BASADUR, M., ELLSPERMANN, S.J., EVANS, G.W.A new methodology for formulating ill-structured problems. International Journal of Management Science 22 (6), 627-645, 1994. 
BAYAZIT, O. Use of analytic network process in vendor selection decisions Benchmarking: An International Journal, Vol. 13 No. 5, pp. 566-79, 2006.

BENDER, P.S., BROWN, R.W., ISAAC, M.H., SHAPIRO, J.F. Improving purchasing productivity at IBM with a normative decision support system, Interfaces 15, 106-115, 1985.

BENTON, W.C, Purchase lot sizing research for MRP systems, International Journal of Production Management 6/1, 5-13, 1985 b.

BENTON, W.C. Multiple price breaks and alternative purchase lot-sizing procedures in materials requirements planning systems, International Journal of Production Research 23/5, 1025-1047, 1985.

BENTON, W.C. Purchase quantity discount procedures and MRP, Journal of Purchasing and Materials Management, 30-34, 1983.

BENTON, W.C. Quantity discount decisions under conditions of multiple items, multiple suppliers and resource limitations. International Journal of Production Research 29 (10), 1953 - 1961, 1991.

BENTON, W.C., WHYBARK, O.C. Material requirements planning (MRP and purchase discounts), Journal of Operations Management 2/2, 137-143, 1982.

BENTON, W.C.; KRAJEWSKI, L. Vendor performance and alternative manufacturing environments, Decision Sciences, 21, 1990.

BERNARD, P. Managing vendor performance, Production and Inventory Management Journal, 1-7, 1989.

BRAGG, D.J., HAHN, C.K.. Material requirements planning and purchasing, Journal of Purchasing and Materials Management, 17-22, 1982.

BRAGLIA, M., PETRONI, A. A quality assurance-oriented methodology for handling trade-offs in supplier selection. International Journal of Physical Distribution and Logistics Management 30 (2), 96-111, 2000.

BRANS, J.P., VINCKE, P., MARESCHAL, B. How to select and how to rank projects: the PROMETHEE method. European Journal of Operational Research 24, 228-238, 1986.

BROWN, R. Rational Choice and Judment - Decision Analysis. Kluwer: Norwell, MA, 2005.

BROWNING, J.M., ZABRISKIE, N.B., HUELLMANTEL, A.B. Strategic purchasing planning, Journal of Purchasing and Materials Management, 19-24, 1983.

BUEDE, D. M. Structuring value attributes, Interfaces, 16, 52-62, 1986 
BUFFA, F.P., JACKSON, W.M. A goal programming model for purchase planning, Journal of Purchasing and Materials Management, 27-34, 1983.

BUNN, M.D. Taxonomy of buying decision approaches. Journal of Marketing 57 (1), 38 - 56, 1993

BURTON, T.T.JIT/repetitive sourcing strategies: "Tying the knot" With your suppliers, Production and Inventory Management Journal, 38-41, 1988.

CARDOZO, R.N., CAGIEY, J.W. Experimental study of industrial buyer behavior, Journal of Marketing Research VIII, 329-934, 1971.

CARR, L. P.; ITTNER, C. D. Measuring the cost of ownership. Journal of Cost Management (Fall): 42-51, 1992.

CAVINATO, J. L. A total cost/value model for supply chain competitiveness. Journal of Business Logistics, 13(2), 285-301, 1992.

ÇEBI, F., BAYRAKTAR, D. An integrated approach for supplier selection. Logistics Information Management 16 (6), 395-400, 2003.

CHAKRAVARTY, A.K., MARTIN, G.E. An optimal joint buyer-seller discount pricing model, Computers and Operations Research 15/3, 271-281. Cooper, S.D. (1977), "A total system for measuring delivery performance", Journal of Purchasing and Materials Management, 22-26, 1988.

CHAN, F.T.S. Interactive selection model for supplier selection process: An analytical hierarchy process approach. International Journal Production Research 41 (15), 3549-3579, 2003.

CHAN, F.T.S., CHAN, H.K. Development of the supplier selection model - A case study in the advanced technology industry. Proceedings of the Institution of Mechanical Engineers Part B - Journal of Engineering Manufacture 218 (12), 1807$1824,2004$.

CHAN, F.T.S., CHAN, H.K., IP, R.W.L., LAU, H.C.W. A decision support system for supplier selection in the airline industry. Proceedings of the Institution of Mechanical Engineers Part B - Journal of Engineering Manufacture 221 (4), 741758, 2007.

CHAN, F.T.S., KUMAR, N. Global supplier development considering risk factors using fuzzy extended AHP-based approach. OMEGA - International Journal of Management Science 35 (4), 417-431, 2007.

CHAPMAN, S.N., CARTER, P.L. Supplier/customer inventory relationships under just in time, Decision Sciences 21, 35-51,1990.

CHAPMAN, S.N., Just-in-time supplier inventory: An empirical implementation model, International Journal of Production Research 27/12, 1993-2007, 1989. 
CHEN, C.T., LIN, C.T., HUANG, S.F. A fuzzy approach for supplier evaluation and selection in supply chain management. International Journal of Production Economics 102 (2), 289-301, 2006.

CHEN, S.J., HWANG, C.L. Lecture Notes in Economics and Mathematical Systems: Fuzzy Multiple Attribute Decision Making. Springer, Berlin, 1991.

CHEN, Y.M. HUANG, P. Bi-negotiation integrated AHP in supplier's selection. Benchmarking: An International Journal, Vol. 14 No. 5, pp. 575-93, 2007.

CHOI, T.Y. E KRAUSE, D.R. The supply base and its complexity: implications for transaction costs, risks, responsiveness, and innovation. Journal of Operations Management, Vol. 24 No. 5, pp. 637-52, 2000.

CHOY, K., CHOW, H., LEE, W., CHAN, F. Development of performance measurement system in managing supplier relationships for maintenance logistic partners, Benchmarking: An International Journal, Vol. 14 No. 3, pp. 352-68, 2007.

CHOY, K., FAN, K.K.H., LO, V. Development of an intelligent customer supplier relationship management system: The application of case-based reasoning. Industrial Management and Data Systems 103 (4), 263-274, 2003.

CHOY, K., LEE, W.B. E LO, V. An intelligent supplier management tool for benchmarking suppliers in outsource manufacturing, Expert Systems with Applications, Vol. 22 No. 3, pp. 213-24, 2002.

CHOY, K., LEE, W.B. A generic supplier management tool for outsourcing manufacturing. Supply Chain Management: An International Journal 8 (2), 140154, 2003.

CHOY, K.L., LEE, W.B. A generic tool for the selection and management of supplier relationships in an outsourced manufacturing environment: The application of case based reasoning. Logistics Information Management 15 (4), 235253, 2002.

CHOY, K.L., LEE, W.B., LAU, H.C.W., LU, D., LO, V. Design of an intelligent supplier relationship management system for new product development. International Journal of Computer Integrated Manufacturing 17 (8), 692-715, 2004.

CHOY, K.L., LEE, W.B., LO, V. A knowledge-based supplier intelligence retrieval system for outsource manufacturing. Knowledge-Based Systems 18 (1), 1-17, 2005.

CHOY, K.L., LEE, W.B., LO, V. An enterprise collaborative management system - A case study of supplier relationship management. The Journal of Enterprise Information Management 17 (3), 191-207, 2004. 
CHOY, K.L., LEE, W.B., LO, V. Design of a case based intelligent supplier relationship management system - The integration of supplier rating system and product coding system. Expert Systems with Applications 25 (1), 87-100, 2003.

CHOY, K.L., LEE, W.B., LO, V. Design of an intelligent supplier relationship management system: A hybrid case based neural network approach. Expert Systems with Applications 24 (2), 225-237, 2003b.

CHOY, K.L., LEE, W.B., LO, V. Development of a case based intelligent customer - Supplier relationship management system. Expert Systems with Applications 23 (3), 281-297, 2002.

CLEMEN, R. E REILLY, T. Making Hard Decision Analysis. Kluwer: Norwell, MA, 2001.

COOPER, M.C. E ELLRAM, L.M. Characteristics of supply chain management and the implications for purchasing and logistics strategy. International Journal of Logistics Management, Vol. 4 No. 2, pp. 13-24.,1993.

CORNER, J. E KIRKWOOD, C. W. Decision and risk analysis applicatins in the operations research leterature, 1970-1989, Operation Research, 39,206-219, 1991

CRAIGHEAD, C.W., BLACKHURST, J., RUNGTUSANATHAM, M. e HANDFIELD, R.B. The severity of supply chain disruptions: design characteristics and mitigation capabilities, Decision Sciences, Vol. 38 No. 1, pp. 131-57.,2007.

CROELL, R.C. Measuring purchasing effectiveness, Journal of Purchasing and Materials Management, 22-26, 1980.

DADA, M., SRIKANTH, K.N. Pricing policies for quantity discounts, Management Science 33/10, 1247- 1252, 1987.

DE BOER, L. Operations research in support of purchasing. Design of a toolbox for supplier selection. Ph.D. Thesis, University of Twente, Enschede, The Netherlands, 1998.

DE BOER, L. E VAN DER WEGEN, L.L.M. Practice and promise of formal supplier selection: a study of four empirical cases. Journal of Purchasing and Supply Management, pp. 109-118, 2003.

DE BOER, L., DE LABRO, E. E MORLACCHI, P. A review of methods supporting supplier selection. European Journal of Purchasing and Supply Management, pp. 75-89, vol. 7, no. 2, 2001.

DE LOOFF, L. Information Systems Outsourcing Decision Making: a Managerial Approach. IDEA Group Publishing, Hershey, PA, 1997. 
DEGRAEVE, Z., ROODHOOFT, F. A mathematical programming approach for procurement using activity based costing. Journal of Business Finance and Accounting 27 (1-2), 69-98, 2000.

DEGRAEVE, Z., ROODHOOFT, F. Determining sourcing strategies: a decision model based on activity and cost driver information. Journal of the Operational Research Society 49 (8), 781-789, 1998.

DEMIRTAS, E.A., ÜSTÜN, Ö. An integrated multi-objective decision making process for supplier selection and order allocation. OMEGA - International Journal of Management Science 36 (1), 76-90, 2008.

DEMIRTAS, E.A., ÜSTÜN, Ö. Analytic network process and multi-period goal programming integration in purchasing decisions. Computer and Industrial Engineering 56 (2), 677-690, 2009.

DING, H., BENYOUCEF, L., XIE, X. A simulation optimization methodology for supplier selection problem. International Journal Computer Integrated Manufacturing 18 (2-3), 210-224, 2005.

EDEN, C., ACKERMANN, F. Strategy Making: The journey of strategic planning. Sage: London, 1998

EDWARDS, M.G. Supplier management evaluation, Journal of Purchasing 3/1, 28$41,1967$.

ELLRAM, L.M., CARR, A. Strategic Purchasing: A History and Review of the Literature. International Journal of Purchasing and Materials Management. Spring, 10-18, 1994.

ELLRAM, L.M. Total Cost of Ownership, an analysis approach for purchasing. International Journal of Purchasing and Materials Management, Vol. 25, No. 8, pp. 423, 1995.

ELLRAM, L.M., SIFFERD, S.P. Purchasing: the cornerstone of the Total Cost of Ownership concept. Journal of Business Logistics 14(1), 163-184, 1993.

FARIS, C.W., ROBINSON, P.J., WIND, Y. Industrial Buying and Creative Marketing. Allyn \& Bacon, Boston, 1967.

FARMER, D. Developing Purchasing Strategies, Journal of Purchasing and Materials Management, 14: $6-11 ., 1978$.

FISHER, L. Industrial Marketing. Brandon, Princeton, 1970

FLOREZ-LOPEZ, R. Strategic supplier selection in the added-value perspective: A Cl approach. Information Sciences 177 (5), 1169-1179, 2007.

FORKER, L.B., MENDEZ, D. An analytical method for benchmarking best peer suppliers. International Journal of Operations and Production Management 21 (1-2), 195-209, 2001. 
FRAZIER, G.L., SPEKMAN, R.E., O'NEAL C.R. Just-in-time exchange relationships in industrial markets, Journal of Marketing, 52-67, 1988.

GABALLA, A.A.. Minimum cost allocation of tenders, Operational Research Quarterly 25/3, 389-398, 1974.

GANESHAN, R., TYWORTH, J.E., GUO, Y. Dual sourced supply chains: the discount supplier option. Transportation Research, 35, 11-23, 1999.

GARFAMY, R.M. A data envelopment analysis approach based on total cost of ownership for supplier selection. Journal of Enterprise Information Management 19 (6), 662-678, 2006.

GENCER, C., GÜRPINAR, D. Analytic network process in supplier selection: A case study in an electronic firm. Applied Mathematical Modeling 31 (11), 24752486, 2007.

GHODSYPOUR, S.H., O'BRIEN, C. The total cost of logistics in supplier selection, under conditions of multiple sourcing, multiple criteria and capacity constraint. International Journal of Production Economics 73 (1), 15-27, 2001.

GHOUDSYPOUR, S.H., O'BRIEN, C.O. A decision support system for supplier selection using an integrated analytic hierarchy process and linear programming. International Journal of Production Economics 56-57 (1-3), 199-212, 1998.

GONZALEZ, M., QUESADA, G., MONGE, C. Determining the importance of the supplier selection process in manufacturing: a case study, International Journal of Physical Distribution \& Logistics Management, Vol. 34 No. 6, pp. 492-504, 2004.

GOODWIN, P., WRIGHT, G. Decision Analysis for Management Judgment. Wiley, Chichester, 1992.

GOYAL, S.K. Comment on: A generalized quantity discount pricing model to increase supplier's profits, Management Science 33/12, 1635-36. Gregory, R.E. (1986), "Source selection: A matrix approach", Journal of Purchasing and Materials Management, 24-29, 1987.

GRANDO, A., SIANESI, A. Supply management: a vendor rating assessment. CEMS Business Review 1, 199-212, 1996.

GRANEMANN, S, GARTNER, I. Modelo Multicriterial para Escolha Modal/SubModal de Transporte. In: XV ANPET Congresso Pesquisa e Ensino em Transportes, ANPET. p. 337-345, 2000.

GREGORY, R.E. Source selection: a matrix approach. Journal of Purchasing and Materials Management 22 (2), 24-29, 1986. 
HA, S.H., KRISHNAN, R. A hybrid approach to supplier selection for the maintenance of a competitive supply chain. Expert Systems with Applications 34 (2), 1303-1311, 2008.

HAHN C.K., KIM, K.H., KIM J.S. Costs of competition: Implications for purchasing strategy, Journal of Purchasing and Materials Management, 2-7, 1986.

HAKANSSON, H., WOOTZ, B. Supplier selection in an international environment - An experimental study, Journal of Marketing Research XII, 46-51, 1975.

HALL, R.W. What's so scientific about MS/OR?, Interfaces 15, 40-45, 1985.

HANG HONGA, G., CHAN PARKB, S., SIK JANGA, D. MIN RHOC, H. An effective supplier selection method for constructing a competitive supply relationship, Expert Systems with Applications, Vol. 28 No. 4, pp. 629-39, 2005.

HINKLE, C.L., ROBINSON, P.J., GREEN, P.E. Vendor evaluation using cluster analysis, Journal of Purchasing, 49-58, 1969.

HO, CHRWAN-JYH, CARTER, P.L, Using vendor capacity planning in supplier evaluation, Journal of Purchasing and Materials Management, 23-30, 1988.

HOJUNG SHIN, V., COLLIER, D.A., WILSON, D.D. Supply management orientation and supplier/buyer performance. Journal of Operations Management, Vol. 18 No. 3, pp. 317-33.,2000.

HOLT, G.D. Which contractor selection methodology?. International Journal of Project Management 16 (3), 153-164, 1998.

HONG, G.H., PARK, S.C., JANG, D.S., RHO, H.M. An effective supplier selection method for constructing a competitive supply-relationship. Expert Systems with Applications 28 (4), 629-639, 2005.

HOU, J., SU, D. EJB-MVC oriented supplier selection system for mass customization. Journal of Manufacturing Technology Management 18 (1), 54- 71, 2007.

HUANG, S.H., KESKA, H. Comprehensive and configurable metrics for supplier selection. International Journal of Production Economics 105 (2), 510-523, 2007.

HWANG, H., MOON, D. H., SHINN, S. W., An EOQ model with quantity discounts for both purchasing price and freight cost, Computers and Operations Research 17/1, 73-78, 1990.

IAÑEZ, M, CUNHA, C. Uma metodologia para a seleção de um provedor de serviços logísticos. Prod., Dez 2006, vol.16, no.3, p.394-412. ISSN 0103-6513, 2006.

I-SHOU UNIVERSITY. A Study on the selection a third-party logistic provider via Fuzzy decision analysis, 2006 
JACKSON, G.C., Just-in-time production: Implications for logistics managers, Journal of Business Logistics 4/2, 1-19, 1983.

JACOBSON, R., AAKER, D.A. The strategic role of product quality, Journal of Marketing, 31-44, 1987.

JAIN, V., TIWARI, M.K., CHAN, F.T.S. Evaluation of the supplier performance using an evolutionary fuzzy-based approach. Journal of Manufacturing Technology Management 15 (8), 735-744, 2004.

JAYARAMAN, V., SRIVASTAVA, R. BENTON, W. Supplier selection and order quantity allocation: a comprehensive model, Journal of Supply Chain Management, Vol. 35 No. 2, pp. 50-8, 1999.

JORDAN, P.C. Purchasing decisions considering future price increases: An empirical approach, Journal of Purchasing and Materials Management, 25-30, 1987.

KAHRAMAN, C., CEBECI, U., ULUKAN, Z. Multi-criteria supplier selection using fuzzy AHP. Logistics Information Management 16 (6), 382-394, 2003.

KARPAK, B., KUMCU, E., KASUGANTI, R. An application of visual interactive goal programming: a case in vendor selection decisions. Journal of Multi-Criteria Decision Analysis 8, 93-105, 1999.

KARPAK, B., KUMCU, E., KASUGANTI, R.R. Purchasing materials in the supply chain: Managing a multi-objective task. European Journal of Purchasing and Supply Management 7 (3), 209-216, 2001.

KEENEY, R. L., GREGORY, R. S. Selecting attributes to measure the achievement of objective. Operations Research, 53, 1-11, 2002.

KEENEY, R. L. Common mistakes in making value trade-offs. Operations Research, 30, 803-838, 2002.

KEENEY, R. L. Value-Focused Thinking: Identifying decision opportunities and creating alternatives. Harvard University Press, Cambridge, Massachusetts, 1996.

KENNEY, R. L. Decisions with Multiple Objetives: Preferences and value tradeoffs. Cambridge University Press: Cambridge, 1993.

KHOO, L.P., TOR, S.B., LEE, S.S.G. The potential of intelligent software agents in the World Wide Web in the automated part procurement. International Journal of Purchasing and Materials Management 34 (1), 46-52, 1998.

KINGSMAN, B.G. Purchasing raw materials with uncertain fluctuating prices, European Journal of Operational Research 25, 358-372, 1986.

KIRKWOOD, C. W. Strategic Decision Making: Multiobjective decision analysis with spreadsheets. Wadsworth: Beltont-USA, 1997. 
KRALJIC, P. Purchasing must become supply management, Harvard Business Review, 109-117, 1983.

KRAUSE, D., PAGELL, M. CURKOVIC, S. Toward a measure of competitive priorities for purchasing, Journal of Operations Management, Vol. 19 No. 4, pp. 497-512, 2001.

KULL, T.J., TALLURI, S.A supply-risk reduction model using integrated multicriteria decision making. IEEE Transactions on Engineering Management 55 (3), 409-419, 2008.

KWONG, C.K., IP, W.H., CHAN, J.W.K. Combining scoring method and fuzzy expert systems approach to supplier assessment: A case study. Integrated Manufacturing Systems 13 (7), 512-519, 2002.

LAFORGE, L.R. MRP lot sizing with multiple purchase discounts, Computers and Operations Research 12/6, 579-587, 1985.

LAMBERSON, L.R., DIEDERICH D., WUORI, J. Quantitative vendor evaluation, Journal of Purchasing and Materials Management, 19-28, 1976.

LAMM, D.V., VOSE, L.C. Seller pricing strategies: A buyer's perspective, Journal of Purchasing and Materials Management, 9-13, 1988.

LAMMING, R.C., COUSINS, P.D., NOTMAN, D.M. Beyond vend or assessment. Relationship assessment programmes. European Journal of Purchasing and Materials Management 2 (4), 173-181, 1996.

LAU, H., LAU, K., FUNG, R., CHAN, F. IP, R. A virtual case benchmarking scheme for vendors' performance assessment, Benchmarking: An International Journal, Vol. 12 No. 1, pp. 61-80, 2005.

LAU, H.C.W., LEE, C.K.M., HO, G.T.S., PUN, K.F., CHOY, K.L. A performance benchmarking system to support supplier selection. International Journal of Business Performance Management 8 (2-3), 132-151, 2006.

LEE, E-K., HA, S. KIM, S-K. Supplier selection and management system considering relationships in supply chain management, IEEE Transactions on Engineering Management, Vol. 47 No. 4, pp. 307-18, 2001.

LEE, H.L., ROSENBLATT, M.J. A generalized quantity discount pricing model to increase supplier's profits, Management Science 32/9, 1177-1185, 1986.

LEOPOULOS, V. KIRYTOPOULOS, K. Risk management: a competitive advantage in the purchasing function, Production Planning \& Control, Special Issue: Purchasing and e-Procurement, Vol. 15 No. 7, pp. 678-87, 2004.

LEVY, M., CRON, W., NOVACK, R. A decision support system for determining a quantity discount pricing policy, Journal of Business Logistics 6/2, 110-141, 1985. 
LI, C.C., FUN, Y.P., HUNG, J.S. A new measure for supplier performance evaluation. IIE Transactions on Operations Engineering 29, 753-758, 1997.

LIAO, Z., RITTSCHER, J.A multi-objective supplier selection model under stochastic demand conditions. International Journal of Production Economics 105 (1), 150-159, 2007.

LIU, F.H.F., HAI, H.L. The voting analytic hierarchy process method for selecting supplier. International Journal of Production Economics 97 (3), 308-317, 2005.

LIU, J., DING, F.Y., LALL, V. Using Data Envelopment Analysis to compare suppliers for supplier selection and performance improvement. Supply Chain Management: An International Journal 5 (3), 143-150, 2000.

MANDAL, A., DESHMUKH, S. G. Vendor selection using interpretive structural modeling (ISM)", International Journal of Operations \& Production Management, Vol. 14 No. 6, pp.52-59.,1994.

MANOOCHEHRI, G.H. Suppliers and the just-in-time concept, Journal of Purchasing and Materials Management 16-21, 1984.

MARKOWSKI, C.A., MARKOWSKI, E.P. An alternative criterion for the quantity discount decision, Journal of Purchasing and Materials Management, 131-34, 1988.

MARTINS, V , FERNANDES, J , MARUYAMA, U, MACIEL, M. Tomada De Decisão Em Gestão De Manutenção Com Base No Método AHP, 2009. Belo Horizonte. 640 Congresso Anual da Associação Brasileira de Materiais. São Paulo : Associação Brasileira de Materiais. v. 1. p. 1-11, 2009.

MASELLA, C., RANGONE, A. A contingent approach to the design of vendor selection systems for different types of co-operative customer/supplier relationship, International Journal of Operations \& Production Management, Vol. 20 No.1, pp.70-84., 2000.

MAZURAK, R.E., RAO, S.R., SCOTTON, D.W. Spreadsheet software applications in purchasing, Journal of Purchasing and Materials Management, 8-16, 1985.

MCFILLEN, J.M., RECK, R.R., BENTON, W.C. An experiment in purchasing negotiations, Journal of Purchasing and Materials Management, 2-8, 1983.

MCGINNIS, M.A., HOLLON, C.J. Packaging: Organization, objectives, and interactions, Journal of Business Logistics 1/1, 1-61, 1978.

MENDOZA, A., SANTIAGO, E., RAVINDRAN, A.R. A three-phase multicriteria method to the supplier selection problem. International Journal of Industrial Engineering 15 (2), 195-210, 2008. 
MENDOZA, A., VENTURA, J.A. An effective method to supplier selection and order quantity allocation. International Journal of Business and Systems Research $2(1), 1-15,2008$.

MIN, H. International supplier selection: a multi-attribute utility approach. International Journal of Physical Distribution \& Logistics Management 24 (5), 24-33, 1994.

MONAHAN, J.P.A quantity discount pricing model to increase vendor profits, Management Science 30/6, 720-726, 1984.

MONCZKA, R.M., GIUNIPERO, L.C., RECK, R.F. Perceived importance of supplier information, Journal of Purchasing and Materials Management, 21-29, 1981.

MONCZKA, R.M., TRECHA, S.J. Cost-based supplier performance evaluation, Journal of Purchasing and Materials Management, 2-7, 1988.

MOORE, D.L., FEARON, H.E. Computer-assisted decision-making in purchasing, Journal of Purchasing 9/4, 5-25, 1972.

MORLACCHI, P. Small and medium enterprises in supply chain: a supplier evaluation model and some empirical results. Proceedings IFPMM Summer School, August, Saltzburg, 1997.

MORLACCHI, P. Vendor evaluation and selection: the design process and a fuzzy-hierarchical model. Proceedings of 8th IPSERA Conference, Dublin, 1999.

MORLACCHI, P., PAVESI, S., SAVOLDELLI, A. Sourcing relationships within the supply chain of Italian machinery sector: supplier selection as a first step to manage supply chain. Proceedings of IFIPWG 5.7 Conference, $15^{\text {th }}$-18th September, Ascona, Switzerland, 1997.

MURALIDHARAN, C., ANANTHARAMAN, N., DESHMUKH, S.G. A multi-criteria group decision-making model for supplier rating. Journal of Supply Chain Management 38 (4), 22-33, 2002.

NARASIMHAN, R. An analytical approach to supplier selection, Journal of Purchasing and Materials Management,27-32, 1983.

NARASIMHAN, R., STOYNOFF, L.K. Optimizing aggregate procurement allocation decisions, Journal of Purchasing and Materials Management, 23-30, 1986.

NARASIMHAN, R., TALLURI, S., MAHAPATRA, S.K. Multiproduct, multicriteria model for supplier selection with product life-cycle considerations. Decision Sciences 37 (4), 577-603, 2006. 
NARASIMHAN, R., TALLURI, S., MENDEZ, D. Supplier evaluation and rationalization via data envelopment analysis: An empirical examination. Journal of Supply Chain Management 37 (3), 28-37, 2001.

NEWMAN, R.G. Insuring quality: Purchasing's role, Journal of Purchasing and Materials Management, 14-20, 1988a.

NEWMAN, R.G. The buyer-supplier relationship under just-in-time, Production and Inventory Management Journal, 45-50, 1988b.

NEWMAN, R.G., SCODRO, J. Price analysis for negotiation, Journal of Purchasing and Materials Management, 8-14, 1988.

NG, S.T., SKITMORE, R.M.CP-DSS: decision support system for contractor prequalification. Civil Engineering Systems: Decision Making Problem Solving 12 (2), 133-160, 1995.

NG, W.L. An efficient and simple model for multiple criteria supplier selection problem. European Journal of Operational Research 186 (3), 1059-1067, 2008.

NYDICK, R.L., HILL, R.P. Using the Analytic Hierarchy Process to structure the supplier selection procedure. International Journal of Purchasing and Materials Management 28 (2), 31-36, 1992.

OGDEN, J.A., PETERSEN, K.J., CARTER, J.R., MONCZKA, R.M. "Supply Management Strategies for the Future: A Delphi Study", The Journal of Supply Chain Management, Summar, pp. 29-48.,2005.

OXENFELDT, A. Cost Benefit Analysis for Executive Decision Making: the Danger of Plain Common Sense. Amacon, New York, 1979.

PAN, A.C. Allocation of order quantity among suppliers, Journal of Purchasing and Materials Management, 36-39, 1989.

PAPAGAPIOU, A., MINGERS, J., THANASSOULIS, E. Would you buy a used car with DEA ?. OR Insight 10 (1), 13-19, 1996.

PAYNE, H.L. Development of a supplier evaluation technique utilizing financial information, Journal of Purchasing 6/4, 21-34, 1970.

PERÇIN, S. An application of the integrated AHP-GP model in supplier selection. Measuring Business Excellence 10 (4), 34-49, 2006.

PETERSEN, K. J., OGDEN J. A., CARTER P. L. B2B E-Marketplaces: An Empirical Investigation of Functionality. International Journal of Physical Distribution and Logistics Management, Vol. 37, No. 1, pp. 4-18.,2007.

PETRONI, A., BRAGLIA, M. Vendor selection using principal component analysis. The Journal of Supply Chain Management: A Global Review of Purchasing and Supply 36 (2), 63-69, 2000. 
PHILLIPS, L., PHILLIPS, M. Facilitated work groups: theory and practice, Journal of Operational Research Society, 44, 533-549, 1993.

PINSONEAULT, A., KRAEMER, K.L. The effects on electronic meetings on group processes and outcomes: an assessment of the empirical research. European Journal of Operational Research 46, 143-161, 1989.

RAMANATHAN, R. Supplier selection problem: Integrating DEA with the approaches of total cost of ownership and AHP. Supply Chain Management: An International Journal 12 (4), 258-261, 2007.

ROBERTS, B.J. A vendor delivery rating model, Journal of Purchasing and Materials Management, 12-16,1978.

ROEHM, H.A., CRITCHFIELD, M.A., CASTELLANO, J.F. Yes, ABC works with purchasing too, Journal of Accountancy, November, pp.58-62, 1992.

RONEN, B., TRIETSCH, D. A decision support system for purchasing management of large projects, Operations Research 36/6, 882-890, 1988.

RONEN, B., TRIETSCH, D. A decision support system for purchasing management of large projects. Operations Research 36 (6),882-890, 1988.

ROODHOOFT, F., KONINGS, J., Vendor selection and evaluation an Activity Based Costing approach. European Journal of Operational Research, Elsevier, vol. 96(1), pages 97-102, January, 1997.

ROSENTHAL, E.C., ZYDIAK, J.L. CHAUDRY, S.S. 'Vendor selection with bundling, Decision Sciences, Vol. 26 No. 1, January-February, pp. 35-48, 1995.

ROSS, A., BUFFA, F.P., DRÖGE, C., CARRINGTON, D. Supplier evaluation in a dyadic relationship: An action research approach. Journal of Business Logistics 27 (2), 75-102, 2006.

RUBIN, P.A., DILTS, D.M., BARRON, B.A. Economic order quantities with quantity discounts: Grandma does it best, Decision Sciences 14, 270-281, 1983.

RUSSO, J.E., SCHOEMAKER, P.J.H. Winning Decisions: Getting it right first time. Currency Doubleday: New York, 2002.

SAATY, T.L. The Analytic Hierarchy Process. McGraw-Hill, New York, 1980.

SADRIAN, A.A. YOON, Y.S. A procurement decision support system in business volume discount environments. Operations Research, Vol. 42 No. 1, JanuaryFebruary, pp. 14-23, 1994.

SAEN, R.F. A decision model for selecting technology suppliers in the presence of nondiscretionary factors. Applied Mathematics and Computation 181 (2), 1609-1615, 2006. 
SAEN, R.F. A new mathematical approach for supplier selection: Accounting for non-homogeneity is important. Applied Mathematics and Computation 185 (1), 84-95, 2007b.

SAEN, R.F. Suppliers selection in the presence of both cardinal and ordinal data. European Journal of Operational Research 183 (2), 741-747, 2007 a.

SARKAR, A., MOHAPATRA, P.K.J. Evaluation of supplier capability and performance: A method for supply base reduction. Journal of Purchasing and Supply Management 12 (3), 148-163, 2006.

SARKIS, J., TALLURI, S. A model for strategic supplier selection. In: Leenders, M. (Ed.), Proceedings of the 9th international IPSERA Conference. Richard Ivey Business School, London, Ontario, pp. 652-661, 2000.

SCHRAMM, F. Modelo de Apoio Decisão para Seleção e Avaliação de Fornecedores da Construção Civil. Mestrado em Engenharia de Produção Universidade Federal Pernambuco, 2008.

SEVKLI, M., KOH, S.C.L., ZAIM, S., DEMIRBAG, M., TATOGLU, E. An application of data envelopment analytic hierarchy process for supplier selection: A case study of BEKO in Turkey. International Journal of Production Research 45 (9), 1973-2003, 2007.

SEYDEL, J. Data envelopment analysis for decision support. Industrial Management and Data Systems 106 (1), 81-95, 2006.

SEYDEL, J. Supporting the paradigm shift in vendor selection: Multicriteria methods for sole-sourcing. Managerial Finance 31 (3), 49-66, 2005.

SHANK, J. K. GOVINDARAJAN, V. Strategic cost management: the value chain perspective. Journal of Management Accounting Research (4): 179-197, 1992b.

SHANK, J. K. GOVINDARAJAN, V.. Strategic cost management and the value chain. Journal of Cost Management (Winter): 5-21, 1992a.

SHARMA, D., BENTON, W.C., SRIVASTAVA, R. Competitive strategy and purchasing decisions. In: Proceedings of the 1989 Annual Conference of the Decision Sciences, Institute,1088-1090, 1989.

SHETH, J.N. A model of industrial buyer behavior, Journal of Marketing, 50-56, 1973.

SHORE, B. A micro-computer based purchasing information system, Journal of Purchasing and Materials Management, 18-12, 1981.

SMYTKA, D.L., CLEMENS, M.W. Total cost supplier selection model: a case study. International Journal of Purchasing and Materials Management 29 (1), 42-49, 1993. 
SOARES, A. Emprego do Método Electre III na Escolha de Prestadoras de Serviço para Transporte de Materiais Perigosos, Graduação em Engenharia de Produção Universidade Federal Fluminense, Brasil, 2001.

SOUKUP, W.R. Supplier selection strategies. Journal of Purchasing and Materials Management 23 (3), 7-12, 1987.

SPEKMAN, R. E., HILL, R. A strategy for effective procurement in the 1980s. Journal of Materials Management, 16, 1-3,1980.

SVENSSON, G. Supplier segmentation in the automotive industry: a dyadic approach of a managerial model, International Journal of Physical Distribution \& Logistics Management, Vol. 34 No. 1, pp. 12-38, 2004.

TALLURI, S. A buyer-seller game model for selection and negotiation of purchasing bids. European Journal of Operational Research 143 (1), 171-180, 2002.

TALLURI, S., BAKER, R.C. A multi-phase mathematical programming approach for effective supply chain design. European Journal of Operational Research 141 (3), 544-558, 2002.

TALLURI, S., NARASIMHAN, R.A note on "a methodology for supply base optimization". IEEE Transactions on Engineering Management 52 (1), 130-139, 2005.

TALLURI, S., NARASIMHAN, R. Vendor evaluation with performance variability: A max-min approach. European Journal of Operational Research 146 (3), 543552, 2003.

TALLURI, S., NARASIMHAN, R., NAIR, A. Vendor performance with supply risk: A chance-constrained DEA approach. International Journal of Production Economics 100 (2), 212-222, 2006.

TALLURI, S., NARASIMHAN, R.A methodology for strategic sourcing. European Journal of Operational Research 154 (1), 236-250, 2004.

TALLURI, S., SARKIS, J. A model for performance monitoring of suppliers. International Journal of Production Research 40 (16), 4257-4269, 2002.

TALLURI, S., VICKERY, S.K., NARAYANAN, S. Optimization models for buyer supplier negotiations. International Journal of Physical Distribution and Logistics Management 38 (7), 551-561, 2008.

TENG, S. JARAMILLO, H. A model for evaluation and selection of suppliers in global textile and apparel supply chains, International Journal of Physical Distribution \& Logistics Management, Vol. 35 No. 7, pp. 503-23, 2005. 
THOMPSON, K. Scaling evaluative criteria and supplier performance estimates in weighted pint pre-purchase decision models. International Journal of Purchasing and Materials Management 27 (1), 27-36, 1991.

THOMPSON, K. Vendor profile analysis. Journal of Purchasing and Materials Management 26 (1), 11-18, 1990.

THOMPSON, K., MITCHELL, H., KNOX, S. Organizational buying behavior in changing times. European Management Journal 16 (6), 698-705, 1998.

TIMMERMAN, E. An approach to vendor performance evaluation. Journal of Purchasing and Supply Management 1, 27-32, 1986.

TRELEVEN, M. Single sourcing: A management tool for the quality supplier, Journal of Purchasing and Materials Management, 19-24, 1987.

TURNER, I. An independent system for the evaluation of contract tenders, Journal of Operational Research Society 39/6, 551-561, 1988.

WADHWA, V. RAVINDRAM, R. Vendor selection in outsourcing, Computers \& Operations Research, Vol. 34 No. 12, pp. 3725-37, 2007.

WAGNER, J., ETTENSON, R., PARRISH, J. Vendor selection among retail buyers: An analysis by merchandise division, Journal of Retailing 65/1, 58-77, 1989.

WANG, G., HUANG, S.H., DISMUKES, J.P. Product-driven supply chain selection using integrated multi-criteria decision-making methodology. International Journal of Production Economics 91 (1), 1-15, 2004.

WANG, G., HUANG, S.H., DISMUKES, J.P.. Manufacturing supply chain design and evaluation. International Journal of Advanced Manufacturing Technology 25 (12), 93-100, 2005.

WEBER, C.A. A data envelopment analysis approach to measuring vendor performance, Supply Chain Management, Vol. 1 No.1, pp. 28-39, 1996.

WEBER, C.A. DESAI, A. Determination of paths to vendor market efficiency using parallel coordinates representation: a negotiation tool for buyers. European Journal of Operational Research, No. 90, pp. 142-55, 1996.

WEBER, C.A., CURRENT, J.R., DESAI, A. Non-cooperative negotiation strategies for vendor selection. European Journal of Operational Research 108, 208-223, 1998.

WEBER, C.A., ELLRAM, L.M. Supplier selection using multi-objective programming: a decision support system approach. International. Journal of Physical Distribution\& Logistics Management 23 (2), 3-14, 1992.

WEBER, C.A.. A decision support system using multicriteria techniques for vendor selection. University Microfilms International, Ann Arbor, MI, 1991. 
WIETERS, C.D. Influences on the design and use of vendor performance rating systems, Journal of Purchasing and Materials Management, 31-35, 1976.

WILLIAMS, R.F. Purchasing the technological product: selecting and weighting criteria for the inherently complex new product. University Microfilms International, Ann Arbor, MI, 1984.

WILLIS, T.H., HUSTON, C.R., POHLKAMP, F. Evaluation measures of just-in-time supplier performance. Production and Inventory Management. Journal 2nd quarter, $1-5,1993$.

VINCKE, P. Multi-Criteria Decision Aid. Wiley, New York, 1986.

WIND, Y., ROBINSON, P.J. The determinants of vendor selection: The evaluation function approach, Journal of Purchasing and Materials Management, 29-41, 1968.

VOKURKA, R.J., CHOOBINEH, J., VADI, L. A prototype expert system for the evaluation and selection of potential suppliers. International Journal of Operations and Production Management 16 (12), 106-127, 1996.

VONDEREMBSE, M.A., TRACEY, M. The impact of supplier selection criteria and supplier involvement on manufacturing performance. The Journal of Supply Chain Management: a Global Review of Purchasing and Supply 35 (3), 33-39, 1999.

WU, T., SHUNK, D., BLACKHURST, J., APPALLA, R. AIDEA: A methodology for supplier evaluation and selection in a supplier-based manufacturing environment. International Journal of Manufacturing Technology and Management 11 (2), 174-192, 2007.

XIA, W., WU, Z. Supplier selection with multiple criteria in volume discount environments. OMEGA - International Journal of Management Science 35 (5), 494504, 2007.

YAN, H. WEI, Q. Determining compromise weights for group decision making. Journal of the Operational Research Society, Vol. 53 No. 6, pp. 680-7, 2002.

YANG, C.C., CHEN, B.S. Supplier selection using combined analytical hierarchy process and grey relational analysis. Journal of Manufacturing Technology Management 17 (7), 926-941, 2006.

YIN, R.K. Case Study Research: Design and Methods. Sage Publications, Newbury Park, 1989.

YOSHIZAKI, H, MONTIBELLER, G. A Framework for Locating Logistica Facilities with Optimisation and Multi-Critério Value Analysis. LSEOR Working Paper 09111, 2009.

ZENS, G. Purchasing and the Management of Materials. Wiley, New York, 1981. 


\section{GLOSSÁRIO}

4PL - Integrador que une os recursos, capacidades e tecnologia de outras organizações para desenhar e gerenciar uma cadeia de fornecimento eficiente.

Bidding (Bid) - Denominação utilizada para licitações, processos de seleção e cotações aonde o objetivo é escolha da melhor oferta.

Budget - Plano que demonstra uma estimativa das receitas, despesas e custos relacionados com uma atividade planejada. Fornece a base para o controle da operação.

Horário de Corte - Período entre o envio do pedido pelo cliente ao prestador de serviços logísticos e o horário de coleta dos veículos para entrega.

Lead Time -Termo amplamente utilizado no mercado de logística que significa o tempo de entrega, normalmente em dias, entre o embarque da mercadoria (coleta) e a entrega ao destinatário final do trajeto de transporte contratado.

LTL - Do inglês Less than Truckload, termo usado pelo transporte rodoviário de carga para designar embarques fracionados que não ocupam a capacidade disponível, em oposição a cargas completas que ocupam todo a capacidade de carga dos caminhões.

Outbound - Termo em inglês utilizado para definir operações de distribuição para produtos acabados.

Trade-off - O termo trade-off ou tradeoff é uma expressão que define uma situação em que há conflito de escolha. Ele se caracteriza em uma ação que visa a resolução de problema mas acarreta outro, obrigando uma escolha. Ocorre quando se abre mão de algum bem ou serviço distinto para se obter outro bem ou serviço distinto. 
V•I•S•A - Visual Interactive Sensitivity Analysis

Vendas Online - Termo utilizado para definir um tipo de transação comercial feita especialmente através da internet. 


\section{APÊNDICE A - INFORMAÇÕES SOBRE O MERCADO DE LOGÍSTICA RELATIVAS AO PROBLEMA}

Em relação aos custos despendidos no mercado de logística, os custos com transportes normalmente representam a sua maior parcela. Uma adaptação aos dados divulgados pelo centro de estudos em logística do Instituto de Pesquisas e Pós-graduação da Universidade Federal do Rio de Janeiro (CEL/Coppead) indicam que em 2006 os custos logísticos estavam divididos em: 4,3\% administrativos, 5,1\% armazenagem, 31,6\% gestão de estoque e 59,0\% transportes.

Analisando os modais de transportes em operação no Brasil, o rodoviário tem larga representatividade pois de acordo com a NTC \& Logística dos R $\$ 154,8$ bilhões gastos com transporte em 2006, $\mathrm{R} \$ 128,9$ bilhões foram gastos no modal rodoviário, representando assim 83,3\% do total (CEL/COPPEAD, 2008).

O mercado nacional de transporte rodoviário de cargas possui 62.789 empresas de transporte de cargas IBGE/PAS (2005), 144.188 empresas frotistas ANTT (2008), 765.930 autônomos ANTT (2008) e 685 cooperativas ANTT (2008), (NTC\&LOGÍSTICA, 2009).

Dentro do modal rodoviário a crescente escolha pelo modelo fracionado (LTL) se deve pela maior representatividade e importância desta modalidade frente às demais nas operações de outbound. Estas operações por estarem ligadas diretamente ao consumidor final representam na maioria das vezes a etapa mais crítica da logística.

No mercado americano, dados revelam que em 2008 cerca de 18\% dos custos com transporte rodoviário seriam no sistema fracionado (IHS Global Insight). Mais do que isso, existe uma tendência de aumento no fracionamento da carga, pois a busca por prazos mais curtos e a necessidade de redução de custos conduz ao compartilhamento dos recursos de transporte. Outra tendência em prol do fracionamento, advinda com a massificação da internet, é a busca das empresas por atingir de forma direta seus consumidores. 


\section{APÊNDICE B - QUADRO RESUMO DAS FASES, ETAPAS E MODELOS AVALIADOS POR DE BOER ET AL. (2001)}

Figura 1AB - Quadro resumo das fases, etapas e modelos avaliados por De Boer et al. (2001)

\begin{tabular}{|c|c|c|c|}
\hline Fase & Método/Etapa & Trabalhos & Análise de De Boer et al. (2001) \\
\hline \multirow{3}{*}{$\begin{array}{l}\text { Definição do problema e } \\
\text { formulação de critérios }\end{array}$} & $\begin{array}{c}\text { Reconhecimento do } \\
\text { problema na seleção de } \\
\text { fornecedores }\end{array}$ & Nenhum & \\
\hline & Formulação de critérios & Mandal e Deshmukh (1994) & $\begin{array}{l}\text { Propõem uma modelagem estrutural interpretativa (ISM) como uma técnica com base no } \\
\text { julgamento do grupo para identificar e sintetizar as relações entre os critérios de escolha de } \\
\text { fornecedores através de um modelo gráfico. Tal modelo se propõe a auxiliar o comprador, } \\
\text { separando os critérios dependentes dos critérios independentes. Os critérios dependentes são } \\
\text { importantes na fase final de escolha, enquanto os critérios independentes são importantes na } \\
\text { seleção de fornecedores aceitáveis. }\end{array}$ \\
\hline & & $\begin{array}{l}\text { Vokurka, Choobineh e Vadi } \\
\text { (1996) }\end{array}$ & $\begin{array}{l}\text { Desenvolveu um sistema especialista, que abrange várias fases do processo de seleção de } \\
\text { fornecedores, entre as quais a formulação dos critérios de seleção do fornecedor. A base } \\
\text { conceitual deste sistema especialista é desenvolvida usando a literatura existente e a } \\
\text { experiência prática de um gerente de compras sênior. }\end{array}$ \\
\hline \multirow{4}{*}{$\begin{array}{l}\text { Pré-qualificação de } \\
\text { fornecedores desejáveis }\end{array}$} & Métodos categóricos & $\begin{array}{c}\text { Zens (1981) e Timmerman } \\
(1986)\end{array}$ & $\begin{array}{l}\text { Modelos qualitativos baseados em dados históricos, experiência de compra e grupo de } \\
\text { critérios. Os fornecedores são divididos em três categorias (positivo, neutro ou negativo). }\end{array}$ \\
\hline & DEA & $\begin{array}{l}\text { Weber e Ellram (1992), } \\
\text { Weber e Desai (1996), } \\
\text { Weber et al. (1998), } \\
\text { Papagapiou et al. (1996) e } \\
\text { Liu et al. (2000) }\end{array}$ & $\begin{array}{l}\text { Além de qualificar fornecedores, o DEA pode ser usado como uma ferramenta de } \\
\text { negociação com fornecedores ineficientes. }\end{array}$ \\
\hline & Análise de agrupamento & $\begin{array}{l}\text { Hinkle et al. (1969) e Holt } \\
\text { (1998) }\end{array}$ & $\begin{array}{l}\text { Método estatistico básico que utiliza um algoritmo de classificação para agrupar uma série de } \\
\text { itens que são descritos por um conjunto de atributos de pontuação numérica, em um grupo, } \\
\text { de tal forma que os diferenciais entre os itens dentro de um cluster são minimos e os } \\
\text { diferenciais entre os itens de diferentes grupos são máximos. Obviamente, a análise de } \\
\text { agrupamento também pode ser aplicada a um grupo de fornecedores que são descritos por } \\
\text { pontuação de acordo com alguns criterios. O resultado é uma classificação de fornecedores } \\
\text { em grupos de fornecedores comparáveis. }\end{array}$ \\
\hline & Sistemas CBR & Ng et al. (1995) & $\begin{array}{l}\text { Categoria de abordagens com inteligência artificial (IA). Basicamente, um sistema CBR é } \\
\text { um software orientado em uma base de dados que fornece ao decisor informações úteis } \\
\text { baseadas em experiências semelhantes e situações decisórias já tomadas. }\end{array}$ \\
\hline \multirow{9}{*}{$\begin{array}{l}\text { Escolha final do } \\
\text { fornecedor }\end{array}$} & Ponderação linear & $\begin{array}{l}\text { Zenz (1981) e Timmerman } \\
\text { (1986) }\end{array}$ & $\begin{array}{l}\text { Utiliza pontuações para os critérios aonde o maior peso indica um maior valor relativo. } \\
\text { Avaliações sobre os critérios são multiplicadas por seus pesos e somadas para obter um } \\
\text { valor único para cada fornecedor. O fornecedor, com a mais alta classificação global, pode } \\
\text { ser selecionado. }\end{array}$ \\
\hline & Outranking & De Boer et al. (1998) & $\begin{array}{l}\text { Durante os últimos } 10 \text { a } 15 \text { anos uma grande variedade de modelos, ligeiramente diferentes, } \\
\text { de ponderação linear foi sugerida. Este caso diz respeito à natureza compensatória do } \\
\text { modelo de ponderação linear. Em um modelo compensatório um valor alto em um critério } \\
\text { pode compensar uma baixa avaliação em outro critério, enquanto em modelos não- } \\
\text { compensatórios diferentes niveis minimos para cada critério são necessários. Esta } \\
\text { abordagem pode ser descrita como "quase" compensatória. }\end{array}$ \\
\hline & $\begin{array}{l}\text { Modelo de avaliação não } \\
\text { compensatório }\end{array}$ & Grando e Sianesi (1996) & $\begin{array}{l}\text { Este modelo não combina avaliações em critérios diferentes de forma a compor uma } \\
\text { avaliação geral. Neste caso, existem apenas informações separadas para a tomada de } \\
\text { decisão. }\end{array}$ \\
\hline & $\begin{array}{l}\text { Variações da ponderação } \\
\text { linear }\end{array}$ & $\begin{array}{l}\text { Gregory (1986) e Soukoup } \\
\text { (1987) }\end{array}$ & $\begin{array}{l}\text { A primeira aplicação apresenta dois métodos de classificação para os fornecedores que } \\
\text { receberem a pontuação máxima e o segunda propõe uma abordagem baseada em simulação } \\
\text { para explicar a incerteza em relação à demanda para um produto ou serviço adquirido. }\end{array}$ \\
\hline & AHP & $\begin{array}{l}\text { Nydick e Hill (1992), } \\
\text { Barbarosoglu e Yazgaç } \\
\text { (1997), Narasimhan (1983) } \\
\text { e Masella e Rangone (2000) }\end{array}$ & $\begin{array}{l}\text { Esta abordagem contorna a dificuldade de ter que fornecer estimativas para os pesos dos } \\
\text { critérios e avaliações de fornecedores. Em vez disso, usando o AHP, o comprador é } \\
\text { obrigado a dar apenas de forma verbal, demonstrações qualitativas sobre o valor relativo de } \\
\text { um critério versus outro critério e de forma semelhante quanto à preferência em relação a } \\
\text { um fornecedor contra outro em um determinado critério. }\end{array}$ \\
\hline & ANP & Sarkis e Talluri (2000) & $\begin{array}{l}\text { Propõem a utilização do processo de análise de rede (ANP), que pode ser considerada } \\
\text { como uma versão mais sofisticada do modelo AHP. }\end{array}$ \\
\hline & $\begin{array}{l}\text { Comparações entre os } \\
\text { fornecedores }\end{array}$ & Willis et al. (1993) & $\begin{array}{l}\text { Este modelo mede cada critério de acordo com sua unidade especifica de análise para } \\
\text { produzir a decisão final. }\end{array}$ \\
\hline & Técnicas estatisticas & $\begin{array}{l}\text { Williams (1984), Min (1994), } \\
\text { Petroni e Braglia (2000) e } \\
\text { Thompson }(1990,1991)\end{array}$ & $\begin{array}{l}\text { A primeira aplicação propõe a utilização da análise conjunta através de uma derivação da } \\
\text { proposta de pesos e critérios, o segundo e o terceiro trabalhos aplicam o método } \\
\text { "indifference trade offf" aonde analisam o comportamento dos componentes principais } \\
\text { para a mesma finalidade. Embora as técnicas sejam diferentes todas têm em comum o } \\
\text { aspecto que o comprador não precisa fornecer pesos numéricos precisos para os critérios. O } \\
\text { último trabalho propõe a simulação de Monte Carlo e a técnica de pontuação "Thurston Case } \\
\mathrm{V} \text { ". Novamente, o comprador não tem que definir os critérios de pesos e atribuir pontuações } \\
\text { de desempenho sobre esses critérios, ao invés disso, basta dar intervalos de pontuações ou } \\
\text { simplesmente classificar de forma qualitativa. No entanto, a utilização destes métodos } \\
\text { estatisticos não produz um processo claro para a maioria dos usuários e o tornam bastante } \\
\text { moroso. }\end{array}$ \\
\hline & Teoria Fuzzy (FST) & $\begin{array}{l}\text { Morlacchi (1997), Morlacchi } \\
\text { (1999), Li et al. (1997) e } \\
\text { Holt (1998) }\end{array}$ & $\begin{array}{l}\text { Este modelo oferece uma maneira matematicamente precisa de modelagem de preferências } \\
\text { estabelecendo pesos de acordo com o nivel de desempenho em cada um dos critérios. FST } \\
\text { pode ser combinada com outras técnicas para melhorar a qualidade do resultado final. Um } \\
\text { exemplo é apresentado pela primeira citação que desenvolveu um modelo que combina o } \\
\text { uso do Fuzzy com o AHP. Em um posterior desenvolvimento dos trabalhos o mesmo autor } \\
\text { em } 1999 \text { enfoca o processo de concepção do modelo apontando as vantagens e } \\
\text { desvantagens do uso de técnicas de abordagens hibridas. Além disso, os outros dois autores } \\
\text { discutem a aplicação do FST na escolha do fornecedor. }\end{array}$ \\
\hline
\end{tabular}


11 APÊNDICE C - MODELO DE PLANILHA PARA OBTENÇÃO DE DADOS DOS FORNECEDORES

Figura 1AC - Planilha de Obtenção das informações utilizada no Estudo de Caso 1

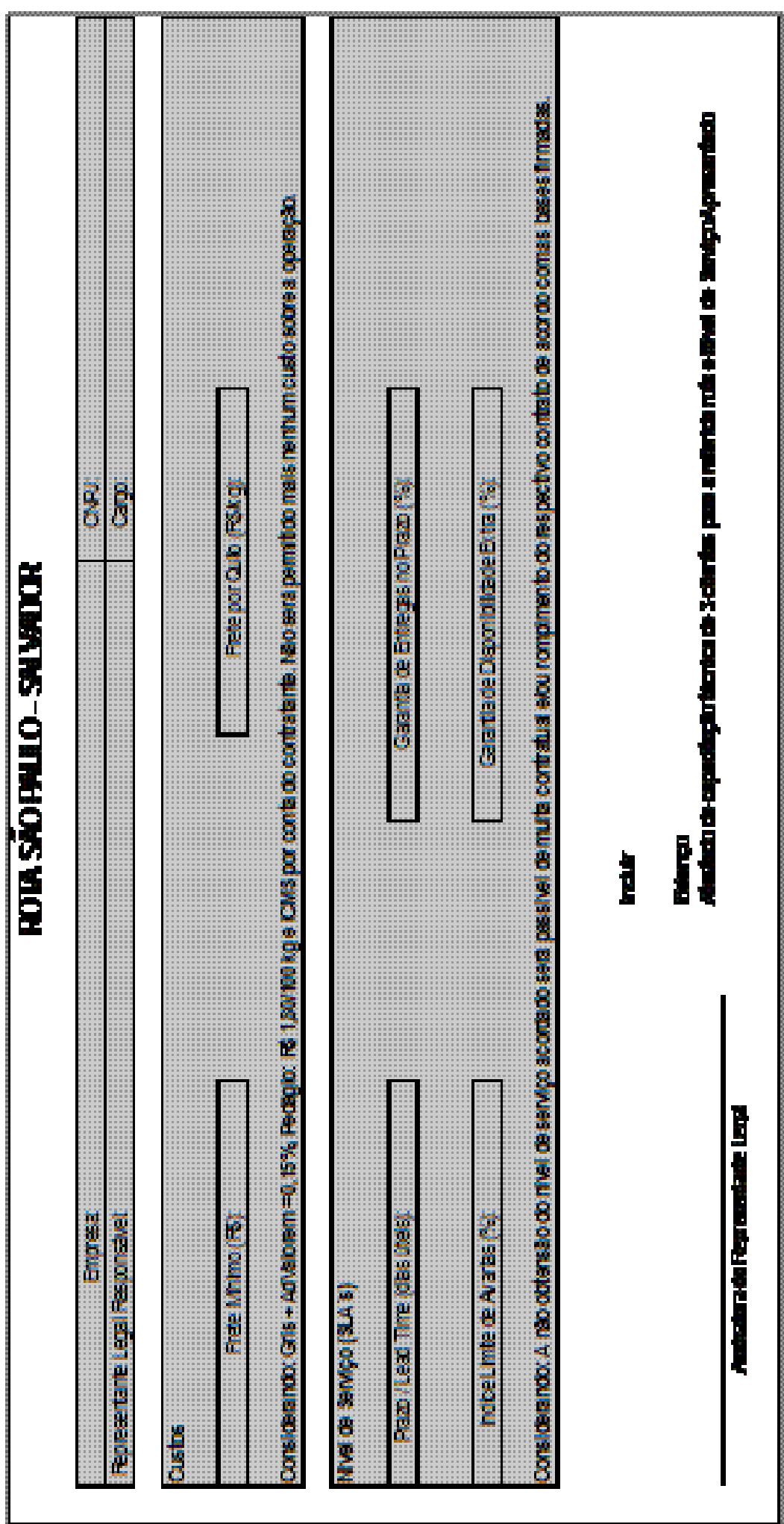


Figura 2AC -Visão Geral da Planilha de Obtenção das informações utilizada no Estudo de Caso 2 (Pasta - Custos Armazenagem)

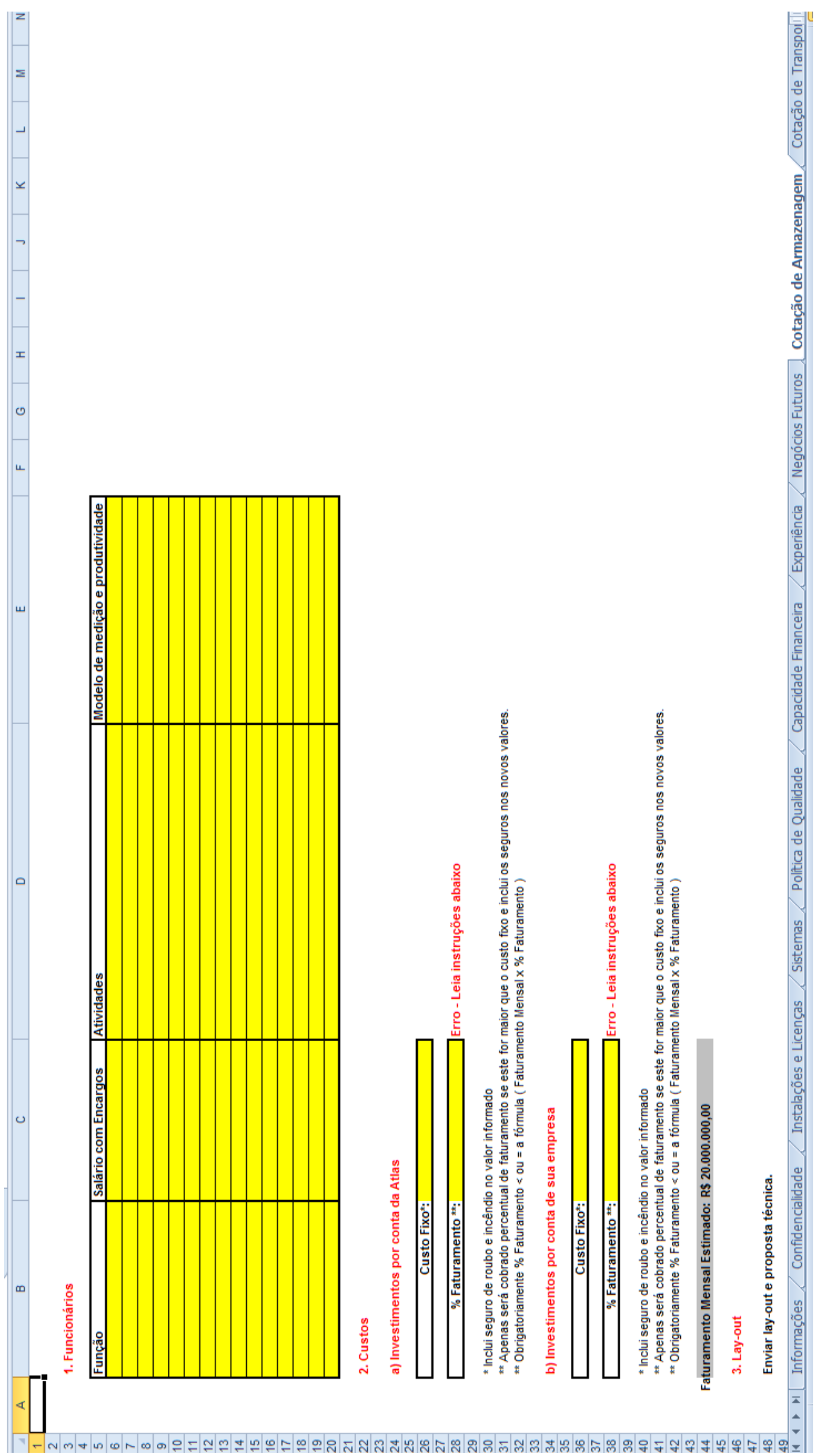




\section{APÊNDICE D - PREMISSAS CONSIDERADAS NOS ESTUDOS DE CASO}

\section{Estudo de Caso 1 - Seleção de Fornecedores de Transporte Fracionado (LTL)}

Seguem as premissas que foram avaliadas, definidas e utilizadas pelos analistas durante a fase de definição e estruturação do problema.

> Área de Atuação: O levantamento de dados foi preenchido considerando as entregas efetuadas na região metropolitana de Salvador. Como grande parte das entregas no estado tem destino os distribuidores e atacadistas presentes nesta região, que se responsabilizam pelas entregas porta a porta, trata-se de mais de 95\% do movimento no estado.

> Produto: Bens de consumo, com valor agregado médio de $\mathrm{R} \$ 20,00$ por quilo, com densidade superior a $300 \mathrm{~kg} / \mathrm{m}^{3}$ (padrão do mercado rodoviário nacional para mercadoria sem cubagem) e devidamente embalada.

> Tipo de operação de transporte: Das opções existentes, o modal ferroviário foi descartado por não existir operação estruturada disponível em mercado para o perfil de carga neste trajeto. A cabotagem é alternativa viável em custos, porém o prazo, incluindo as pontas rodoviárias necessárias (Armazém em São Paulo/Porto de Santos e Porto Salvador/ Clientes) torna a operação inviável. O modal aéreo é opção em termos de prazo, porém seus custos médios são muito elevados quando comparados com o valor agregado do produto e margem de contribuição. A opção escolhida pelo embarcador foi o modal rodoviário.

> Tipo de operação de transporte rodoviário: O volume diário para esse destino impossibilita que a operação seja realizada através de veículos dedicados ( $F T L)$. A decisão foi utilizar empresas de rodoviário fracionado $(L T L)$, pois o período contratado com os clientes na maioria dos casos inviabiliza a consolidação da carga.

> Transportadoras Escolhidas: Através de consultas a revistas especializadas foram escolhidas 30 transportadoras para envio da RFQ. Após análise dos materiais recebidos e excluídas as empresas em que o nível de serviço oferecido era incompatível com os níveis previamente estabelecidos nos critérios de 
rejeição, foram selecionadas empresas para atendimento a essa região e a atual empresa contratada, aqui denominadas:

- Transportadora "A": Transportadora de grande porte conceituada pelo seu elevado nível de serviço.

- Transportadora "B": Líder de mercado na região possui elevado nível de serviço, mas inferior ao da transportadora "A".

- Transportadora "C": Transportadora de grande porte que atende de forma satisfatória a região.

- Transportadora "D": Atual transportadora que atende de forma satisfatória a operação, porém, comparada com as demais transportadoras, é uma empresa de menor porte.

O nome das transportadoras utilizadas por razão de confidencialidade não foi aqui citado.

A transportadora "D", atual operador, mesmo não atendendo os critérios de inclusão e rejeição definidos foi incluída no processo para que fosse possível comparar as transportadoras postulantes com o cenário atual. O nível de restrição nos critérios foi alto justamente porque o principal anseio dos decisores com o processo de seleção era uma melhora substancial no nível de serviço.

\section{Estudo de Caso 2 - Seleção de Prestadores de Serviços de Armazenagem $(4 P L)$}

Seguem as premissas que foram avaliadas, definidas e utilizadas pelo cliente, contratante e grupo de decisores durante a fase de definição e estruturação do problema.

> Área de Atuação: Operações de logística integrada (transportes e armazenagem) em sete estados brasileiros. Os prestadores serão escolhidos em função de sua capacidade de realizar os serviços de armazenagem e estando aptos e com um custo adequado também seriam os responsáveis pela operação de transportes. Caso contrário, serão contratados outros operadores para a área de transportes. 
A escolha por selecionar o melhor prestador de armazenagem se deve ao fato deste serviço ser o mais complexo e crítico na ótica do cliente.

> Produto: Bens de consumo, com valor agregado médio de $\mathrm{R} \$ 80,00$ por quilo, com densidade superior a $300 \mathrm{~kg} / \mathrm{m}^{3}$ (padrão do mercado rodoviário nacional para mercadoria sem cubagem) e devidamente embalada.

> Tipo de operação de armazenagem: recebimento, triagem, armazenagem, controle de qualidade, picking, packing e expedição.

> Prestadores Escolhidos: Em cada uma destas praças, um gerente local da contratante selecionou e encaminhou as cinco melhores empresas de prestação de serviços de armazenagem, caso existam neste número, com base em seu profundo contato local dentro deste segmento. Pelo porte da contratante, a quase totalidade dessas empresas já tinha contato comercial com a mesma. Não foram incluídas neste processo empresas com amplitude nacional e global por serem consideradas concorrentes da contratante e desta forma não possibilitarem um desenvolvimento estruturado e confiável de negócios entre as empresas, um dos objetivos deste processo e incluso no processo de inclusão e rejeição. 


\section{ANEXO A - PUBLICAÇÕES PESQUISADAS POR WEBER ET AL. (1991)}

Em acordo com a ordem dos critérios definida na página 29:

Tabela 1A - Aplicação dos critérios de seleção de Dickson, Weber et al. (1991)

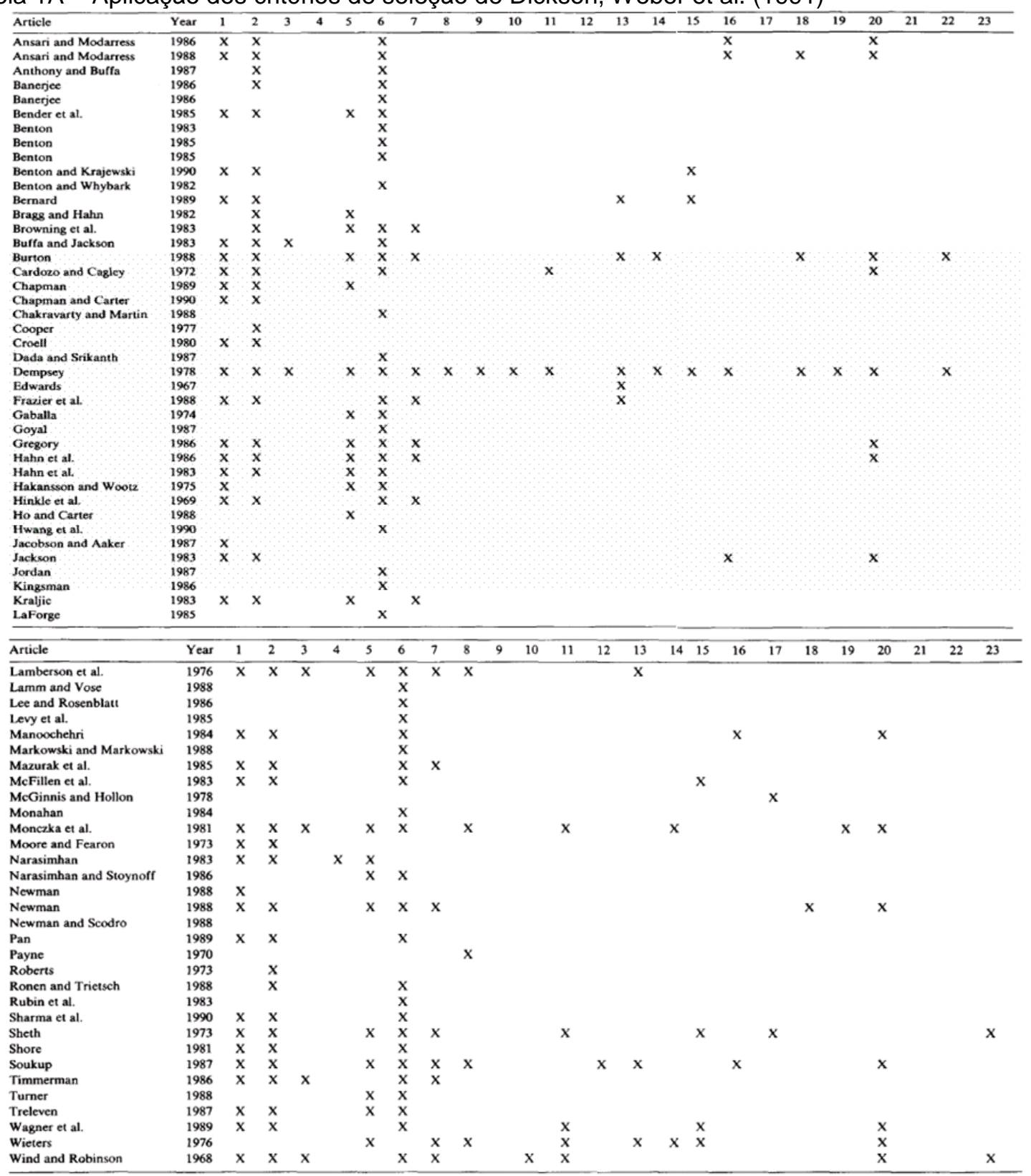




\section{ANEXO B - PUBLICAÇÕES PESQUISADAS POR DEGREAVE ET} AL. (2000)

Tabela 1B - Publicações para seleção de fornecedores entre 1986 e 1999 Fonte: Adaptação de Degreave et al., (2000)

\begin{tabular}{|c|c|c|c|c|c|c|}
\hline \multirow{2}{*}{\multicolumn{3}{|c|}{$\begin{array}{l}\text { Apenss } 1 \text { item } \\
\text { Sem gerencismento de inventário so longo do tempo }\end{array}$}} & \multicolumn{4}{|l|}{ Multiplos itens } \\
\hline & & & \multicolumn{2}{|c|}{$\begin{array}{l}\text { Sem gerencismento de inventário so } \\
\text { lonfo do tempo }\end{array}$} & \multicolumn{2}{|c|}{$\begin{array}{l}\text { Com gerencismento de inventário so longo } \\
\text { do tempo }\end{array}$} \\
\hline Possificag̣io / & $\begin{array}{l}\text { Abordagens de } \\
\text { Custo Total }\end{array}$ & $\begin{array}{l}\text { Programaçio } \\
\text { Matemática }\end{array}$ & $\begin{array}{l}\text { Clessificaçäo / } \\
\text { Pondereçio únesr }\end{array}$ & $\begin{array}{l}\text { Progremsçäo } \\
\text { Matemática }\end{array}$ & $\begin{array}{l}\text { Programaçio } \\
\text { Matemática }\end{array}$ & Estatistica \\
\hline $\begin{array}{l}\text { Timmerman } \\
\text { (1986) (categorical } \\
\text { method, linear } \\
\text { averaging) }\end{array}$ & $\begin{array}{l}\text { Timmerman } \\
\text { (1986) (cost } \\
\text { ratio method) }\end{array}$ & $\begin{array}{l}\text { Chaudhry } \\
\text { et al. (1993) }\end{array}$ & $\begin{array}{l}\text { Grando and } \\
\text { Sianesi (1996) }\end{array}$ & Tumer (1988) & $\begin{array}{l}\text { Bender et al. } \\
\text { (1985) }\end{array}$ & $\begin{array}{l}\text { Ronen and } \\
\text { Trictsch (1988) }\end{array}$ \\
\hline Gregory (1986) & $\begin{array}{l}\text { Monceka and } \\
\text { Trecha (1988) }\end{array}$ & $\begin{array}{l}\text { Weber and } \\
\text { Current (1993) }\end{array}$ & & $\begin{array}{l}\text { Current and } \\
\text { Weber (1994) }\end{array}$ & \multirow[t]{8}{*}{$\begin{array}{l}\text { Degracve and } \\
\text { Roodhooft } \\
\text { (1999b) }\end{array}$} & \\
\hline $\begin{array}{l}\text { Nydick and Hill } \\
\text { (1992) }\end{array}$ & $\begin{array}{l}\text { Smytka and } \\
\text { Clemens } \\
\text { (1993) }\end{array}$ & Pan (1989) & & Akine (1993) & & \\
\hline Barbarosoglu and & & & & Sadrian and & & \\
\hline Yazgaç (1997) & & & & Yoon (1994) & & \\
\hline Willis et al. (1993) & & & & $\begin{array}{l}\text { Rosenthal } \\
\text { et al. (1995) }\end{array}$ & & \\
\hline Liet al. (1997) & & & & Benton (1991) & & \\
\hline Soukup (1987) & & & & & & \\
\hline Thompson (1990) & & & & & & \\
\hline
\end{tabular}




\section{ANEXO C - PUBLICAÇÕES PESQUISADAS POR DE BOER ET} AL. (2001)

Tabela $1 \mathrm{C}$ - Posicionamento da literatura sobre seleção de fornecedores Fonte: Tradução de De Boer et al., (2001)

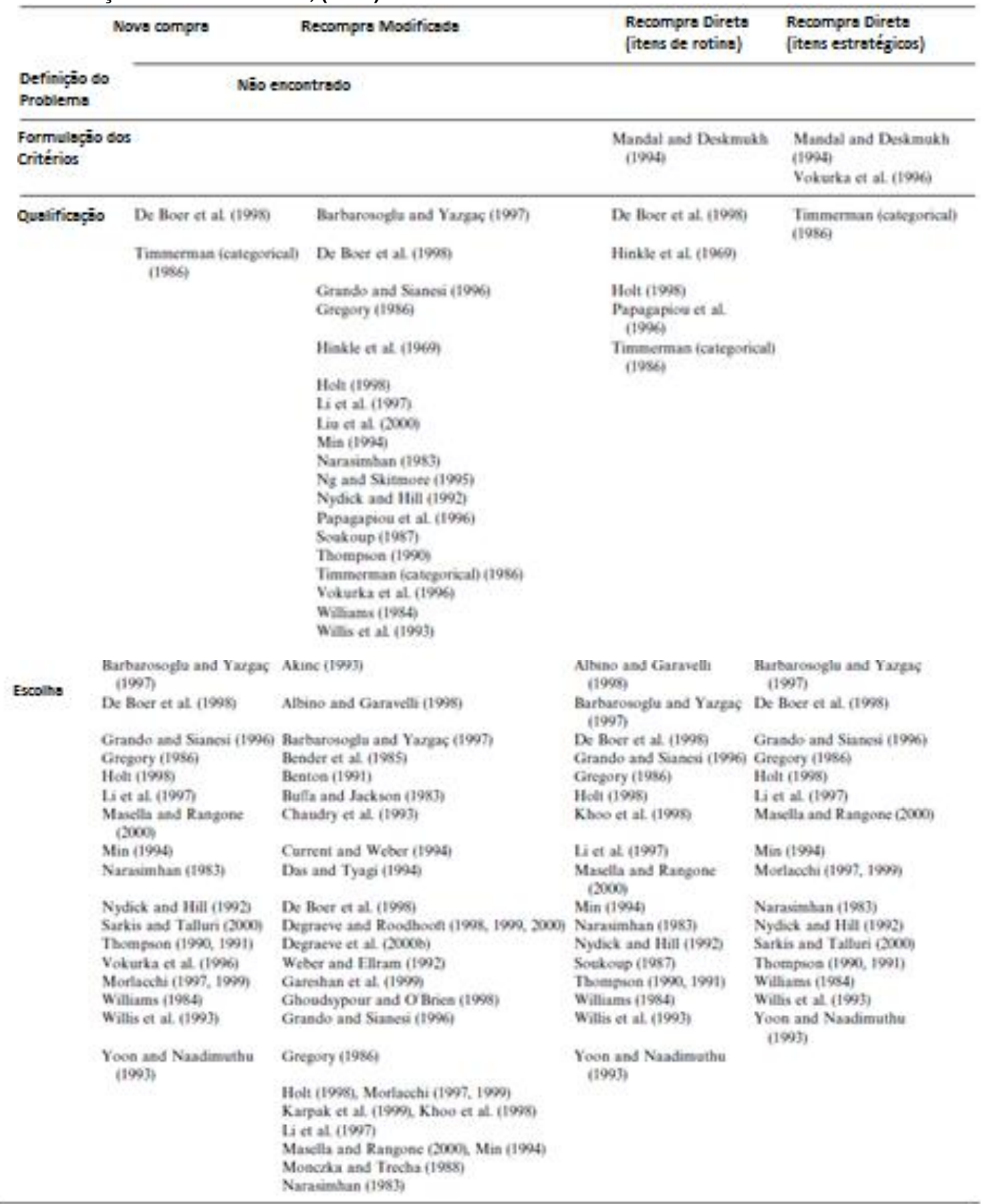


Tabela 1C cont. - Revisão na Literatura de seleção de fornecedores Fonte: Tradução de De Boer et al., (2001)

Nows compre
Recomprs Modificeds
Recompre Direts

[itens de rotina]
Recompra Direts

[rtens estratégicos]

Escoling

\author{
Nydick and Hall (1992) \\ Pan (1989) \\ Petroni and Braglia $(2000)$ \\ Roeen and Trictsch (1988) \\ Rosenthal et al. (1995) \\ Sadrian and Yope (1994), Turner (1985) \\ Semyik and Clemeas (1993) \\ Soukoup (1987) \\ Thompocen (1990, 199!) \\ Timmerman (costetatio) (1956) \\ Vokurka et al. (1996) \\ Weber and Current (1993) \\ Weber and Desai (1996) \\ Weber (1991) \\ Weber et al (1991, 1999, 2000) \\ Williams (1954) \\ Willis et al (1993) \\ Yeos and Naditnuthu (1993)
}




\section{ANEXO D - PUBLICAÇÕES PESQUISADAS POR HO ET AL. (2010)}

\section{$D E A$ - Análise envoltória de dados}

14 dos 78 artigos encontrados, 17,95\%, utilizaram esta metodologia, conforme Tabela 1D.

Tabela 1D - Artigos publicados utilizando metodologia DEA, Ho et al. (2010)

\begin{tabular}{ll}
\hline Authors & Applications \\
\hline Braglia and Petroni (2000) & $\begin{array}{l}\text { Bottling machines and packag } \\
\text { lines manufacturing }\end{array}$ \\
Liu et al. (2000) & $\begin{array}{l}\text { Agricultural and construction } \\
\text { equipment manufacturing }\end{array}$ \\
Forker and Mendez (2001) & $\begin{array}{l}\text { Electronic components } \\
\text { manufacturing }\end{array}$
\end{tabular}
Evaluating criteria

Outputs - Profitability; Quality; Delivery compliance.

Inputs - Management capabilities; Production facilities and capacity; Technological capabilities; Financial position; Experience; Geographical location.

Outputs - Supply variety; Quality. Inputs - Price index; Delivery performance; Distance.

Output - Acceptable parts per million. Inputs - Role of management leadership and quality policy; Role of the quality department; Training; Product/service design; Supplier quality management; Process management; Quality data and reporting; Employee relations.

Narasimhan et al. (2001) Telecommunications industry

Talluri and Baker (2002)

Talluri and Sarkis $(2002$

Talluri and Narasimhan (2004)

Telecommunications industry

Garfamy (2006)

Ross et al. (2006)
Supply chain management

Supply chain management

Manufacturing - supplier evaluation and managemen accounting

Communications industry

$\begin{array}{ll}\text { Saen (2006) } & \begin{array}{l}\text { Nuclear power industry } \\ \text { Seydel (2006) }\end{array} \\ \text { Talluri et al. (2006) } & \begin{array}{l}\text { Consumer products } \\ \text { manufacturing } \\ \text { Pharmaceutical industry }\end{array} \\ \text { Saen (2007a) } & \text { Supply chain management } \\ \text { Wu et al. (2007) } & \text { Aviation electronics }\end{array}$

Outputs - Quality; Price; Delivery; Cost reduction performance; Other Inputs - Quality management practices and systems; Documentation and self-audit; Process/manufacturing capability; Management of the firm; Design and development capabilities; Cost reduction capability; Supplier performance assessment.

Outputs - Number of shipments to arrive on time; Number of bills received from the supplier without errors; Service quality experience; Service quality credence.

Inputs - Total cost of shipments; Number of shipments per month.

Outputs - Number of shipments to arrive on time; Number of bills received from the supplier without errors; Service quality experience; Service quality credence.

Inputs - Total cost of shipments; Number of shipments per month

Outputs - Quality; Price; Delivery; Cost reduction performance; Other. Inputs - Quality management practices and systems; Documentation and self-audit; Process/manufacturing capability; Management of the firm; Design and development capabilities; Cost reduction capability; Supplier performance assessment.

Output - A unit of product.

Inputs - Manufacturing cost; Quality cost; Input technology; After sales service cost; Price.

Outputs - Percentage of order acknowledgements with a promise ship date within $24 \mathrm{hrs}$ of PO issue; Percentage of suppliers shipping notices received at buyer within $24 \mathrm{hrs}$ of ship date; Percentage of orders shipped to buyer on or before the original promised ship date; Percentage of orders shipped on or before final ship date; Percentage of orders delivered by the due date; Percentage of products/items not rejected upon inspection.

Inputs - Dollar value of contracted; Dollar value of performance incentives associated with contracted items; Purchase order stability; Buyer's forecast accuracy; Buyer's comprehensiveness of forecast.

Outputs - Electricity capacity; Amount of know-how transfer. Input - Cost.

Outputs - Price; Quality; Lead time; Quantity; Delivery; Technology; Service.

Outputs - Quality; Delivery.

Input - Price.

Outputs - Number of bills received from the supplier without errors. Input - Total cost of shipments; Supplier reputation.

Outputs - Revenue; Satisfaction. Input - Cost; Judgment. 


\section{Programação Matemática}

9 dos 78 artigos encontrados, $11,54 \%$, utilizaram as variações de modelos desta metodologia. A distribuição entre estes modelos foi a seguinte, Figura 1D:

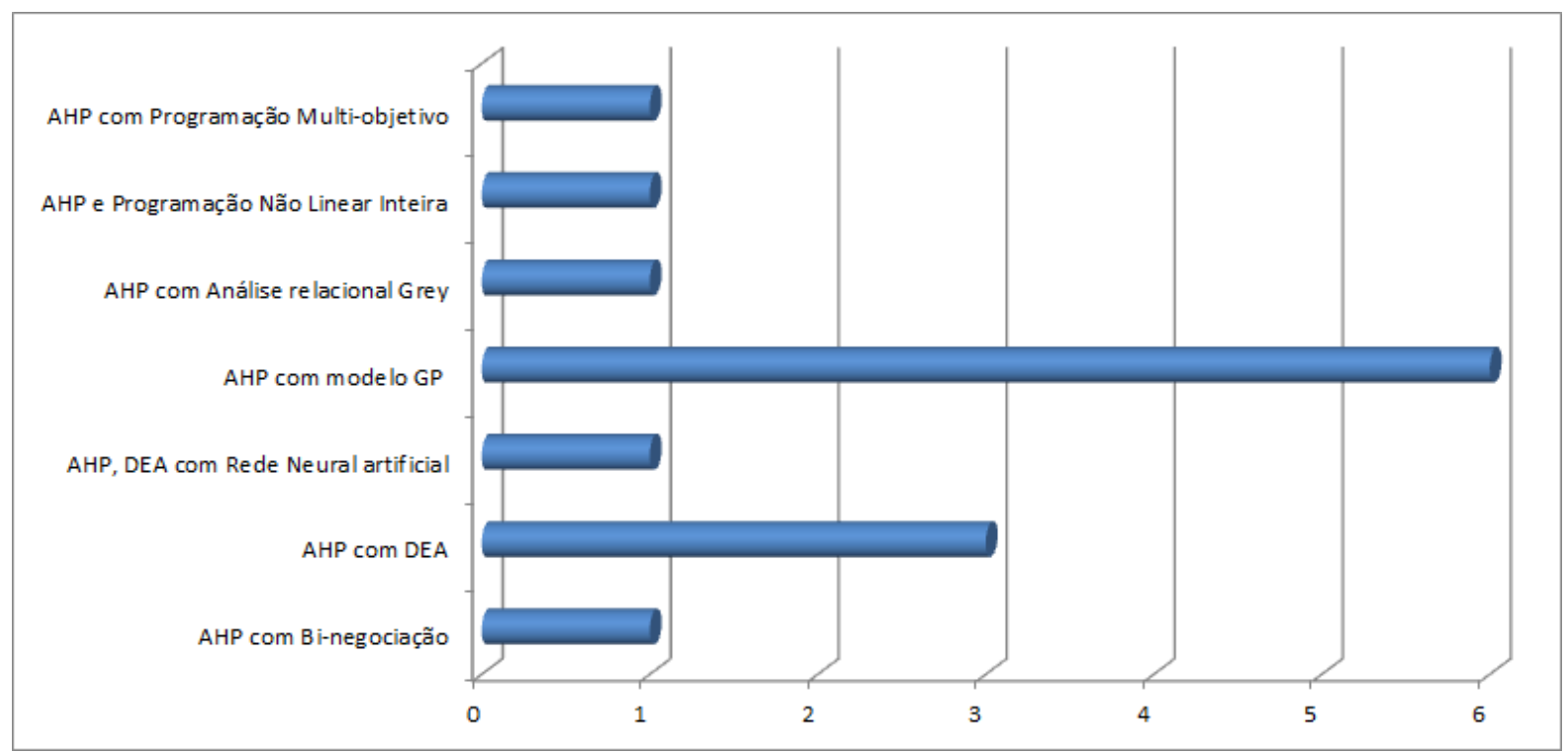

Figura 1D- Tipos de modelos de programação matemática publicados

Fonte: Dados extraídos de (Ho et al., 2010)

Os trabalhos publicados que utilizaram programação matemática estão descritos na Tabela 2D:

Tabela 2D - Artigos publicados utilizando programação matemática, Ho et al. (2010)

\begin{tabular}{|c|c|c|c|}
\hline Approach & Authors & Applications & Evaluating criteria \\
\hline Linear programming & $\begin{array}{l}\text { Talluri and Narasimhan } \\
\text { (2003) }\end{array}$ & Pharmaceutical industry & Price; Quality; Delivery. \\
\hline Linear programming & $\begin{array}{l}\text { Talluri and Narasimhan } \\
(2005)\end{array}$ & $\begin{array}{l}\text { Telecommunications } \\
\text { industry }\end{array}$ & $\begin{array}{l}\text { Quality; Price; Delivery; Cost reduction performance; } \\
\text { Other; Quality management practices and systems; } \\
\text { Documentation and self-audit; Process/manufacturing } \\
\text { capability; Management of the firm; Design and } \\
\text { development capabilities; Cost reduction capability; } \\
\text { Supplier performance assessment. }\end{array}$ \\
\hline Linear programming & $\mathrm{Ng}(2008)$ & $\begin{array}{l}\text { Agricultural and } \\
\text { construction equipment } \\
\text { manufacturing }\end{array}$ & Supply variety; Quality; Distance; Delivery; Price. \\
\hline $\begin{array}{l}\text { Binary integer linear } \\
\text { programming }\end{array}$ & Talluri (2002) & Pharmaceutical industry & Price; Quality; Delivery. \\
\hline $\begin{array}{l}\text { Mixed integer linear } \\
\text { programming }\end{array}$ & Hong et al. (2005) & Agriculture industry & Delivery; Quality; Price; Quantity. \\
\hline $\begin{array}{l}\text { Mixed integer nonlinear } \\
\text { programming }\end{array}$ & $\begin{array}{l}\text { Ghodsypour and O'Brien } \\
\text { (2001) }\end{array}$ & Hypothetical case & $\begin{array}{l}\text { Price; Ordering cost; Perfect rate; On-time delivery; } \\
\text { Capacity. }\end{array}$ \\
\hline Goal programming & Karpak et al. (2001) & $\begin{array}{l}\text { Hydraulic gear pump } \\
\text { manufacturing }\end{array}$ & $\begin{array}{l}\text { Product cost; Quality of castings purchased; Delivery } \\
\text { reliability of castings purchased }\end{array}$ \\
\hline $\begin{array}{l}\text { Multi-objective } \\
\text { programming }\end{array}$ & Narasimhan et al. (2006) & $\begin{array}{l}\text { Personal computer } \\
\text { manufacturing }\end{array}$ & $\begin{array}{l}\text { Direct cost; Indirect-coordination cost; Quality; } \\
\text { Delivery reliability; Complexity of supply arrangement. }\end{array}$ \\
\hline $\begin{array}{l}\text { Multi-objective } \\
\text { programming }\end{array}$ & $\begin{array}{l}\text { Wadhwa and Ravindran } \\
(2007)\end{array}$ & Hypothetical case & Price; Lead time; Rejects. \\
\hline
\end{tabular}




\section{Os artigos utilizando a abordagem individual do $A H P$ foram 7 dos 78 artigos encontrados, 8,97\%, Tabela 3D:}

Tabela 3D - Artigos publicados utilizando metodologia AHP, Ho et al. (2010)

\begin{tabular}{|c|c|c|}
\hline Authors & Applications & Evaluating criteria \\
\hline Akarte et al. (2001) & Automobile castings & $\begin{array}{l}\text { Maximum casting size; Minimum section thickness; Casting } \\
\text { complexity; Software aid; Pattern making; Sand preparation; Molding; } \\
\text { Core making; Melting and pouring; Heat treatment; Machining; } \\
\text { Dimensional tolerance; Surface roughness; Testing facilities; Quality } \\
\text { certification; Quality awards; Total casting cost; Sample delivery time. }\end{array}$ \\
\hline Muralidharan et al. (2002) & Bicycles manufacturing & $\begin{array}{l}\text { Quality; Delivery; Price; Technical capability; Financial position; Past } \\
\text { performance attitude; Facility; Flexibility; Service. }\end{array}$ \\
\hline Chan and Chan (2004) & $\begin{array}{l}\text { Semiconductor assembly } \\
\text { equipment manufacturing industry }\end{array}$ & Cost; Delivery; Flexibility; Innovation; Quality; Service. \\
\hline Hou and $\mathrm{Su}(2007)$ & Printer manufacturing & $\begin{array}{l}\text { Quality; Cost; Technology; Production capability; R\&D; Delivery \& } \\
\text { Location; Performance \& Service. }\end{array}$ \\
\hline
\end{tabular}

CBR - Raciocínio baseado em casos

Os artigos utilizando $C B R$ também foram 7, representando $8,97 \%$ do total, Tabela 4D:

Tabela 4D - Artigos publicados utilizando metodologia CBR, Ho et al. (2010)

\begin{tabular}{|c|c|c|}
\hline Authors & Applications & Evaluating criteria \\
\hline Choy and Lee (2002) & $\begin{array}{l}\text { Consumer products } \\
\text { manufacturing }\end{array}$ & $\begin{array}{l}\text { Delivery; Shipment quality; Product price; Manufacturing capability; } \\
\text { Customer service; Management commitment, Product development; } \\
\text { Process improvement; Quality planning; Quality assurance supply; } \\
\text { Quality assurance production; Inspection and experimentation; Quality } \\
\text { staff; Organizational culture; Achievement of sales and marketing } \\
\text { objectives. }\end{array}$ \\
\hline Choy et al. (2002) & $\begin{array}{l}\text { Consumer products } \\
\text { manufacturing }\end{array}$ & $\begin{array}{l}\text { Compliance with due date; Compliance with quality; Rejection in } \\
\text { incoming quality; Rejection in production line; Rejection from } \\
\text { customers; Price; Inquiry response time; Quality staff; Product } \\
\text { development time; Product variety; Product line. }\end{array}$ \\
\hline Choy and Lee (2003) & $\begin{array}{l}\text { Consumer products } \\
\text { manufacturing }\end{array}$ & $\begin{array}{l}\text { Delivery; Shipment quality; Product price; Manufacturing capability; } \\
\text { Customer service; Product innovation; Product development time; } \\
\text { Number of quality staff; Culture innovation; Financial status. }\end{array}$ \\
\hline Choy et al. (2003a) & $\begin{array}{l}\text { Consumer products } \\
\text { manufacturing }\end{array}$ & $\begin{array}{l}\text { Delivery; Shipment quality; Product price; Customer service; Quality; } \\
\text { Development; Organizational culture. }\end{array}$ \\
\hline Choy et al. (2004a) & $\begin{array}{l}\text { Consumer products } \\
\text { manufacturing }\end{array}$ & Same as Choy et al. (2002) \\
\hline Choy et al. (2005) & $\begin{array}{l}\text { Consumer products } \\
\text { manufacturing }\end{array}$ & $\begin{array}{l}\text { Price; Delivery; Quality; Innovation level; Level of technology; } \\
\text { Culture; Commercial awareness; Production flexibility; Ease of } \\
\text { communication; Current reputation. }\end{array}$ \\
\hline
\end{tabular}


ANP - Processo de análise de redes

Os artigos utilizando a abordagem ANP foram 3 ou 3,85\% do total, apresentados na Tabela 5D:

Tabela 5D - Artigos publicados utilizando metodologia ANP, Ho et al. (2010)

\begin{tabular}{lll}
\hline Authors & Applications & Evaluating criteria \\
\hline Sarkis and Talluri (2002) & $\begin{array}{l}\text { High technology metal-based } \\
\text { manufacturing }\end{array}$ & Culture; Technology; Relationship; Cost; Quality; Time; Flexibility. \\
Hypothetical case & $\begin{array}{l}\text { Flexibility; On-time delivery; Price; Delivery lead-time; Quality; } \\
\text { Market share; Personnel capability; Process capability; Top } \\
\text { management capability; Financial capability. }\end{array}$ \\
Gencer and Gürpinar (2007) & Flectronic industry & $\begin{array}{l}\text { Facility location; Number of working years; References; Service } \\
\text { capability; Communication capability; Organization structure; Number } \\
\text { of personnel; Education status of the personnel; The last term profit; }\end{array}$ \\
& $\begin{array}{l}\text { Exporting status; Appropriateness of the materials price to the market } \\
\text { price; Machine capacity and capability; Manufacturing technology; }\end{array}$ & $\begin{array}{l}\text { Facilities manufacturing capacity; Technical capability; Manufacturing } \\
\text { planning capability; Handling and packaging capability; } \\
\text { Appropriateness of the quantity; Appropriateness of the delivery date; } \\
\text { Appropriateness of the packaging standards; The period of procuring } \\
\text { materials; Quality system certifichte of the supplier; Quality manual; } \\
\text { Documentation control; Archive of quality records; Usage of worth }\end{array}$ \\
& $\begin{array}{l}\text { instructions; Process control capability; Product identification; } \\
\text { Receiving inspection; Calibration control; Non-conforming material } \\
\text { control system; Corrective and preventive action system; Audit } \\
\text { mechanism; Training }\end{array}$ \\
\hline
\end{tabular}

Teoria Fuzzy (FST)

Os artigos utilizando a teoria Fuzzy foram 3 dos 78, o que representa 3,85\%, Tabela 6D:

Tabela 6D- Artigos publicados utilizando teoria Fuzzy, Ho et al. (2010)

\begin{tabular}{lll}
\hline Authors & Applications & Evaluating criteria \\
\hline Chen et al. (2006) & High-technology manufacturing & $\begin{array}{l}\text { Profitability of supplier; Relationship closeness; Technological } \\
\text { capacity; Conformance quality; Conflict resolution. }\end{array}$ \\
Sarkar and Mohapatra (2006) & Hypothetical case & $\begin{array}{l}\text { Price; Quality; Delivery lead time; Attitude; Quality systems in } \\
\text { operation at the supplier's place; Financial capability of the supplier; } \\
\text { Production facilities and capacity; Management and organization; } \\
\text { Technological capability; Breadth of product line; Supplier's } \\
\text { proximity; Existence of IT standards; Labor problems at the supplier's } \\
\text { place; Reputation. }\end{array}$ \\
& $\begin{array}{l}\text { Cost reduction effort; Delivery delays; Price; Reliability; Commit to } \\
\text { quality; Responsiveness; Commit to improvement; Delivery mistakes; } \\
\text { Florez-Lopez (2007) }\end{array}$ & $\begin{array}{l}\text { Fluctuation on costs; Order mistakes; Outgoing quality; Timely } \\
\text { communication; Customer service; Technical assistance. }\end{array}$ \\
\hline
\end{tabular}

Smart - Avaliação técnica com simples atributo

Os artigos utilizando a abordagem SMART foram apenas 2 do total ou 2,56\%, são eles, Tabela 7D: 
Tabela 7D - Artigos publicados utilizando metodologia SMART, Ho et al. (2010)

\begin{tabular}{lll}
\hline Authors & Applications & Evaluating criteria \\
\hline Barla (2003) & Glass manufacturing industry & $\begin{array}{l}\text { Reliability of subcontractor; Capability of subcontractor; Quality } \\
\text { organization; Geographical condition; Financial condition; Service; } \\
\text { Price. }\end{array}$ \\
Huang and Keskar (2007) & PC manufacturing industry & $\begin{array}{l}\text { Reliability; Responsiveness; Flexibility; Cost and financial; Assets and } \\
\text { infrastructure; Safety; Environment. }\end{array}$ \\
\hline
\end{tabular}

GA - Algoritmo Genético

O artigo que utilizou GA, 2,56\%, foi descrito na Tabela 8D:

Tabela 8D - Artigos publicados utilizando algoritmo genético, Ho et al. (2010)

\begin{tabular}{lll}
\hline Authors & Application & Evaluating criteria \\
\hline Ding et al. (2005) & Textile industry & $\begin{array}{l}\text { Order-to-delivery lead-time; Ratio of on-time delivery; Inventory } \\
\text { position; Resource utilization; Cost. }\end{array}$ \\
\hline
\end{tabular}

\section{AHP Integrados}

Os artigos utilizando a abordagem $A H P$ Integrada com outros métodos foram 14 dos 78, o que representa $17,95 \%$. Eles foram divididos na Figura 2D de acordo com a metodologia combinada ao AHP:

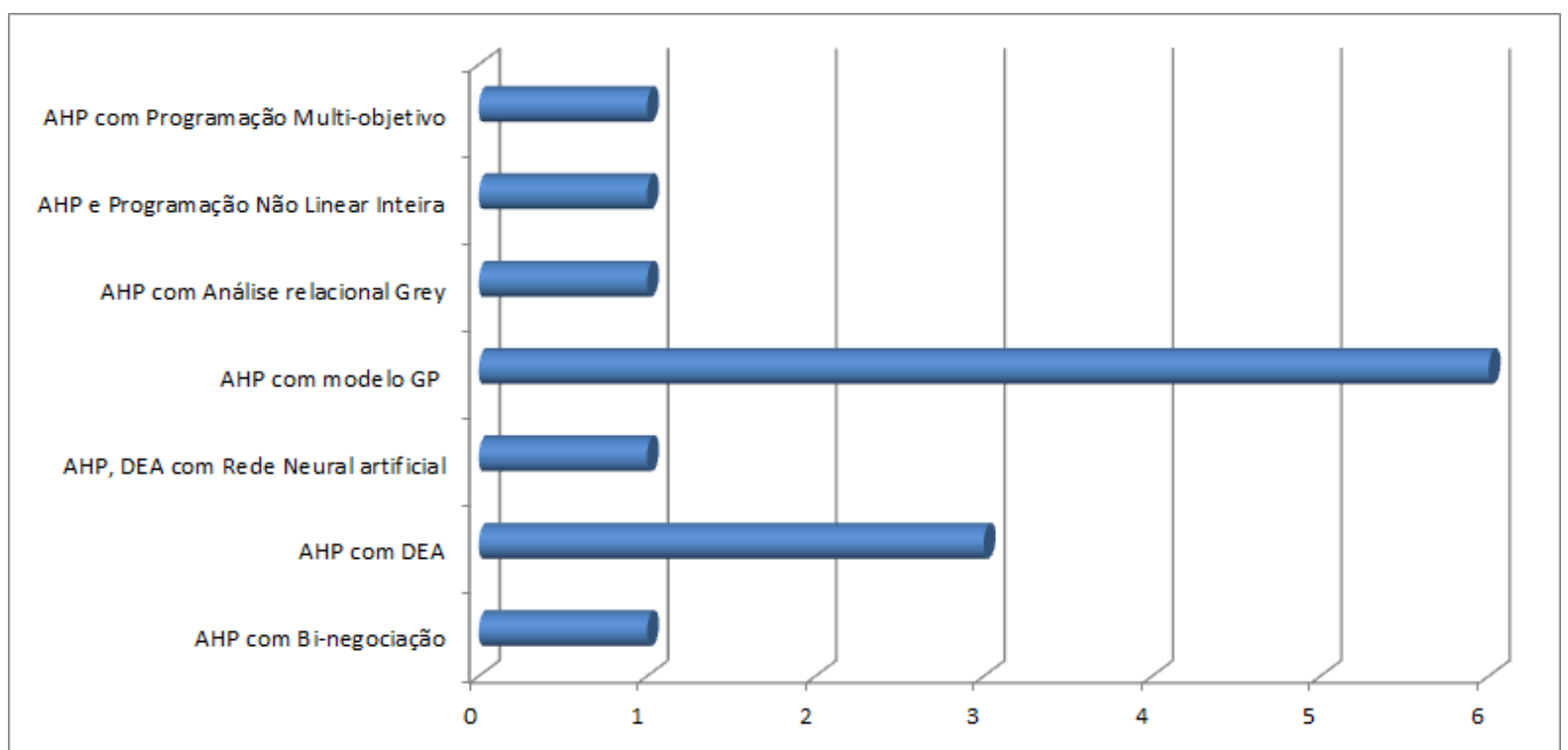

Figura 2D - Tipos de modelos AHP Integrados publicados

Fonte: Dados extraídos de (Ho et al., 2010) 
Estes 14 trabalhos foram publicados de acordo com a Tabela 9D:

Tabela 9D - Artigos publicados utilizando modelo AHP Integrado, Ho et al. (2010)

\begin{tabular}{|c|c|c|c|}
\hline Approaches & Authors & Applications & Evaluating criteria \\
\hline AHP-Bi-negotiation & Chen and Huang (2007) & $\begin{array}{l}\text { High-end computer } \\
\text { manufacturing }\end{array}$ & $\begin{array}{l}\text { Cash-to-cash cycle time; Inventory days of supply; } \\
\text { Order quantity; Visitation to supplier facilities; } \\
\text { Performance history; Production flexibility; Quality } \\
\text { performance; Position in the industry and reputation; } \\
\text { EDI capability; Organization structure; Price; Logistics } \\
\text { cost; Value-added productivity; Supply chain response } \\
\text { time; Delivery lead time; Fill rate. }\end{array}$ \\
\hline AHP-DEA & Ramanathan (2007) & Hypothetical case & $\begin{array}{l}\text { Manufacturing costs; Quality; Technology; After-sales } \\
\text { service. }\end{array}$ \\
\hline AHP-DEA & Saen (2007b) & Hypothetical case & Two unknown inputs and two unknown outputs. \\
\hline AHP-DEA & Sevkli et al. (2007) & TV set manufacturing & $\begin{array}{l}\text { Shipment quality; Delivery; Cost; Number of } \\
\text { employees; Organizational structure; Training; Number } \\
\text { of technical staff; Management commitment; Inspection } \\
\text { and control; Quality planning; Quality assurance; } \\
\text { Production capacity; Maintenance; Lead-time; Up to } \\
\text { date; Storage; Development; Reputation; Location; } \\
\text { Price; Patent; Technical capability; RFID; EDI; Internet. }\end{array}$ \\
\hline AHP-DEA-ANN & Ha and Krishnan (2008) & Auto parts manufacturing & $\begin{array}{l}\text { Production facilities; Quality management intention; } \\
\text { Quality system outcome; Claims; Quality improvement; } \\
\text { Response to claims; On-time delivery; Organizational } \\
\text { control; Business plans; Customer communication; } \\
\text { Internal audit; Data administration. }\end{array}$ \\
\hline AHP-GP & Çebi and Bayraktar (2003) & Food manufacturing & $\begin{array}{l}\text { Lead time; Supply lots; Flexibility; Delivery conditions; } \\
\text { Capacity; Involvement; Improvement effort; Problem } \\
\text { solving; Reputation; Financial strength; Management; } \\
\text { Communication; Past experience; Sales representative. }\end{array}$ \\
\hline AHP-GP & Wang et al. (2004) & Automobile manufacturing & $\begin{array}{l}\text { Delivery reliability; Flexibility and responsiveness; } \\
\text { Cost; Assets. }\end{array}$ \\
\hline AHP-GP & Wang et al. (2005) & Automobile manufacturing & Same as Wang et al. (2004) \\
\hline AHP-GP & Perçin (2006) & Automobile manufacturing & $\begin{array}{l}\text { Manufacturing facilities/capabilities; Conformance } \\
\text { quality; Flexibility; Delivery reliability; Technical } \\
\text { capability; Continuous improvement programs; } \\
\text { Technical information sharing; Technological } \\
\text { compatibility; Product innovation capabilities; } \\
\text { Suppliers' organizational structure; Reputation and } \\
\text { position in industry; Financial strength; Management } \\
\text { skills; Performance history; Geographical location; } \\
\text { Long-term relationship; Response to complaints; } \\
\text { Communication systems; Warranty support; Repair and } \\
\text { maintenance service. }\end{array}$ \\
\hline AHP-GP & Kull and Talluri (2008) & $\begin{array}{l}\text { Precision turned steel } \\
\text { products manufacturing }\end{array}$ & $\begin{array}{l}\text { Delivery risk; cost risk; quality risk; flexibility risk; } \\
\text { confidence risk. }\end{array}$ \\
\hline AHP-GP & Mendoza et al. (2008) & Hypothetical case & Flexibility; Quality; Price; Service; Delivery. \\
\hline $\begin{array}{l}\text { AHP-grey relational } \\
\text { analysis }\end{array}$ & Yang and Chen (2006) & $\begin{array}{l}\text { Laptop computer } \\
\text { manufacturing }\end{array}$ & $\begin{array}{l}\text { Quality; Finance; Customer service; Production } \\
\text { capacity; Design \& technical capability; IT system; } \\
\text { Turnover; Cost; Delivery; Distance. }\end{array}$ \\
\hline $\begin{array}{l}\text { AHP-mixed integer } \\
\text { nonlinear programming }\end{array}$ & $\begin{array}{l}\text { Mendoza and Ventura } \\
(2008)\end{array}$ & Hypothetical case & Flexibility; Quality; Price; Service; Delivery. \\
\hline $\begin{array}{l}\text { AHP-multi-objective } \\
\text { programming }\end{array}$ & Xia and Wu (2007) & Hypothetical case & $\begin{array}{l}\text { Price; Technical level; Defects; Reliability; On-time } \\
\text { delivery; Supply capacity; Repair turnaround time; } \\
\text { Warranty period. }\end{array}$ \\
\hline
\end{tabular}




\section{Modelos Fuzzy Integrados}

Os artigos utilizando a teoria Fuzzy (FST) Integrada a outras metodologias foram 9, representando $11,54 \%$ do total. Estes trabalhos foram combinados na Figura 3D com as seguintes metodologias:

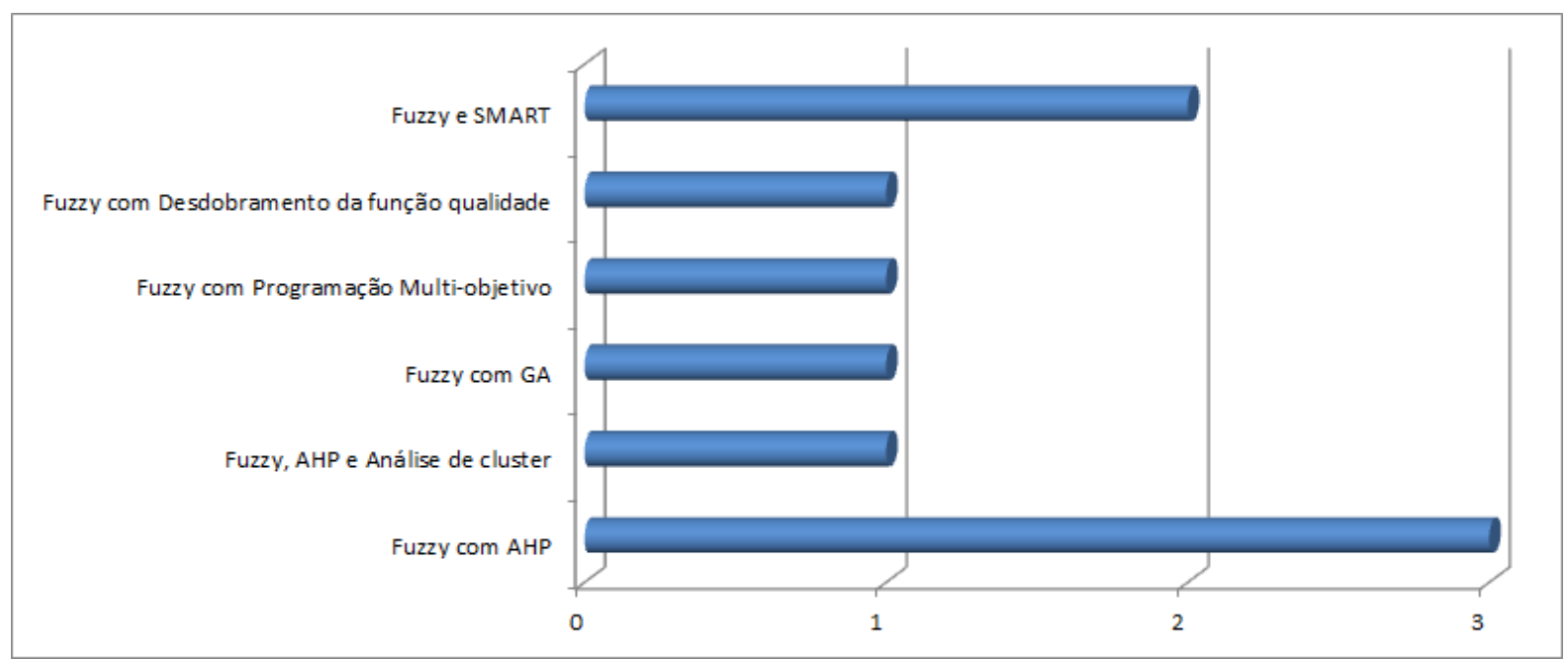

Figura 3D - Tipos de modelos Fuzzy Integrados publicados

Fonte: Dados extraídos de (Ho et al., 2010)

Os mesmos estão descritos na Tabela 10D:

Tabela 10D - Artigos publicados utilizando modelo Fuzzy Integrado, Ho et al. (2010)

\begin{tabular}{|c|c|c|c|}
\hline Approaches & Authors & Applications & Evaluating criteria \\
\hline Fuzzy-AHP & Kahraman et al. (2003) & White good manufacturing & $\begin{array}{l}\text { Financial; Management; Quality systems; Handling; } \\
\text { Use in manufacturing; Other business consideration; } \\
\text { End use; Follow up; Customer support; Customer } \\
\text { satisfiers; Professionalism. }\end{array}$ \\
\hline Fuzzy-AHP & Chan and Kumar (2007) & Manufacturing & $\begin{array}{l}\text { Cost; Quality; Service performance; Supplier's profile; } \\
\text { Risk factor. }\end{array}$ \\
\hline $\begin{array}{l}\text { Fuzzy-AHP-cluster } \\
\text { analysis }\end{array}$ & Bottani and Rizzi (2008) & Beverage manufacturing & $\begin{array}{l}\text { Economical value; Number of orders per year; Waiting } \\
\text { time. }\end{array}$ \\
\hline Fuzzy-GA & Jain et al. (2004) & $\begin{array}{l}\text { Automobile part } \\
\text { manufacturing }\end{array}$ & $\begin{array}{l}\text { Part rejection rate; Delivery performance; Residual } \\
\text { stress; Surface finish. }\end{array}$ \\
\hline $\begin{array}{l}\text { Fuzzy-multi-objective } \\
\text { programming }\end{array}$ & Amid et al. (2006) & Hypothetical case & Cost; Quality; Service level (or on-time delivery). \\
\hline $\begin{array}{l}\text { Fuzzy-multi-objective } \\
\text { programming }\end{array}$ & Amid et al. (2008) & Hypothetical case & Cost; Net rejections; Net late deliveries. \\
\hline Fuzzy-QFD & Bevilacqua et al. (2006) & $\begin{array}{l}\text { Clutch couplings } \\
\text { manufacturing }\end{array}$ & $\begin{array}{l}\text { Experience of the sector; Capacity for innovation to } \\
\text { follow up the customer's evolution in terms of changes } \\
\text { in its strategy and market; Quality system certification; } \\
\text { Flexibility of response to the customer's requests; } \\
\text { Financial stability; Ability to manage orders on-line } \\
\text { (EDI-system); Geographical position. }\end{array}$ \\
\hline Fuzzy-SMART & Kwong et al. (2002) & $\begin{array}{l}\text { Electrical appliances } \\
\text { manufacturing }\end{array}$ & $\begin{array}{l}\text { Product quality; Product construction; Product safety; } \\
\text { Quality system; Engineering; Product and planning } \\
\text { control; Research and development. }\end{array}$ \\
\hline Fuzzy-SMART & Chou and Chang (2008) & $\begin{array}{l}\text { IT hardware } \\
\text { manufacturing }\end{array}$ & $\begin{array}{l}\text { Cost; Quality; Delivery; Organizational culture and } \\
\text { strategy; Technical capacity. }\end{array}$ \\
\hline
\end{tabular}




\section{Outras abordagens}

Houve ainda 9 trabalhos dos 78, 11,54\%, que utilizaram outros tipos de abordagens, Figura 4D:

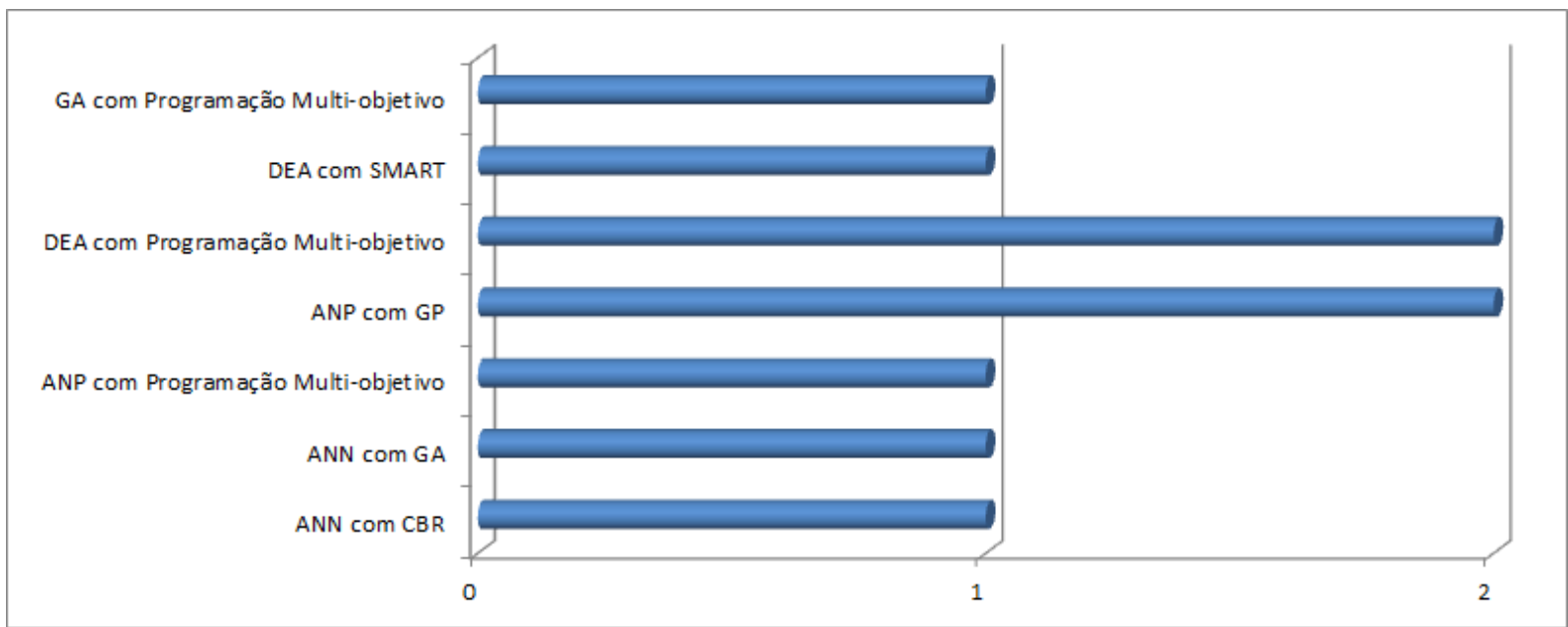

Figura 4D - Outras abordagens publicadas

Fonte: Dados extraídos de (Ho et al., 2010)

\section{Detalhada através dos trabalhos, Tabela 11D:}

Tabela 11D- Artigos publicados utilizando outras abordagens, Ho et al. (2010)

\begin{tabular}{|c|c|c|c|}
\hline Approaches & Authors & Applications & Evaluating criteria \\
\hline ANN-CBR & Choy et al. (2003c) & $\begin{array}{l}\text { Consumer products } \\
\text { manufacturing }\end{array}$ & $\begin{array}{l}\text { Compliance with due date; Compliance with quality; } \\
\text { Rejection in incoming quality; Rejection in production } \\
\text { line; Quality system and implementation; Price; } \\
\text { Response time; Technical competence; Product } \\
\text { development time; Product innovation; Cultural } \\
\text { innovation. }\end{array}$ \\
\hline ANN-CBR & Choy et al. (2004b) & $\begin{array}{l}\text { Consumer products } \\
\text { manufacturing }\end{array}$ & $\begin{array}{l}\text { Compliance with due date; Compliance with quality; } \\
\text { Rejection in incoming quality; Rejection in production } \\
\text { line; Rejection from customers; Parts price; Response } \\
\text { time; ISO quality system installed; Product development } \\
\text { time; Use of the Internet and database; VMI readiness. }\end{array}$ \\
\hline ANN-GA & Lau et al. (2006) & Hypothetical case & $\begin{array}{l}\text { Delivery efficiency; Reliability of quality; } \\
\text { Responsiveness to the market trend; Competitiveness of } \\
\text { cost. }\end{array}$ \\
\hline $\begin{array}{l}\text { ANP-multi-objective } \\
\text { programming }\end{array}$ & $\begin{array}{l}\text { Demirtas and Üstün } \\
(2008)\end{array}$ & $\begin{array}{l}\text { Refrigerator } \\
\text { manufacturing }\end{array}$ & $\begin{array}{l}\text { Low defect rate; Process capability; On-time delivery; } \\
\text { Process flexibility; Response to changes; Support to } \\
\text { design process; Consistency; Mutual trust and ease of } \\
\text { communication; Unit cost; Break in line; Measurement } \\
\text { and assessment; Order delays; Customer complaints; } \\
\text { Inability to meet further requirements. }\end{array}$ \\
\hline ANP-GP & $\begin{array}{l}\text { Demirtas and Üstün } \\
\text { (2009) }\end{array}$ & $\begin{array}{l}\text { Refrigerator } \\
\text { manufacturing }\end{array}$ & Same as Demirtas and Üstün (2008) \\
\hline $\begin{array}{l}\text { DEA-multi-objective } \\
\text { programming }\end{array}$ & Weber et al. (2000) & Manufacturing & Price; Delivery; Quality. \\
\hline $\begin{array}{l}\text { DEA-multi-objective } \\
\text { programming }\end{array}$ & Talluri et al. (2008) & Pharmaceutical industry & Price; Quality; Delivery. \\
\hline DEA-SMART & Seydel (2005) & $\begin{array}{l}\text { Consumer products } \\
\text { manufacturing }\end{array}$ & $\begin{array}{l}\text { Quality; Price; Lead time; Quantity; Service; Delivery; } \\
\text { Technology. }\end{array}$ \\
\hline $\begin{array}{l}\text { GA-multi-objective } \\
\text { programming }\end{array}$ & Liao and Rittscher (2007) & Hypothetical case & Cost; Quality; Delivery; Flexibility. \\
\hline
\end{tabular}

